\title{
Integrated Energy Efficient Window-Wall Systems
}

\author{
Phase 1: Concept Development
}

Final Report Reporting Period 9/30/99-12/31/02

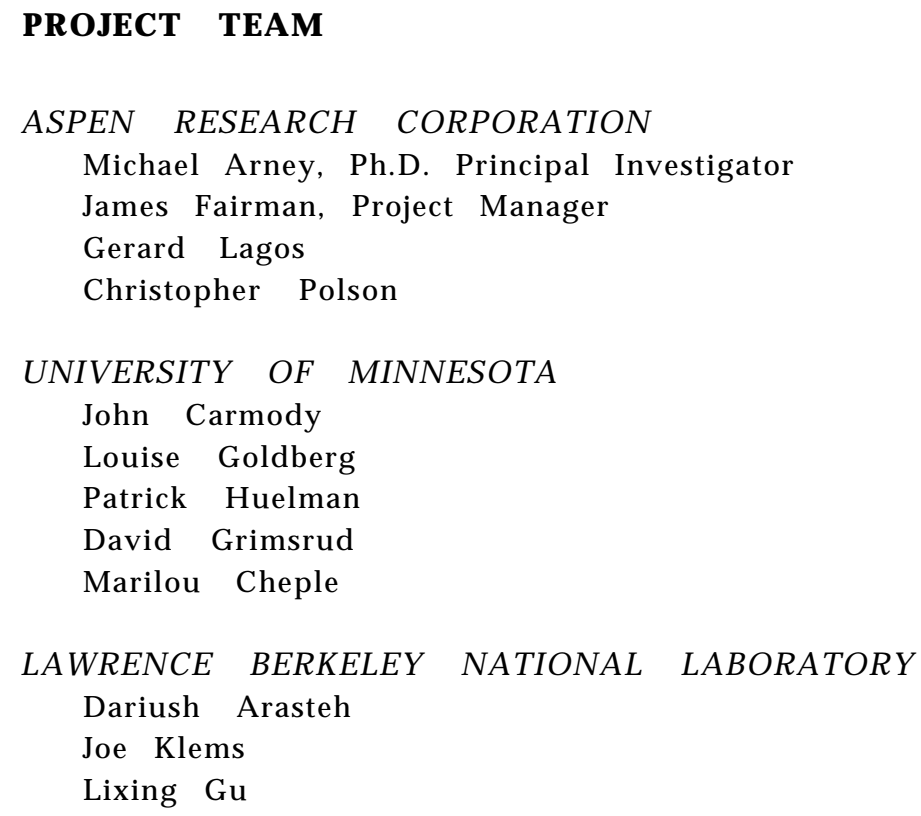

December, 2001

DE-FC26-99FT40649

Aspen Research Corporation 1700 Buerkle Road

White Bear Lake, MN 55110 


\section{DISCLAIMER}

"This report was prepared as an account of work sponsored by an agency of the United States Government. Neither the United States Government nor any agency thereof, nor any of their employees, make any warranty, express or implied, or assumes any legal liability or responsibility for the accuracy, completeness, or usefulness of any information, apparatus, product, or process disclosed, or represents that its use would not infringe privately owned trademark, manufacturer or otherwise does not necessarily constitute or imply its endorsement, recommendation, or favoring by the United States Government or any agency thereof. The views and opinions of authors expressed herein do not necessarily state or reflect those of the United States Government or any agency thereof."

\section{ABSTRACT}

The building industry faces the challenge of reducing energy use while simultaneously improving construction methods and marketability. This paper describes the first phase of a project to address these concerns by designing an Integrated Window Wall System (IWWS) that can be commercialized. This work builds on previous research conducted during the 1990's by Lawrence Berkeley national Laboratories (LBNL). During this phase, the objective was to identify appropriate technologies, problems and issues and develop a number of design concepts. Four design concepts were developed into prototypes and preliminary energy analyses were conducted Three of these concepts (the foam wall, steel wall, and stiffened plate designs) showed particular potential for meeting the project objectives and will be continued into a second phase where one or two of the systems will be brought closer to commercialization.

\section{ACKNOWLEDGMENTS}

Normally a project such as this benefits from only one organization and involves a limited number of participants. By contrast, this project involved a larger number of participants from four different organizations or institutions. Aspen Research Corporation served as a focal point for an impressive body of talents and skills.

A project like this is quite diverse. Many people were instrumental in creating leverageable knowledge as well as creating the prototypes. The team from Aspen Research Corporation was headed by Michael Arney, and included Jim Fairman, Chris Mathis, Christopher Polson, who was the lead designer for the Steel Wall; Gerard Lagos, who was the lead designer for the Manufactured Stud Wall; Shannon Koenig and Louisa Arney, who created order from the chaos of the components knowledge base, and Yuli Kornblum, Brian Peterson, Vilyan Krugman, Doug Becklin, Kevin Roth, Doug Wilken, Charles Scripter, and Russell Pylkki.

The work and knowledge from the University of Minnesota team, headed by John Carmody was indispensable for this project. Patrick Heulman and Louise Goldberg were the lead designers of the two Stiffened Plate concepts. Other University of Minnesota team members were Marilou Cheple and David Grimsrud.

The Lawrence Berkeley National Laboratories, under the direction of Dariush Arasteh, also provided advice in the development portions of the project. We also would like to thank the Lawrence Berkeley National Laboratories for lending us the original LBNL window-wall unit. Other LBNL team members include: Lixing $\mathrm{Gu}$, who performed many of the DOE-2 simulations, and Brent Griffith. Leo Rainer and Dick Bourne of the Davis Energy Group provided an excellent assessment of existing and emerging construction systems.

We would also like to acknowledge the contribution of Andersen Windows in constructing all of the window-wall prototypes shown in this report, as well as furnishing all of the windows and window parts. In addition, Andersen Windows provided us with extremely valuable advice and information on window design and marketing which we could not obtain anywhere else. The Andersen Windows participants were J. R. Helget, who actually constructed all of the prototypes, Mark Mikkelson, Steve Johnson, Dave Plummer, Tim Kelley, Dave Green, and Bob Bishoff.

Lastly, we would like to gratefully acknowledge the support and encouragement of Samuel Taylor of the Windows and Glazing Research Program, U. S. Department of Energy; William Haslebacher, project manager of the National Energy Technology Laboratory (NETL). We are very grateful for the research funding from the U. S. Department of Energy and the Andersen Corporation, under Kurt Heikkila and Mike Koenig, without which this project would not have begun. 


\section{EXECUTIVE SUMMARY}

The building industry is faced with a number of challenges. Significant energy use reduction is essential in addressing concerns over global warming and air pollution from the burning of fossil fuels. In addition, unstable energy supplies and prices make energy conservation a necessary priority. One way to significantly conserve substantial amounts of energy is to construct more energy-efficient buildings. In addition to being energy-efficient, the buildings of the future must be healthy, durable, affordable, able to accommodate technological changes, and have a low impact on the environment. In the residential building industry, these challenges must be met; in addition, other existing problems must be addressed such as a shortage of skilled labor, many product installation failures, and an inefficient construction process involving many trades and limited coordination.

Window and wall construction techniques have exhibited a number of improvements in recent years, but the window/wall interface continues to be a problem. Moreover, traditional stick build construction has many inefficiencies. During the 1990's, The Lawrence Berkeley National Laboratories (LBNL) explored the concept of an integrated window/wall system that would solve the interface problems and take advantage of the potential synergy from designing the window and the wall as one system.

The objective of this project is to build on the LBNL effort and further develop an Integrated Window Wall System (IWWS) that can be commercialized. This report documents the first phase of the project which includes:

- The identification of technologies, problems and issues.

- The development of design concepts.

Four design concepts have been developed into prototypes and preliminary analysis has been conducted. During this phase of the project, it became clear that while energy efficiency is a major rationale for the IWWS, the major challenge is to simultaneously resolve issues such as marketability, moisture management, structural design, building codes, sustainable materials, and a more efficient construction process. In addition, the IWWS presents an opportunity for integration with other systems such as ventilation, window attachments, communications and controls, and on-site energy production.

In the current phase, many different components and building systems were assessed for their potential use in an integrated window-wall prototype. A number of systems were identified for their potential uses in an integrated system. From this list, five designs were created, resulting in four functioning prototypes. Each prototype is intended to illustrate the different possible philosophies for energy efficient design. Results indicate that each prototype has the potential to create an energy-efficient envelope unit with a number of related advantages. 
These designs include:

- A manufactured window-wall panel which uses an improved stick built approach, and offers a new, foolproof technique for window installation that is defect-free.

- A manufactured foam window-wall, which merges SIPS panel technology with post-and-beam construction techniques.

- A manufactured steel wall, which demonstrates a technique for maximizing the benefits of steel while reducing the energy demands normally found in steel construction.

- A stiffened plate window-wall which creates an alternative to stick built methods. The panelized system increases the stiffness, structural integrity and moisture resistance of a panel while substantially reducing thermal short-circuits.

- A ventilated stiffened plate window-wall which utilizes a ventilated wall cavity as a heat exchange device. This system has the advantages of the stiffened plate structure, moisture resistance, and reduced thermal short-circuits. (A prototype was not built of this design during Phase One).

Each system has its advantages and disadvantages. However, simulations show that the foam wall, steel wall, and stiffened plate designs potentially can yield substantial energy savings while solving a number of other problems. Energy analysis was done using a full house simulation of the wall systems with different windows ranging from standard low-E to advanced electrochromic glazing. A detailed energy analysis of the constructed prototypes was also conducted.

Phase One of the IWWS project focussed on the integration of energy efficiency, moisture management, and structural design while exploring the issues of manufacturing and construction. The emphasis was on the wall system and the window-wall interface. Based on these results, Phase Two will involve further analysis and redesign of the prototypes to result in one or two systems brought closer to commercialization. Phase two will involve market research for the system. Revised designs will explore a fuller integration of the window technologies and attachments to the wall system. Issues such as sustainable materials, ventilation, and control systems will be included in the redesigns. 


\section{TABLE OF CONTENTS}

Acknowledgments 2

Executive Summary 3

Table of Contents $\quad 5$

$\begin{array}{ll}\text { 1. Introduction } & 7\end{array}$

1.1 Background

1.2 Summary of Building Industry Problems

1.3 Project Description

2. Wall Systems and Components - Experimental

2.1 Introduction

2.2 Brief History

2.3 Wall Systems in Residential Construction

2.4 Insulation Materials

3. Window Systems and Components - Experimental 27

3.1 Introduction

3.2 Glazing Technologies

3.3 Frame Materials

3.4 Window Installation

3.5 Design Options for the IWWS

4. Other Systems Related to the IWWS - Experimental

4.1 Introduction

4.2 Ventilation and the Integrated Window/Wall System

4.3 Sensor and Control Technologies

5. Key Design Issues for the IWWS - Experimental

5.1 Introduction

5.2 Moisture Management

5.3 Building Codes

5.4 Sustainable Design

5.5 The Building Process

6. Integrated Design - Experimental
6.1 Introduction
6.2 Defining Integration
6.3 Previous Approaches to Integrated Window Walls
6.4 General Design Criteria for IWWS 
7. Results and Discussion - Design Concepts

7.1 Introduction

7.2. Manufactured Stud Wall

7.3 Foam Wall

7.4 Steel Wall

7.5 Stiffened Plate

7.6 Other Concepts

7.7 Energy Analysis - Part 1

7.8 Energy Analysis - Part 2

8. Conclusion

9. Appendices

9.1 Wausau factory trip report

9.2 Composite QFD Matrix

10. References and Bibliography 


\section{Introduction}

This report documents phase one of an effort to develop and test an Integrated, Energy Efficient Building Window and Wall System (IWWS) for residential and small commercial buildings. It represents a deliverable that is part of a contract between Aspen Research Corporation and the US Department of Energy. This introduction begins with background on the national energy situation and DOE's Roadmap efforts. This is followed by a summary of the underlying problems found in the building industry in general, residential window and wall systems in particular. Finally, the project objectives, scope, and methodology are described.

\subsection{BACKGROUND}

\section{Energy Prices}

The nation is presently experiencing instabilities in energy prices caused in part by the fact that demand for energy has grown faster than the supply. According to the Annual Energy Outlook 2001, the demand for energy in the residential sector is expected to rise by about 28 percent by the year 2020. Seventy-five percent of this rise will be due to the increasing demand for electricity. The increasing demand is due in large part to the number of new homes that are being built in the Southern and Southeastern United States. Although the efficiency of the new houses is certainly better than the old housing stock, the average square footage of new houses is also increasing. To promote wise energy usage this growth in house size should be tempered by encouraging increasing efficiencies in the building industry:

"from additional gains in equipment efficiency and more stringent building codes, requiring more insulation, better windows, and more efficient building designs ... is expected to forestall even larger increases." (National Energy Outlook, 2000)."

\section{Global Warming}

There is a twofold effect created by an increasing standard of energy efficiency. Currently, the nation and the world are faced with the growing threat of global warming. As this nation's 
appetite for fossil fuels has increased, so has the amount of greenhouse gases that are released into the environment, leading to a gradual increase in the mean temperature of the planet. The increasing residential building market and its reliance on traditional fossil fuels to supply its heating and air-conditioning needs directly leads to global warming. One of the most effective ways to deal with the increase in energy demand and greenhouse gas production is to install energy efficient windows in residential homes.

\section{Obstacles to Innovation}

One way to deal with the energy needs and carbon dioxide production prevalent in a growing economy is to have government agencies insist upon an ever more stringent set of energy efficiency requirements. This has necessarily led to more strict building codes to effectively mandate energy efficiency. However, such mandates are usually met with resistance from the building industry. The building industry exemplifies a diverse and highly competitive market where margins are razor thin; such a reality guarantees an unacceptably small return on development investments in energy efficiency technology. The matter is further complicated by state and municipal code officials who are charged with guarding the public safety and well-being, and very often view energy efficiency with low priority. Moreover, in today's litigating society, most companies prefer to introduce proven products as a way to avoid costly problems with product liability.

For these reasons, the U. S. Department of Energy is funding a number of projects whose aim is to assist in the development and testing of energy efficient products. This present research study investigates the feasibility of creating a marketable entity called "The Integrated Window-Wall System". The study develops and expands upon the existing work begun by the Lawrence Berkeley National Labs. The concept of a manufactured window-wall product is not new; in fact, the Andersen Corporation has offered similar products twice in its history. However, the idea of using a window-wall combination to create an energy efficient envelope is novel.

\section{DOE Roadmaps}

The United States Department of Energy convened a series of meetings with industrial leaders in the window industry to determine a technology roadmap for the next twenty years. This conference resulted in the Window Industry Technology Roadmap. A similar conference was convened to address the issues of the building envelope, resulting in the Building Envelope Technology Roadmap. These two roadmaps detail and prioritize the technological barriers to the industry as viewed by the industrial participants.

Each of these roadmaps, while developed separately, identified the highest priority technological barrier to be the achievement of true systems integration. This refers to the integration of all the 
components of the building envelope including the window into a single, functional, and energy efficient system. Furthermore, this need to understand systems integration was identified as a nearterm (0-3 year) goal.

This daunting task has been the main thrust of the Integrated Building Window/Wall System project from its inception. The present project, at approximately the halfway point, has identified many of the barriers to achieving this true integration with the suggestion of some possible solutions. However, as both roadmaps indicate, none of this activity is meaningful unless it is accepted in the marketplace and implemented on a large scale. The next phase of this project will address both of these marketplace issues.

In addition to the integration issues identified in the Technology Roadmaps, other longer-term developments were also identified. These include, the need to develop products that can be upgraded as features advance, and the importance of product durability and energy efficiency. The Integrated Building Window/Wall System project has researched many of these other issues as the topic of integration was addressed. While these are long term goals, the foundation laid now will support their success.

\subsection{SUMMARY OF BUILDING INDUSTRY PROBLEMS}

The building industry is a vital and important part of the national and global economy. It faces a number of challenges if it is to bring its performance up to that of several other key industries. The building industry operates in a fragmented way, and many building owners have a low opinion of the industry. There is a need for improvement in the way buildings are designed, built, and operated. The building industry was developed from a cottage or craft base rather than a high technology base. Innovation occurs slowly through field experience. This contributes to another challenge; the amount of research and development in the building industry is relatively low compared to other industries.

Generally, there is a lack of knowledge about long-term building performance and a limited use of life cycle cost analysis. Many building decisions are based on short-term economics resulting in long-term problems on operating costs, maintenance, and durability. A final challenge is the need to understand the total impact of buildings on the environment. The construction of residential buildings require significant amounts of wood, minerals, water, and energy. Resource use and sustainability are becoming increasingly important issues to the building industry and society.

This section indicates the problems to be addressed in the IWWS project. They are divided into two categories - general 
problems associated with residential buildings that are relevant to the IWWS project, and specific problems with conventional residential building technology.

\subsubsection{General Problems}

1. Broader societal issues

- Global warming and air pollution from burning fossil fuels (buildings consume about one third of the total energy).

- Diminishing material resources (including availability and cost of wood products)

- Increasing landfill problems (construction waste contributes $40 \%$ of total)

2. General building industry issues

- Skilled labor shortage

- Many product failures

- Many installation failures

- Inefficient construction process involving multiple trades and limited coordination

- Limited systems thinking and design integration

3. Homeowner and builder issues

- Housing costs are too high for average families

- High costs for heating and cooling a home

- Uncomfortable and unresponsive heating and cooling systems

- Poor indoor air quality

- Poor quality housing construction

- Poor durability of materials and assemblies

- Need to accommodate rapidly changing technologies in the home

- Increasing need for security

\subsubsection{Residential Building Problems}

1. Problems with existing frame wall construction.

- Wall assemblies are made up of many parts with one or two functions each (i.e. siding, house wrap, sheathing, framing, insulation, air/vapor barrier, interior finish). This requires many steps, many seams and connections, and many trades to interact. This results in longer time for construction, greater cost, and more opportunity for failure to occur.

- Frame structural systems are inefficient using much more materials than are required to do the job. Multiple plates, trimmers, studs and oversized headers contribute to this 
waste.

- Water enters wall assemblies from the exterior via rain penetration and is absorbed by materials. Inadequate flashing and reliance on sealants that ultimately fail are problems. This water intrusion contributes to material degradation, lack of durability, and may contribute to mold growth creating indoor air problems.

- Water vapor enters wall cavities from the inside or outside via diffusion and air leakage. Poorly installed air and vapor barriers are common. Electrical outlets and other penetrations create avenues for moisture transport.

- Increased levels of insulation within cavities has reduced the drying potential of walls.

- Increased levels of insulation within cavities are not cost effective because of the required increase in structural framing to accommodate it.

- Installation of insulation in wall cavities is not always perfect - materials do not fill the cavities, they could slip or settle resulting in poorer than expected field performance.

- Thermal short circuits exist through framing members including headers, studs, and plates.

- Many connections are dependent on sealants and adhesives with a potential for failure (especially organic adhesives).

- Some materials are combustible and toxic when burned.

- Some materials outgas and contribute to indoor air problems.

2. Problems with existing structurally insulated panels (SIPs).

- Water intrusion and material degradation occur.

- Neither large openings nor openings near the panel edges can be made because of structural limitations.

3. Problems with window installation.

- Rough openings are imperfect resulting in large, uneven gaps that must be covered. These gaps are prone to water and air intrusion, which can be a thermal weakness if not carefully insulated. (The advantage of conventional rough openings is that they are forgiving in terms of movement and they avoid placing any vertical loads on the window unit).

- Standard installation practice is prone to failure. With the barrier approach, the entire water protection system relies on sealants with a potential for failure. With the membrane approach, correct use and overlapping of flashing is often not done resulting in water penetration into walls.

- Improved installation practices are still tedious and require skilled labor, time and attention. This is only beginning to be understood in residential construction, but there are few 
trained installers. Even some of the best recommended practices still rely on paper flashings with adhesives and other details that are prone to long term failure.

4. Problems with conventional windows.

- Uncontrolled air leakage.

- Condensation at cold surfaces (window edges and frames).

- Discomfort near windows due to drafts and radiant heat transfer. This often means heat must be delivered to the room perimeter near the windows.

- Energy transfer weaknesses in window edges and frames.

- Window properties are static, making them a compromise between ideal properties for underheated versus overheated conditions.

- Conventional methods for adjusting window properties in response to dynamic conditions (i.e. shades, thermal shutters) rely on occupant operation which is not optimal.

- Windows are a weak point in home security. Expensive security systems must often be installed in existing windows.

- Windows are a weak point structurally during hurricanes and tornadoes.

- Glass requires a significant amount of energy in its manufacture.

5. Heating, cooling and ventilation in houses.

- Houses have significant indoor air quality problems. Pollutants and moisture must be removed and fresh air provided while energy use must be minimized.

- In some cases outside air is poor quality requiring filtering and suggesting alternatives to fresh air for ventilation.

- Centralized air handlers and duct distribution systems are inefficient.

- Control systems do not integrate house systems with components.

\subsection{PROJECT DESCRIPTION}

\subsubsection{Objectives}

The purpose of this effort is to develop and test an Integrated, Energy Efficient Building Window and Wall System (IWWS). The effort combines material and construction processes that incorporate the wall construction, window, and other attachments into an integrated system. Integration of the window/wall system with other systems such as heating, ventilation, air conditioning (HVAC), other utilities, and overall house control systems will be explored. The project effort also is intended to develop spin-off 
products aimed at the retrofit and remodeling market, both for residential and low-rise commercial construction. Critical objectives of the project are:

- Superior energy efficiency and dynamic performance in both summer and winter.

- Improved wall and window system durability and longterm performance.

- Elimination of many construction elements and steps that typically result in air, water or thermal leaks.

- Systems-based integration of the wall system with HVAC, utilities and comfort controls.

- Ease and efficiency of application into existing construction practice.

- More rapid delivery of a weatherable building envelope and a potential shortening of the construction process.

- Applicability to both residential and light commercial construction.

- Advanced active and passive glazing technologies as well as thermal storage and heat recovery potential.

- Retrofit and product line extension potential.

- Reduction of construction site waste.

- Increased use of environmentally sustainable and recyclable building materials.

- Design for disassembly, reuse and recycling.

\subsubsection{Project Scope}

The project effort is focussed on a wall panel containing a window that explores the integration of the following construction components:

- Improved levels of passive insulation through elimination of installation defects, thermal bridges and air leaks.

- Advanced window technologies resulting in both heating and cooling energy savings.

- Integrated solar shading and night-time insulation.

- Potential for integrated passive ventilation, electrical conduit, and other systems utilities.

- Increased use of efficient and sustainable materials.

\subsubsection{Project Methodology}

The project uses methodology which includes:

- Applied research into quantifying the energy efficiency 
implications and potential resulting from advanced levels of building systems integration.

- Industrial design and prototyping; laboratory-level testing of components and prototypes.

- Preliminary market evaluations to gauge prototype acceptance.

- Preliminary systems engineering, pilot-scale testing, and thermal modeling.

- Energy and environmental savings assessment. 


\section{Wall Systems and Components}

\subsection{INTRODUCTION}

The desire to including new and novel building components and systems into a house is pitted against the resistance of the building industry to change. Rather than embracing new and promising technologies, the construction trades ardently adhere to present day building practices. In fact, the building and construction industry is considered one of the most conservative industries in the world. The reasons for resistance to change are, by and large, quite formidable. The building and construction trades are quite diverse and no company or entity maintains a sizeable market share. Instead, competition is intense and profit margins are small. In order for a company in the building industry to survive and prosper, it must mass-produce its products as efficiently and inexpensively as possible. If a

company's product proves to be defective or not applicable over a reasonable period of time, then the incurred liabilities could easily place that company in bankruptcy. Therefore, the industry accepts new technologies very cautiously. This means that, up until now, improvements in energy performance have been achieved by incrementally modifying different components which go into a traditional structure (e.g. changing the insulation material, or changing the window).

This section includes a brief history of the building industry followed by a review of current and emerging wall construction systems and materials. Appendix 9.2 includes an evaluation of current wall system components using a composite QFD matrix.

\subsection{A BRIEF HISTORY OF THE BUILDING INDUSTRY}

Since the building industry is conservative by nature, it is insightful to consider the roots of traditional construction methods. Timber construction dates back to the Middle Ages. From the 14th century onward, particularly in Western Europe, half-timber construction emerged as a new form of house building. This type of construction featured a frame of squared timbers, with vertical posts spaced about one meter apart and horizontal girts spaced at the same distance. Diagonal braces were run through the outside 
walls for lateral stability. The English half-timber frame was similar, but it eliminated the horizontal girts and diagonal bracing by using closely spaced verticals about sixteen inches apart. In both systems the space in the outside wall was filled with an enclosure material to impart added rigidity to the frame; brick or wattle and daub were often used. All the timbers of the frame were attached together by elaborate dovetail or mortise-and-tenon joints. Nail fasteners were expensive at this time and not often used. Half-timber framing would remain the standard way of building with wood in Europe until the 19th century. When the European settlers arrived in North America, they attempted to apply this popular building technique to their Colonial style of housing, only to find a lack of masonry building materials and an overabundance of timber. They therefore reverted to the continental style of half-timber construction with diagonal bracing placed on the exterior surface. The horizontal girts were eliminated in deference to the English style of framing. This building practice was widely adopted in the Northeast and MidAtlantic states since it was amenable to the Georgian, Dutch colonial, and English Colonial styles of architecture.

\section{Light Frame Construction}

This style persisted up until the 1830's when the industrialization of saw mills, lumber mills and the mass production of nails made balloon frame construction possible. In this technology, heavy timbers and mortise-and-tenon joints were abandoned in favor of light timber construction. The walls were framed with $2 \times 4$ wooden studs placed at 16 inches on center and capable of reaching 20 feet in elevation. Diagonal stiffness was achieved either by mortising diagonal braces into the studs or by nailing thick boards onto the vertical studs. The second story was built mid-span to the framing. The exterior of the wall was sheathed by a number of materials including ship lap, brick veneer or stucco. Tar paper was placed between the siding and the stud framing to provide a moisture barrier. The interior drywall consisted of wooden lathes covered with plaster. If insulation was to be used, it was of a particulate form and was poured-in from the top of the wall.

As the European immigrants moved westward, they tended to build only single story houses. These pioneers still used the $2 \times 4$ or $2 \times 6$ framing construction. However, they lacked the skilled carpenters needed to make mortised diagonal braces.

Nevertheless, the advent of nail foundries lead to an abundance of inexpensive nail fasteners. Therefore they eliminated the diagonal braces and depended on the stresses and friction in the nails to provide diagonal stability, and the framing was intended to be 10 feet high. This so-called western style house had the wall unit running from the footings on the foundation up to the rafters or roof trusses. If a second story were desired, the framing carpenters would build the second story flooring on top of the first floor framing and then build another 10-foot-high length of framing. Thick lateral stabilizing boards were still used as needed. 


\section{Twentieth Century Improvements}

Early in the 20th century, gypsum board replaced plastercovered lathes for the inner dry wall. Later in the 20th century, plywood was invented and became the sheathing of choice. Both innovations served to greatly improve the lateral stability of the wall. There was a corresponding drop both in cost and construction time.

In the 1960s, fiberglass batts became the insulation material of choice. These batts consisted of fluffed fiberglass glued to kraft paper or aluminum foil. The kraft paper or aluminum foil primarily served as a moisture barrier. In 1973, the energy crisis began. Home construction changed again. In addition to the structural and moisture barrier properties of a house, a wall was required to be an energy barrier. As a response, carpenters carefully sealed most of the avenues for air infiltration. It was also during this time that the energy efficient window was introduced. Prior to the 1970's, single paned windows were normal construction practice. During and after the energy crisis, the window evolved from double-glazed to low-emissivity coated double glazed windows to argon filled low-emissivity coatings. Today, state of the art consists of insulated glass units having dual low-emissivity coatings, argon filled, with a warm-edge spacer.

Throughout the history of the building industry, the standard $2 \times 4$ or $2 \times 6$ studs spaced 16 inches on center has persisted up to this day. In the 14 th century, such a standard was necessary to compensate for the lack of a financially viable fastening

technology. However, today the consensus opinion in the building industry is that the practice constitutes a gross overuse of building materials. Other studies have verified this consensus both by theory and by demonstration projects. In conclusion, after six centuries of improvements in technology, it is feasible to reengineer the window/wall component of the building envelope to achieve improved energy savings and still achieve the structural integrity expected of a modern house.

\subsection{WALL CONSTRUCTION METHODS}

\section{B ackground}

Understanding what wall construction methods are currently used in the single family housing market in the United States is key to the development of the Integrated Energy Efficient Window Wall System (IWWS) for two reasons: One, the IWWS will need to be integrated into the majority of wall construction methods. And two, understanding conventional wall construction methods will help in deciding on the techniques to be used for constructing the IWWS.

\section{Current Market}

According to the U.S. Census, around 1.5 million new single family homes were built or placed in the U.S. in 1998 (Figure 2.1).
Section 2.3: Wall Construction Methods contributed by the Davis Energy Group. 


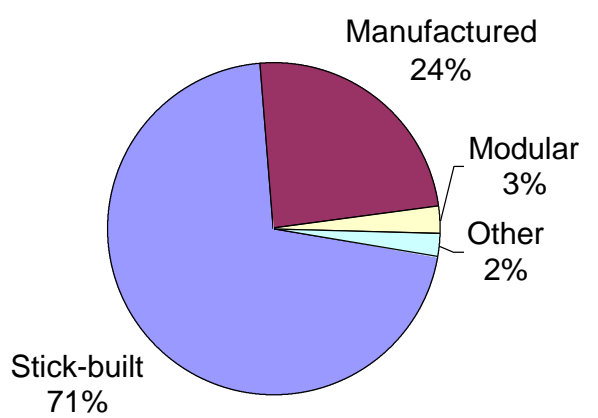

Figure 2.1: Distribution of Single Family Construction Methods

Table 2.1: Industry Association Production Statistics

\begin{tabular}{|lrc|}
\hline & $\begin{array}{c}1998 \\
\text { Market } \\
\text { Share }\end{array}$ & $\begin{array}{c}\text { Annual } \\
\text { Growth } \\
\text { Rate }\end{array}$ \\
\hline Concrete & 102,080 & $10 \%$ \\
ICF & 19,720 & $50 \%$ \\
SIP & 10,000 & $4 \%$ \\
Panelized & 192,000 & $2 \%$ \\
\hline
\end{tabular}

Almost a quarter were manufactured homes built to HUD codes with $67 \%$ of these placed in the South. Of the rest, over $90 \%$ were stick-built. The remaining 75,000 homes consist of modular, panelized and other methods. These numbers tend to conflict somewhat with those claimed by various industry associations as shown in Table 2.1. This is possibly due to two reasons. One, the numbers are not exclusive, i.e. ICF may be a subset of concrete, and SIP may be a subset of panelized. And two, an industry may count as a housing start any house that contains even a small piece of their system, even if the majority of the structure is stick-built.

In order for an integrated window wall product to have a significant market penetration it is obvious that it will need to integrate with stick-built construction. However, because of the historically slow adaptation of new technologies in the residential building sector, it may be easier to adapt the IWWS to some lower volume but more flexible construction method first, in order to demonstrate the viability of the concept.

\section{Future Trends}

While stick-built construction currently enjoys the vast majority of the single family construction market and will remain so for the foreseeable future, there is enormous pressure on builders to find alternative methods for several reasons:

- Price stability: The cost of construction lumber can vary by over $100 \%$ within one year's time. This can cause severe budget problems with builders who must project final costs well in advance.

- Quality: As the size of the trees that are harvested for construction lumber has fallen, the quality has diminished substantially. The small trees produce more warped and damaged lumber, causing higher material and labor costs.

- Skilled labor shortage: Builders are finding it difficult to find enough trained framers to build quality stick-built construction, so the lower skill levels required to use more prefabricated products is attractive.

- Energy efficiency: Although stick-built construction can be highly energy efficient it takes more attention to detail than most builders are economically able to provide. Many of the alternative construction methods offer more reliable energy savings and are more forgiving of installation errors.

- Sustainability: As the public has become aware of the environmental impact of using virgin timber for house construction a "green" market has arisen among many home purchasers.

Promoters of alternative construction methods tout many of these factors when comparing their systems, but so far, the residential construction industry has proven immovable. Residential builders are highly risk averse and do not like to be the 
first to try out new technology unless it can be proven to have significant advantages.

\section{Site Built Stick Frame Construction}

All of the components for the house are delivered to the site in discrete units and constructed on-site from discrete components and materials. Components are purchased from individual distributors, e.g. wood from a lumber yard, windows from a window distributor. Many construction tasks such as exterior and interior sheathing, roofing, concrete, etc., are handled by specialized subcontractors.

In stick framing, the "studs" are the most essential structural member. Studs are oriented vertically and withstand both the weight of materials they support and inward/outward air pressures on the wall. Supported weight includes structure above the wall (floors, walls, ceilings, roofs, furnishings, and occupants), wall materials (wall surfaces, insulation, wiring, plumbing, and the framing system itself) and objects hung on the walls, such as shelves, cabinets, and appliances. Pressures may result from either the wind or from blowers that pressurize or depressurize the house.

Studs are spaced at a constant interval (typically 16 " or 24 ") that is compatible with exterior siding and gypsum board interior surface panel thickness and dimensions. Light, non-structural insulation is placed between the studs. All studs are secured together at top and bottom by horizontal "plates" that are typically of the same cross-sectional dimension as the studs. A double "top plate" is conventionally used in wood construction for added strength and to tie across the lower top plate joints. A single plate is adequate at the bottom because it is strengthened by securement to the floor structure.

Gypsum board ("drywall") is the most common interior finish surface. In cold climates with wood exteriors, or in all climates with stucco exteriors, a "sheathing" layer is commonly used as an exterior surface underlayment. The sheathing is typically a woodbased product (plywood or oriented strand board (OSB)) under wood exterior panels, and a foam plastic panel under stucco. Wind and seismic design requirements often necessitate structural wood sheathing on portions of exterior walls. This added "shear" layer often covers a full wall, when only a portion is needed, to maintain a uniform wall thickness.

Where spacings wider than $16^{\prime \prime}$ or $24^{\prime \prime}$ are needed for door or window openings, "headers" are supported by studs at each side. Headers are "stick" beams that span horizontally to carry structural loads from above to the studs that support them. Trimmers and cripples provide additional strength to these more heavily-loaded studs. For door openings, the bottom plate is omitted or cut out after the wall is erected. For windows, the bottom or "sill" of the framed opening is a horizontal member of the same cross-sectional dimension as the studs, joining short studs that extend downward to the bottom plate. Thus, the framed window opening is defined by studs on the two sides, a header at 
the top, and a sill at the bottom. This opening is made slightly larger than the exterior structure ("jamb") of the manufactured window that it will contain. Since the framing members are not reliably plumb, square, and level when installed, the installer uses shims to true the window within acceptable tolerances.

Wood

Stick framing with graded wood lumber is by far the most common residential structural wall construction method in the U.S. While the types, dimensions, and grades of lumber and surface panels have gradually changed over time, the basic configuration and methodology have not. The structural systems are not fully designed by the architect or other building designer. Instead, the framing crew does the design, assembling walls as they always have, using extra wood to assure structural adequacy.

Unfortunately, this strategy carries a double penalty. The extra wood is more expensive and less valuable thermally than the insulation it replaces. So, conventional framing costs more to install and requires more heating and cooling energy when compared to "engineered" structural systems. Conventional wood studs spaced 16" apart, with single bottom and double top plates, should theoretically fill $14 \%$ of a wall. However, according to a 1991 study on residential construction having conventionallyframed walls in Northern California concluded that 30 to $36 \%$ of the total net wall area (excluding window and door openings) was occupied by wood framing members.

Steel

Framing with cold-formed sheet steel C channels is gaining market share but represents less than $5 \%$ of current construction. The majority of steel residential construction is built stick-for-stick, i.e. exactly the same as wood stick frame but with steel members substituted for wood, with studs placed in top and bottom "tracks". The only key difference with wood construction is that the steel tracks cannot carry vertical loads and so all vertical framing members must be aligned. The high thermal conductivity of the steel studs results in the loss of insulation efficacy, so exterior insulating sheathing should be used. There is also ongoing research into insulating steel studs that use a perforated profile to lower their conductivity.

\section{Relationship to IWWS}

Because wood and steel stick framing is custom-designed on the job in response to the building drawings, an IWWS system can easily be integrated with either. A major reason to consider this integration is that current practice for integrating windows causes significant and unnecessary heat transfer through walls, and adds cost and complexity to the on-site work. The most logical integration strategy is to fabricate full height IWWS units that extend from the floor to the top of the wall studs, ready to be 
joined by a continuous top plate into which the studs are secured. Since total wall thickness may vary with stud depth (typically 3.5" or $\left.5.5^{\prime \prime}\right)$ and surface thickness $\left(1 / 2^{\prime \prime}\right.$ or $5 / 8^{\prime \prime}$ drywall, various exterior types), it may be necessary to produce either varying thickness IWWS units or a "sleeve" system that varies the IWWS thickness through a reasonable range.

The IWWS unit offers an opportunity to integrate additional shear strength around windows, thereby eliminating some or all shear panels that now add considerable cost to conventional exterior walls. They might also include structural tie-down systems that currently complicate wall framing.

It is doubtful that IWWS units can include one or both wall surfaces and still be integrated with conventional wall framing. Including a drywall interior surface would probably dictate that drywall on adjacent opaque walls be oriented vertically, adding additional drywall joints to tape and finish. Also, pre-placed drywall on the IWWS panel might complicate on-site electrical wiring, especially on second floors where access from the exterior side might be difficult. A pre-placed exterior sheathing could be workable, particularly if it provided shear strength and finished flush with conventional framing members.

\section{Improved Stick Framing}

\section{OVE Framing}

Optimum Value Engineered (OVE) framing has been promoted by the National Association of Homebuilders (NAHB) Research Foundation since 1977, primarily as a technique to reduce construction costs rather than to increase energy-efficiency. OVE includes many techniques for reducing the quantity of wood in exterior walls, especially at corners, wall joints, and top plate. OVE also incorporates framed rather than solid headers, facilitating header insulation. As OVE and related systems have evolved, a popular feature has been 2 × 6 studs on 24" centers, allowing R-19 insulation between studs and alignment of trusses directly over studs in load-bearing walls.

\section{Engineered Wall Framing (EWF)}

EWF, used in California for three utility sponsored residential projects in the early 1990's, demonstrates an advanced stick-built wall system that integrates rigid foam insulation between the studs (Figure 2.2). The wall consists of $1-1 / 4 " \times 3-1 / 2 "$ oriented-strand wood studs on 24 " centers filled with rigid foam insulation. Foam spacers on the inside of the studs provide an insulating airspace and room for running pipe and wire without compromising the insulation layer. Unlike structural insulated panels, EWF does not require structural surface layers. Since "buckling" is the primary failure mode for studs, EWF can reduce framing requirements by using the rigid insulation to resist buckling. The rigid insulation also provides a surface to support stucco, eliminating the need for a sheathing layer, and a foil surface to increase the effectiveness of
Figure 2.2: Engineered Wall Framing Components

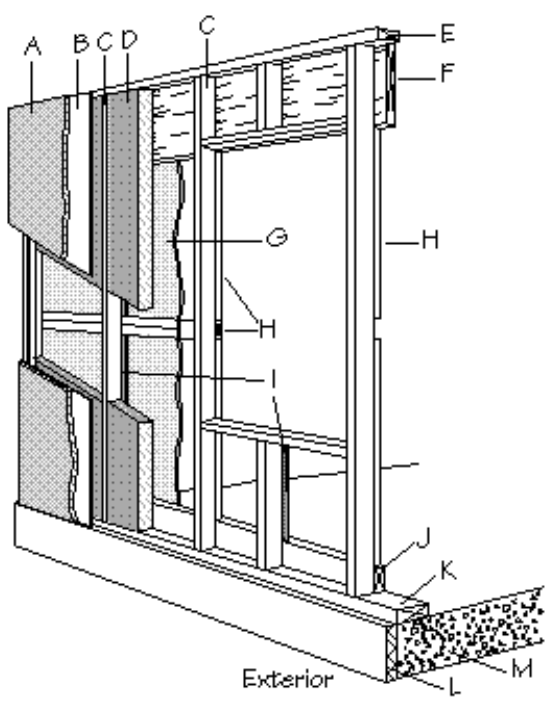

A - Stuoco on wire meoh

B - Foam core board with water barrier

C - 1-1/4" $\times 3-1 / 2^{\prime \prime}$ orierted-strand wood (OSW) gtuds on 24" certers

D - 3-1/2" rigid foam insulation panel

E - 1-1/4" $\times 3-1 / 2 "$ OSW top plate

$F-1-1 / 4 " \times 14$ " OSW header which, along with the top plate forms the continuous "L" header G- Drywall (laid horizoritaly)

$\mathrm{H}$ - 1-1/4" OSW spacer for drymall attachmert

I - Foam ingulation spacer

$J$ - 3"OSW backer

$K$ - Ripped 2" $\times 6^{\prime \prime}$ pregsure-treated gill

L. - 2" $2^{\prime \prime} 12^{\prime \prime}$ rigid foam perimeter ingulation

$\mathrm{H}$ - Conorete glab 
the airspace.

\section{Relationship to IWWS}

Both OVE and EWF systems offer strategies for the design of the IWWS units. From OVE, engineered headers and use of steel joiners to eliminate redundant wood structural members are obvious tactics for IWWS design. From EWF, integral rigid insulation and shallower LSL framing members to facilitate a shear panel are also attractive strategies.

\section{Masonry Wall Construction}

While masonry is almost always used for foundation and basement construction, its use for whole house construction tends to be concentrated in areas that require very high strength for hurricanes such as South Florida. Providing high levels of wall insulation can be problematic, but its high thermal mass can be of significant benefit in climates with high diurnal temperature swings such as the Southwest.

- Concrete Masonry Units (CMU): The primary method of residential masonry construction. Precast, hollow blocks of concrete are stacked to form walls, then cores are filled with reinforcing bar and concrete.

- Insulated Concrete Forms (ICF): Polystyrene forms that are stacked or assembled and then filled with concrete. The forms are left in place to provide significant insulation value. Lower overall labor cost compared to adding insulation to CMU construction can make up for the higher material cost.

- Autoclaved Aerated Concrete Units: Similar to traditional CMUs, however, the material is lightweight and can be cut with a handsaw or band saw. The units accept nails or screws for attachment of finishes. Raceways or channels for wiring and plumbing can be made by routing the assembled wall.

- Rammed Earth: A mixture of earth (usually from the site) and cement is mixed and "rammed" into forms, or sprayed like gunnite onto wire mesh. Because of the low strength of the material, the walls must be over one foot thick.

- Adobe: An asphalt stabilized earth block that is stacked to form walls. A common vernacular construction method in the Southwest but it should not be used anywhere there is significant rainfall without protection by large overhangs.

Relationship to IWWS

Many of the potential advantages of IWWS, such as added shear resistance and the elimination of framing are not needed in masonry construction. The chief benefit of its use would be the 
better window integration it provides, but this is not as critical to masonry construction as the materials are inherently resistant to moisture problems.

\section{Building Systems}

Building systems refers to a construction method which uses components which are pre-manufactured in a factory and then transported to the building site for placement and final finish. The component can be as simple as a pre-cut stud or as complex as an entire modular building.

\section{Industrialized Housing}

Industrialized housing refers to buildings which are typically $90 \%$ or more factory-built and then trucked to the site in one or more floors or sections. They belong to one of two subcategories depending on what codes the structure most meet.

"Manufactured" or "HUD-code" buildings are built to HUD standards and must have a rigid metal frame. "Modular" or "systems built" buildings are built to local model-codes and are placed on permanent foundations. Almost all aspects of industrialized construction occurs in a controlled factory setting. Walls, floors, and roofs are assembled into modules using traditional stick-built techniques in most cases. Some manufacturers use steel, others have experimented with the use of structural insulated panels. Once the modules are completed they are trucked to the sites and placed on a preconstructed foundation using a crane. Finish work is then completed on site. Because the buildings must withstand the dynamic loads of being moved on a truck as a unit, they typically use more wood in the wall than stick built buildings. Many manufacturers use this as a selling point by highlighting the extra studs, plates and shear panels that they use, but it will have an adverse effect on energy and material usage. A list of modular home manufacturers is provided in Table 2.2.

\section{Relationship to IWWS}

Because the construction methods used are very similar to stick-built construction, an IWWS will have many of the same benefits in modular construction. In addition, the controlled factory environment and the ability to fully engineer the integration method, provide for an ideal environment for using an IWWS.

\section{Hybrid Modular / Panelized Housing}

Some modular manufacturers use a hybrid approach which combines the speed and quality control of modular construction with the design flexibility of panelized components. 
Table 2.2: Modular Home Manufacturers

\begin{tabular}{|c|c|c|c|}
\hline Company & City & State & Web Site \\
\hline Active Homes Corp. & \multirow[t]{7}{*}{ Marlette } & \multirow[t]{7}{*}{$\mathrm{Ml}$} & http://www.activehomes.com \\
\hline All American Homes & & & http://www.allamerhomes.com \\
\hline Apex Homes Inc. & & & http://www.apexhomesusa.com \\
\hline Cardinal Homes Inc. & & & http://www.cardinalhomes.com \\
\hline Carolina Building Solutions Inc. & & & http://www.new-era-homes.com \\
\hline Crest Homes & & & http://www.cresthomes.com \\
\hline Crestline Homes Inc. & & & http://www.crestlinehomes.com \\
\hline Customized Structures & Claremont & $\mathrm{NH}$ & http://www.custruct.com \\
\hline DeLuxe Homes of PA & \multirow[t]{2}{*}{ Berwick } & \multirow[t]{2}{*}{ PA } & http://www.deluxehomes.com \\
\hline Design Homes Inc. & & & http://www.designhomesinc.com \\
\hline Epoch Corporation & \multirow[t]{3}{*}{ Pembroke } & \multirow[t]{3}{*}{$\mathrm{NH}$} & http://www.epoch-corp.com \\
\hline Future Home Technology Inc. & & & http://www.fhtmodular.com \\
\hline Haven Homes & & & http://www.havenhomes.com \\
\hline Heckaman Homes & \multirow[t]{2}{*}{ Nappanee } & \multirow[t]{2}{*}{ IN } & http://www.heckamanhomes.com \\
\hline Liberty Homes Inc. & & & http://www.libertyhomesinc.com \\
\hline Manorwood Homes & Pine Grove & PA & http://www.manorwood.com \\
\hline $\begin{array}{l}\text { Mod-U-Kraf Homes Inc. } \\
\text { Modular Structures of PA }\end{array}$ & Rocky Mount & VA & $\begin{array}{l}\text { http://www.mod-u-kraf.com } \\
\text { http://msiofpa.com }\end{array}$ \\
\hline Nationwide Homes & Martinsville & VA & http://www.nationwide-homes.com \\
\hline New Era Building Systems Inc. & \multirow[t]{4}{*}{ Strattanville } & \multirow[t]{4}{*}{ PA } & http://www.new-era-homes.com \\
\hline Norse Building Systems & & & http://www.insideoutinc.com/norsehomes/ \\
\hline Oxford Homes Inc. & & & http://www.oxfordhomesinc.com \\
\hline Pengrove Building Systems & & & http://www.users.penn.com/ pengrove \\
\hline Penn Lyon Homes Inc. & Selinsgrove & PA & http://www.pennlyon.com \\
\hline Pinnacle Building Systems Corp. & Bristol & IN & http://www.modguys.com \\
\hline R-Anell Custom Homes Inc. & \multirow[t]{2}{*}{ Denver } & \multirow[t]{2}{*}{$\mathrm{NC}$} & http://www.r-anell.com \\
\hline Ritz-Craft Homes & & & http://www.ritz-craft.com \\
\hline Rochester Homes & \multirow[t]{4}{*}{ Rochester } & \multirow[t]{4}{*}{ IN } & http://www.rochesterhomesinc.com \\
\hline Samson Homes & & & http://www.samsonhomes.com \\
\hline Unibilt Industries Inc. & & & http://www.unibilt.com \\
\hline Wardcraft Homes & & & http://www.wardcraft.com \\
\hline Westchester Modular Homes & Wingdale & NY & http://www.westchester-modular.com \\
\hline
\end{tabular}

Table 2.3: Panel System Manufacturers

\begin{tabular}{|llll|}
\hline Company & City & State & Web Site \\
\hline American Standard Building Systems & Martinsville & VA & www.asbsystems.com \\
Bernhard-Thomas Building Systems & Shelton & CT & www.btbuildingsystems.com \\
Citation Homes & Spirit Lake & IA & www.citationhomes.com \\
Eastern Exterior Wall Systems, Inc. & Bethlehem & PA & www.eews.com \\
Forest Homes & Selinsgrone & PA & www.foresthomes.com \\
Greco Homes & Puyallup & WA & www.grecohomes.com \\
Harvest Homes & Delanson & NY & www.harvesthomesinc.com \\
Northern Design & Hudson Falls & NY & www.northerndesign.com \\
Wausau Homes & Wausau & WI & www.wausauhomes.com \\
Norvell \& Wallace Lumber Co & Nashville & TN & www.norvell-wallace.com \\
\hline
\end{tabular}


Panel systems are components that are built at the factory, then installed and finished on-site. The most common panel systems are roof and floor trusses which are used in the majority of residential construction. The same factory production techniques can be used to produce walls too.

\section{Pre-cut (component)}

This is the "house kit" and is the simplest and least finished of the panel systems. All of the components are engineered and precut at the factory but are assembled and installed on-site from detailed instructions. Its principle benefits are higher quality materials and less construction waste. Many steel framing systems use pre-cut systems.

\section{Panelization}

A panelized house is made up of a set of wall panels, floor decks, and roof and floor trusses, all of which are manufactured at a factory, then trucked to the site. At the site they are unloaded using a crane and assembled using conventional construction techniques. Panels can be delivered open or closed. Open panels, the most common, have exterior sheathing and sometimes with windows and doors installed, but insulation, plumbing, electrical, and interior finish are applied on-site. This leaves the walls open for inspection by local officials. Closed panels have all electrical, plumbing, insulation, and interior sheathing installed at the factory. Because they are closed when they arrive on-site, these panels must be inspected at the factory and must have a code stamp applied to them so that the local building official can verify their compliance. Although the walls are constructed in a controlled factory environment, most manufacturers appear to use conventional framing techniques and have not developed a more integrated method. A list of panel system manufacturers is provided in Table 2.3 .

\section{Modular Shear Wall}

A relatively new panelized building product, the modular shear wall, is a prefabricated wall panel that is used for adding shear strength to a conventional wall. It comes with a template for installing the foundation bolts and integrates directly into a conventional wall. Two versions are currently available, a wood panel made by Simpson (Figure 2.3) and a steel panel made by Simplified Structural Systems (Figure 2.4). In conventional construction, shear is provided by adding plywood or OSB sheathing to the exterior of the framed wall. Because the sheathing adds $7 / 16$ " to the thickness of the wall, either the sheathing must be added to the whole wall, or the non-sheathed sections must be furred out. In addition, construction of the shear wall is time consuming as it must be heavily nailed. A modular shear wall

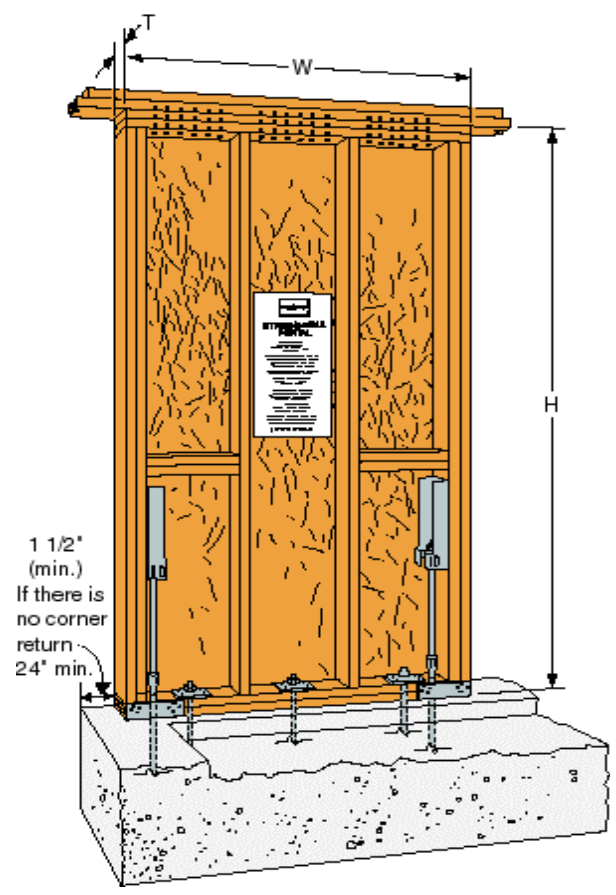

Figure 2.3: Simpson Strong-Wall®

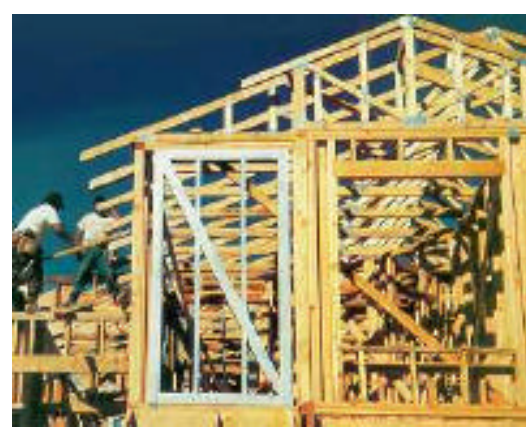

Figure 2.4: Simplified Structural Systems Hardy Frame® 


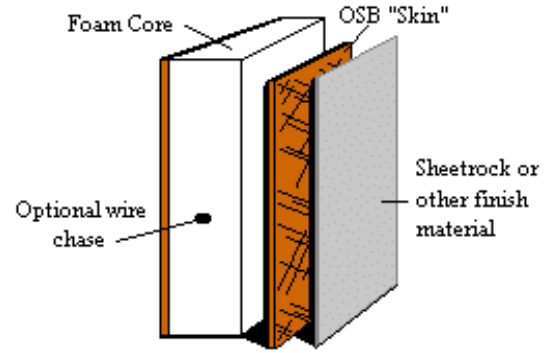

Figure 2.3: SIP Construction Detail addresses both of these issues, and in addition provides a preapproved system that does not need inspection, and a consistent product in quality and performance. Because it is a modular product it cannot be adjusted in the field, so coordination between the architect and the framing crew is critical.

\section{Structural Insulated Panel}

Structural insulated panels (SIPs), also known as "structural sandwich panels", are one panel system that has taken advantage of the factory environment in order to build a more integrated structure. They consist of a foam core sandwiched between two facings or "skins" (Figure 2.5). The facings are typically plywood or OSB but can also be drywall or steel. The foam used is either expanded polystyrene (EPS), extruded polystyrene (XEPS), or urethane. Openings for windows and doors can be either site-cut or pre-cut. In the case of pre-cut, detailed plans are provided to the manufacturer. Then, the individual panels are routed out and coded at the factory. Individual panels are joined in the field using many different techniques including single $2 x$ spline, double $2 x$ spline, double thin spline, thermally broken spline, cam locks, and PVC spline.

\subsection{INSULATION MATERIALS}

Four insulation materials that are in use in residential construction are listed below.

Fiberglass batts - Commonplace but does not create a seal between fiberglass batts and wood studs. The R-value diminished when wet.

Polystyrene foam - Improved R-value per inch compared to fiberglass batts. Polystyrene foam is installed as sheathing or in cavities. Rigid boards are easy to cut to size and install. Leakage can occur around the boards, and termites and other pests like to nest in the foam.

Polyurethane foam - Higher R-value per inch than polystyrene. Polyurethane requires special spraying equipment to install and the excess is cut away with a saw. The foam adheres to the wood walls and studs, reducing air leakage. The material is not fire resistant and must be used in conjunction with a fire retardant.

Polyisocyanurate foam - Also has a very high R-value. The foam can be sprayed or poured into a cavity. It requires special equipment to install. The foam adheres to the wood walls and studs, reducing air leakage. The material is fire resistant and can be used in most insulation applications. 


\section{Window Systems and Components}

\subsection{INTRODUCTION}

In the 1950's the technique of producing float glass was developed (molten glass "floats" over a tank of molten tin), which provides extremely flat surfaces, uniform thicknesses, and few if any visual distortions. This float glass is used in virtually all residential windows today. This was a key breakthrough that has become important decades later because the high-quality surface of float glass is required for the application of thin coatings that are commonly used in windows today.

Information in this section is contributed by John Carmody and Dariush Arasteh

Before 1965, single-glazed windows with storm windows and screens were prevalent in the United States. The most important trend in windows between 1965 and 1980 was a significant change to insulating glazing (two panes of glass sealed together with an air space in between). Although double-glazed units were developed before 1965, the seals were not maintained consistently, resulting in product failure. In the late 1970's, triple-glazed units were developed in response to the energy crisis of the time. By 1980, the demand for insulating glazing accelerated - the market reflected this trend with window sales of 50 percent single glazing, 45 percent double glazing, and 5 percent triple glazing. Today, nearly 90 percent of all residential windows sold include insulated glazing (two or more layers). The market for conventional tripleglazed windows has been diminishing because a number of other technological breakthroughs have created a new series of energyefficient windows with better performance and fewer drawbacks (although triple glazing is still used in combination with other features).

This chapter provides an overview of current and emerging window technologies and practices that pertain to the IWWS project: glazing technology, frame materials, and installation.

\subsection{GLAZING TECHNOLOGY}

There are three fundamental approaches to improving the energy performance of glazing products:

1. Alter the glazing material itself by changing its chemical composition or physical characteristics. An example of this 
Table 3.1. Center of glass window properties for typical glazing units.

\begin{tabular}{|lccc|}
\hline Glazing Type & U-factor & SHGC & VT \\
\hline single-clear & 1.11 & 0.86 & 0.90 \\
single-gray tint & 1.11 & 0.73 & 0.68 \\
double-clear & 0.49 & 0.76 & 0.81 \\
double-gray tint & 0.49 & 0.62 & 0.62 \\
double-ss tint & 0.49 & 0.48 & 0.69 \\
$\begin{array}{l}\text { double-low-E } \\
\text { (high solar gain) }\end{array}$ & 0.30 & 0.71 & 0.75 \\
$\begin{array}{l}\text { double-low-E } \\
\text { (moderate solar gain) }\end{array}$ & 0.26 & 0.53 & 0.75 \\
$\begin{array}{l}\text { double-low-E } \\
\text { (low solar gain) }\end{array}$ & 0.25 & 0.39 & 0.70 \\
$\begin{array}{l}\text { triple-low-E } \\
\text { (moderate solar gain) }\end{array}$ & 0.15 & 0.50 & 0.65 \\
$\begin{array}{l}\text { triple-low-E } \\
\text { (low solar gain) }\end{array}$ & 0.13 & 0.33 & 0.56 \\
\hline
\end{tabular}

is tinted glazing.

2. Apply a coating to the glazing material surface. Reflective coatings and films have been developed to reduce heat gain and glare, and more recently, low-emittance coatings have been developed to improve both heating and cooling season performance.

3. Assemble various layers of glazing and control the properties of the spaces between the layers. These strategies include the use of two or more panes or films, lowconductance gas fills between the layers, and thermally improved edge spacers. Laminated glazing is another form of assembling layers to achieve certain properties.

Two or more of these approaches may be combined as discussed below. Thermal improvements to the window sash and frame are discussed later in the next section.

\section{Clear Glazing}

Relative to all other glazing options, clear single glazing allows the highest transfer of energy (i.e., heat loss or heat gain depending on local climate conditions) while permitting the highest daylight transmission.

Storm windows added onto the outside of window frames during the stormy winter season were the first double-glazed windows. The intent was to reduce infiltration from winter winds by providing a seal all around the operating sash. Improving the insulating value of the glazing was an important secondary effect.

Double glazing, compared to single glazing, cuts heat loss approximately in half due to the insulating air space between the glass layers. In addition to reducing the heat flow, a double-glazed unit with clear glass will allow a high transmission of high levels of visible light and solar heat gain.

When manufacturers began to experiment with factory-sealed, double-pane glass to be installed for year-round use, they encountered a number of technical concerns, such as how to allow for differential thermal movement between the two panes, how to prevent moisture from forming between the panes and condensing on an inaccessible surface, and how to allow for changes in atmospheric pressure as the assembly was moved from factory to installation site. These issues have been successfully addressed over the years with a variety of manufacturing techniques and material selections.

When double-glass units first came on the market, the two glass layers were often fused around the perimeter to make a permanently sealed air space. In recent years, however, spacers and polymer sealants have largely replaced glass-to-glass seals, and have proven sufficiently durable for residential applications. The layers of glass are separated by and adhere to a spacer, and the sealant, which forms a gas and moisture barrier, is applied around the entire perimeter. Normally, the spacer contains a desiccant material to absorb any residual moisture that may remain in the air 
space after manufacture. Sealed insulating glass units are now a mature, well-proven technology. Designs utilizing high-quality sealants and manufactured with good quality control should last for decades without seal failure.

In addition to sealed insulating glass units, some manufacturers offer double-glazed units with nonsealed removable glazing panels. A blind or shade may be located between the glazings, or the inner glazing may be added in winter and removed in summer. In these double-glazed designs, the inner glazing fits snugly to the sash, and the unsealed air space is normally vented to the exterior with a small tube to prevent condensation from forming in the air space. Three or more glazing layers can provide even more insulating value.

\section{Tinted Glazing}

Both plastic and glass materials are available in a large number of tints. The tints absorb a portion of the light and solar heat. Tinting changes the color of the window and can increase visual privacy. The primary uses for tinting are to reduce glare from the bright outdoors and reduce the amount of solar energy transmitted through the glass.

Tinted glazings retain their transparency from the inside, although the brightness of the outward view is reduced and the color is changed. The most common colors are neutral gray, bronze, and blue-green, which do not greatly alter the perceived color of the view and tend to blend well with other architectural colors. Many other specialty colors are available for particular aesthetic purposes.

Tinted glass is made by altering the chemical formulation of the glass with special additives. Its color changes with the thickness of the glass and the addition of coatings applied after manufacture. Every change in color or combination of different glass types affects transmittance, solar heat gain coefficient, reflectivity, and other properties. Glass manufacturers list these properties for every color, thickness, and assembly of glass type they produce.

Tinted glazings are specially formulated to maximize their absorption across some or all of the solar spectrum and are often referred to as "heat-absorbing." All of the absorbed solar energy is initially transformed into heat within the glass, thus raising the glass temperature. Depending upon climatic conditions, up to 50 percent of the heat absorbed in a single layer of tinted glass may then be transferred via radiation and convection to the inside. Thus, there may be only a modest reduction in overall solar heat gain compared to other glazings. Heat-absorbing glass provides more effective sun control when used as the outer layer of a double-pane window, as discussed later in the chapter.

There are two categories of tinted glazing: the traditional tints that diminish light as well as heat gain, and spectrally selective tints that reduce heat gain but allow more light to be transmitted to the interior. The traditional tinted glazing often forces a trade-off between visible light and solar gain. For these bronze and gray tints, there is a greater reduction in visible transmittance than there 


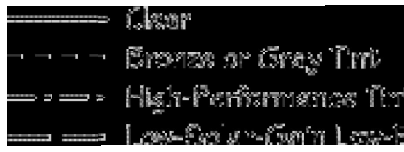

Source: Lawrence Berkeley National Laboratory. is in solar heat gain coefficient. This can reduce glare by reducing the apparent brightness of the glass surface, but it also reduces the amount of daylight entering the room. For windows where daylighting is desirable, it may be more satisfactory to use a highperformance tint or coating along with other means of controlling solar gain. Tinted glazings can provide a measure of visual privacy during the day when they reduce visibility from the outdoors. However, at night the effect is reversed and it is more difficult to see outdoors from the inside.

The primary purpose of bronze or gray tinted glass is to reduce solar heat gain, but it also reduces visible light as compared to clear single glazing. The tint has no effect on the U-factor.

To address the problem of reducing daylight with traditional tinted glazing, glass manufacturers have developed highperformance tinted glass that is sometimes referred to as "spectrally selective." This glass preferentially transmits the daylight portion of the solar spectrum but absorbs the nearinfrared part of sunlight. This is accomplished with additives during the float glass process. Like other tinted glass, it is durable and can be used in both monolithic and multiple-glazed window applications. These glazings have a light blue or light green tint and have visible transmittance values higher than conventional bronze- or gray-tinted glass, but have lower solar heat gain coefficients. Typical spectral transmittance plots are shown in Figure 3.1. Because they are absorptive, they are best used as the outside glazing in a double-glazed unit. They can also be

Figure 3.1. Spectral transmittance curves for common tinted and low-emittance glazings.

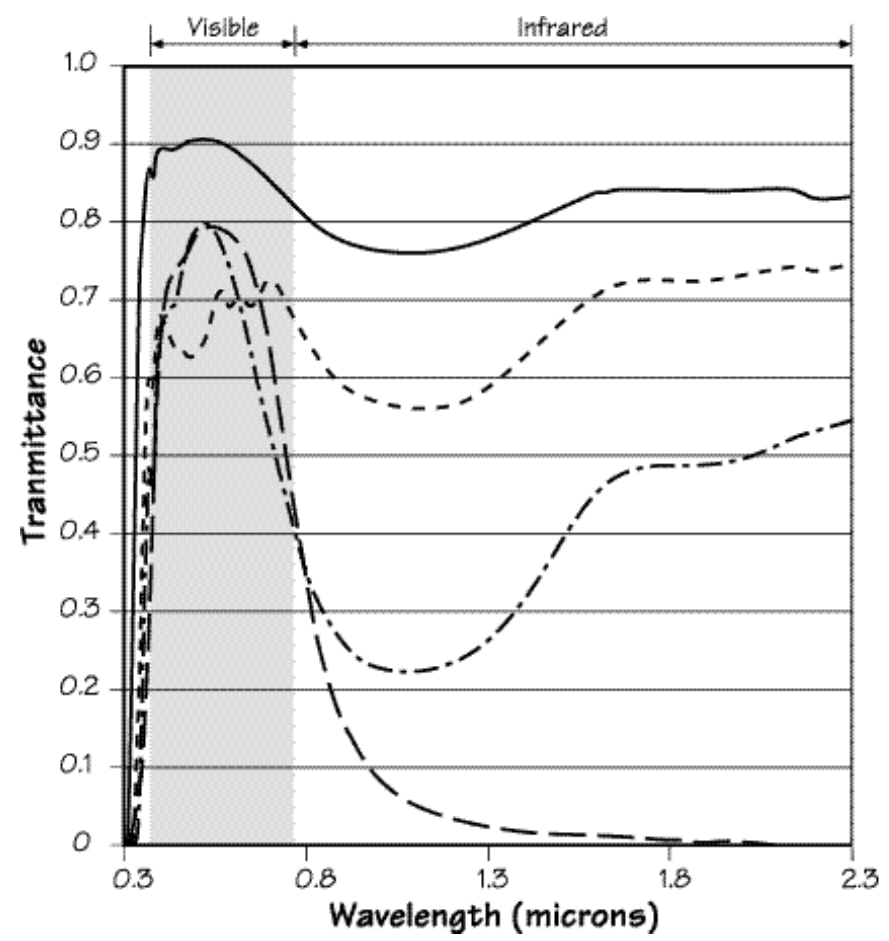


combined with low-E coatings to enhance their performance further. High performance tinted glazings provide a substantial improvement over conventional clear, bronze, and gray glass, and a modest improvement over the existing green and blue-green colored tinted glasses that already have some selectivity.

Tinted glazing is much more common in commercial windows than in residential windows. Residential solar gains are more typically controlled using blinds, drapes, or other decorative window treatments. However, tinted glazings can be used in combination with the more traditional residential sun controls, where increased solar gain control or privacy is needed. In retrofit situations, when windows are not being replaced, tinted plastic film may be applied to the inside surface of the glazing. The applied films are effective at reducing solar gains but are not as durable as tinted glass.

Tinted glazing is in place for the life of the window; this has both advantages and disadvantages. On the positive side, the tinted glazing requires no maintenance or operation from the inhabitants. On the other hand, it cannot respond to changing conditions. It cuts out solar heat and light not only in the summer but also in the winter, when they might be desired.

Double-pane units can be assembled using different glass types for the inner and outer layers. Typically, the inner layer is standard clear glass, while the outer layer is tinted. Compared to a clear double IG unit, the solar heat gain coefficient is primarily reduced because the tinted glass reduces transmitted radiation. In addition, this design further reduces solar heat gain because the inner clear glass as well as any gas fill and any low-E coating keep much of the heat absorbed by the outer glass from entering the building interior.

\section{Reflective Coatings}

As the SHGC is lowered in single-pane tinted glazings, the daylight transmission (VT) drops even faster, and there are practical limits on how low the SHGC can be made using tints. If larger reductions are desired, a reflective coating can be used to lower the solar heat gain coefficient by increasing the surface reflectivity of the material. These coatings usually consist of thin metallic layers. The reflective coatings come in various metallic colors (silver, gold, bronze), and they can be applied to clear or tinted glazing. The solar heat gain coefficient of the substrate can be reduced a little or a lot, depending on the thickness and reflectivity of the coating, and its location in the glazing system. Some reflective coatings are durable and can be applied to exposed surfaces; others must be protected in sealed insulating glass units.

Similar to tinted films in retrofit situations, reflective coatings may be applied to the inner glass surface of an existing window by means of an adhesive-bonded, metallic-coated plastic film. The applied films are effective at reducing solar gains but are not as durable as some types of coated glass.

As with tinted glazing, the visible transmittances of reflective 
glazings are usually reduced substantially more than the solar heat gain coefficient. Reflective glazings are usually used in commercial buildings for large windows, for hot climates, or for windows where substantial solar heat gains and/or glare are present. In residences, they are usually reserved for special cases. For example, a picture window looking west over a large body of water experiences substantial solar gains and reflected glare during summer afternoons and may require a reflective glazing.

\section{Low-Emittance Coatings}

The principal mechanism of heat transfer in multilayer glazing is thermal radiation from a warm pane of glass to a cooler pane. Coating a glass surface with a low-emittance material and facing that coating into the gap between the glass layers blocks a significant amount of this radiant heat transfer, thus lowering the total heat flow through the window. The improvement in insulating value due to the low-E coating is roughly equivalent to adding another pane of glass to a multipane unit.

The solar spectral reflectance of low-E coatings can be manipulated to include specific parts of the visible and infrared spectrum (Figure 3.2). This is the origin of the term "spectrally selective glazings," which can allow specific portions of the energy spectrum to be "selected," so that desirable wavelengths of energy are transmitted and others specifically reflected. A glazing material can then be designed to optimize energy flows for solar heating, daylighting, and cooling.

Figure 3.2. Spectral transmittance curves for glazings with low-emittance coatings.
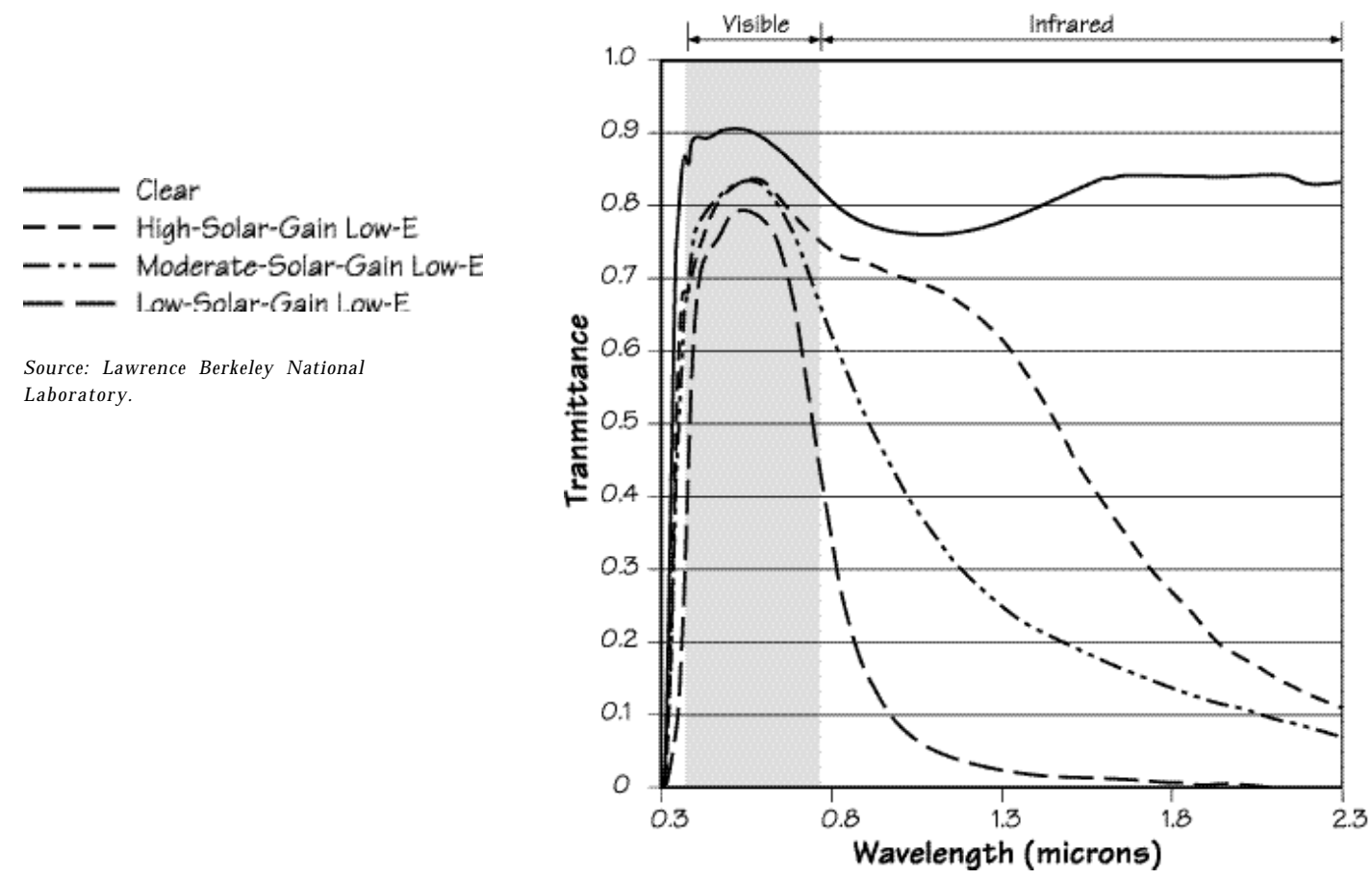
With conventional clear glazing, a significant amount of solar radiation passes through the window, and then heat from objects within the house is reradiated back to the glass and then from the glass outside. However, a glazing design for maximizing energy efficiency in the winter would ideally allow all of the solar spectrum to pass through, but would block the reradiation of heat from the inside of the house. The first low-E coatings were designed to have a high solar heat gain coefficient and a high visible transmittance to transmit the maximum amount of sunlight into the interior while reducing the U-factor significantly.

A glazing designed to minimize summer heat gains but allow for some daylighting would allow most visible light through, but would block all other portions of the solar spectrum, including ultraviolet light and near-infrared, as well as long-wave heat radiated from outside objects, such as paving and adjacent buildings. These second-generation low-E coatings were designed to reflect the solar near-infrared, thus reducing the total solar heat gain coefficient while maintaining high levels of light transmission. Unfortunately, in colder weather, low-solar-gain coatings reduce the beneficial solar gain that could be used to offset heating loads. Low-E coatings can be formulated to have a broad range of solar control characteristics while maintaining a low U-factor.

\section{Coating Types}

There are two basic processes for making low-E coatings-sputtered and pyrolytic. The best of each type of coating is colorless and optically clear. Some coatings may have a slight hue or subtle reflective quality, particularly when viewed in certain lighting conditions or at oblique angles.

A sputtered coating is multilayered (typically, three primary layers, with at least one layer of metal) and is deposited on glass or plastic film in a vacuum chamber. The total thickness of a sputtered coating is only $1 / 10,000$ of the thickness of a human hair. Sputtered coatings often use a silver layer and must be protected from humidity and contact. For this reason they are sometimes referred to as "soft coats." Since sputtering is a low-temperature process, these coatings can be deposited on flat sheets of glass or thin plastic films. While sputtered coatings are not durable in themselves, when placed into a sealed double- or triple-glazed assembly they should last as long as the sealed glass unit. Sputtered coatings typically have lower emittances than pyrolytic coatings. They are available commercially with emittance ratings of $\mathrm{e}=0.20$ to as low as $\mathrm{e}=0.04$ ( $\mathrm{e}=0.15$ means that 85 percent of the long-wavelength radiant energy received by the surface is reflected, while e $=0.04$ means 96 percent is reflected). For uncoated glass, $\mathrm{e}=0.84$, which means only 16 percent of the radiant energy received by the surface is reflected. Low-solar-gain sputtered coatings are created by altering the number of coating layers and their thicknesses, which causes the coating to reflect the sun's near-infrared energy as well as the long-wave infrared.

A typical pyrolytic coating is a metallic oxide, most commonly 
tin oxide with some additives, which is deposited directly onto a glass surface while it is still hot. The result is a baked-on surface layer that is quite hard and thus very durable, which is why this is sometimes referred to as a "hard coat." A pyrolytic coating can be ten to twenty times thicker than a sputtered coating but is still extremely thin. Pyrolytic coatings can be exposed to air, cleaned with normal cleaning products, and subjected to general wear and tear without losing their low-E properties.

Because of their greater durability, pyrolytic coatings are available on single-pane glass and separate storm windows, but not on plastics, since they require a high-temperature process. In general, though, pyrolytic coatings are used in sealed, doubleglazed units with the low-E surface inside the sealed air space. While there is considerable variation in the specific properties of these coatings, they typically have emittance ratings in the range of $\mathrm{e}=0.40$ to $\mathrm{e}=0.15$. Pyrolytic coatings with low-solar-heat gain properties are just coming to market.

A laminated glass with a spectrally selective low-E sputtered coating on plastic film sandwiched between two layers of glass offers the energy performance of single-pane, spectrally selective glass and the safety protection of laminated glass. However, in this configuration, since the low-E surface is not exposed to an air space, there is no effect on the glazing U-factor.

Low-solar-gain low-E coatings on plastic can also be applied to existing glass as a retrofit measure, thus reducing the SHGC of an existing clear glass considerably while maintaining a high visible transmittance. Other conventional tinted and reflective films will also reduce the SHGC but at the cost of lower visible transmittance. Reflective mirrorlike metallic films can also lower the U-factor, since the surface facing the room has a lower emittance than uncoated glass.

The technology to produce low-E coatings has been evolving quickly, and the market price has been dropping at a corresponding rate. Once the initial hurdle of making a substantial investment in the necessary production machinery has been met, there is a market incentive for manufacturers to provide coatings on as much of the glass produced as possible. Thus, windows with low-E coatings have become a standard residential window product. Approximately 40 percent of window products now sold in the United States have low-E coatings, and the figure will continue to rise.

High-solar-gain products are best suited to buildings located in heating-dominated climates and particularly to south-facing windows in passive solar designs. Moderate-solar-gain coatings reduce heat loss and allow a reasonable amount of solar gain, and are suitable for climates with both heating and cooling concerns. Low-solar-gain low-E glazings are ideal for buildings located in cooling-dominated climates. In heating-dominated climates with a modest amount of cooling or climates where both heating and cooling are required, low-E coatings with high, moderate, or low solar gains may result in similar annual energy costs depending on 
the house design and operation. While the high-solar-gain glazing performs better in winter, the low-solar-gain performs better in summer.

Until recently all of the low- to moderate-solar-gain low-E options were produced by sputtering. New pyrolytic coatings are available from several manufacturers which are colorless and provide good spectral selectivity but with only a moderate

Table 3.2. Properties of common window assemblies.

\begin{tabular}{|c|c|c|c|c|c|c|c|}
\hline $\begin{array}{l}\text { Frame } \\
\text { Type }\end{array}$ & $\begin{array}{l}\text { \# of } \\
\text { Glazings }\end{array}$ & $\begin{array}{l}\text { Glazing } \\
\text { Description }\end{array}$ & $\begin{array}{l}\text { Gap } \\
\text { (inch) }\end{array}$ & Gas* & $\begin{array}{l}\text { U-factor } \\
\left(\text { Btu } / \mathrm{hr}-\mathrm{ft}^{2}-{ }^{\circ} \mathrm{F}\right)\end{array}$ & $\begin{array}{l}\text { OTAL WINDOW } \\
\text { SHGC } \\
\text { (Solar Heat Gain } \\
\text { Coefficient) }\end{array}$ & $\begin{array}{l}\text { VT } \\
\text { (Visible } \\
\text { Transmittance) }\end{array}$ \\
\hline$A L$ & 1 & Clear & $\mathrm{n} / \mathrm{a}$ & $\mathrm{n} / \mathrm{a}$ & 1.25 & 0.76 & 0.74 \\
\hline$A L$ & 1 & Bronze & $\mathrm{n} / \mathrm{a}$ & $\mathrm{n} / \mathrm{a}$ & 1.25 & 0.65 & 0.56 \\
\hline$A L$ & 2 & Clear & 0.375 & Air & 0.79 & 0.68 & 0.67 \\
\hline$A L$ & 2 & Bronze & 0.375 & Air & 0.79 & 0.57 & 0.50 \\
\hline$A L$ & 2 & HP Tint & 0.375 & Air & 0.79 & 0.46 & 0.57 \\
\hline$A L$ & 2 & HS Low-E & 0.50 & Argon & 0.64 & 0.64 & 0.62 \\
\hline$A L$ & 2 & MS Low-E & 0.50 & Argon & 0.61 & 0.49 & 0.62 \\
\hline$A L$ & 2 & LS Low-E & 0.50 & Argon & 0.60 & 0.38 & 0.57 \\
\hline ATB & 1 & Clear & $\mathrm{n} / \mathrm{a}$ & $\mathrm{n} / \mathrm{a}$ & 1.08 & 0.70 & 0.69 \\
\hline ATB & 1 & Bronze & $\mathrm{n} / \mathrm{a}$ & $\mathrm{n} / \mathrm{a}$ & 1.08 & 0.60 & 0.52 \\
\hline ATB & 2 & Clear & 0.50 & Air & 0.64 & 0.62 & 0.62 \\
\hline ATB & 2 & Bronze & 0.50 & Air & 0.64 & 0.52 & 0.47 \\
\hline ATB & 2 & HP Tint & 0.50 & Air & 0.64 & 0.41 & 0.53 \\
\hline ATB & 2 & HS Low-E & 0.50 & Argon & 0.52 & 0.58 & 0.57 \\
\hline ATB & 2 & MS Low-E & 0.50 & Argon & 0.49 & 0.45 & 0.58 \\
\hline ATB & 2 & LS Low-E & 0.50 & Argon & 0.48 & 0.34 & 0.53 \\
\hline $\mathrm{W} / \mathrm{V}$ & 1 & Clear & $\mathrm{n} / \mathrm{a}$ & $\mathrm{n} / \mathrm{a}$ & 0.90 & 0.63 & 0.64 \\
\hline W / V & 1 & Bronze & $\mathrm{n} / \mathrm{a}$ & $\mathrm{n} / \mathrm{a}$ & 0.90 & 0.54 & 0.48 \\
\hline W / V & 2 & Clear & 0.50 & Air & 0.49 & 0.56 & 0.58 \\
\hline $\mathrm{W} / \mathrm{V}$ & 2 & Bronze & 0.50 & Air & 0.49 & 0.46 & 0.44 \\
\hline W / V & 2 & HP Tint & 0.50 & Air & 0.49 & 0.37 & 0.49 \\
\hline $\mathrm{W} / \mathrm{V}$ & 2 & HS Low-E & 0.50 & Argon & 0.36 & 0.52 & 0.53 \\
\hline W / V & 2 & MS Low-E & 0.50 & Argon & 0.33 & 0.40 & 0.53 \\
\hline W / V & 2 & LS Low-E & 0.50 & Argon & 0.32 & 0.30 & 0.50 \\
\hline W / V & 3 & MS Super & 0.50 & Argon & 0.26 & 0.38 & 0.46 \\
\hline W / V & 3 & LS Super & 0.50 & Argon & 0.24 & 0.25 & 0.40 \\
\hline INS & 2 & Clear & 0.50 & Air & 0.44 & 0.59 & 0.62 \\
\hline INS & 2 & Bronze & 0.50 & Air & 0.44 & 0.49 & 0.47 \\
\hline INS & 2 & HP Tint & 0.50 & Air & 0.44 & 0.38 & 0.53 \\
\hline INS & 2 & HS Low-E & 0.50 & Argon & 0.30 & 0.55 & 0.57 \\
\hline INS & 2 & MS LOW-E & 0.50 & Argon & 0.27 & 0.42 & 0.58 \\
\hline INS & 2 & LS Low-E & 0.50 & Argon & 0.26 & 0.31 & 0.53 \\
\hline INS & 3 & MS Super & 0.50 & Argon & 0.18 & 0.39 & 0.49 \\
\hline INS & 3 & LS Super & 0.50 & Argon & 0.17 & 0.26 & 0.43 \\
\hline
\end{tabular}

FRAME TYPE CODES:

$A L=$ Aluminum

$A T B=$ Aluminum, Thermally Broken

$W / V=$ Wood/Vinyl

INS = Insulated Frame
GLAZING TYPE CODES:

$H P=$ High-performance

HS $=$ High-solar-gain low $-E(e=0.15-0.20)$

$M S=$ Moderate-solar-gain low- $E(e=10)$

$L S=$ Low-solar-gain (or "spectrally selective") low-E (e=0.04)

MS Super = 3-layer insulating glazing, two layers with high-solar-

gain low-E coatings.

LS Super $=3$-layer insulating glazing, two layers with low-solar-gain

low-E coatings. 
reduction in emittance. These coated glazings can withstand handling and long-term storage, and can be used in nonsealed IG units.

\section{Gas Fills and Gap Width in Multiple-Glazed Units}

Another improvement that can be made to the thermal performance of insulating glazing units is to reduce the conductance of the air space between the layers. Originally, the space was filled with air or flushed with dry nitrogen just prior to sealing. In a sealed glass insulating unit, air currents between the two panes of glazing carry heat to the top of the unit and settle into cold pools at the bottom. Filling the space with a less conductive, more viscous, or slow-moving gas minimizes the convection currents within the space, conduction through the gas is reduced, and the overall transfer of heat between the inside and outside is reduced.

Manufacturers have introduced the use of argon and krypton gas fills, with measurable improvement in thermal performance (see Figure 3.3). Argon is inexpensive, nontoxic, nonreactive, clear, and odorless. The optimal spacing for an argon-filled unit is the same as for air, about $1 / 2$ inch $(12 \mathrm{~mm})$. Krypton has better thermal performance, but is more expensive to produce. Krypton is particularly useful when the space between glazings must be thinner than normally desired, for example, $1 / 4$ inch $(6 \mathrm{~mm})$. A mixture of krypton and argon gases is also used as a compromise between thermal performance and cost.

Filling the sealed unit completely with argon or krypton presents challenges that manufacturers continue to work on. A typical gas fill system adds the gas into the cavity with a pipe inserted through a hole at the edge of the unit. As the gas is pumped in, it mixes with the air, making it difficult to achieve 100

Figure 3.3. U-factor as a function of air-space thickness and emittance.

Gas fill between panes

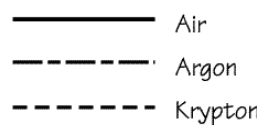

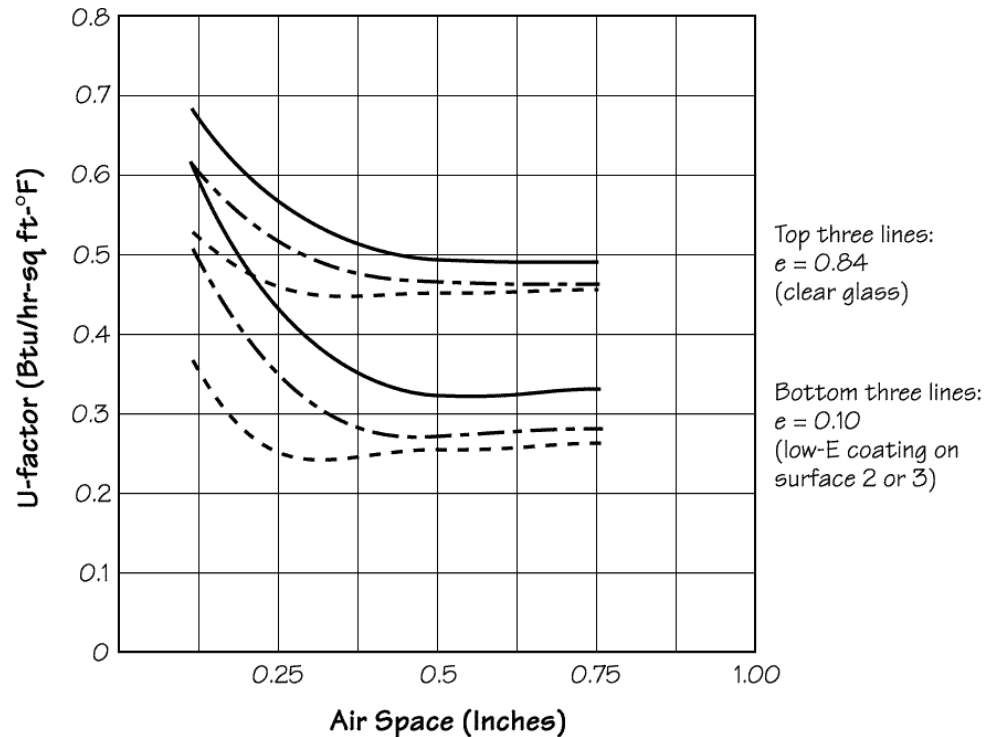


percent purity. Recent research indicates that 90 percent is the typical concentration achieved by manufacturers today. Some manufacturers are able to consistently achieve better than 95 percent gas fill by using a vacuum chamber. An uncoated doublepane unit filled with 90 percent argon gas and 10 percent air yields a slightly more than 5 percent improvement in the insulating value at the center of the glass, compared to the same unit filled with air. However, when argon and krypton fills are combined with low-E coatings and multipane glazings, more significant reductions of 15 to 20 percent can be achieved.

The gases are inert, nontoxic, and occur naturally in the atmosphere, but maintaining long-term thermal performance is certainly an issue. Studies have shown less than 0.5 percent leakage per year in a well-designed and well-fabricated unit, or a 10 percent loss in total gas over a twenty-year period. The effect of a 10 percent gas loss would only be a few percent change in U-factor on an overall product basis. Keeping the gas within the glazing unit depends largely upon the quality of the design, materials, and, most important, assembly of the glazing unit seals.

\section{Thermally Improved Edge Spacers}

The layers of glazing in an insulating unit must be held apart at the appropriate distance by spacers. The spacer system must serve a number of functions in addition to keeping the glass units separated by the proper dimension:

- accommodate stress induced by thermal expansion and pressure differences;

- provide a moisture barrier that prevents passage of water or water vapor that would fog the unit;

- provide a gas-tight seal that prevents the loss of any special low-conductance gas in the air space;

- create an insulating barrier that reduces the formation of interior condensation at the edge.

Older double-pane wood windows used a wood spacer that could not be hermetically sealed and thus was vented to the outside to reduce fogging in the air gap. Modern versions of this system function well but, because they are not hermetically sealed, cannot be used with special gas fills or some types of low-E coatings. Early glass units were often fabricated with an integral welded glass-to-glass seal. These units did not leak but were difficult and costly to fabricate, and typically had a less-thanoptimal narrow spacing. The standard solution for insulating glass units (IGUs) that accompanied the tremendous increase in market share of insulating glass in the 1980's was the use of metal spacers and sealants. These spacers, typically aluminum, also contain a desiccant that absorbs residual moisture. The spacer is sealed to the two glass layers with organic sealants that both provide structural support and act as a moisture barrier. There are two generic systems for such IGUs: a single-seal spacer and a double- 


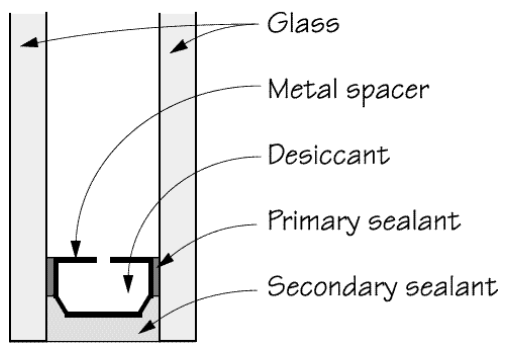

Figure 3.4. Double-seal metal spacer.

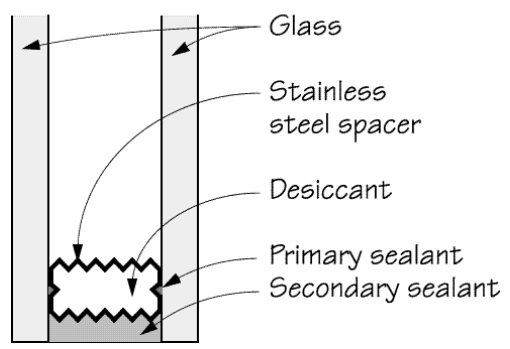

Figure 3.5. Stainless steel spacer.

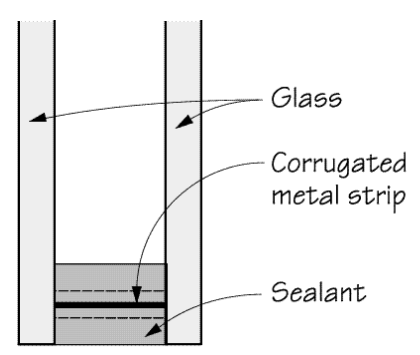

Figure 3.6. Butyl tape spacer with metal.

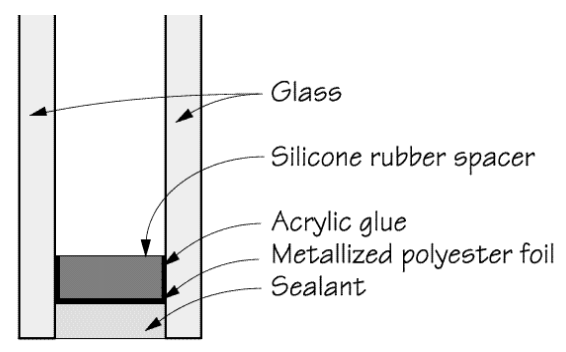

Figure 3.7. Silicone foam spacer. seal system.

In the single-seal system, an organic sealant, typically a butyl material, is applied behind the spacer and serves both to hold the unit together and to prevent moisture intrusion. These seals are normally not adequate to contain special low-conductance gases. In a double-seal system (Figure 3.4), a primary sealant, typically butyl, seals the spacer to the glass to prevent moisture migration and gas loss, and a secondary backing sealant, often silicone, provides structural strength. When sputtered low-E coatings are used with double-seal systems, the coating must be removed from the edge first ("edge deletion") to provide a better edge seal.

Since aluminum is an excellent conductor of heat, the aluminum spacer used in most standard edge systems represented a significant thermal "short circuit" at the edge of the IGU, which reduces the benefits of improved glazings. As the industry has switched from standard double-glazed IGUs to units with low-E coatings and gas fills, the effect of this edge loss becomes even more pronounced. Under winter conditions, the typical aluminum spacer would increase the U-factor of a low-E, gas fill unit slightly more than it would increase the U-factor of a standard doubleglazed IGU. The smaller the glass area, the larger the effect of the edge on the overall product properties. In addition to the increased heat loss, the colder edge is more prone to condensation. The temperature effect at the edge can be clearly seen in a series of infrared images later in this chapter.

Window manufacturers have developed a series of innovative edge systems to address these problems, including solutions that depend on material substitutions as well as radically new designs. One approach to reducing heat loss has been to replace the aluminum spacer with a metal that is less conductive, e.g., stainless steel, and change the cross-sectional shape of the spacer (Figure 3.5). These designs are widely used in windows today.

Another approach is to replace the metal with a design that uses materials that are better insulators. The most commonly used design incorporates spacer, sealer, and desiccant in a single tape element. The tape includes a solid, extruded thermoplastic compound that contains a blend of desiccant materials and incorporates a thin, fluted metal shim of aluminum or stainless steel (Figure 3.6). Another approach uses an insulating silicone foam spacer that incorporates a desiccant and has a high-strength adhesive at its edges to bond to glass (Figure 3.7). The foam is backed with a secondary sealant. Both extruded vinyl and pultruded fiberglass spacers have also been used in place of metal designs.

There are several hybrid designs that incorporate thermal breaks in metal spacers or use one or more of the elements described above. Some of these are specifically designed to accommodate three- and four-layer glazings or IGUs incorporating stretched plastic films. All are designed to interrupt the heat transfer pathway at the glazing edge between two or more glazing layers.

Warm edge spacers have become increasingly important as 
manufacturers switch from conventional double glazing to higherperformance glazing. For purposes of determining the overall window U-factor, the edge spacer has an effect that extends beyond the physical size of the spacer to a band about 2-1/2 inches $(64 \mathrm{~mm})$ wide. The contribution of this $2-1 / 2$-inch-wide "glass edge" to the total window U-factor depends on the size of the window. Glass edge effects are more important for smaller windows, which have a proportionately larger glass edge area. For a typical residential-size window (3 by 4 feet/0.8 by 1.2 meters), changing from a standard aluminum edge to a good-quality warm edge will reduce the overall window U-factor by approximately .02 $\mathrm{Btu} / \mathrm{hr}-\mathrm{sq} \quad \mathrm{ft}-{ }^{\circ} \mathrm{F}$.

A more significant benefit may be the rise in interior surface temperature at the bottom edge of the window, which is most subject to condensation. With an outside temperature of $0^{\circ} \mathrm{F}$, a thermally improved spacer could result in temperature increases of $6-8^{\circ} \mathrm{F}\left(3-4^{\circ} \mathrm{C}\right)$ at the window sight line-or $4-6^{\circ} \mathrm{F}\left(2-4^{\circ} \mathrm{C}\right)$ at a point one inch in from the sight line, which is an important improvement. As new highly insulating multiple layer windows are developed, the improved edge spacer becomes an even more important element.

\section{Multiple Panes or Films}

By adding a second pane, the insulating value of the window glass alone is doubled (the U-factor is reduced by half). As expected, adding a third or fourth pane of glass further increases the insulating value of the window, but with diminishing effect.

Triple- and quadruple-glazed windows became commercially available in the 1980's as a response to the desire for more energyefficient windows. There is a trade-off with this approach, however. As each additional layer of glass adds to the insulating value of the assembly, it also reduces the visible light transmission and the solar heat gain coefficient, thereby reducing the window's value for providing solar gains or daylighting. In addition, other complications are encountered. Additional panes of glass increase the weight of the unit, which makes mounting and handling more difficult and transportation more expensive.

Because of the difficulties discussed above, it is apparent there are physical and economic limits to the number of layers of glass that can be added to a window assembly. However, multiple-pane units are not limited to assemblies of glass. One popular innovation is based on substituting an inner plastic film for the middle layer of glass. The plastic film is very lightweight, and because it is very thin, it does not increase the thickness of the unit. The glass layers protect the inner layer of plastic from scratching, mechanical abuse, corrosion, weathering, and visual distortions caused by wind pressure. Thus, the strength and durability of plastic as a glazing material are no longer issues when the plastic is protected from physical abuse and weathering by inner and outer layers of glass. The plastic films are specially treated to resist UV degradation and they are heat shrunk so they remain flat under all conditions. 
The plastic inner layer serves a number of important functions. It decreases the U-factor of the window assembly by dividing the inner air space into multiple chambers. Units are offered with one or two inner layers of plastic. Secondly, a low-E coating can be placed on the plastic film itself to further lower the U-factor of the assembly. Also, the plastic film can be provided with spectrally selective coatings to reduce solar gain in hot climates without significant loss of visible transmittance.

With continuing improvements in frame and spacer design, overall window U-factors as low as 0.10 seem possible. Such windows would have a remarkable energy performance. The loss of heat is so low that the diffuse sunlight gained through a northfacing window on a cold, cloudy winter day is greater than the heat losses over the full day. At this threshold of performance, a window can take on a new role in buildings as a net energy provider rather than a net energy loser. Thus, very-highperformance windows can have a lower seasonal heating loss than even a highly insulated wall in a cold climate. South-facing windows have always had this potential; however, highly efficient multilayer window technologies mean that a window facing in any direction can be a passive solar collector.

\section{Performance Comparison of Different Glazing Types}

Figure 3.8 illustrates the impact of glazing type alone on total house energy performance. The total cost of heating and cooling for a typical 2000-square-foot house is shown with ten different window glazing units using the same frame (standard wood or vinyl).

In the heating-dominated climate (Boston), the single glazed cases have the poorest performance. Reductions in energy costs occur by changing to double glazing. With both single and double glazing, adding tinted glass makes the performance worse. Adding low-E coatings to double glazing represents further improvement, and using a triple-glazed unit with low-E coatings results in the lowest energy costs. Looking at the different types of low-E coatings, the high-solar-gain coatings result in the lowest heating cost but are a little higher on cooling cost compared to the low-solar-gain coatings. In a cold climate where heating predominates, the high-solar-gain coatings perform slightly better on an annual basis, but all low-E coatings represent very good performance.

In the cooling-dominated climate (Phoenix), the clear single glazing also has the poorest performance. Reductions in energy costs occur by changing to double glazing and using tinted glass. The high-performance tint with double glazing represents an improvement over the bronze tint. Adding low-E coatings to double glazing in a hot climate does not necessarily represent further improvement-the type of low-E coating can affect performance greatly. High-solar-gain low-E coatings are not much better than clear double glazing since there is little solar control. Low-solar-gain low-E coatings, on the other hand, result in excellent performance. Using triple-glazed units with low-E coatings can result in the low energy costs as long as the low-solar- 
Figure 3.8. Annual energy performance for a 2000-square-foot house with different glazing types using a wood or vinyl frame in two U.S. climates.

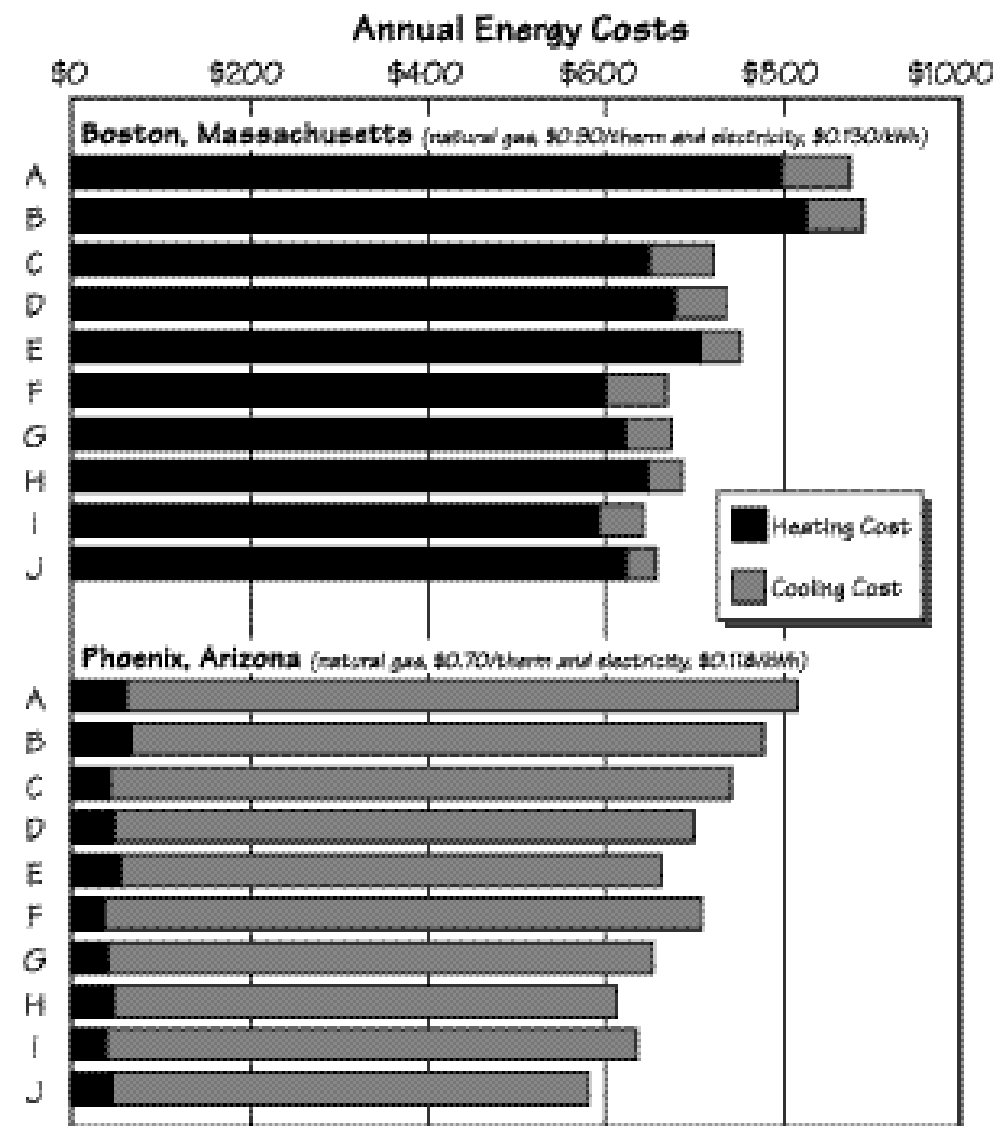

Note: The annual energy performance figures shown here were generated using RESFEN for a typical $2000 \mathrm{sq} f \mathrm{ft}$ house with $300 \mathrm{sq} \mathrm{ft}$ of window area $(15 \%$ of floor area). The windows are equally distributed on all four sides of the house and include typical shading (interior shades, overhangs, trees, and neighboring buildings). The heating system is a gas furnace with air-conditioning for cooling. The figures are based on typical energy costs for each location. U-factor, SHGC, and VT are for the total window including frame.

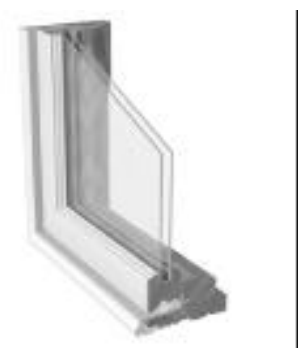

All windows in this comparison have identical wood or vinyl frames.
Window A

Clear, Single Glazing

$U$-Factor $=0.90, \quad S H G C=0.63, \quad V T=0.64$

\section{Window B}

Single Glazing, Bronze or Gray Tint $U$-Factor $=0.90, \quad S H G C=0.54, \quad V T=0.48$

Window C

Clear, Double Glazing

$U$-Factor $=0.49, \quad S H G C=0.56, \quad V T=0.58$

Window $D$

Double Glazing, Bronze or Gray Tint

$U$-Factor $=0.49, \quad S H G C=0.46, \quad V T=0.44$

Window E

Double Glazing, High-Performance Tint $U$-Factor $=0.49, \quad S H G C=0.37, \quad V T=0.49$

Window $F$

Double Glazing, High-Solar-Gain Low-E $U$-Factor $=0.36, \quad$ SHGC $=0.52, \quad V T=0.53$

Window G

Double Glazing, Moderate-Solar-Gain LowE

$U$-Factor $=0.33, \quad S H G C=0.40, \quad V T=0.53$

Window $\mathrm{H}$

Double Glazing, Low-Solar-Gain Low-E $U$-Factor $=0.32, \quad S H G C=0.30, \quad V T=0.50$

\section{Window I}

Triple Glazing, Moderate-Solar-Gain LowE

$U$-Factor $=0.26, \quad S H G C=0.38, \quad V T=0.46$

Window J

Triple Glazing, Low-Solar-Gain Low-E U-Factor $=0.24, \quad S H G C=0.25, \quad V T=0.40$ 
gain coatings are used.

\section{Smart Windows}

The ideal window would be one whose optical properties could readily change in response to changing climatic conditions or occupant preferences. Researchers have been hard at work on new glazing technologies for the next generation of "smart windows." After many years of development, various smart window technologies are now in prototype testing phases and should be commercially available in the near future. As with other window technologies, the homeowner, architect, or contractor will need to understand these new systems in order to properly specify them.

There are two basic types of smart windows-passive devices that respond directly to environmental conditions such as light level or temperature, and active devices that can be directly controlled in response to occupant preferences or heating and cooling system requirements. The main passive devices are photochromics and thermochromics; active devices include liquid crystal, dispersed particle, and electrochromics.

The most promising smart window technology as we enter the 21 st century is devices based on electrochromic coatings, which is described below. Although not yet commercially available, they appear to have a good chance to meet performance, cost, and manufacturing requirements that would result in a marketable window system.

\section{Electrochromic Glazing}

Electrochromics can change transparency over a wide continuous range, from about 5 to 70 percent light transmittance over a seven-minute time period, with a corresponding wide range of control over solar heat gain. The coating darkens as it switches and provides a view out under all switching conditions. Switching occurs at very low DC voltage (1-2 volts), so power supplies and wiring should not be expensive. Removing the voltage stops the electrochromic process without affecting the window's present state of transmittance. Reversing the voltage returns the window to its original state. The reversible process can continue over the thousands of cycles needed for a long lifetime window (Figure 3.9).

Electrochromics could be dynamically operated by computer, by occupant signal, or by simple thermostat or photocell controls. This offers the potential for occupant adjustments and calibration to changing local conditions.

Initial studies show that smart windows are likely to have the greatest energy benefits in commercial buildings where lighting and cooling energy costs as well as related mechanical equipment costs are significant. By increasing the use of daylighting and reducing the cooling loads, smart windows not only reduce annual energy costs, but may also reduce the peak electric demand charges and the required size of the cooling equipment, both of which can be very substantial costs in commercial buildings.

Many of these same benefits may also be of value in homes, especially in more extreme climates. In principle, most of the benefits 

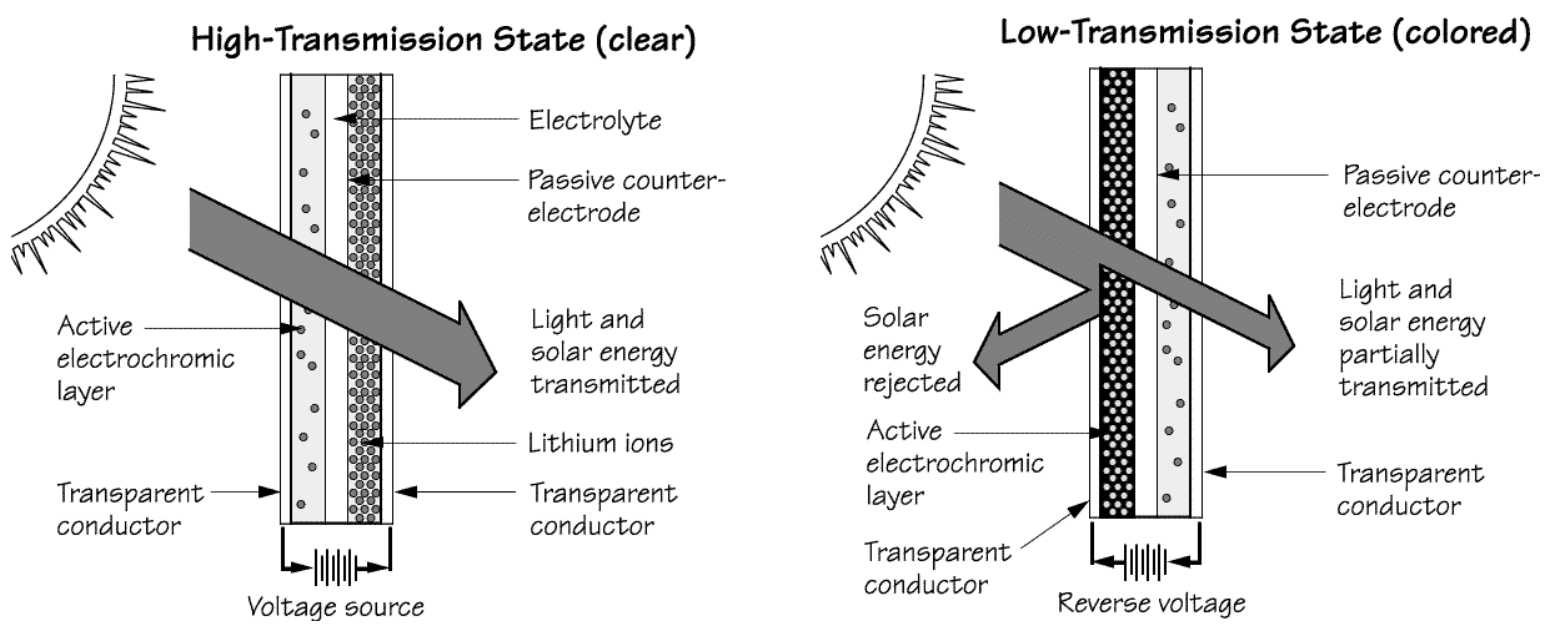

Figure 3.9. Schematic diagram of a five-layer electrochromic coating (not to scale). A reversible low-voltage source moves ions back and forth between an active electrochromic layer and a passive counterelectrode. When the lithium ions migrate into the active electrochromic layer, an electrochemical reaction causes that layer to darken. When the voltage is reversed and the ions are removed, the electrochromic layer returns to its clear state.

of smart windows might be captured by the intelligent and consistent use of existing manual or automated window control technology. But experience shows that people are often inconsistent and unpredictable in drawing curtains or adjusting blinds, and the cost of motorized controls is an obstacle. By making these control features an integral and dependable part of the building, smart windows can make potential energy savings predictable and guaranteed.

\subsection{WINDOW FRAME MATERIALS}

At the beginning of the century, most residential windows were built on site by local carpenters. Millwork suppliers then started to manufacture window sash and even entire window units. Prefabricated steel-framed "factory" windows became popular for a while in the 1920's. Prefabricated wood-framed windows finally became big business with the tract home building that started during World War II and mushroomed in the 1950's After the war, aluminum manufacturers turned their plants to domestic production and quickly found a large market with prefabricated, aluminum-framed windows. Until the mid-1980's, well over one-half of all residential windows in the United States were aluminum-framed. Aluminum frames have been losing residential market share, initially to wood-framed windows and more recently to a relative newcomer, vinyl frames. During the 1990's new frames have been introduced made from fiberglass and engineered thermoplastics and new composite materials.

The material used to manufacture the frame governs the physical characteristics of the window, such as frame thickness, weight, and durability, but it also has a major impact on the 
Table 3.3. Typical U-factors for frame materials.

$\begin{array}{lr}\text { Frame Material } & \begin{array}{r}\text { U-factor } \\ \text { (Btu/hr-sq ft-º })\end{array} \\ \begin{array}{l}\text { Aluminum } \\ \text { (no thermal break) }\end{array} & 1.7-2.4 \\ \begin{array}{l}\text { Aluminum } \\ \text { (with thermal break) }\end{array} & 0.8-1.3 \\ \begin{array}{l}\text { Aluminum-clad wood/ } \\ \text { reinforced vinyl }\end{array} & 0.4-0.6 \\ \text { Wood and vinyl } & 0.3-0.5 \\ \begin{array}{l}\text { Insulated vinyl/ } \\ \text { Insulated fiberglass }\end{array} & 0.2-0.4\end{array}$

thermal characteristics of the window. Increasingly, manufacturers are producing hybrid or composite sash and frames, in which multiple materials are selected and combined to best meet the overall required performance parameters. Thus, a simple inspection of the inner or outer surface of the frame is no longer an accurate indicator of the total material or its performance.

Table 3.3 indicates the U-factors of various standard frame types. Since the actual U-factor depends on specific dimensions and design details, these values are only for illustrative purposes. While it is useful to understand the role that frame type plays in window thermal performance, the frame U-factor is not normally reported by manufacturers. The window U-factor, as given on an NFRC certified rating or label, incorporates the thermal properties of the frame, as well as the glazing. Since the sash and frame represent from 10 to 30 percent of the total area of the window unit, the frame properties will definitely influence the total window performance.

The remainder of this section describes aluminum, wood, and vinyl frames, and introduces some new frame materials that are commercially available.

\section{Aluminum Frames}

After World War II, aluminum became one of the most common residential window frame materials. Light, strong, durable, and easily extruded into the complex shapes required for window parts, it can be fabricated to extremely close tolerances, to create special forms for the insertion of glazing, weather-stripping, and thermal breaks. Aluminum frames are available in anodized and factorybaked enamel finishes that are extremely durable and lowmaintenance. Aluminum is widely used for storm window units because of its light weight and corrosion resistance, and for sliding glass doors because of its strength.

The biggest disadvantage of aluminum as a window frame material is its high thermal conductance. It readily conducts heat, greatly raising the overall U-factor of a window unit. Because of its high thermal conductance, the thermal resistance of an aluminum frame is determined more by the amount of surface area of the frame than by the thickness or the projected area, as with other frame materials. Thus, an aluminum frame profile with a simple compact shape will perform better than a profile with many fins and undulations.

In cold climates, a simple aluminum frame can easily become cold enough to condense moisture or frost on the inside surfaces of window frames. Even more than the issue of heat loss, condensation problems have spurred development of better insulating aluminum frames.

The most common solution to the heat conduction and condensation problem of aluminum frames is to provide a "thermal break" by splitting the frame components into interior and exterior pieces and using a less conductive material to join them. There are many designs available for thermally broken aluminum frames. 
Current technology with standard thermal breaks has improved aluminum frame U-factors from roughly 2.0 to about half of that. This is difficult to achieve throughout the entire product, though. While easier to insert in the bulkier main frame, it is problematic to include thermal breaks in the thinner sash components that hold the glazing. In addition, as glazing systems with higher insulating values are developed, a frame with a Ufactor of 1.0 or above may not be consistent with the energy efficiency of the other window components. However, innovative new thermal break designs combined with changes in frame design have been used in Europe to achieve U-factors lower than 0.5 , but at a higher cost than current thermally broken frames. In hot climates, where solar gain is often more important than conductive heat transfer, improving the insulating value of the frame is less important than using a solar control glazing system.

The residential market share of aluminum windows has been steadily declining since the early 1980's This reduction in market share has been seen for both new construction and renovation projects. Many of the companies that fabricated aluminum windows have switched to fabricating vinyl windows.

\section{Wood Frames}

The traditional window frame material is wood, because of its availability and ease of milling into the complex shapes required to make windows. Today, wood units tend to be thought of as "high end" windows because competing products are often less expensive. Wood is not intrinsically the most durable window frame material, because of its susceptibility to rot and of high maintenance requirements, but well-built and well-maintained wood windows can have a very long life.

Wood is easy to repair and maintain with simple tools and materials well understood by the average householder. A coat of paint protects the surface and allows an easy change in color schemes. Frames are generally made of kiln-dried lumber to reduce shrinkage, which results in better operation and weathertightness over their lifetime. Water-repellent and/or chemical treatments can be applied in the factory to reduce swelling and warping, improve paint retention, and increase wood's resistance to decay and insect attack.

Cladding the exterior face of a wood frame with either vinyl or aluminum creates a permanent weather-resistant surface. Clad frames thus have lower maintenance requirements, while retaining the attractive wood finish on the interior.

Newer vinyl and enameled metal claddings offer much longer protection to wood frames. However, they are generally available in a limited number of colors, and refinishing these surfaces may be a difficult task. Dark-colored finishes absorb more of the sun's energy, so they tend to be more susceptible to aging from heat and ultraviolet damage.

From a thermal point of view, wood-framed windows perform well, with frame U-factors in the range of 0.3 to $0.5 \mathrm{Btu} / \mathrm{hr}$-sq $\mathrm{ft}-{ }^{\circ} \mathrm{F}$. The thicker the wood frame, the more insulation it provides. 
However, metal cladding, metal hardware, or the metal reinforcing often used at corner joints can lower the thermal performance of wood frames. If the metal extends through the window from the cold side to the warm side of the frame, it creates a thermal short circuit, conducting heat more quickly through that section of the frame.

\section{Vinyl Frames}

Plastics are relative newcomers as window frame materials in North America. Vinyl, also known as polyvinyl chloride (PVC), is a very versatile plastic with good insulating value, high impact resistance, and excellent resistance to abrasion, corrosion, air pollutants, and termites. Because the color goes all the way through, there is no finish coat that can be damaged or deteriorate over time. Recent advances have improved dimensional stability and resistance to degradation from sunlight and temperature extremes.

Developed and marketed for more than thirty years in Europe, vinyl frames first became available in the U.S. in the 1960's In 1983, vinyl windows constituted about 3 percent of all residential window sales in the United States, mostly for remodeling and replacement. Since then, the use of vinyl windows has risen steadily in new construction and more dramatically in the remodeling and replacement market. Vinyl windows now represent about 46 percent of all residential windows sold (Figure 4-11).

Similar to aluminum windows, vinyl windows are fabricated by cutting standard lineal extrusions to size and assembling the pieces into complete sash and frame elements. A small number of companies produce the standard lineal extrusions, and a much larger number of companies assemble window units by combining the sash and frame with glazing, weather-stripping, and hardware. This process lends itself to readily fabricating the custom sizes needed for the replacement window market.

Vinyl window frames require very little maintenance. They do not require painting and have good moisture resistance. To provide the required structural performance, vinyl sections often need to be larger than aluminum window sections, closer to the dimensions of wood frame sections. Larger vinyl units will often need to incorporate metal or wood stiffeners.

Since vinyl has a higher coefficient of expansion than either wood or aluminum, vinyl window frame profiles should be designed and assembled to eliminate excessive movement caused by thermal cycles. Vinyl frames with heat-welded joints are stiffer than mechanically joined vinyl frames, so they provide excellent resistance to temperature and handling stresses both at the job site and during shipping. In some cases, a vinyl window assembly consists of both welded and mechanically fastened components. Interior webs also strengthen the frame, while improving its thermal performance. AAMA (American Architectural Manufacturers Association) has developed standards for vinyl 
extrusions to ensure impact resistance, dimensional stability, and color retention. New vinyls are being developed that are more resistant to heat and ultraviolet radiation and a variety of new colors are being developed as well.

In terms of thermal performance, most vinyl frames are comparable to wood. Large hollow chambers within the frame can allow unwanted heat transfer through convection currents. Creating smaller cells within the frame reduces this convection exchange, as does adding an insulating material. Most manufacturers are conducting research and development to improve the insulating value of their vinyl window assemblies.

\section{Insulated Vinyl}

Insulated vinyl frames are identical in most of their characteristics to standard vinyl frames. The major difference between insulated vinyl and standard vinyl frames is improved thermal performance. In insulated vinyl frames, the hollow cavities of the frame are filled with insulation, making them thermally superior to standard vinyl and wood frames. Usually these high-performance frames are used with high-performance glazings (see Figure 4-17).

\section{Hybrid Frames and New Materials}

Manufacturers are increasingly turning to hybrid frame designs that use two or more of the frame materials described above to produce a complete window system. The wood industry has long built vinyland aluminum-clad windows to reduce exterior maintenance needs. Vinyl manufacturers and others offer interior wood veneers to produce the finish and appearance that many homeowners desire. Split-sash designs may have an interior wood element bonded to an exterior fiberglass element. We are likely to see an ever-increasing selection of such composite designs as manufacturers continue to try to provide better-performing products at lower cost. It may be important for a homeowner to learn about these materials from the perspective of maintenance requirements and options for interior finishes. However, it becomes increasingly difficult to estimate the thermal properties of such a frame from simple inspection. The best source of information is an NFRC label that provides the thermal properties of the overall window.

\section{Wood Composites}

Most people are familiar with composite wood products, such as particle board and laminated strand lumber, in which wood particles and resins are compressed to form a strong composite material. The window industry has now taken this a step further by creating a new generation of wood/polymer composites that are extruded into a series of lineal shapes for window frame and sash members. These composites are very stable, and have the same or better structural and 
thermal properties as conventional wood, with better moisture resistance and more decay resistance. They can be textured and stained or painted much like wood. They were initially used in critical elements, such as window sills and thresholds in sliding patio doors, but are now being used for entire window units. One example of this material is Fibrex used in windows by the Andersen Corporation and its subsidiaries. This approach has the added environmental advantage of reusing a volume of sawdust and wood scrap that would otherwise be discarded. Since wood composites are produced as lineals, they have all the manufacturing advantages of vinyl and aluminum in terms of fabricating custom sizes.

\section{Fiberglass}

Vinyl windows have captured a large share of the new and retrofit window market in the last fifteen years in part because of the ability to produce a wide range of lineal extrusions that can be assembled into windows. Other polymer-based technologies are beginning to challenge this market, although to date they have captured only a small market share. Windows can be made of glass-fiber-reinforced polyester, or fiberglass, which is pultruded into lineal forms and then assembled into windows. These frames are dimensionally stable and have good insulating value by incorporating air cavities (similar to vinyl). Because the material is stronger than vinyl, it can have smaller cross-sectional shapes and thus less area. Fiberglass windows are typically more expensive than vinyl windows.

\section{Engineered Thermoplastics}

Another alternative to vinyl is extruded engineered thermoplastics, a family of plastics used extensively in automobiles and appliances. Like fiberglass, they have some structural and other advantages over vinyl but are also more expensive and have not yet captured a large market share. These high-performance frames are typically used with high-performance glazings.

\section{Performance Comparison of Different Frame Types}

While the overall window performance is often dominated by the glazing type, there are some notable differences in thermal performance between frame materials. Figure 3.10 illustrates the impact of frame type alone on total house energy performance. The total cost of heating and cooling for a typical 2000-square-foot house is shown with five different window frame types using the same glazing (double glazing with a low-solar-gain low-E coating).

In all four cities, the worst performance is attributed to the case with aluminum frame windows with no thermal break. Some reductions in energy costs occur by substituting a thermally broken aluminum frame. Wood and vinyl frames represent further improvement and using an insulated vinyl or fiberglass frame results in the lowest energy costs. In heating-dominated cities, such as Boston and Chicago, improving the frame reduces the U-factor and thus the heating load. In cities with significant cooling costs and smaller heating requirements, such as Atlanta 
Figure 3.10. Annual energy performance for a 2000-square-foot house with different frame types using identical low-E glass in four U.S. climates.

\section{Annual Energy Costs}

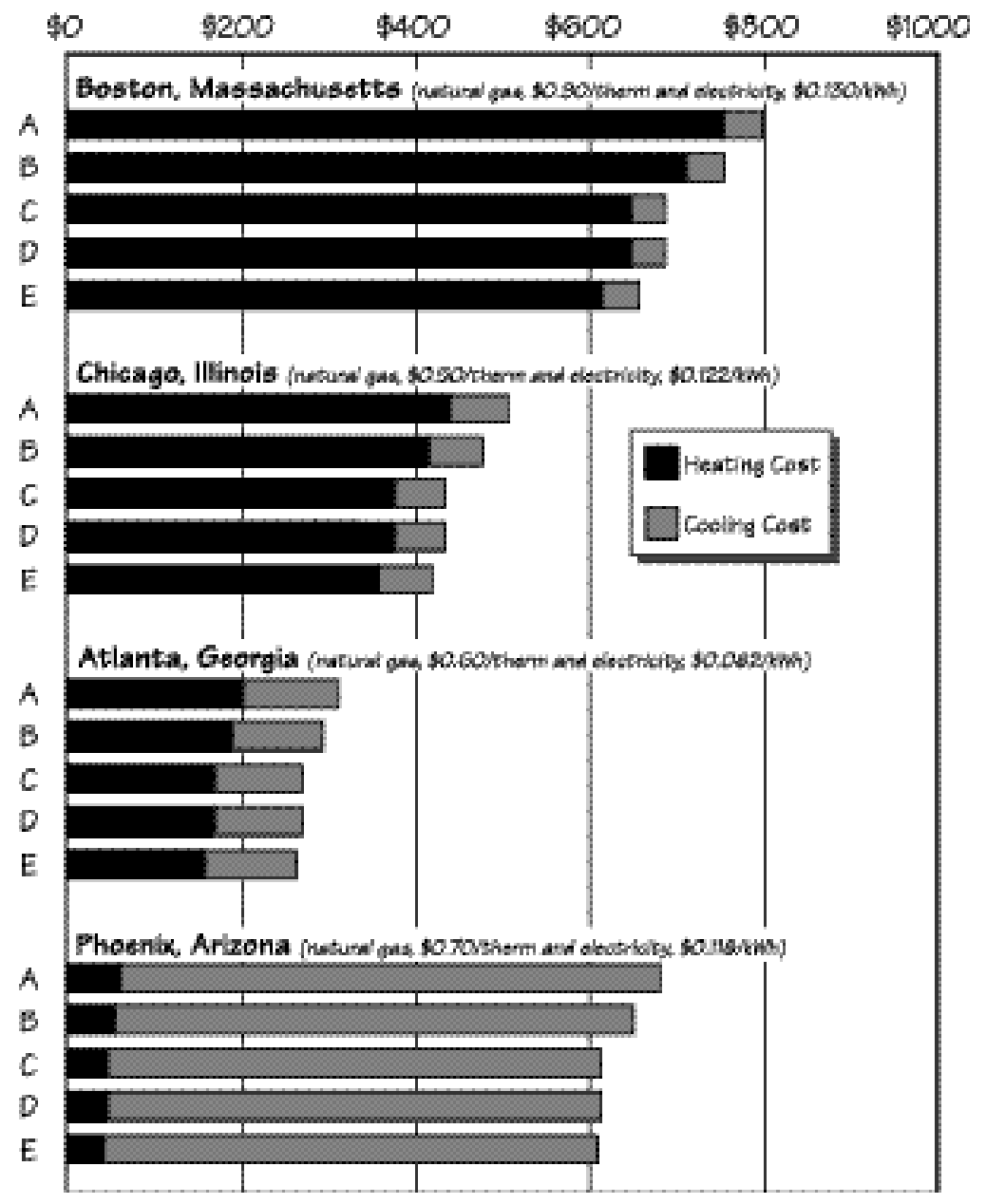

Note: The annual energy performance figures shown here were generated using RESFEN for a typical $2000 \mathrm{sq} f \mathrm{ft}$ house with $300 \mathrm{sq} \mathrm{ft}$ of window area (15\% of floor area). The windows are equally distributed on all four sides of the house and include typical shading (interior shades, overhangs, trees, and neighboring buildings). The heating system is a gas furnace with airconditioning for cooling. The figures are based on typical energy costs for each location (see Chapter 6). U-factor, SHGC, and VT are for the total window including frame. mines

Fovis Guats

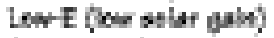

Alvithm Find

LFromolod

atotos

$\operatorname{tag} \theta$

\section{粗小}

Pusto Glwi!

Ler-E be solst paly

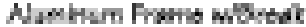

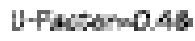

5HGC0.4

VTOAB

Nindar 6

Probs chins

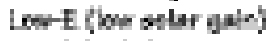

Mas Gartrat

ufwh-oze

$4+65=0 \mathrm{NO}$

rTaso

Wribow 0

Doith Gurn

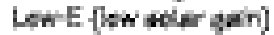

ind Fins

$\Delta F=t=0 B$

stgoros

wabos

\section{Stadow}

Dedth olsty |cw-I the wher gely

heloted Herglew frams

Ifactoroth

stwoss:

Mass 
and Phoenix, changing the frame material has less of an effect since U-factor has less influence. Nevertheless, Figure 4-19 shows definite improvement in performance in the warmer cities by using a wood or vinyl frame compared to an aluminum frame. This improvement occurs in part because of the improved U-factor, but also because wood and vinyl frames are wider than aluminum. Consequently, for the same window opening size, there is less total glass area with the wider frames. This results in better cooling performance because of the reduction in glazing area. Normally, using a high-performance frame material is not a separate strategy in any climate, but is usually combined with high-performance glazing to maximize energy-savings.

\subsection{WINDOW INSTALLATION}

No matter how advanced the glazing and frame materials may be in a window unit, the ultimate performance also depends on the quality of its installation. Improper installation can contribute to air leakage, unnecessary heat loss, condensation, and water leakage. This not only may lead to diminished energy performance but deterioration of walls, insulation, and the window unit itself.

Essentially, installing a window creates a break in several important aspects of the building envelope. A properly installed window must maintain barriers keeping air and water from penetrating the wall and it must restrict vapor flow. It must also reduce heat loss and condensation around the window unit. In addition, the installation must meet several structural and functional requirements. Building loads cannot rest on the window frame, the installation must allow for movement, the window must protect against forced entry, and yet it must maintain ease of operation.

The installation of a window and any treatments added to its exterior or interior can affect the energy efficiency of the total assembly, no matter how advanced the window unit. There are important differences in the details of how a window is installed, depending on the type of construction (wood versus masonry) or exterior cladding material (i.e., wood siding, stucco, brick veneer). In addition, each operator type, frame material, and individual manufacturer may have its own recommended installation practices. It is important to refer to the appropriate manufacturer's instructions and not to rely solely on general guidelines.

Given the importance of proper installation, however, there are some emerging guidelines for installation. AAMA has developed an installer training and registration program and ASTM has developed a Window Installation Standard Practice.

\section{Water Tight Installation}

While there are many wall materials and construction assemblies, there are two fundamental approaches to water control-the surface barrier system and the membrane/drainage system. Determining which of these systems is used in the wall 


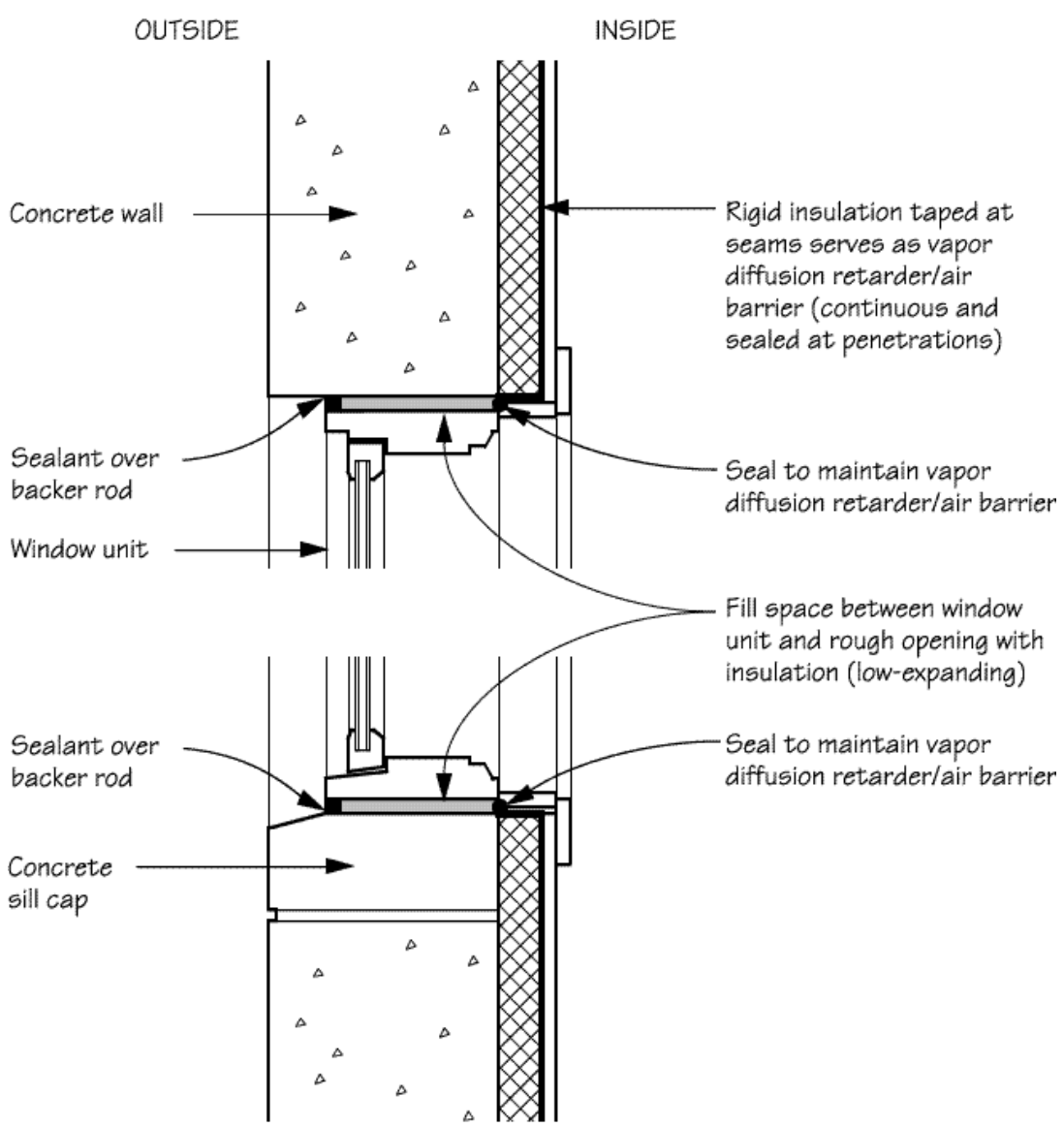

Figure 3.11. Installation of a block frame window in a wall assembly with a surface barrier system.

affects the window installation approach.

\section{Surface Barrier System}

A wall with a surface barrier system relies on the outermost surface to be weather resistant. Solid walls of masonry, concrete or brick with no cavities are surface barrier systems. Some types of stucco walls are barrier systems if they make no provision for drainage within the wall. Windows placed into a wall with a surface barrier system rely on a sealant joint between the frame and opening in the wall (Figure 3.11). With this type system, there is only one line of defense against water intrusion requiring very careful installation. There is no provision for drainage of moisture that enters the wall.

In a surface barrier system, a block frame window unit is typically used (a frame with no mounting flanges). The window is typically attached to the wall directly through the frame.

\section{Membrane/Drainage System}

A wall with a membrane/drainage system accepts that small 


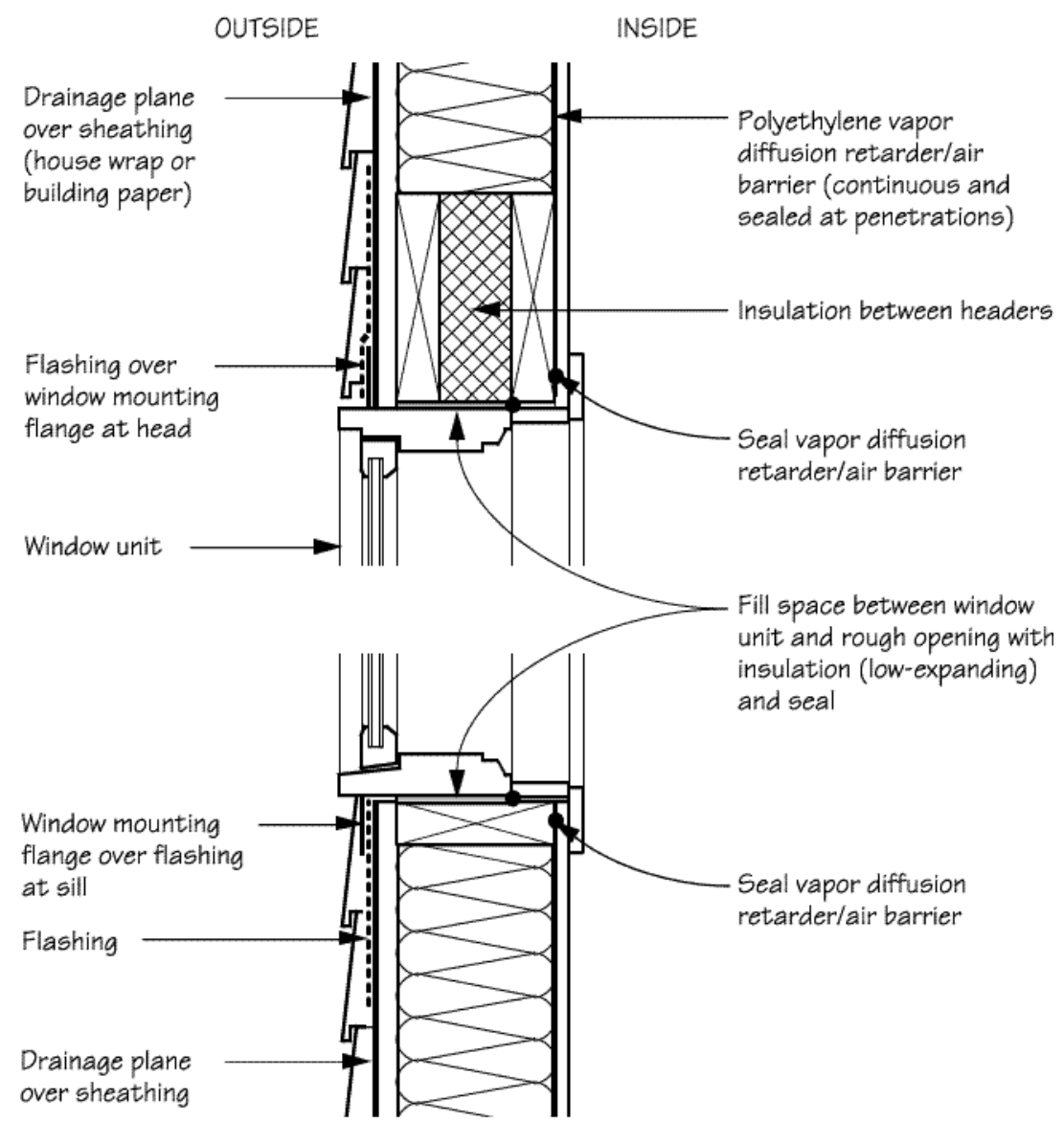

Figure 3.12. Installation of a window with a mounting flange in a wall assembly with a membrane/drainage system.

amounts of water may penetrate the outermost wall surface. The system is designed to control and drain away any residual water that penetrates the wall. Typically there is a weather resistant barrier such as house wrap or building paper placed behind the exterior cladding material (wood siding, brick veneer, or stucco). There are two basic approaches to installation. In the first one, the house wrap is installed first and covers the window openings.

Then, the membrane is cut in a " $Y$ " at the window opening and folded back to become flashing at the top and sides. In the second approach, the drainage plane is installed at the same time as separate flashing pieces, overlapped shingle-style and open at the base so that water drains to the exterior. In some cases, this requires flashing and weep holes at the base of the wall. It is important to use caution when sealing a window unit to the exterior cladding of a membrane/drainage wall system so that water within the drainage plane is not blocked and is allowed to escape (Figure 3.12).

In membrane/drainage systems, a window with a mounting 
Figure 3.13. Window installation using membrane/drainage system.

A

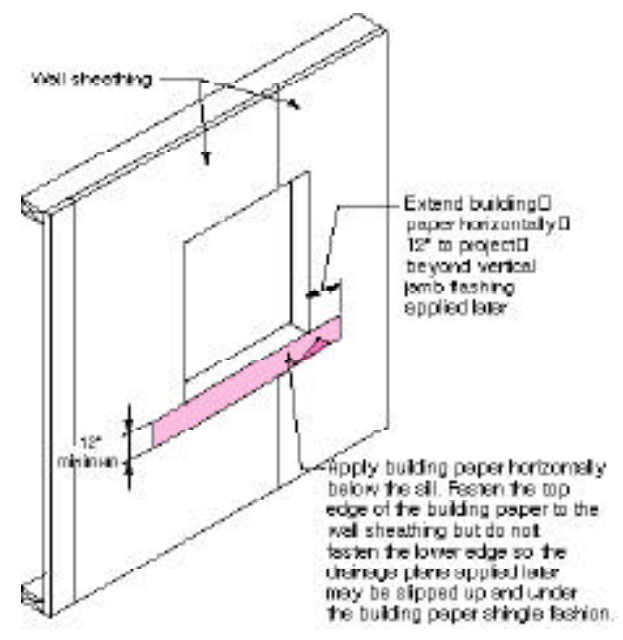

B

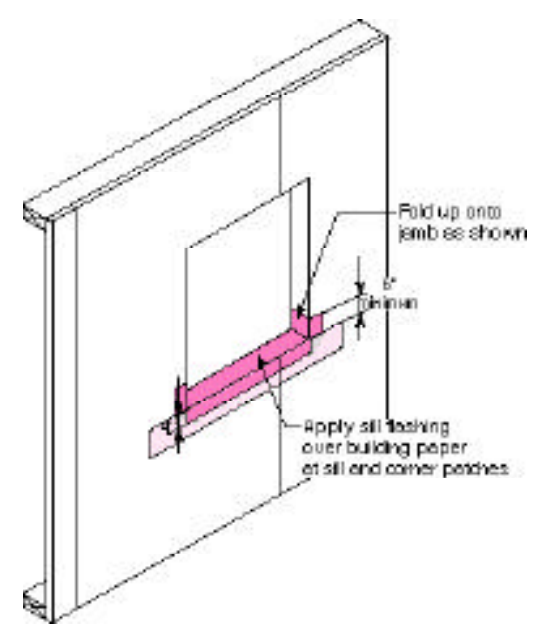

C

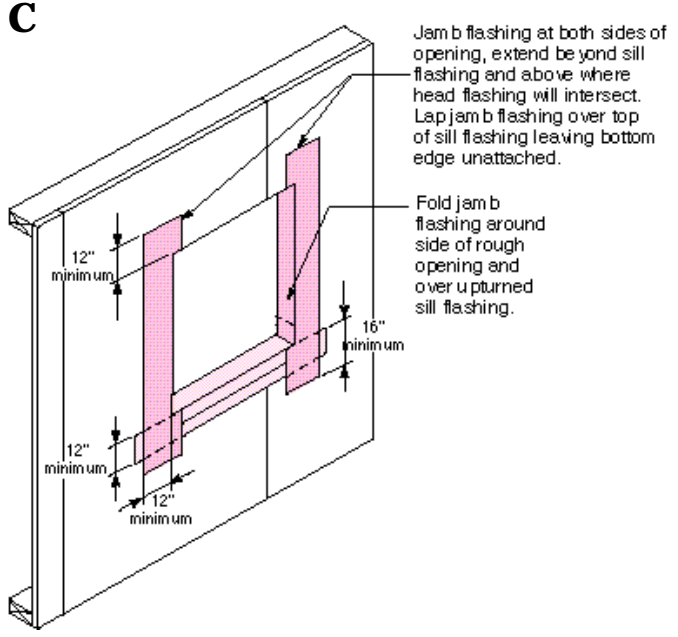

D

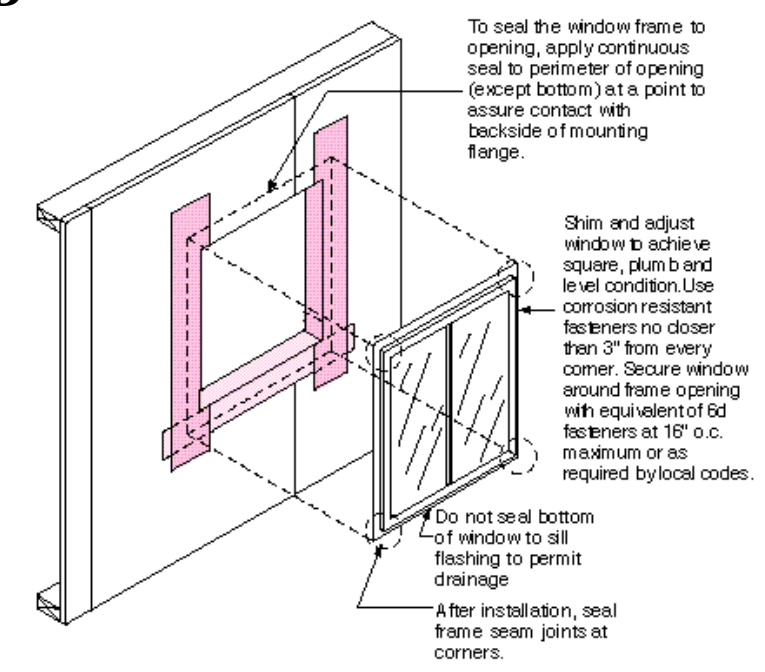

E
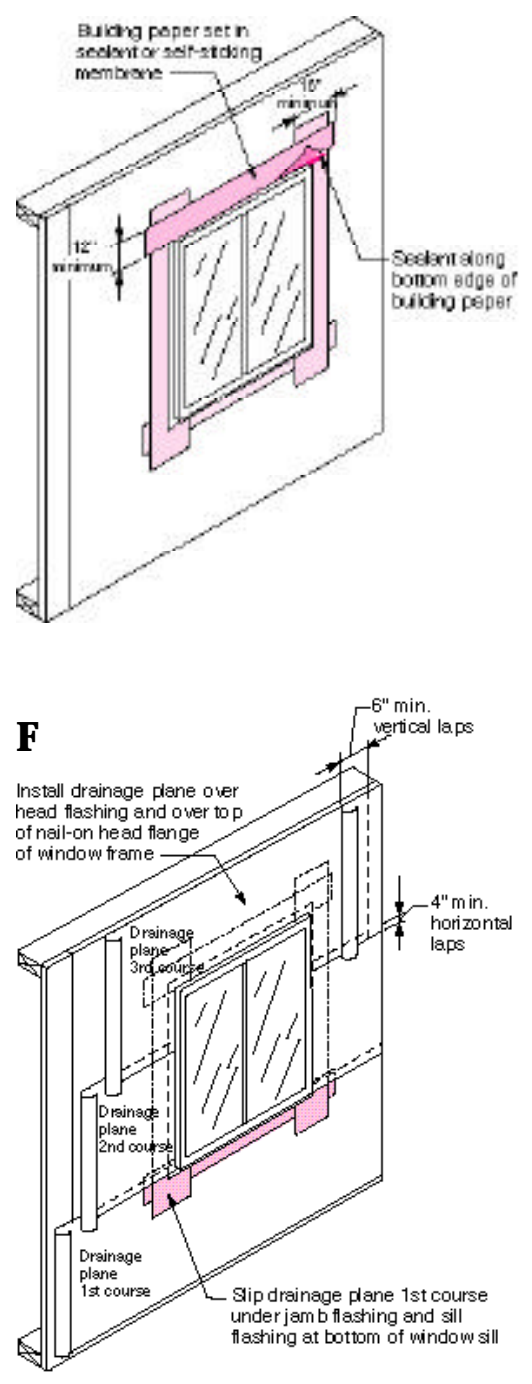
flange (nail fin) is typically used to attach the frame to the wall. Block frame windows with brick mold may also be used with a membrane/drainage system. The integrity of the drainage membrane must be preserved by the proper use of flashings and sealants in this type of installation. The placement of flashings must follow a careful sequence resulting in the overlapping of all materials in weatherboard (shingle style) fashion. One common procedure recommends that the flashing beneath the sill is placed first, then the jamb flashings, then the window is installed with mounting fins over these flashings, and then the head flashing over the top window fin (Figure 3.13). There are a number of variations and intricate procedures involving proper flashing depending on the exact wall assembly and construction sequence. Consult manufacturer's instructions and the information resources on the following pages.

\section{Insulating Around Window Units}

Windows are always placed into openings in walls that are sized slightly larger than the window unit itself. This additional space around the window, typically $1 / 4$ to $1 / 2$ inch (6 to $12 \mathrm{~mm}$ ) on each side, is essential in providing construction tolerances and allowing for any movement of the building over time. However, it also creates a gap between the careful detailing of the window unit and the insulation of the wall.

As window insulating values improve, attention should focus on how to maintain a continuous insulating envelope between window and wall. As much care should be given to preventing infiltration and conduction heat losses at the joint between window unit and wall as is given to insulating the wall or selecting the window unit. The two most important ways to cut heat loss at the perimeter of a window are to place insulation into all voids and to use sealants to close off even the most minute air paths. Special attention must be given to the mounting of thermally broken aluminum frame windows, so that the integrity of the thermal barrier is not compromised.

Many window units are attached to the building with a fin mounting system; a casing placed over the fin provides a visual finish from the exterior. At this joint between the inside and the outside of the building, there is minimum thickness of material and a considerable air space that should be filled with an insulating material. Fiberglass insulation can be manually stuffed into the void, or a foaming insulation can be shot in to provide a tight fit. Foam that expands, however, can exert undue pressure, distorting the window frame and causing even greater air leakage through the window. If insulating foam is used, it is essential that it have low expansion characteristics and that it be applied as directed by the manufacturer.

\section{Air and Vapor Retarders}

Any air barrier or water vapor retarder used in residential construction must maintain its integrity at the window opening, as 
illustrated in Figures 3.11 and 3.12. An interior plastic vapor barrier can be laid continuously across a window opening and cut on the diagonals to form an $X$ cut at the window. The triangular edges are wrapped into the framed opening before the window is inserted. Alternatively, an exterior barrier, such as house wrap or tar paper, is cut in the form of a modified " $\mathrm{I}$ " then folded into the window opening at the sill and jambs to make friction contact with the window unit. Caulking then creates a continuous seal from the window unit to the air and/or vapor barrier.

Forming a continuous vapor barrier is essential for extreme climates, either very cold or very hot and humid. Even when condensation has been visibly eliminated from window glazing and frame surfaces by selecting thermally improved products, it can still cause problems. Water vapor will migrate unnoticed from high-pressure areas to low-pressure areas. If a hole in the vapor barrier envelope of a house happens to allow the water vapor to contact a cold surface, it will condense on the cold surface and collect there. If this surface is in the interior of a wall or between a window frame and a wall, the moisture can cause rot or rust damage, or render insulating materials ineffective. Such a condition can go undetected for years.

\section{Installation Information}

Window Installation Guidelines

AAMA 2400-99 (formerly CAWM 400-95) - Standard Practice for Installation of Windows with Integral Mounting Flange in Wood-Frame Construction

AAMA 2410-99 (formerly CAWM 410-97) - Standard Practice for Installation of Sliding Glass Doors with Integral Mounting Flange in Wood-Frame Construction

AAMA "Installation Master" Installer Training and Registration Program American Architectural Manufacturers Association (AAMA)

1827 Walden Office Square, Suite 104

Schaumberg, IL 60173-4268

Phone: (847) 303-5664

Fax: (847) 303-5774

www.aamanet.org

Residential Window and Door Installation Guide, Version 1.2

Association of Window and Door Installers

515 N. Flagler Drive

West Palm Beach, FL 33401

(407) 655-0696

Window and Door Installation Certification Program Procedural Guide

National Certified Testing Laboratories

National Accreditation \& Management Institute, Inc.

152 Leader Heights Rd.

York, PA 17403

(717) 741-9572

CSA A440.4 - Window and Door Installation

Canadian Standards Association

178 Rexdale Boulevard

Rexdale, Ontario M9W 1R3

CEGS Section 08520 - Aluminum Window Installation Guide Specification

Department of the Army Engineer Division, Huntsville

CEHND-ED-ES (GS Section)

PO Box 1600

Huntsville, AL 35807-4301 
Installing Wood Windows and Doors (videotape) and Participant's Notebook

Window and Door Manufacturers Association

1400 East Touhy Avenue, Suite G-54

Des Plaines, IL 60018

(847) 299-5200

Standard Practice of the Installation of Exterior Windows, Doors, and Skylights American Society for Testing and Materials (ASTM)

100 Barr Harbor Drive

West Conshohocken, PA 19428-2959

Phone: (610) 832-9598

Fax: (610) 832-9599

www.astm.org

\subsection{WINDOW DESIGN OPTIONS FOR THE IWWS}

This section illustrates possible window configurations that become possible with an integrated window wall panel. Figure 3.14 shows options for window area, ventilation, and operating sashes in pockets. Figures 3.15 and 3.16 show conceptual wall sections incorporating daylight and shading devices as well as ventilation through the wall.

Figure 3.14: Window configuration options for an integrated window wall panel.

Window Area
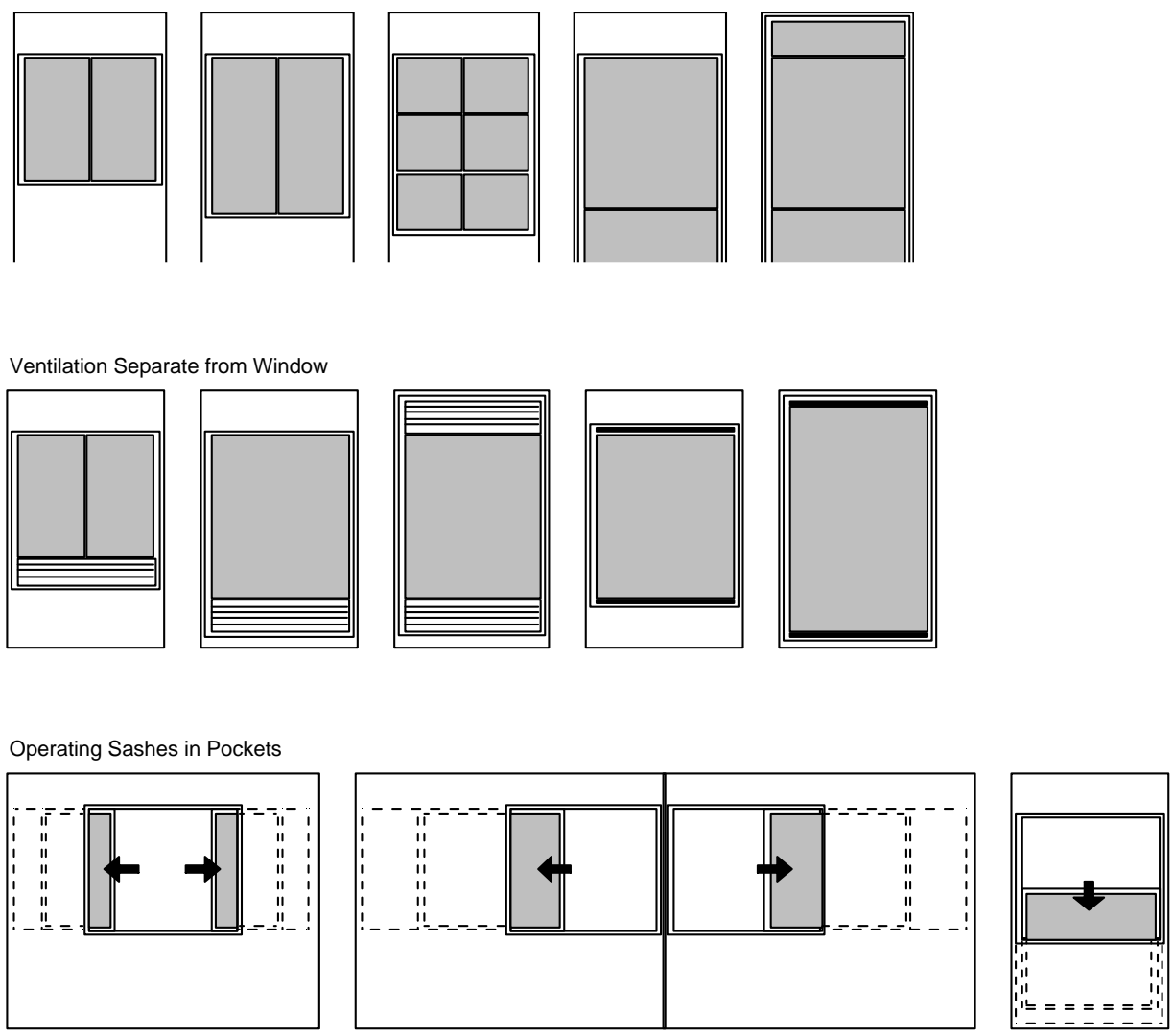
Figure 3.15: Section options for an integrated window wall panel.

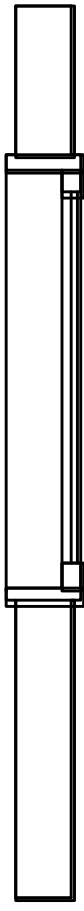

A

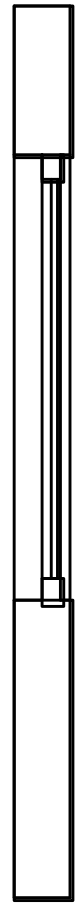

B
Window sash

mounted into

SIP or framed

joint window in SIP or framed panel

Window / Wall Sections-2
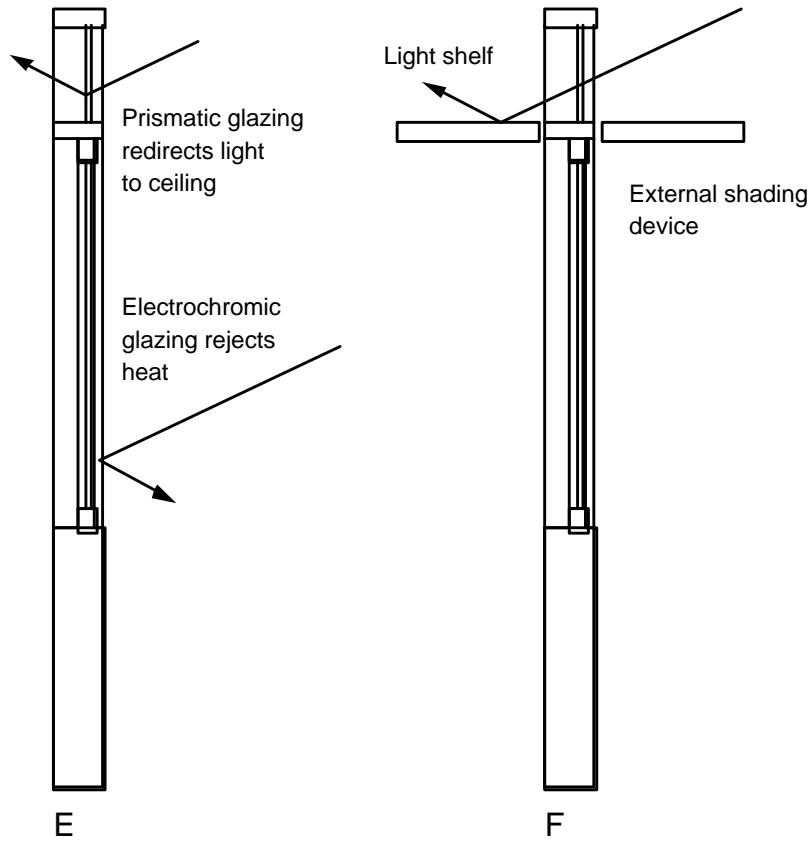

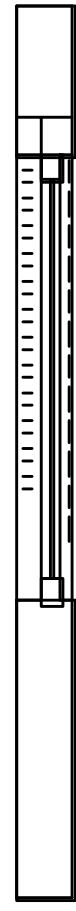

Built in shades and/or shutters with control system

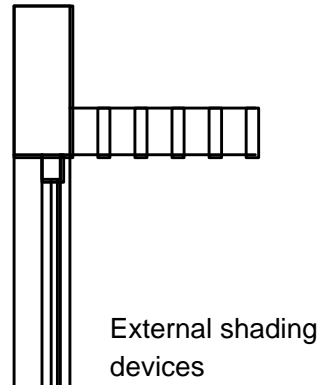

C devices 
Figure 3.15: Section options for an integrated window wall panel.
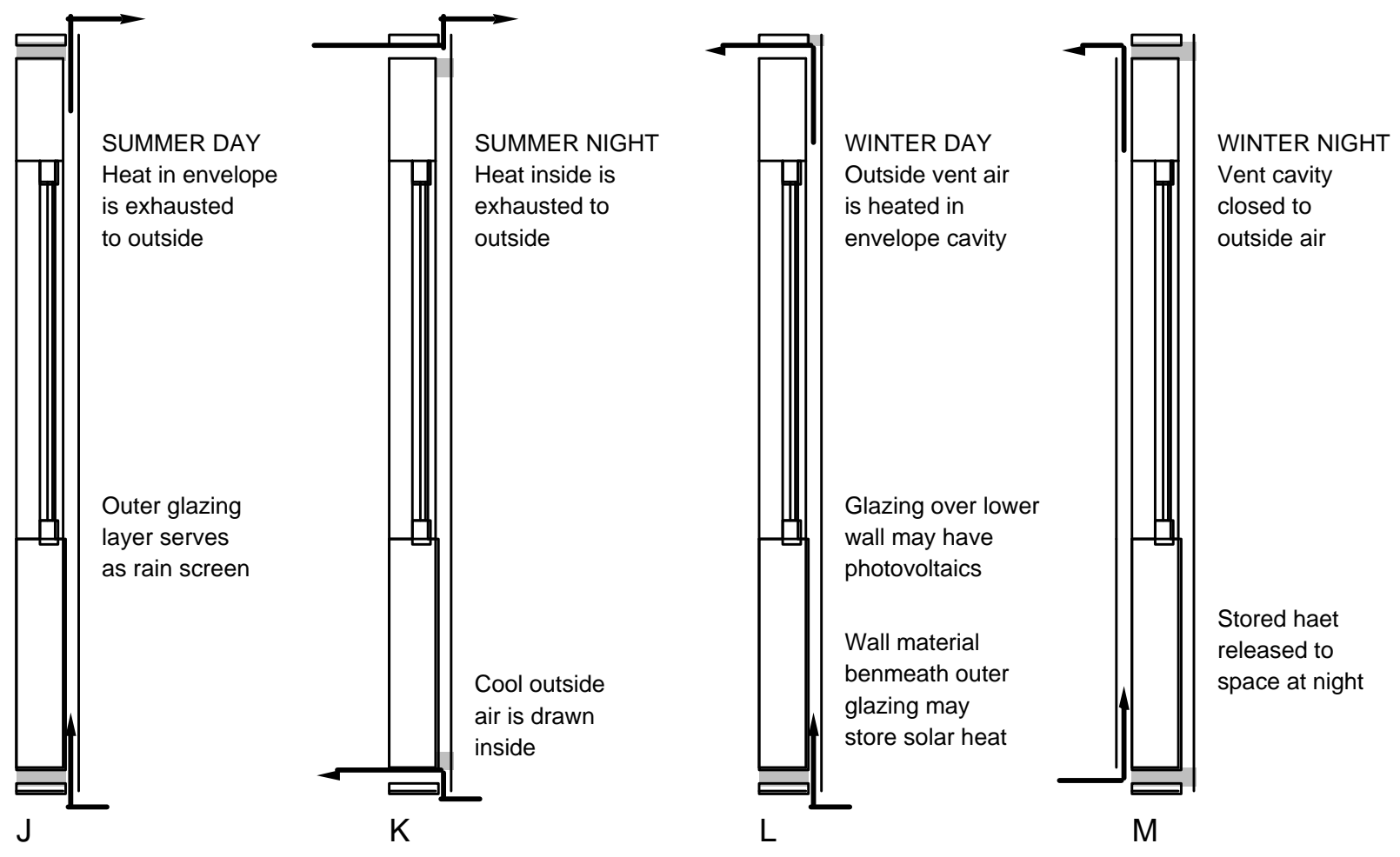

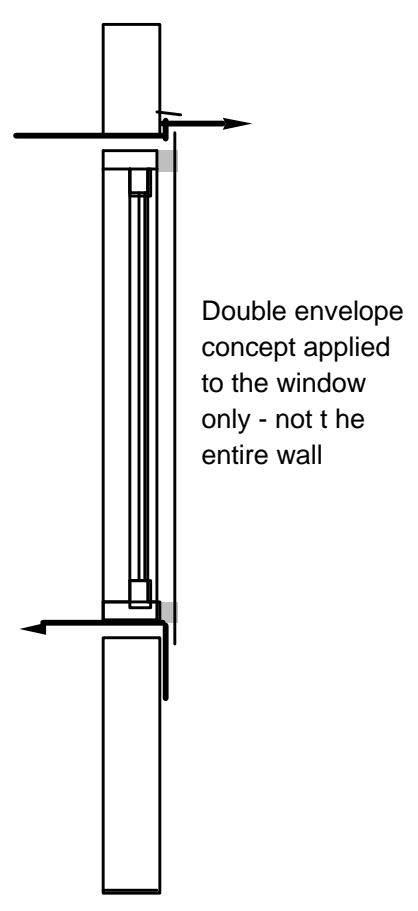

$\mathrm{N}$

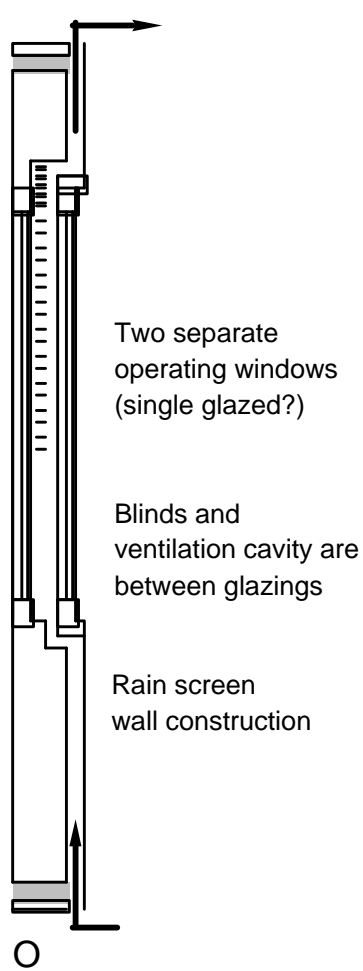




\section{Other Systems Related to IWWS}

\subsection{INTRODUCTION}

Incorporation of heating, ventilation, air conditioning, plumbing and electrical services into an exterior wall panel have a direct effect on the overall building performance. For example, an electrical service box may be required for a particular home design, but will lack sufficient insulation. Another example is a throughthe-wall air conditioner, which creates a thermal short circuit and many opportunities for air infiltration. Another example can be found in traditional ductwork, which is sometimes inadequately sealed and can create an air leak.

However, these services present a prime opportunity to enhance the energy efficiency of a home. Since HVAC and electrical chases can be found in most wall cavities, there is an opportunity to use them as conduits for communication devices, such as LonTalk or BacNet wires. And, because of the close proximity of the wire chases to the windows, they may be used to facilitate active controls in window-wall units.

Any panelized window-wall design must be able to accommodate the following services:

- Electrical utility service chases

- Electrical sockets

- Ventilation ductwork along with service grilles

- Through-the-wall air conditioners

- Accessible and repairable water and sewer pipes

In the remainder of this chapter, two critical systems that require direct integration with the IWWS are examinedventilation and electrical sensors and controls.

\subsection{VENTILATION AND THE IWWS}

This section examines the role that an integrated window wall system could play in a residential ventilation system. The section examines current trends in residential ventilation and suggests optional paths the Integrated Window/Wall System (IWWS)/ ventilation track could follow.

Section 4.2: Ventilation and the IWWS was contributed by David Grimsrud, Department Wood and Paper Science, University of Minnesota 
There is a trend in the United States to require a modest amount of mechanical ventilation in new residences. Proponents argue that infiltration and natural ventilation using operable windows are inadequate to provide ventilation on a continuous basis throughout an annual weather cycle (Hadlich and Grimsrud, 1999; Sherman, 1999). While some disagree with this perspective, increasing evidence from field studies shows low ventilation rates when measurements are made in new houses (Holton and Beggs, 2000; Rudd and Lstiburek, 2000).

A basis for this discussion is the public review draft about to be issued of the new ASHRAE residential ventilation standard (ASHRAE, 2000). In essence, the standard calls for continuous mechanical ventilation with capacity installed to increase ventilation when unusual occupancy or sources are present. We adopt the position that the IWWS will be used in new houses that will be designed to include mechanical ventilation. What design features should be incorporated into the wall system?

\section{Generic Ventilation Designs}

A mechanical ventilation design may be a single-sided exhaust, a single-sided supply, or a balanced system. Each has its advantages and disadvantages

A single point supply system is a simple, straightforward design. Used most commonly in humid climates, it offers the most control over air quality entering the house. Supply air enters at the fan; exhaust air leaves the structure through designed exhaust openings and leakage sites. A major advantage of this design is that air enters the house from a known location. This means that treating and conditioning that air is simplest of any of the three classes of ventilation. Another significant advantage is that the system can be adjusted easily to pressurize the house. This is a particular advantage when humidity control is a major issue in the design. Air that leaks into the wall will be house air that has lower relative humidity than outside air. It is commonly believed that this pressurization advantage turns into a disadvantage in coldclimate regions of the country but this argument has little objective evidence to support it.

The simplest form of mechanical ventilation in terms of builder experience is the single point exhaust system using quiet fans rated for continuous operation. Supply air in this case enters the house through design openings and randomly located leakage sites and is exhausted by the fan. If the building is tight the supply air can only enter through design openings. The advantage of this is the control it gives the designer and owner to specify where air enters the building. It also provides the possibility of cleaning or enhancing the quality of the air that enters (Rudd and Lstiburek, 2000).

The exhaust system depressurizes the house. This is an advantage if one is attempting to prevent indoor air from entering wall cavities. It is a disadvantage if one is concerned with soil gas contamination entering the living space or if one is concerned about outdoor air entering the wall cavities (a potential problem in 
humid climates).

A third system option is a balanced system. Its advantages are that it does not change the pressure balance on the house and therefore can be used in any climate. It can be used to treat the incoming air stream. It can be used for energy and moisture exchange between supply and exhaust air streams. Its major disadvantage is cost.

\section{House Requirement}

All systems work best if the house is tight enough so that air enters and leaves the house through its designed openings. People understand the difficulties that occur in a house when the structure does not prevent liquid water from entering. There is less appreciation for the difficulties that occur when the other major fluid in the house, air, is allowed to enter and leave haphazardly.

\section{IWWS Compatibility}

There are several implications of this for the integrated window/wall system design. The assembled system should have low air leakage. If supply or exhaust ventilation systems are desired for the structure, air outlets (supply system) or inlets (exhaust system) should be provided in the panel.

In the context of IWWS we recommend that one wall unit per room be equipped with a slot ventilation device that has the following properties:

- Has capability to provide filtration of supply air

- Provides tempering of air in cold weather

- Has capability to provide dehumidification and/or cooling of incoming air

- Adjusts to pressure conditions on exterior shell to prevent over/under ventilation.

- Provides homeowner control of inlet

This list is appropriate for an exhaust air system. If a supply air system is chosen only features four and five would be required. Items one through three would be handled in different parts of the system, likely not at the wall.

Commercial ventilation slot devices exist that can be incorporated into a wall. An example is the AIRLETÔ marketed by American Aldes (www.americanaldes.com). Several options are available with different control strategies. Simple filtration of incoming air can be provided; "constant flow" capabilities are available and the homeowner can turn off the inlets. Another set of vent openings, though simpler in terms of capabilities, is provided by Titon, Inc. (www.titon.com).

TNO in the Netherlands has developed a "constant flow" inlet for commercial applications using passive ventilation. Measured performance shows a variation of flow of $\pm 10 \%$ over a pressure 
differential from 1 to $30 \mathrm{~Pa}$ (NatVent, 1999).

It is unclear whether the devices described in the previous two paragraphs (or others like them) are sensitive enough or reliable enough to function in a residential setting. Even less clear is how incoming air would be tempered (if too cold), or cooled (if too warm), or dried (if too humid). The commercial devices must be tested before considering them for the design. Clearly large mechanical systems could be installed to accomplish these tasks but the IWWS goals should include simplicity. Therefore, design solutions must be elegant and economical.

\section{Hybrid Ventilation}

In the discussion to this point the exhaust point for the ventilation system was assumed to be a quiet, continuously rated mechanical fan. It could also be a passive stack. Unfortunately, passive stacks exhibit the same type of ventilation characteristic as ordinary infiltration. In the winter when the difference between the indoor temperature, $\mathrm{T}_{\mathrm{i}}$, and the outdoor temperature, $\mathrm{T}_{\mathrm{o}^{\prime}}$ is large, ventilation rates are large. In "shoulder" seasons when $T_{i}-T_{o}$ is small, ventilation rates are small as is seen in houses that rely on infiltration for ventilation.

Yoshino, Liu, and Wada (1999) have pointed out that a hybrid combination of a passive stack coupled with a mechanical fan and a controlled damper can eliminate many of the large ventilation swings in a residence. They demonstrate that the mechanical fan can be used to boost the ventilation in the passive stack when the driving pressures are too small. At the other extreme, a damper can reduce ventilation flow when the driving pressures are too large. The control algorithm is simple: when $\left(\mathrm{T}_{\mathrm{i}}-\mathrm{T}_{\mathrm{o}}\right)<10 \mathrm{C}$, the fan operates; when $\left(\mathrm{T}_{\mathrm{i}}-\mathrm{T}_{\mathrm{o}}\right)>23 \mathrm{C}$ the damper restricts flow.

\section{Summary and Recommendations}

The integrated window/wall system should be capable of accommodating current trends in residential ventilation. Tight construction and ventilation inlets or outlets allow discussion of conditioning and controlling outdoor air quantity and quality. The design of systems to condition incoming air is a natural transition to a discussion of the wall as a possible appliance for conditioning the house.

\section{Ventilation References}

ASHRAE (2000) "Public review draft of SPC 62.2, residential ventilation", ASHRAE, Atlanta. www.ASHRAE.org

Hadlich, D.E. and Grimsrud, D.T. (1999) “ Residential pollutants and ventilation strategies: moisture and combustion products ", ASHRAE Transactions, 105(2), 833848 .

Holton, J.K. and Beggs, T.R. (2000) "Comparative ventilation systems tests in a mixed climate", ASHRAE Trans. 106(2), to be published. 
NatVent (1999) "Natural Ventilation for Offices. NatVent ${ }^{\mathrm{TM}}$ Project Report", Building Research Establishment, Garston, Watford WD2 7JR, UK.

Rudd, A. and Lstiburek, J. (2000) " Measurement of ventilation and interzonal distribution in single family houses", ASHRAE Transactions, 106(2) to be published.

Sherman, M.H. (1999) "Indoor air quality for residential buildings", ASHRAE Journal, 41(5), 26-30

Yoshino, H., Liu, J., and Wada, J. (1999) “Test house for performance evaluation of residential ventilation system and calculation results of hybrid ventilation system", in Proceedings of the 7 th International Symposium on Building and Urban Environmental Engineering and Management, Sapporo, Japan Oct., pp. 109-116.

\subsection{SENSOR AND CONTROL TECHNOLOGIES}

An active integrated building window/wall system (IWWS) could lower energy costs, improve comfort via active microclimate control, and increase human safety. To attain these goals, one must incorporate a collection of sensors, and active controls.

If the IWWS is to provide any active control over the environment, it must be capable of communication, which can be achieved by one of several off-the-shelf protocols/technologies. This control should be implemented as a part of a larger smart home system. (The issue of a whole house control system, versus stand-alone active IWWS "devices" will be discussed in the section on Active Control Handshaking.) One would like to monitor and control solar heat gain and light levels. By actively controlling these physical conditions, one could minimize energy usage, while maximizing the comfort of the occupant.

Advances in logic controllers, microprocessors and electronic controls will make such "smart controls" possible. Likewise, novel sensor technologies have recently arisen, covering a wide range of noxious, poisonous and undesirable gases, as well as advances in sensors for temperature, pressure, relative humidity, gas flow, vibration and noise, to name just a few.

\section{The Window/wall and the Home Network}

The IWWS will be a key tool in the regulation of day-lighting, solar heat gain, privacy and possibly other functions. However, the IWWS will be an appliance, serving as one functional device of a "smart house" network, along with myriads of other appliances and sensors.

The IWWS will have some local control of its functions, but must be slaved to the house controller to allow smooth integration and operation of the entire residence. We must therefore examine the state-of-affairs in the home-automation market. 


\section{Status of Home Automation}

There are a number of home-automation protocols in existence. However, there is no universal home-automation standard. While the dream of a house filled with smart appliances is quite feasible, it is also clear that lack of such a standard may create an unacceptable risk to the typical appliance manufacturer.

Clearly, the IWWS product will require a communication gateway, with the option of being attached to multiple physical layers; power lines, wireless links (RF or IR), telephone lines, fiberoptic, coaxial, or twisted-pair. This gateway must have the capability of detecting the type of LAN used by the house network, such as EtherNet, ArcNet, MS/TP [EIA-485] or LonTalk, as well as the application protocol attempting to "handshake", X10, CEBus, Smart House, LonWorks or BACNet. The IWWS gateway must be a very flexible "plug and play" device.

\section{The Competing Home Automation Protocols}

$X 10$

X10 is the oldest of the automated house protocols. It uses the existing power-lines within the residence as the communications bus, so it is inexpensive to implement. Thus X10 is automatically targeted at both the existing and new construction residential markets.

X10 has more than a 25 year history, and commercial products for this protocol are plentiful and inexpensive. A number of home networking vendors, such as Honeywell and IBM, are using the $\mathrm{X} 10$ protocol to control low-level functions. Applications of X10 are commercially available for Win95/98/NT, Xwindows, and

Macintosh. Free-ware and Share-ware software are also widely available.

The $\mathrm{X} 10$ protocol is proprietary. $\mathrm{X} 10$ is also quite slow: It transmits and receives data at $120 \mathrm{bits} / \mathrm{sec}$. X10 can address 256 distinct units in the house network, and its "language" is structured for switching binary states.

The envisioned IWWS will need greater interfacing capabilities than simply switching solo binary states.

\section{Smart House Limited Partnership}

The Smart House is a proprietary system by the Smart House Limited Partnership for the National Association of Home Builders (NAHB). This protocol is open for licensing. The goal of Smart House is to provide a complete wiring, communication and gas distribution system which will standardize all new residential construction.

The Smart House system is rather expensive. This system requires that a dedicated six-wire cable be run to every proprietary item in the network; it does not use the power line as a communications bus, unlike other systems. Extrapolating from the present home computer market, one who implements the Smart House proprietary solution is probably raising the possibility that 
he/she will be replacing obsolescent hardware and/or software frequently.

Home Plug-n-Play \& Common Applications Language (EIA-709)

The CEBus Industry Council (CIC) standard integrates the CEBus and LONWorks control protocols under one umbrella. Both CEBus and LONWorks are complete multilevel protocols, defining the application, the transporting, the networking, the data linking and the physical layers. Also at this time, CIC and Microsoft Corporation are jointly creating a "Simple Control Protocol" standard.

CEBus (EIA-600)

CEBus (Consumer Electronics Bus) is a public-domain home automation protocol conceived and developed by the Electronic Industries Association (EIA). Its beginnings were in 1984 when EIA standardized the infrared (IR) transceiving protocol for remote controls of televisions and such. CEBus will interface to power lines, twisted pairs, coaxial cables, RF, IR and fiber optic cabling.

\section{LONWorks (EIA-709)}

Created by Echelon Corporation, LONWorks is targeted at both the commercial and residential control markets. At the physical communication level, LONWorks has defined protocols to couple to all common physical layer media, excluding telephone lines.

At one point all LONWorks-compatible devices carried a proprietary "Neuron" chip which handled all LAN considerations. Now the LONWorks protocol is publicly available as EIA-709 and can be implemented on any microprocessor. Motorola has announced the discontinuance of manufacturing the "Neuron" chip. Toshiba and Echelon have announced a continuance of their partnership in producing the "Neuron" chip.

\section{BACNet (ANSI/ASHRAE-135)}

BACNet (Building Automation Control Net) is an open, commercial building control protocol designed by ASHRAE and the U.S. Department of Energy. Due to the political and economic forces within the U.S. Government, such as Housing and Urban Development (HUD), one could reasonably foresee this protocol being "pushed" into the home automation market. If this does indeed occur, we must wonder; would BACNet products successfully carve out market share in the home automation market or would BACNet eventually be "absorbed" into the Home Plug-n-Play standard?

\section{Physical Communication Buses}

There are two categories of possibilities: Communication methods requiring the installation of new cabling and 
communication methods not requiring the installation of new cabling.

New cabling is expensive, especially when retrofitting a residence. For this reason, methods of communicating via wireless techniques, telephone lines, and power lines are very attractive. Some of the prominent consortiums pushing high-transmission rate, "no new wires", methods are Bluetooth and HomeRF (wireless), HomePNA (telephone lines), and HomePlug (power lines).

It should be noted that HomePNA Ethernet devices, transceiving at $10 \mathrm{Mbps}$, are now readily available at places like Circuit City, Best Buy, or Radio Shack.

A common perception is that all new construction will eventually follow the "Smart Wiring" Standard (EIA-606). Then homeowners would move into a residence pre-wired for networking. No new technology is required.

HomePlug envisions the house power lines eventually handling ALL communications in the home. If this works (the technology is currently being field-tested) HomePlug would appear to have a good chance of capturing the retrofit market as well as a large share of new construction. HomePlug is currently field testing the "PowerPacket", which is a 14 Mbps power line network device developed by Intellon ("No New Wires") Corporation.

Summary of Home Controls

The central controller and appliances of the future will contain inexpensive and intelligent gateways. These gateways will couple to a finite selection of physical buses (selected at the time of installation) and will automatically detect the LAN, network and application protocols.

\section{An overview of Electronic Sensor Component Technologies}

An active IWWS component is useless, unless one actually measures some physical parameter. For this, we need to select appropriate sensors to permit control of solar heat gain, and daylighting.

Some options for temperature measurement are stand-alone thermistors, thermocouples, resistive thermal devices (RTDs) and electronic thermometer ICs. All of these devices are very compact, and fairly easy to instrument or couple with the electronic controls.

Thermistors, while often considered to be a somewhat fragile semiconductor device, are actually quite robust, and are readily available at a very low cost. These are also available in surface-mount electronic packages, if this is desirable. One minor drawback of the thermistor is their nonlinear resistance, as a function of temperature; however this behavior is mathematically simple, and a computer control has no problem calculating the temperature from the output of this device. In exchange for this nonlinearity, the thermistor provides a steep resistance curve over the temperature range of interest; this large resistance change, 
relative to its nominal resistance, allows one to obtain good resolution.

Thermocouples have an advantage in that they are very robust, "self powering" and quite linear, however their disadvantage is that they produce very little voltage change for moderate temperature changes. Additionally, a thermocouple requires an "ice point" reference, which must be provided electronically.

$R T D s$, while quite linear, provide only a relatively small resistance change relative to their total resistance, over moderate temperature ranges. Again, this lack of signal variation tends to limit the usefulness of this device for comfort level temperature measurements.

Electronic thermometer ICs are also available at a low cost. These active components provide a linear voltage output that is proportional to the temperature (e.g. a slope of $10 \mathrm{mV} / \times \mathrm{F}$ ). However, each additional electronic component increases the current drain of the system.

The thermistor and electronic thermometer both have the advantage of good "signal response" for a given temperature change, and should be strongly considered for such an application.

Such stand-alone temperature sensors may be desirable if we wish to measure the temperature at multiple points within the IWWS unit; for example, one could measure both interior and exterior wall temperatures. Using the knowledge of this temperature gradient, one may be able to optimize overall home conditions. In the case above, the central home controller could draw air in from the cooler side of the home, while changing the glazing or blinds to minimize solar heat gain on the warm side of the home.

A measurement of light level can be obtained via inexpensive cadmium sulfide cells (CdS), photodiodes, phototransistors, or even a small inexpensive solar cell.

The CdS cell changes resistance with light level. While very nonlinear, they provide a good range of variation over normal light levels. The photodiode, as does the solar cell, generates a current that is dependent on the light level. A resistive load easily converts this current into a usable voltage signal. The phototransistor would be a slightly more expensive option, requiring additional electronic components to convert its output into a useful signal for a controller.

Any of these light-measuring devices could be incorporated into the system with little difficulty. However, the photodiode, solar-cell and CdS would require fewer electronic components for signal production.

Active Control Handshaking

The smart IWWS on board controller should work in conjunction with a main house controller. This device controller would be subservient to the main house controller.

The need for this hierarchical system would become 
immediately obvious, upon installation of independent "smart devices". These devices would almost certainly begin competing in the form of an electromechanical oscillation, unless great care is taken in all aspects of the control logic. If this were to happen, one would see a feedback/overshoot control problem, due to these sensor inputs to the control "feedback loop", coming from more than one source. This competition effect would be eliminated by denying the decision process to these smart devices, limiting them to carrying out the commands from the central controller.

\section{Microclimate Control}

The occupant will not only desire that the home be energy efficient, but will also require that the occupied rooms be comfortable. From an occupant standpoint, comfort will be more important than overall energy efficiency, and this must be factored in to any control system.

The home control system could permit the occupant to adjust the conditions in the occupied rooms, while compensating for these adjustments via control of the rest of the home, maximizing the overall energy efficiency.

One example could be compensating for the solar heat gain in an occupied room, whose blinds are open for lighting purposes, by circulating air from the cooler rooms throughout the home. And we may also desire that the system draw outside air into the house, as part of the cooling and climate control.

\section{Application Limitations: Power Consumption and Sources}

It would be desirable to avoid the use of 120 VAC home wiring for powering these active controls. This would add difficulty to the mechanical installation process. For this reason, we wish to limit power consumption, and consider either a method of selfpowering, or use only a low power source (such as a common $12 \mathrm{~V}$ DC power supply, plugged into an outlet).

One method of independently powering an IWWS control system would be through passively available solar energy, e.g. solar cells. This requires that the power consumed by these sensors and any active components must be minimized. The total power and current available from a solar cell depends on the efficiency, the active area, and solar flux. While research and scientific labs have solar cells with efficiencies upwards to $25 \%$, many off-the-shelf solar cells are operating at an efficiency of 10$15 \%$. To provide a more easily understood capability for such cells, Plastecs (a manufacturer of economically priced solar cells) sells a $8.5 "$ x 4.3" solar cell, rated to produce $300 \mathrm{~mA}$ at $7.2-9.9 \mathrm{~V}$ for a cost of $\$ 50.00$ (single unit price). We should note that these manufacturer ratings are often for optimal conditions, whereas everyday use will generally result in actual available power in the range of $1 / 2$ to $1 / 3$ the optimal rated value.

If it is desired to incorporate devices, such as fans for active local ventilation/cooling, an external power source may be required. One specific example is a small "pancake" fan rated at 
26 CFM, which draws a maximum of $160 \mathrm{~mA}$ at $12 \mathrm{~V}$. This may exceed the power obtainable from a passive power source. A similar power deficit may occur if we require electrical motors to drive mechanical blinds, for lighting, privacy, or solar heat gain control.

\section{Major Organizations Advancing Home Automation}

W G 1

IEC/ISO JTC1 SC25 Working Group 1

http: / / www.metrolink.com/sc25wg1

ASHRAE Technical Committee 4.11, Smart Building Systems http: / / www.ashrae.org

BFRL: Building and Fire Research Laboratory

Cybernetic Building Systems

National Institute of Standards and Technology

http:/ / www.bfrl.nist.gov

C A B A

Continental Automated Building Association (CABA)

http: / / www.caba.org

CEDIA

Custom Electronic Design and Installation Association

http://www.cedia.org

H A N A

Home Automation and Networking Association

http: / / www.homeautomation.org

N A H B

National Association of Home Builders

http:/ / www.nahb.org

UPnP / Home A P I

Universal Plug and Play

http:/ / www.upnp.org

\section{Corporations in the Building Automation Market}

- Advanced Building Technologies

- Andover

- Domosys

- Echolon

- Energy Controls International

- $\mathrm{GE}$

- Honeywell

- I B M 
- IC AMS

- Intellon

- JDS

- Johnson/Yokogawa

- Microsoft

- Novar

- Siebe

- Siemens

- Smartlinc

- Sun Microsystems

- TCS/BAsys

- Trane

- TSI 


\section{Key Design Issues for the IWWS}

\subsection{INTRODUCTION}

In the course of developing the IWWS, it was necessary to document a series of design issues. These include moisture management, building codes, sustainable design, and the building process itself. These are not components or systems in the traditional sense, but they play an important role in understanding and setting design criteria for the IWWS.

\subsection{MOISTURE MANAGEMENT}

Moisture is a fact of life and is present everywhere. However, the presence of excess moisture in a house or building envelope can cause a number of problems, ranging from mold and mildew, condensation on walls and windows, poor indoor air quality, decreased insulating value of the insulation, siding and paint failure, deterioration of building materials, and even structural damage. Recent studies suggest that moisture damage represents over $90 \%$ of all building and building material failures in the United States costing owners billions of dollars annually. A 1995 study by Cheple at the University of Minnesota found that $54 \%$ of new homes built in 1991 and 1992 in the Twin Cities had three or more critical moisture indicators. Another recent report by ASTM states that, except for structural errors, moisture damage is the leading cause of problems in buildings in the United States costing owners billions of dollars annually. Moisture-related problems led the list of top callbacks for Minnesota builders in a 1994 survey by the Builders Association of Minnesota and the University of Minnesota. Moisture problems have quickly become the nemesis of this decade for the home building industry.

\section{Basics of Moisture Movement}

Almost all moisture problems, with the exception of high indoor humidity being capable of providing a suitable environment for mold growth, are a result of liquid water. This could be as bulk water movement or as condensation of water vapor. We will review the key moisture movement mechanisms for water both as a liquid and as a gas (water vapor).

Section 5.2: Moisture Management contributed by Pat Huelman and Marilou Cheple, University of Minnesota. 


\section{Movement Mechanisms for Liquid Water}

Liquid water flow is potentially the most devastating to building performance and, therefore, must remain as the primary concern in new home construction. The three key mechanisms for liquid flow are gravity, fluid pressure, and capillary action.

Gravity - This mechanism is primarily responsible for the entry of bulk water into the home through leaks in the roof, walls, windows, and below grade components. This is controlled by shingles, cladding systems, and foundation drainage systems. Common problems include poor flashing details for roof and wall penetrations and poor site drainage.

Fluid Pressure - This type of moisture movement is caused by a pressure, such as wind-driven rain, or hydrostatic pressure on a below grade wall or slab. Wind pressures can be controlled with a vented rain screen behind the cladding and hydrostatic pressure can be relieved with a foundation drainage system. If the pressure is not controlled, a weather barrier, such as a building paper or house wrap, must be used above grade and a waterproofing membrane must be employed below grade. Common problems include the improper application of building paper, house wrap, and flashing and inadequate foundation drainage.

Capillary Action - The flow of liquid moisture through small interconnected pores or spaces due to adhesion and surface tension - commonly referred to as "wicking". This is a very powerful mechanism and depending on pore size and available water the moisture can rise many feet against the force of gravity. Capillarity can be controlled by sealing the pores or making the pores very large, such as washed aggregate. Common problems include capillary rise from the footing into the foundation wall and capillary suction of water behind siding.

\section{Movement Mechanisms for Water Vapor}

Before discussing water vapor movement, it is important to briefly review psychometrics or the study of air, water, and temperature relationships. The bottom line of psychometrics is fairly simple - warm air can hold more water vapor than cold air can hold. This also can help in understanding the term relative humidity, which is the amount of moisture in the air compared to the amount of moisture it is capable of holding. So given a fixed amount of water vapor in a given volume of air, its relative humidity will be higher at a cold temperature and lower at a warm temperature. Another way of looking at this is that as cold air is heated its relative humidity goes down and as warm air is cooled its relative humidity goes up. The critical point is when the water vapor is high and the air cools sufficiently that the air reaches $100 \%$ relative humidity - the dew point - and the water vapor will begin to condense into liquid water. This can lead to significant 
moisture accumulation inside the building envelope in cold climates by two distinct movement mechanisms: vapor diffusion and air flow.

Diffusion - Similar to heat which travels from hot to cold, water vapor will move from an area of high water vapor concentration to an area of low water vapor concentration. In the winter the outdoor air has less water vapor than the house air. Therefore, in the winter there is a constant pressure for indoor water vapor to move towards the outdoors. If this movement is not carefully controlled the water vapor may condense as it reaches a cold surface during its migration. This movement by diffusion can be easily controlled by a vapor retarder installed on the warm side (interior) of the wall and ceiling insulation. Common trouble spots are rim joists and cantilevered floors.

Air Flow - Warm air moving from indoors to outdoors in the winter carries with it not only heat, but also water vapor that can condense inside the cooler ceiling and wall cavities. In a typical home, this moisture movement mechanism can move 10 to 100 times more water vapor than diffusion. For this type of moisture flow to occur it is necessary to have moisture in the house air, a hole in the building envelope, and a pressure difference pushing air to the outside in the winter or drawing air inward when air conditioning. Because it is important to have some moisture in the house air and because the pressures are very difficult to manage due to varying outside conditions, the primary means to control this airflow is a continuous air barrier in the exterior wall and ceiling assemblies. Common problem areas are ceiling bypasses (including chimneys, plumbing vents, fireplace chases, dropped soffits, and recessed lights) electrical boxes, rough openings for windows and doors, rim joists, and interior partition walls at the exterior walls and ceiling.

\section{Sources of Moisture}

When evaluating moisture control in buildings, it is critical to identify whether the moisture is coming from external or internal sources. Below is a list of potential moisture contributors.

\section{External Moisture Contributors}

Above the grade, exterior moisture generally moves into the home as a liquid or bulk water. It is also possible for snow to be blown into the attic or roof system. However, below the grade water vapor can be a significant movement mechanism for ground moisture to enter the home through the foundation walls, floor slab, or crawl space. 
Above grade - The greatest concern for above grade components is the leakage of bulk water. A second concern is capillary action of water under the shingles, roof drip edge, and siding systems. Brick, masonry, concrete, and stucco not only support capillary action, but can also absorb large quantities of bulk water. In the summer this water can be evaporated by the sun and driven into the wall system as water vapor. This is one area of concern for summer moisture movement because the water vapor can condense inside the wall, especially if the house is air-conditioned. Another critical issue for above grade components is "splashback", where rain or roof water hits the ground or other surfaces near the house and splashes back up onto the foundation or wall cladding. Lawn sprinklers can cause similar problems.

Below grade - This is perhaps the most underrated moisture source in new homes. In addition to bulk water penetration, moisture can also move into the house by capillary action, diffusion and air flow into the home. Capillary action can wick moisture from the soil into the footing and up into the foundation wall to subsequently evaporate into the home. Moisture movement by diffusion is quite different below grade. If the soil is saturated the flow of moisture will be inward toward the house, even in the winter, and in most homes there is a very large surface area exposed to the soil. Last, but not least, is air flow. If the basement is drawing air in from the outside - which is frequently the case due to the stack effect, exhaust fans, and return duct leakage moisture-laden soil gas can be pulled into the home. Even small amounts of airflow could contribute large amounts of water vapor into the home.

\section{Internal Moisture Contributors}

There are a number of internal sources for moisture. Unless there is a plumbing leak or an overflow of a fixture or appliance, this moisture generally moves throughout the house as water vapor.

Building materials - Many building materials will pick up moisture during high humidity conditions (summer) and release this moisture during low humidity conditions (winter). This seasonal fluctuation can represent a large moisture load for the home in late fall and early winter. The moisture released by building materials following construction can be very significant. This new construction related moisture release could be a gallon or more per day for the first 12 to 18 months.

Occupants - Clearly occupants can generate substantial amounts of moisture in the home. This can be directly from 
the occupants themselves through respiration and perspiration and indirectly through bathing, cooking, cleaning, and washing. There are many other lifestyle factors like house plants, indoor firewood storage, aquariums, refrigerator defrost, and pets. Of particular concern would be humidifiers and moisture resulting from improper venting of combustion gases.

A typical home will generate three to four gallons of water per day. A house with good site drainage and dry foundation construction and low occupant contributions might only generate one to two gallons. However, a house with inadequate below grade moisture control and high internal contributions might be as high as five or six gallons per day.

\section{Strategies for Moisture Control}

\section{Above Grade Moisture Control}

For above grade assemblies, moisture control focuses on the drainage of liquid water for the exterior surfaces and protection against airflow across the thermal envelope.

Air Barrier - A continuous air barrier toward the interior of the thermal envelope is needed to retard air transported moisture movement into the wall and ceiling assemblies. This is usually achieved with a durable, polyethylene membrane that is sealed at all openings, penetrations, and seams.

Vapor Diffusion Retarder - To slow diffusion, simply use a material with a low perm rating on the interior side of the thermal insulation. This could be polyethylene, kraft paper facing, foil back drywall, or vapor retarder paint.

Weather Barrier - A combination of sheathing and building paper or house wrap to prevent wind-driven rain and capillary water from getting into the wall system or onto moisture susceptible sheathings. Also, long overhangs can reduce capillarity by protecting the wall cladding from frequent wetting.

Rain Screen - A vented airspace between the cladding and sheathing will equalize air pressures preventing winddriven rain entry and will provide a "drop" zone and drying capability for capillary water.

Capillary Break - The key areas for capillary breaks are at the roof drip edge and flashing for wall openings, trim boards, or adjacent roof areas. The siding should be held up a minimum of $3 / 4$ " from the horizontal surface of the flashing and a minimum of 3 " from a roof surface. Siding should also be a minimum of 6" from the ground or any horizontal surface. The end grain of all exposed wood trim, siding, and decking must be sealed to prevent capillary suction. 


\section{Below Grade Moisture Control}

For below grade assemblies, moisture control will focus on protection from ground moisture.

Site Drainage - Bulk water must be directed away from the home with gutters, downspouts, and careful site grading.

Dry Foundation Construction - Foundation waterproofing or dampproofing with a foundation drainage system should be used to control ground moisture.

Capillary Break - To prevent capillary rise up the foundation use a dampproofing material or sheet of durable polyethylene on top of the footing before the foundation wall is poured or the block is laid.

Dry Slab Construction - To control moisture under the slab, install 4 " of large washed aggregate as a drainage layer and capillary break and place a strong, durable polyethylene membrane below the slab to control diffusion. All penetrations should be sealed to retard soil gas entry.

\section{Remove Interior Moisture Sources}

Another important indoor moisture control strategy is to reduce moisture generation within the home. A direct vent should be provided for the clothes dryer, firewood should not be stored indoors, and moisture released from cooking and cleaning should be minimized.

\section{Control Interior Humidity}

The last moisture control strategy is to remove or dilute indoor moisture. In the winter, ventilation - exhausting moist indoor air and bringing in dry outdoor air - is the easiest way to reduce indoor moisture levels. A mechanical ventilation system should be installed to immediately remove moisture from baths, kitchen, laundry room and any other point sources. General house ventilation may also be needed to remove moisture from disperse sources, such as people, plants, and pets. In the summer, ventilation is not as effective and it may be necessary to use a dehumidifier to keep interior moisture levels under control.

\section{Special Issues and Concerns}

\section{Building Pressures}

Building pressures can have a profound impact on energy performance, moisture accumulation and drying, as well as indoor air quality. It is critical to recognize and design for a wide range of building pressures not only for structural considerations, but also for the thermal and moisture impacts on the individual materials.

Building pressures are a result of both natural and mechanical forces. The natural forces are created by temperature and wind 
effects around the building. Mechanical forces include a variety of air handling equipment ranging from exhaust fans to clothes dryers to forced-air heating/cooling systems. The venting of atmospheric combustion equipment also plays a role in the building pressure.

Wetting vs. Drying

There are very few instances where a materials or system is completely static. In other words, materials in a building are constantly taking on or giving up moisture. As long as this happens within the prescribed limits for an individual material, little harm is done. Likewise, if drying quickly follows wetting, there may be limited impact.

In general, our greatest concern is when the wetting rate exceeds the drying rate for a critical time period. That critical time period is a function of the material and the specific environmental conditions.

Another key in determining moisture-induced damage is the amount of safe storage within or around the material in question. Some materials can store a large amount of water without significant damage. However, this might quickly change with freezing conditions or the addition of a food source that could support biological activity.

Exterior Water at Elements and Joints

One of the greatest concerns today is the entry of exterior water into cavity framed building envelopes. It can have a dramatic impact on the sheathing, thermal insulation and framing system.

There are several approaches to controlling or managing this exterior water at the building cladding. One approach is to develop a layer that does not let water penetrate into the building envelope. This could be done with a perfectly sealed membrane or perhaps with a material that is capable of shedding all of the water that reaches it. A second approach is to accept that water moves past the cladding system. At that point the water is either stored, as in a mass wall system, or relieved through a drainage system. This later approach is frequently called a vented rain screen or drainage system.

\section{Wall Failure Modes}

There are a number of moisture failure modes for contemporary wall systems. These failures can result in both direct and indirect impacts. Direct impacts include cladding failures, deterioration of envelope materials and framing systems. Indirect impacts are more removed from the actual damages, but can be just as serious. Moisture damage can frequently contribute to indoor air quality concerns or moisture damage of non-wall 
components.

\section{Moisture-Related Recommendations for IWWS}

The following recommendations are intended to enhance the moisture performance of the IWWS design. There are a number of essential functions that must be provided in a successful IWWS. The must be a weather barrier and drainage pathway to protect the structural and insulation materials from exterior water. There must be an air barrier and vapor retarder to protect condensation susceptible materials from both interior and exterior humidity. In most designs there must be capillary breaks between critical materials to prevent excessive wetting of susceptible materials. It will be important to provide some opportunity for diffusion drying to occur outward in the heating mode and inward in the cooling mode.

There are several other functions that could also be considered. It may be possible to provide internal drainage to remove excess moisture accumulation. Likewise, pressure modulation could be used in lieu of or in conjunction with the air barrier to reduce the potential for wetting. Ventilation drying might be considered in systems susceptible to moisture accumulation.

There are a number of critical elements in the exterior envelope for exterior moisture control. Important connections include the roof soffit, roof/wall intersections, door and window installation, deck ledgers, trim detailing, and the wall foundation transition. Components that will require close attention to moisture issues are the cladding, sheathing, weather and drainage planes, and the windows and doors.

In setting specific recommendations for the IWWS, it may be useful to separate those recommendations that would be pertinent for all climate zones from those that might be climate dependent.

\section{Generic or Universal Solutions}

Based on the literature review of moisture management and performance of existing systems, the following items are recommended for the IWWS.

- The IWWS must have an exterior moisture management strategy incorporating both a weather barrier and drainage plane.

- There must be inherent control of both vapor diffusion and air transport.

- There should be a specific strategy for drying by diffusion or ventilation the critical and/or susceptible materials in the system.

\section{Climate Specific Issues}

For hot-humid climates, special attention will be required for the exterior air barrier and vapor retarder. Also, the interior 
finishes must have high permeability to provide the opportunity for drying to the interior.

Extremely rainy climates will necessitate increased concern for a continuous drainage plane and drainage cavity. For moisture adsorptive claddings, there must be a low permeability material to prevent inward migration of water vapor. Structural drying will need to occur to the interior. Conversely, in extremely dry climates the exterior water management methods might be modified or eliminated.

For very cold climates there should be additional condensation protection. This would likely require an enhanced vapor retarder, resilient air barrier, and special attention to thermal bridging.

In conclusion, it will be important to decide if a truly universal design should be developed. This may result in over engineering or certain redundancies that could add to costs. However, climate specific approaches would have drawbacks as well, including increased inventory, improper application or misplacement.

\subsection{BUILDING CODES}

\subsubsection{Objectives}

This section will detail some code requirements for a proposed IWWS product as well as provide some design references for meeting code requirements.

The realities of the residential building code will largely determine the limits of the window wall design. Building code officials have as their primary responsibility to protect and defend the interests of the future homeowners. It is convenient for code officials to accept traditional wall construction because it has been proven by centuries of practice and therefore is considered safe. Nontraditional building methods, however, do not enjoy the benefits of centuries of practice and therefore require special treatment to convince building officials and builders of their safety, durability and efficacy. This will have to be done through market research, training and product evaluation reports by an applicable code body.

\subsubsection{General Code}

Each state and local municipality has its on code requirements but most point to larger national code bodies. In one form or another codes require that wall construction "be capable of accommodating all loads imposed ... and of transmitting the resulting loads to the supporting structural elements". Code bodies try to address the biggest concerns in housing while ensuring safe, comfortable dwelling. Below are paraphrased excepts form ASCE 7-98 "Minimum Design Loads for Buildings"

Structural:

Buildings, structures and all parts thereof, shall be designed to safely support factored loads in load combinations 
defined in ASCE 7-98, without exceeding strength limit states of the material or component.

Serviceability:

Structural systems and members thereof shall be designed to have adequate stiffness to limit deflections, lateral drift, vibration, or any other deformation that adversely affect the intended use or performance of a building.

Self-straining forces:

Provision shall be made for anticipated self-straining forces arising from differential settlements of foundations and from restrained dimensional changes due to temperature, moisture, shrinkage, creep, and similar effects.

Counteracting structural actions:

All structural members and systems, and all components and cladding in a building shall be designed to resist forces due to earthquakes and wind, with consideration for overturning, sliding and uplift and continuous load paths shall be provided for transmitting these loads to the foundation.

Where all or a portion of the resistance to these forces is provided by dead load the minimum load shall be taken as the minimum dead load likely to be in place during the event causing the considered forces. Consideration shall be given to the effects of vertical and horizontal deflections resulting from such loads.

Other concerns mentioned or addressed in code books:

- Fastening

- Durability

- Energy

- Air Infiltration

- Ventilation

- Sound

- Life Safety (Egress)

- Fire (hr Rating)

Although most of the residential code requirements focus on platform framing (currently most common framing) or balloon framing construction, the codes do allow for non-conventional construction if the equivalent detailing and the structures are designed in accordance with accepted engineering practice.

The various building codes generally are very good at setting standards for safety and serviceability issues, but for performance, durability, and sustainability it is much more difficult to set requirements because of the variety of products and advances in 
technologies.

\subsubsection{Building Code Evolution}

The complexity of the building code system is seen as an obstacle to many builders and home manufactures for not only residential construction but also commercial construction. The inclusion of energy code requirements in local and state codes has proved to be expensive and sometimes difficult. The creation of the international code council will hopefully reduce the code complexity and provide a path for energy codes to be implemented. For residential energy code most states and municipalities still have their own requirements or no requirements. These energy codes provide minimum code requirements and compliment other national energy programs. For residential energy code most states and municipalities still have their own requirements or no requirements. Figure 5.1 shows the

Figure 5.1: Building Code Organization.

\section{Previous code environment}
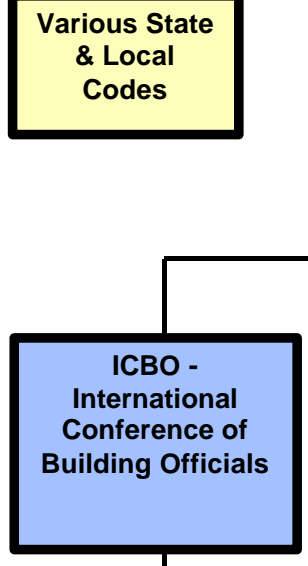

Uniform Building Code
CABO - Council of American Building Officials

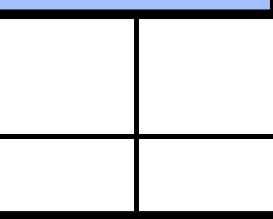

BOCA - Building

Officials Code

Administration

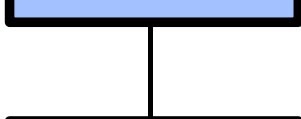

National Building Code
CABO - One \& Two Family Dwelling Code

\section{Expected Code Environment Year 2000}

\section{Various State \& Local Codes}

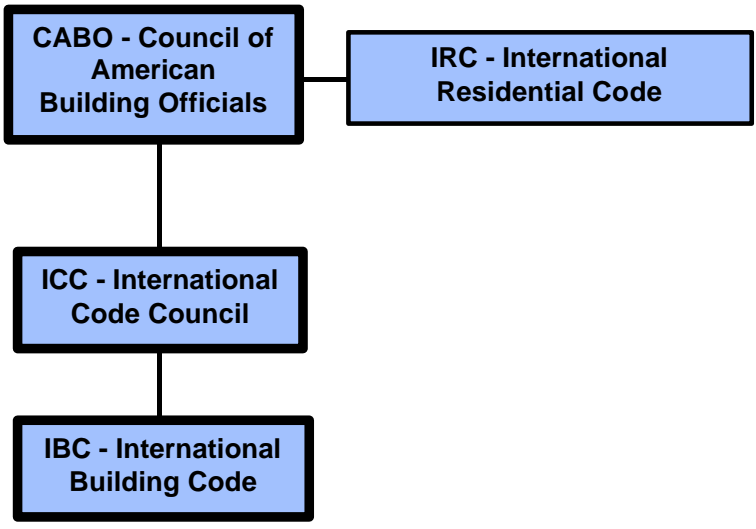


evolution to the International Code.

\subsubsection{Actual IBC Code Adoption by State}

Actual adoption of the single code concept has gone slowly. Below is an up to date $(9 / 11 / 01)$ listing of the IBC (International Building Code), IECC (International Energy Conservation Code), and IRC (International Residential Code) adoption progress. Table 5.1 and Figures 5.2 and 5.3 indicate state adoption. Updates are found at http://capwiz.com/icc/Adoptions9 10.pdf.

\subsubsection{Energy Code.}

The maps Figures 5.2 and 5.3 are not an indication of the current energy code environment. For the most up to date energy codes individual state energy offices must be contacted. Several web references are listed below which can facilitate energy code requirements. How does the energy code work? Energy codes typically set minimum requirements for a "model" structure. The U-value is multiplied by the area (UA) of proposed components and/or the building envelope are compared to the composite UA for the entire "model" building (or U-value for an individual component if the design by prescriptive component method is used). The envelope energy usage is based on local conditions (i.e. Heating Degree Days) and regional concerns. Several codes set a minimum value for certain components (i.e. windows maximum U-value 0.37 or minimum wall R-value 19). MECcheck (Model Energy Code check) is a method to check a residential building for meeting the most up to date energy standards. The system is available for all states and most cities but is not a requirement of all code bodies. Several states make unique adjustments to satisfy local concerns. The MECcheck software has many of the adjustments available (i.e. Minnesota, Georgia) Three approaches are used to comply with the standard (detailed at http:// www.eren.doe.gov):

1. "The prescriptive approach, the simplest of the three approaches, allows builders or designers to select from various combinations of energy conservation measures based on "climate zone" location. Each combination or "package" specifies insulation levels, glazing areas, glazing U-values (thermal performance), and sometimes heating and cooling equipment efficiency. By locating the correct climate zone and looking up the appropriate table of packages, builders and officials can ensure the project meets one of the packages listed for that zone.

2. The trade-off worksheet approach enables builders to vary insulation levels in the ceiling, wall, floor, basement wall, slab-edge and crawl space; glazing and door areas; and glazing and door U-values. Based on the proposed plans and specifications, the builder enters simple information on a MECcheck worksheet then hand-calculates a total "UA- 
Table 5.1: Current Status of Building Code Adoption.

$$
\begin{aligned}
& X=\text { Effective Statewide } \\
& L=\text { Adopted by Local Governments } \\
& A=\text { Adopted Statewide }
\end{aligned}
$$

\begin{tabular}{|c|c|c|c|c|}
\hline & IBC & IECC & IRC & Comments \\
\hline Alabama & $\mathrm{L}$ & $\mathrm{L}$ & $\mathrm{L}$ & No state codes \\
\hline Alaska & $\bar{x}$ & & $\bar{x}$ & Adopted March 2001 \\
\hline Arizona & $L$ & $L$ & $\mathrm{~L}$ & \\
\hline \multicolumn{5}{|l|}{ Arkansas } \\
\hline \multicolumn{5}{|l|}{ California } \\
\hline \multirow{2}{*}{\multicolumn{5}{|c|}{ Connecticut }} \\
\hline & & & & \\
\hline \multicolumn{5}{|c|}{ District of Columbia } \\
\hline Florida & & & & Effective January 1, 2002 \\
\hline Georgia & & & & Effective January 1, 2001 \\
\hline \multicolumn{5}{|l|}{ Hawaii } \\
\hline Idaho & $A$ & $\mathrm{~L}$ & & Effective July 1, 2002 \\
\hline Illinois & $\mathrm{XL}$ & $\mathrm{XL}$ & $X L$ & X: I-Codes adopted to cover construction of Industrialized \\
\hline \multicolumn{5}{|r|}{ 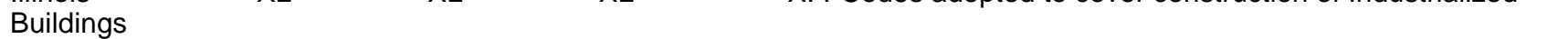 } \\
\hline Indiana & & & $\mathrm{X}$ & IRC effective June 22, 2001. \\
\hline lowa & $\mathrm{L}$ & $\mathrm{L}$ & $\mathrm{L}$ & \\
\hline Kansas & $\mathrm{L}$ & $\mathrm{L}$ & $\bar{L}$ & \\
\hline Kentucky & $\bar{A}$ & & $\bar{A}$ & IBC \& IRC Effective January 2002 \\
\hline \multicolumn{5}{|r|}{ 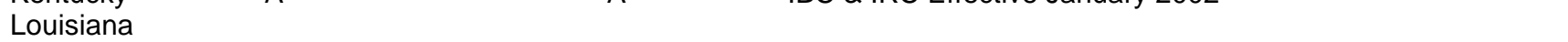 } \\
\hline Maine & $\mathrm{L}$ & $\mathrm{L}$ & $\mathrm{L}$ & \\
\hline \multicolumn{5}{|r|}{ 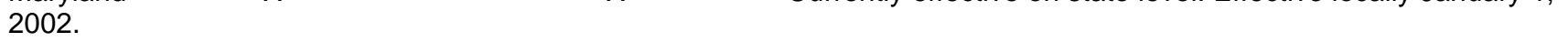 } \\
\hline Massachusetts & A & & & \\
\hline Michigan & $\mathrm{X}$ & $\mathrm{X}$ & $\mathrm{X}$ & Effective July 31, 2001. \\
\hline \multicolumn{5}{|l|}{ Minnesota } \\
\hline \multicolumn{5}{|l|}{ Mississippi } \\
\hline Missouri & $\mathrm{L}$ & $\mathrm{L}$ & $\mathrm{L}$ & \\
\hline \multicolumn{5}{|l|}{ Montana } \\
\hline \multirow{2}{*}{\multicolumn{5}{|c|}{ Nevada }} \\
\hline & & & & \\
\hline \multicolumn{5}{|l|}{ New Hampshire } \\
\hline \multicolumn{5}{|l|}{ New Jersey } \\
\hline New Mexico & $\mathrm{L}$ & & $\mathrm{L}$ & \\
\hline \multicolumn{5}{|l|}{ New York } \\
\hline \multicolumn{5}{|l|}{ North Dakota } \\
\hline Ohio & A & & $\mathrm{X}$ & Effective January 2002 \\
\hline \multirow{2}{*}{\multicolumn{5}{|c|}{ Oregon }} \\
\hline & & & & \\
\hline \multicolumn{5}{|l|}{ Pennsylvania } \\
\hline Rhode Island & A & & & $A=$ Effective September 2001 \\
\hline \multicolumn{5}{|r|}{ Effective July 1, 2001. IRC Effective July 1, 2002.} \\
\hline South Dakota & $\mathrm{X}$ & & & \\
\hline \multicolumn{5}{|l|}{ Tennessee } \\
\hline $\begin{array}{l}\text { Texas } \\
\text { available for loc }\end{array}$ & $\begin{array}{c}\mathrm{L} \\
\text { adoption. }\end{array}$ & $A L$ & A & Effective September 1, 2001, IRC mandated, IECC, IMC, IPC \\
\hline Utah & A & $A$ & $A$ & A=Effective January 1, 2002. \\
\hline Vermont & & & & \\
\hline Virginia & & & & \\
\hline Washington & & & & \\
\hline West Virginia & $A$ & $A$ & $A$ & Effective July 2002 \\
\hline Wisconsin & & & & \\
\hline Wyoming & & & & \\
\hline
\end{tabular}


Figure 5.2: Current Building Code Environment.

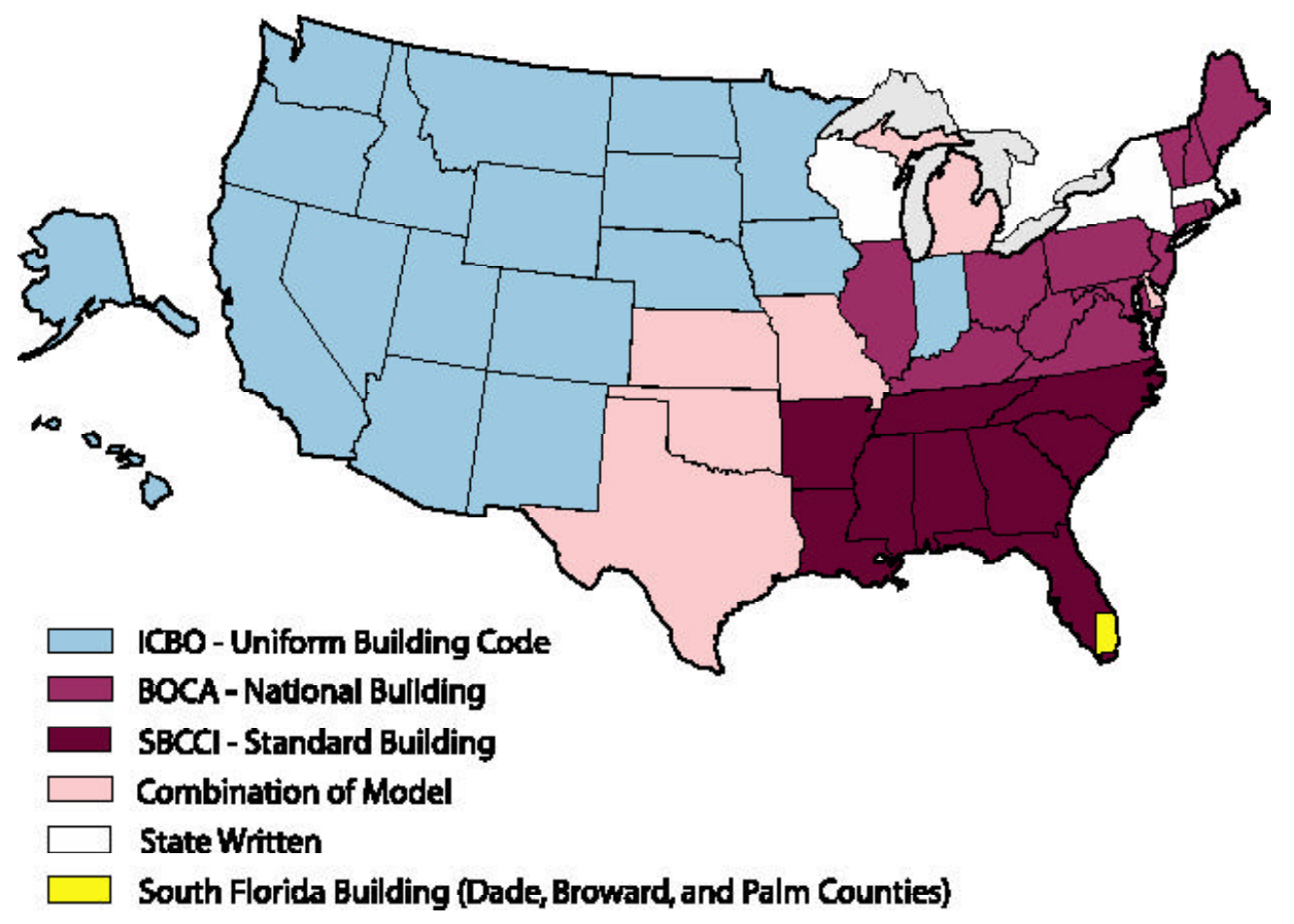

Figure 5.3: Building Code Environment Expected in 2002.

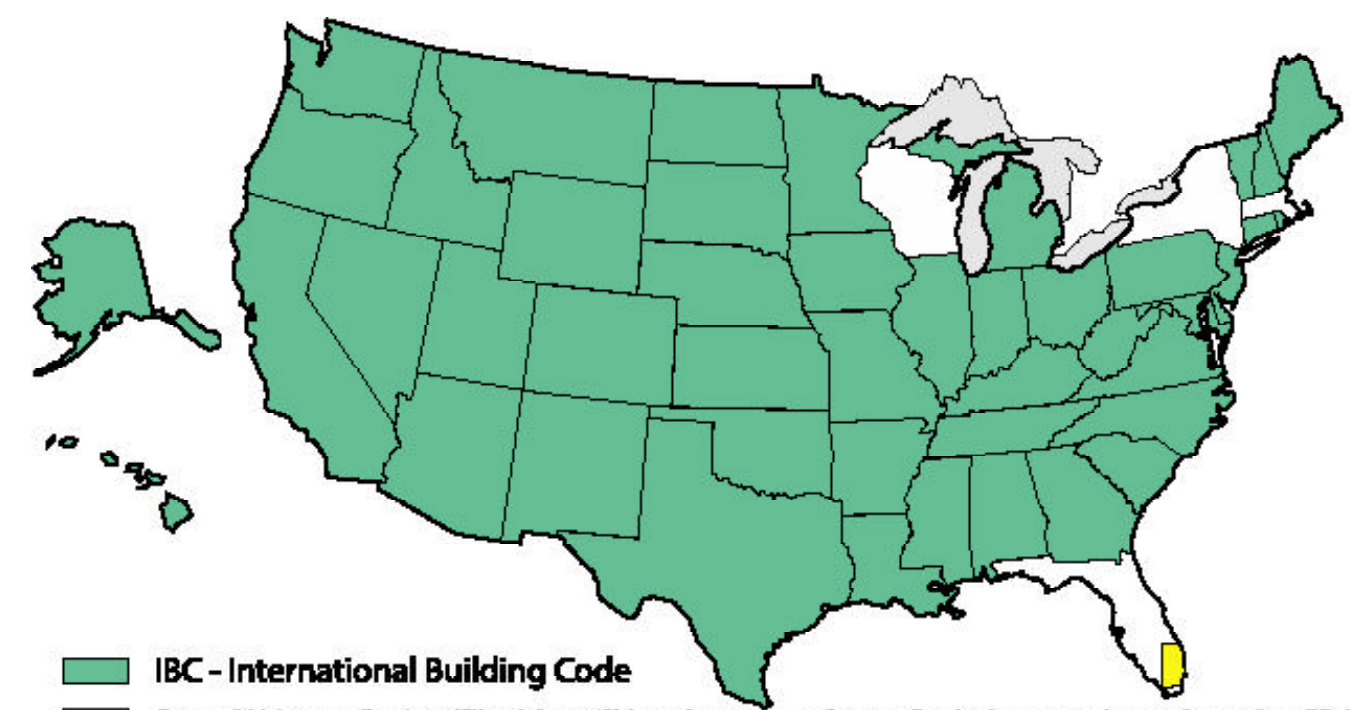

State Written Codes (Florida will implement a State Code in 2001 based on the SBC. Wisconsin and New York are looking at adopting the l-Codes)

South Florida Building (Dade, Broward, and Palm Counties) 
value" for the project. By comparing the project's UA-value to the value required for the climate zone, the builder can determine if the project passes the MEC requirements. If the project does not pass, the builder can use the worksheet to examine different combinations of insulation levels, window or door products and areas until compliance is achieved. The worksheet is suitable for use during the plan check and field inspection phases of the project.

3. The MECcheck software approach performs the same calculations as the trade-off worksheet but automates the procedure using Windows-based software. Special features allow builders to trade off heating and air conditioning equipment efficiency, as well as windows and insulation. The software generates a report that is suitable for plan checking and field inspection." Examples of the software approach is attached to this document.

The application of the IWWS may require special performance consideration. This should not be a problem since energy codes by nature are designed for performance. In general, as with structural code consideration, the energy code does not intentionally limit method, design or insulation systems as long as the product meets the intent of the code and is in compliance. A composite UA would have to be analyzed and tested for accuracy then classified with the individual code body in order to avoid some code restrictions.

(This could be similar to an NFRC rating)

The present energy codes do not have an influence in faulty construction techniques, poor installation of components, and/or at component interfaces (present intentions notwithstanding). This fact is unfortunate since problems of variable heat loss, infiltration and lack of moisture control occur at the component interfaces.

Component interface problems cannot be addressed exclusively by inspection because of the long-term nature of these problems.

Moreover, inspections do not always occur. Currently the trade-off approach gives credit for high efficiency heating and cooling systems allowing cheaper, less energy efficient components to be used in other parts of buildings. The goal is to achieve maximum performance for the lifetime of the home.

\subsubsection{Energy Code References}

www.eren.doe.gov/buildings/codes_standards/buildings /

bcap-energy.org/update.html

www.eren.doe.gov/EE/buildings_envelope.html

\subsubsection{Residential Code References}

One very good guide for residential construction is produced by PATH (partnership for advancing technology in housing). The Residential Structural Design Guide, 2000 Edition gives good background into housing history, and design input for performance, and efficient designs. 
http: / / www.intlcode.org/

http://www.icbo.org/

http://www.pathnet.org/

\subsubsection{Conclusion}

The limits to the window-wall design reside within the residential codes and applying them to market demands.

Traditional wall construction is proven and considered safe. Compelling arguments must be made to convince builders, consumers, and code officials that new technology and innovations can be sustainable, durable and meet the requirements for building performance. Nontraditional residential construction methods will require special treatment including detailed engineering analysis and testing to convince building officials and builders of there potential. In general, the code does not intentionally limit method, design or insulation systems as long as the product meets the intent of the code and is in compliance. If radical changes are made in the formulation of the IWWS, some difficultly may arise in the market implementation phase due to code considerations. Multiple code evaluation reports and independent test would be required. From an energy stand point this hurdle can be overcome since energy codes generally are designed for performance. A composite UA would have to be analyzed and tested for accuracy then classified with the individual code body in order to avoid some code restrictions. (This may have to be similar to a NFRC rating).

\subsection{SUSTAINABLE DESIGN}

Sustainable design is emerging as a high priority for all buildings. Sustainable design guidelines, standards, and practices are evolving rapidly. This section of the report provides a brief introduction to sustainable design, and a set of design issues to be considered during the development of the IWWS project.

\subsubsection{Background}

"Sustainable development involves...meeting the needs of the present without compromising the ability of future generations to meet their own needs."

-Earth Summit, Rio de Janeiro, 1992

This statement, adopted by the President's Council on Sustainable Development, is often used as a general definition of sustainability. According to the AIA Handbook, "...sustainability refers to the ability of a society, ecosystem, or any such ongoing system to continue functioning into the indefinite future... For architecture, this means design that delivers buildings and communities with lower environmental impacts while enhancing health, productivity, community, and quality of life." This suggests that sustainability is not limited to impacts on the natural 
environment, but on people and the community.

In addition to the term sustainable design, high performance buildings, green design, and ecological design are used to generally refer to a similar set of ideas. Whatever the precise name and definition, sustainable design is not just about preserving the natural environment, it is about applying good design practices and good business principles.

Sustainable design generally addresses six categories of strategies: site, water, energy, indoor environment, materials and waste. Site and water do not have a direct bearing on the IWWS project but the other four do. In the following section each of these topics is discussed in relation to the IWWS. The goals and strategies are drawn from the Minnesota Sustainable Design Guide which is compatible with LEED and other accepted guidelines.

\subsubsection{Energy Environmental Concerns}

Buildings are energy intensive in their construction and operation. According to the Worldwatch Institute about 40 percent of the world's total energy usage is dedicated to the construction and operation of buildings. Buildings consume energy, from the mine to foundry to construction site. In the United States, construction and material production account for roughly 9 percent of energy use. In contrast, buildings operation accounts for approximately 30 percent of U.S. energy consumption. This energy use has serious impacts on the environment. Buildings account for about one-third of the emissions of heat-trapping carbon dioxide from fossil fuel burning and two-fifths of acid rain-causing sulfurdioxide and nitrogen oxides. Buildings also contribute to other side effects of energy use, including oil spills, nuclear waste generation, river damming, toxic runoff from coal mines, and mercury emissions from coal burning (Worldwatch Institute, 1992, 1994).

In view of these environmental concerns, sustainable design embodies the following goals:

- Reduce total energy consumption of buildings

- Reduce air pollution, global warming, and ozone depletion impacts of energy sources

- Slow depletion of fossil fuel reserves

The sustainable design goals listed for energy are translated into the following strategies related to the IWWS:

- Optimize Building Envelope Thermal Performance

- Provide Daylighting Integrated with Electric Lighting Controls

- Maximize Mechanical Systems Performance

- Use Renewable or Other Alternative Energy Sources 


\subsubsection{Interior Environmental Quality Environmental Concerns}

A healthy, productive, and comfortable environment is expected at home and in the workplace. Yet many modern buildings create unhealthy and potentially dangerous interior environments for their occupants. Lighting may be inadequate or incorrect for it's intended function. Thermal conditions may become extreme, and it's control may be unaccessible to the occupants. Ventilation systems installed to protect air quality often subject occupants to stale air, or harbor and spread unhealthy molds, bacteria, and viruses. The medical, human comfort, performance and productivity costs of unhealthy interior environments may run into the tens of billions of dollars each year (Roodman \& Lenssen, 1995). Research also shows that buildings with daylight, fresh air, and occupant control are consistently rated as more comfortable and contribute to occupants' performance and productivity.

In view of these environmental concerns, sustainable design embodies the following goals:

- Provide an environment for occupants that is physiologically and psychologically healthy

- Minimize production and transmission of air pollution

- Provide the full range of supportive sensory conditions (olfactory, thermal, vibroacoustic, tactual and visual) for occupants

- Provide needed operational control of systems to occupants

- Produce environments that enhance human comfort, wellbeing, performance andproductivity

The sustainable design goals listed for indoor environmental quality are translated into the following strategies related to the IWWS:

- Provide a Clean and Healthy Environment

- Use Low VOC-emitting Materials

- Control Moisture to Prevent Microbial Contamination

- Provide Ample Ventilation for Pollutant Control and Thermal Comfort

- Provide Appropriate Thermal Conditions

- Provide Views, Viewspace, andConnection to Natural Environment

\subsubsection{Materials Environmental Concerns}

Building design and construction use significant quantities of natural resources and materials. The building industry consumes 3 billion tons of raw materials annually - 40 percent of the total material flow in the global economy. The manufacturing process of 
new materials is water and energy intensive and contributes to environmental degradation and pollution. Harvesting, extraction, mining, and processing new materials pollute the air and rivers and threaten ecosystems and wildlife habitat. North America, Europe and Japan consume more than 25 percent of the world's annual 3.5 billion cubic meters of wood production (Worldwatch Institute, 1991). According to the Natural Resource Defense Council (NRDC), at present rates of destruction the rain forests will be gone by 2050. In addition, global wood production is expected to double over the next 30 years. Consumption of other raw materials and natural resources continue to accelerate.

In view of these environmental concerns, sustainable design embodies the following goals:

- Minimize consumption and depletion of material resources

- Minimize the life-cycle impact of materials on the environment

- Minimize the impact of materials on indoor environmental quality

The sustainable design goals listed for materials are translated into the following strategies related to the IWWS:

- Use Materials with Low Environmental Impact During Their Life Cycle

- Use Salvaged and Remanufactured Materials

- Use Recycled Content Products and Materials

- Use Materials from Renewable Sources

- Use Locally Manufactured Materials

- Use Durable Materials

- Use Materials that are Reusable, Recyclable or Biodegradable

Using tools such as BEES and Athena, the life cycle impacts of the IWWS designs can be evaluated.

\subsubsection{Waste Environmental Concerns}

Waste is generated throughout the life of a building. Brick, metals, wood, cardboard, and other waste is generated and landfilled during building demolition, renovation, and construction. According to the US Environmental Protection Agency, construction and demolition waste represents $1 / 4$ to $1 / 3$ of all waste landfilled in the U.S. The construction and demolition waste stream, once thought to total between 30 and 40 millions tons of waste materials annually in the United States, is more likely to total over three times that amount (Yost, 1999). Landfilling construction and demolition waste, instead of recycling it, is a loss of material resources. During building operations, waste such as 
paper, aluminum cans, and glass is also generated; it too is a burden on our landfills and a loss of our natural resources.

In view of these environmental concerns, sustainable design embodies the following goals:

- Encourage better management of waste

- Minimize use of resources

- Minimize waste generated from construction, renovation, and demolition of buildings

- Minimize waste generated during building occupancy

The sustainable design goals listed for waste are translated into the following strategies:

- Design for Less Material Use

- Design for Adaptability

- Design for Disassembly

- Recycle Construction Waste

- Reduce and Recycle Packaging Waste

\subsection{THE BUILDING PROCESS}

This discussion is limited to the delivery of construction materials and products and the scheduling of the construction process. It does not include tasks such as excavation, sewer and water hookup, permits, surveys, appliance or equipment selection. The process typically used for the construction of wood-frame stick-built walls is described in some detail. Four alternatives are then compared and contrasted.

\subsubsection{Foundations}

Foundation types vary across the country and by location. In cold climates, basements are the norm; in cooling climates, crawl spaces or slab foundations dominate. If a basement is constructed, the actual structure may be concrete block, poured concrete, insulated concrete foundations, or wood. A crawl space foundation has similar options. A slab may be post-form, shallow frost-proof.

\subsubsection{Above-ground Wall Alternatives}

\section{Wood-Frame Construction}

On-site construction or stick-built. The sequencing of a typical stick-built wood-frame house has not changed much in many years. Materials to be delivered to the site in dimensional or precut lengths include:

- sill plates

- sill gasket material

- rim joists 
- floor joists or trusses

- subflooring

- stud wall material

- bracing material

- top plates

- exterior sheathing

- house wrap

- miscellaneous glues and fasteners

- miscellaneous lumber for any hand framing, stairs, specialty details

Roof trusses may be delivered with this load, but more often are delivered at a separate time, often directly from the manufacturer. A crane is often scheduled to assist in setting the roof trusses.

Windows may come from the lumber company, but often are delivered from the manufacturer or from a window distributor.

In most cases, the framing crew is responsible for laying out the framing according to the plans, constructing the entire framing system including walls and floors, setting the roof trusses, placing the roof sheathing, installing the windows and doors, placing the exterior sheathing and installing house wrap. They may also install some insulation, particularly in corners and places where the framing may prohibit access at a later time.

Until a few years ago, the framing crew almost always completed the exterior of the house except in the case of stucco. However, with the dramatic increase of the use of vinyl siding, vinyl siding contractors have taken over this task. If hardboard or wood is chosen for the siding, the framing crew may be the installer or a specialty subcontractor may be employed.

\section{Heating, Ventilation and Air Conditioning}

The heating contractor is one of the first subcontractors to the site after the framers. It is advantageous for the heating contractor to be involved in the design stage of the project, making sure that the heating plant is properly sized and that framing will accommodate the supply and return ducts. In many new houses, the heating contractor also installs the ventilation system. In some areas of the country, however, a separate ventilation contractor will install the ventilation system. In heating climates, a temporary furnace may be installed during construction. If the heating plant is in the basement, the contractor returns to install the permanent heating plant after the basement floor has been poured. He/she also returns near the end of the project to install the final controls as well as the covers for the supply outlets and the return inlets. Along the way, the heating contractor must meet with code officials to verify compliance with local and state codes. 


\section{Plumbing}

The plumber makes a minimum of two trips to the house. The plumbing crew needs to be in the house as soon as the rough framing is complete and before the basement is poured. In many cases, the plumbing crew will begin work before the exterior sheathing is in place. He/she will install the supply and waste pipes from the water and sewer rough-ins to and from the fixtures according to the plans and specs. The plumber returns near the end of the process to install the fixtures and to verify with code officials that there are no leaks in the system and that water pressure is adequate. In many cases, the plumber installs the water heater. If the house is to be heated with hot water, the plumber may be the subcontractor for this task. Recently, hot water radiant heat in the floor has become popular. Specialty subcontractors have taken on this responsibility.

\section{Electrical}

The electrical contractor and crew will also be at the site immediately after rough framing is complete or just before. Electrical and plumbing contractors often compete for the same framing spaces as do heating contractors. The plumber may have a priority because of greater restraints of space and limited ability to place water and sewer lines. The heating contractor has some priority because of the size of the ducts and the physics of airflow. Electrical rough-in includes placing the main circuit breaker box, installing electrical boxes, light boxes, switch boxes and specialty items according to the plans and the state codes, drilling the wood studs to accommodate wiring, and pulling wires from the main supply to each outlet, light and switch. Often one or two outlets are installed for the use of the subcontractors during the construction process. The electrical contractor returns near the end of the construction process to install the outlets and switches and again at the very end to place fixtures and cover plates.

\section{Insulation}

After rough-ins for HVAC, electrical and plumbing are completed and the proper inspections performed, the insulation contractor may install the wall insulation. Typical insulation types include fiberglass batts, mineral wool batts, cotton batts, blown-in fiberglass, blown-in cellulose, blown-in rock wool, wet-sprayed cellulose, and expanded foams. In some systems, rigid insulation board is applied to the exterior of the framing as sheathing. Attic cavities are filled with blown-in or batt insulation after the drywall is in place. The insulation contractor in heating climates is also responsible for installing the interior (warm side) vapor barrier in most cases.

Drywall

Drywall is the interior wall choice in almost all homes in the 
country today. This has become a three-specialty process in most instances. Installing of the drywall is completed by one crew, another crew tapes and coats, and still another crew sprays ceilings (and walls in some). There may also be a crew to remove excess drywall and scraps and haul it away for recycling.

\section{Finishing and Painting}

Interior finishing materials are delivered after the drywall steps are complete. The finisher or finishing crew may install kitchen, bath, and specialty cabinetry, stair railings, etc. Today's new product offer a variety of options for pre-finished cabinetry, trim and woodwork. The painters job may include touch-up on pre-finished materials, or may include complete painting and staining. With the advent of vinyl, metal and other materials, the painters job varies greatly from one project to another.

\subsubsection{Pros and Cons}

\section{General}

Given the number of subcontractors involved and the incredibly large number of variables in the process (both in terms of materials and workmanship), the stick-built wood-frame house has a high risk factor for error. The most compelling reason for builders and subcontractors to continue to build a stick-built wood frame house today is the familiarity that the trades have with the product and the process. General contractors are comfortable with this method and can predict costs within an acceptable risk factor. They seem most reluctant to try either new products or new methods if they perceive it will increase the risk for greater liability or less profit.

\section{Windows}

Windows and their installation present a special problem. There have been a considerable number of documented reports of water damage from poor quality windows and poor quality installation of windows. A lack of understanding of how to avoid water intrusion and poor flashing details contribute to this problem. An avoidance of responsibility for the quality of installation hampers improvement of this situation.

\section{Excess framing material}

Only recently has there been a concerted effort to make the stick-built structure more efficient. Because this process has not been engineered carefully, the industry has overbuilt to avoid failure. A new look at optimizing the structure is beginning to be used, but at the present has only a small market share and has experienced some resistance from code officials.

Too much framing can also lead to energy loss. Thermal bridging is the term used to refer to heat loss through solid materials. If an excessive amount of framing material prohibits 
adequate insulation, huge heat loss can and does occur.

Imperfect materials and process

The energy efficiency of the stick-built framing process relies in part on the quality of installation of each material or product. For instance, the effectiveness of wall insulation is greatly reduced if the insulation is not carefully installed to avoid gaps and voids. Insulation contractors are paid to do the job quickly. Care is not always taken to make sure that each cavity is properly filled.

\section{Reliance on sealants and adhesives}

The introduction of great new adhesives and sealants has allowed workers to rely on these products to make up for poor or careless workmanship and products. This has been especially true with exterior protection from water intrusion. Sealants have become the water protection mechanism. Unfortunately, these products are durable for only a few years. If they are not replaced, the protection is lost. Most homeowners are not aware of this responsibility. This is an industry problem that is largely the result of lack of information and knowledge transfer from the contractor to the homeowner. The home buyer wants and expects a maintenance-free house; the contractor allows the home buyer to believe that is what they have.

\section{Moisture intrusion}

One problem that plagues the stick-built process is the potential for water intrusion from rain or snow during construction. As mentioned above, the heating, electrical, and plumbing contractors often begin their work before the roof is in place, sometimes before the roof sheathing is in place. Not only can wood framing members become wet, but ducts may be filled with water. If the house is enclosed before water is removed or had a chance to dry, the materials and the indoor air quality can be negatively impacted. In some cases, insulation is installed before the exterior sheathing is protected. This can also lead to moisture accumulation in the wall cavity.

\subsubsection{Modular Factory-built Wood-frame Construction}

Factory assembly of walls or sections of the house framing can eliminate some of the risk factors mentioned above. The building components are more controlled and water intrusion issues are likely to be less problematic. Workers in the factory can install plumbing, electrical and heating rough-ins quickly and efficiently. Even the drywall installation is more controlled. The completed walls or sections are then shipped to the site and assembled in a short time span. The roof is pre-assembled and placed immediately. In some cases, the roof is a completed component. This process necessarily requires cooperation with local code officials who must visit the factory. The subcontractor's role may 
be limited to finishing work at the site.

Ideally, the advantage of the factory-built modular is quality control and efficiency. How well this works, of course, depends on the integrity and management of the factory owners as well as on the quality of the materials they choose to include in their product. Because transportation is costly, the location of the site with relationship to the factory may limit viability.

With today's technology, modular and factory-built housing can be indistinguishable from stick-built housing. Many stick-built general contractors have begun to use factory-built walls and modules exclusively.

\subsubsection{Steel-frame Stick Built House}

Essentially, the steel-frame stick built house is identical to the wood-frame stick-built house; wood sticks are merely replaced, stick-for-stick, with steel studs. Contractors who use steel point to the following advantages:

- Steel prices are less volatile than wood, making estimates more accurate

- The product is consistent

- Steel studs can be ordered to an exact measurement, making less waste on the job site

- Steel is stronger than wood and can be placed 24" on center and loads can line up and be transferred easily

On the other hand, some of problems can be:

- In heating climates, thermal bridging is a huge problem (this must be compensated for with the use of exterior insulation that may be much more expensive that other types)

- Floor joists made from steel can give the floor an unpleasant bounce

- Framing is considerably slower

- The framer must know which gauge steel can be used in a bearing vs. a partition wall

- Headers are not precut and must be made up on site

- Suppliers must cut the material carefully - it can't be used or reused easily if it is too short

\subsubsection{Structural Insulated Panels (SIPs)}

Structural Insulated Panels are comprised of a layer of expanded polystyrene that is structurally laminated and pressure cured between two layers of oriented strand board. These panels can be used for walls, floors, and ceilings. They are manufactured in various widths and thus can be equivalent to insulated stud walls with regard to R-value.

One of the marketing point advantages of SIPS is their 
potential to be a very tight building envelope. The panels are wedged together, creating little opportunity for air infiltration. Another advantage is that the panels can be put together in a short time by fairly unskilled laborers. The time savings can be significant. The economics, of course, must factor the cost of the product (still fairly high) with the cost of labor. More and more, SIPs are becoming very cost competitive with stick-built.

SIP manufacturers claim that SIPs have high racking strength for wind and snow loading, are 2.5 times stronger than a stick-built wall, and can save energy costs in part due to less thermal bridging. Panels can be precut to save time on the site. Electrical chases can also be precut or can be prepared on-site.

SIP manufacturers also claim that SIPs are environmentally friendly because the polystyrene can be recycled and will use less dimensional lumber. Those less enthusiastic about SIPs express concern about off gassing from the adhesives in the OSB.

\subsubsection{Insulated Concrete Forms}

The use of insulated concrete forms for the entire building envelope of a residential house is growing some in popularity. Benefits of this type of construction methods include:

- reduced air infiltration due to a continuous envelope from the foundation to the roof line

- manufacturers claim the cost is equivalent to $2 \times 6$ wood frame construction

- manufacturers also claim that the construction method and reduced infiltration can lead to $25-50 \%$ energy savings on heating costs

- the houses are reportedly very quiet; 30\% less sound is reported to travel through the walls compared to wood or steel framing

- may withstand hurricanes, tornadoes and fires better than wood or steel-framed houses

- reportedly requires lower skilled workers and less time to construct than steel or wood-framed 


\section{Integrated Design}

\subsection{INTRODUCTION}

The purpose of this section is to define integration as it related to this project. In addition, previous integrated window wall designs are described. Finally, the general design criteria for the prototypes is set.

\subsection{DEFINING INTEGRATION}

A key concept of the IWWS project is integration. Integration essentially means that elements are designed to work together as a whole rather than be inefficient and fail due to lack of coordination. Lack of integration also fails to take advantage of opportunities for synergies that arise from whole systems design. There are four levels of integration to be addressed in this project-the basic wall assembly, the window/wall interface, the window with various attachments, and the IWWS with other components and systems in the building. This section of the chapter discusses these four levels of integration.

\subsubsection{Integration within a Wall Assembly}

The conventional wood (or steel) frame wall is a good example of lack of integrated design. Wall assemblies are made up of many parts with one or two functions each (i.e. siding, house wrap, sheathing, framing, insulation, air/vapor barrier, interior finish). This requires many steps, many seams and connections, and many trades to interact. This results in longer time for construction, greater cost, and more opportunity for failure to occur.

A critical problem with conventional wall construction is water intrusion and damage. Water enters wall assemblies from the exterior via rain penetration and is absorbed by materials.

Inadequate flashing and reliance on sealants that ultimately fail are problems. This water intrusion contributes to material degradation and lack of durability and may contribute to mold growth and indoor air problems. In addition, water vapor enters wall cavities from the inside or outside via diffusion and air leakage. Poorly installed air and vapor barriers are common and electrical outlets 
and other penetrations create avenues for moisture transport. This moisture also contributes to material degradation and lack of durability and may contribute to mold growth and indoor air problems.

Thermal problems exist with conventional construction as well. Installation of insulation in wall cavities is not always perfectmaterials do not fill the cavities or they slip or settle resulting in poorer than expected field performance. In addition, thermal short circuits exist through framing members including headers, studs, and plates.

In creating an integrated window/wall system, it is essential to design components to do multiple jobs thus eliminating so many layers and seams. It is important to avoid reliance on hard-to-find skilled labor. Systems must be designed that minimize erection time in the field. Designs must have a high degree of thermal integrity reducing energy use, and must eliminate moisture penetration or manage it through drainage techniques.

\subsubsection{Integration of the Window and Wall}

The window/wall interface, as it exists in conventional residential construction, presents a number of chronic problems. Rough openings are imperfect resulting in large, uneven gaps that must be covered. These gaps are prone to water and air intrusion and can be a thermal weakness if not carefully insulated. Standard window installation practice is prone to failure. With the barrier approach, the entire water protection system relies on sealants with potential for failure. With the membrane approach, correct use and overlapping of flashing is often not done resulting in water penetration into walls.

Unfortunately, improved installation practices are still tedious and require skilled labor, time and attention. This is only beginning to be understood in residential construction and there are few trained installers. Even some of the best recommended practices still rely on paper flashings with adhesives and other details prone to long term failure.

Applying the concept of integration to this problem basically means that the window and wall are designed as one system. By doing this, problems of the existing installation practices can be avoided. This could mean that the window frame and wall basically fuse together into one piece eliminating the joint, or that the separate components of the system are designed to connect in a reliable and foolproof manner. In addition to solving the problems mentioned above, the benefit of this type of integration is that an IWWS could be delivered to the site as one piece reducing time spent on site for window installation, and reducing dependence on well-trained window installers. Construction time can be reduced while callbacks and failures are virtually eliminated. 


\subsubsection{Integration of the Window and Attachments}

Windows provide connection to light, air and view from the exterior environment. Because they are basically openings in the wall, they must respond to many dynamic conditions of solar radiation, temperatures, winds, as well as sunlight intensity and direction. The properties of a typical window are static, making them a compromise between ideal properties for underheated versus overheated conditions. In addition, windows are a weak point in home security, and structurally during hurricanes and tornadoes.

The performance of the window assembly can be enhanced by the use of the number of attachments. Typically, these include exterior shading devices such as awnings are overhangs, insect screens (which also provide some shading when installed on the exterior), and interior shades or blinds. Less typical attachments include thermal shutters and shades (exterior or interior), exterior security screens, and possibly interior light shelves or other daylight redirecting mechanisms. A drawback of these conventional methods for adjusting window properties in response to dynamic conditions (i.e. shades, thermal shutters) is that they rely on occupant operation which is not optimal.

While these various systems do not necessarily result in major functional problems, they are separate pieces, each with their own look and method of installation. The appearance of some of these attachments is not necessarily attractive or well coordinated with the overall house design. For example, exterior roll down shades or interior insulating shutters can have a tacked-on appearance. In addition, multiple systems from different manufacturers are likely to be more costly than a coordinated kit of parts from one manufacturer. Applying the concept of integrated design to window attachments can result in more efficient, better looking, and possibly less costly systems offering a wide range of features. Integrated design also presents the opportunity for a coordinated control system to operate these attachments.

\subsubsection{Integration of the IWWS with Other House Systems and Components}

An integrated window/wall system must interface with the adjacent wall, floor, and ceiling components of the house. If not properly designed, an integrated window/wall panel could have problems similar to the interface found between a conventional wall and window. Joints and connections must be designed that cannot rely on highly skilled labor but completely eliminate potential water and air leakage problems.

In addition to designing an effective interface between the IWWS and other adjacent components, the opportunity exists to integrate the window/wall system with electrical and HVAC systems. Many current problems in housing exist because of the failure to design the whole house as a system. For example, there is typically discomfort near windows due to drafts and radiant heat transfer. This often means heat must be delivered to the room 


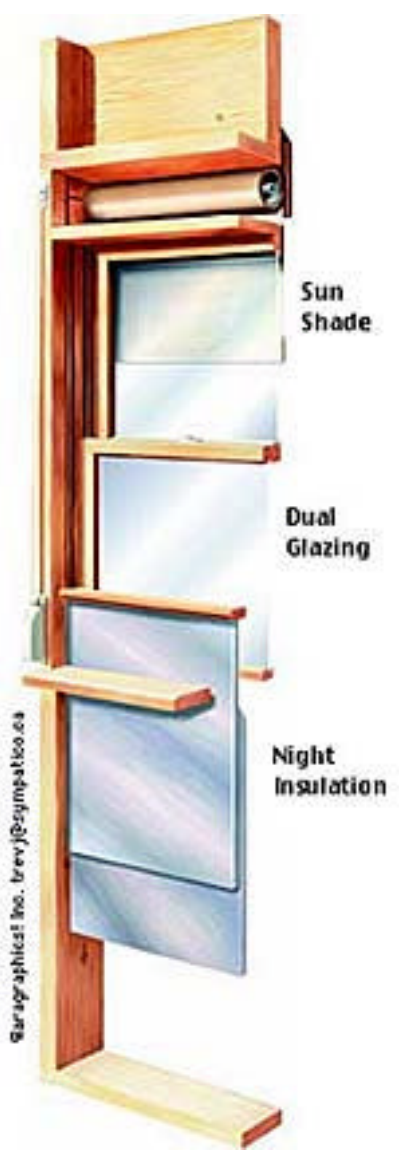

Figure 6.1: Integrated Window System developed by Lawrence Berkeley National Laboratories. perimeter near the windows. This requires long duct runs and wastes energy.

Some obvious opportunities for integration are to connect the operation of window and any auxiliary devices (shades) to an overall house control and security system. Windows should be designed to be sufficiently comfortable so that the need for perimeter heating can be eliminated. The IWWS could provide controlled ventilation through the wall. Also, raceways and access for future power and communications must be provided. Another aspect of integrated design is to use low VOC materials in the IWWS so that there is no contribution to indoor air problems.

The need for design integration at all four levels described here presents the critical challenge and opportunity for the IWWS project. As prototypical systems are developed, they will respond to and be evaluated based on these issues.

\subsection{PREVIOUS WINDOW-WALL DESIGNS}

There have undoubtedly been many efforts to combine windows and walls into a single product. Some panelized construction today is shipped with windows in place. These efforts have usually not completely integrated the two elements into an optimized design. Two previous examples of IWWS that are the foundation for this project are described below.

\subsubsection{Lawrence Berkeley National Laboratories Integrated Window System}

Researchers in the field of high performance windows have concluded that even by using high performance insulating glass units, low conductivity frames, and warm edge spacers, there are still untapped sources for improving energy efficiency in the design and use of residential windows. While such high performance windows are a dramatic improvement over conventional units, they do not reduce conductive losses through wall framing around the window, offer guarantees against excessive wall/window infiltration nor do they adapt to the daily and seasonal potentials for night insulation and summer shading.

To meet this need, LBNL researchers have been working on the design, development, and prototyping of Integrated Window Systems (IWS) since 1993 (Figure 6.1). Integrated Window Systems are a form of panelized construction where the wall panel includes an operable or fixed window sash, recessed night insulation, integral solar shading, and is built in a factory setting in order to minimize thermal short circuits and infiltration at joints. Integrated Window Systems can be built in modular lengths to facilitate their installation with conventional wood frame stick construction or other forms of panelized construction.

The prototype IWS uses the wall framing to anchor the window sash, thereby doing away with the window frame. The use of supporting lumber (jack studs, headers) is also reduced. Thin, high performance night insulation is installed in the outer inch of the cavity below the window adjacent to the storage 
position of the night window insulation. When the night insulation is deployed the window's thermal resistance doubles to approximately R-12 while the wall remains well insulated. A retractable solar shade screen, installed above the window in space freed up by the replacement of the conventional header with a compact engineered header, can be operated either manually or by an electric motor.

\subsubsection{The Andersen Windows Strutwall®}

In the 1950's, the Andersen Window Corporation pioneered structural window unit panels called Strutwall@. The windows and walls were fully integrated in the factory. Andersen supplied both Strutwall windows and doors to provide better installation and to reduce air infiltration. The improved installation speed and the faster formation of the exterior envelope lead to lower on-site labor costs and less job site waste. The Strutwall ${ }^{\circledR}$ units optimized the use of framing members around the window and eliminated operation steps during installation.

The completely framed panel had a maximum height of $7^{\prime}-8$ " and was initially designed to fit any $2 " \times 4$ " frame wall construction. Any unit could be incorporated into conventionally framed single units, side by side multi-units (e.g. townhouses), and units constructed from factory manufactured panels with a continuous $2 \times 6$ header. These units were sold with a variety of sizes and glazing options. Other options included box headers, sheathing, extension jambs, and complete priming.

The wood in the Strutwall ${ }^{\circledR}$ units was treated with a

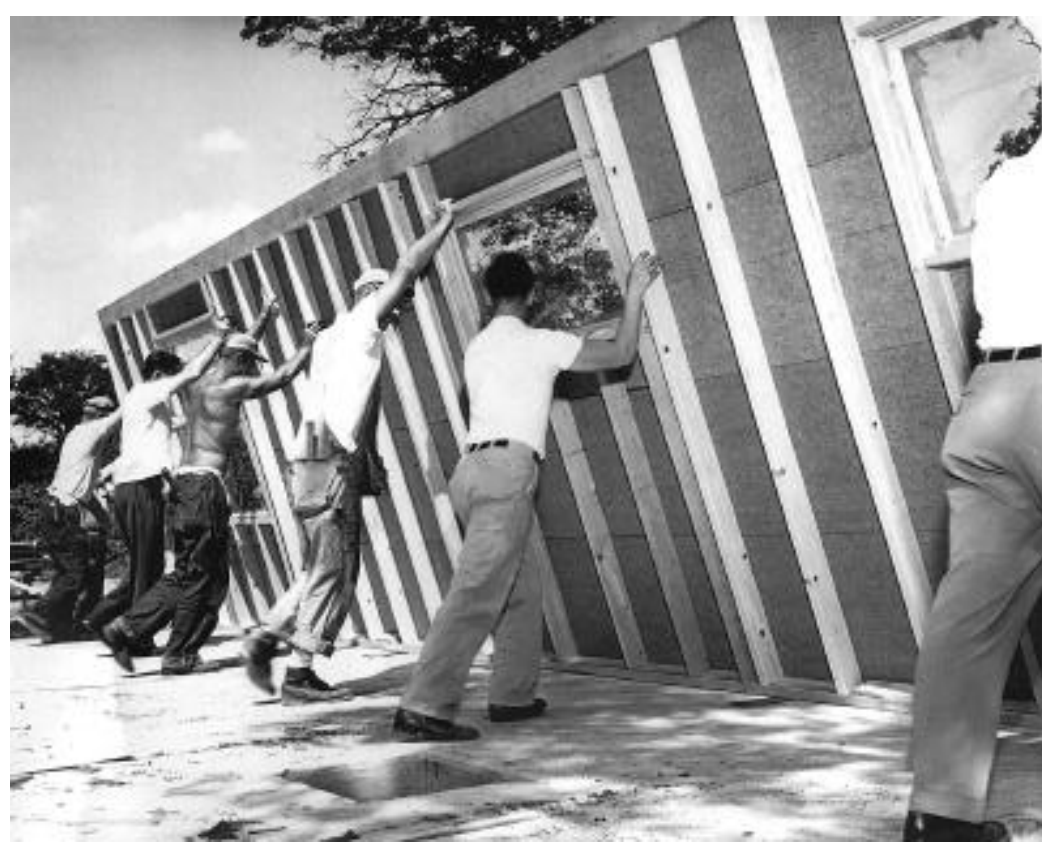

Figure 6.2: Strutwall developed by Andersen Window Corporation. 
preservative. The side struts and lower cripples were made from structural grade Douglas fir; the window parts were constructed from Ponderosa pine. Upper cripples were not required in a Strutwall®. The side struts were designed to meet the structural demands of a one-story home with a specified roof span.

The window was usually integrated into Strutwall@ at the factory, but could also be installed at the job site. At the job site, the Strutwall was installed in a tilt up fashion by attaching the unit to an adjacent side stud. The $2 "$ x 6" header would then be placed upon and fastened to the side struts. The installation was very simple and straightforward (Figure 6.2).

The Strutwall was well received by the marketplace. The builders provided a lot of positive feedback for this product which generated a lot of demand. However, various municipal code and regulatory bodies throughout the country resisted the product, making wide spread use of the product difficult. Unfortunately, the building industry reverted back to the traditional building methods because of this cumbersome introduction. In reality this product would have fit nicely into today's panelized home industry.

Panelized houses are being made today. Several companies are now specializing in creating the window-wall panel and then shipping it to a job site. During this project, part of the IWWS team toured the Wausau Homes factory in Wausau, Wisconsin, and observed first hand the manufacturing process of a window-wall assembly. A full report of this trip can be found in Appendix 9.2. It is remarkable that window-wall panel assemblies still feature $2 \times 4$ and $2 \times 6$ studs spaced apart by $16^{\prime \prime}$ on center. The workers mostly use the same tools and techniques as if they were constructing the window-wall assembly on site. The windows are also installed using traditional techniques. Nevertheless, a few advantages were demonstrated at this factory which are highlighted in Appendix 9.2. Panelized housing is a viable alternative to standard stick-built construction and affords the building industry the largest possible opportunity to create a product which is consistent, affordable, energy efficient, and profitable.

\subsection{GENERAL DESIGN CRITERIA}

Based on the issues identified throughout the report, a general set of criteria for the IWWS was developed.

1. Reduce the number of parts and systems required thus reducing costs for materials and labor.

- Design components to do multiple jobs.

- Avoid reliance on hard-to-find skilled labor.

- Design systems that minimize erection time in the field.

- Integrate window and wall to avoid existing interface and 
installation problems.

2. Create very high performance assemblies and components.

- Design for a high degree of thermal integrity reducing energy use.

- Design to eliminate moisture penetration or manage it through drainage techniques.

- Design for structural strength and stability as required. Make the wall panel load bearing to take typical vertical loads from ceiling and roof joists above.

- Create systems and materials with a long life.

- Use materials resistant to UV degradation and stable in a wide range of temperatures.

- Use materials that are fire resistant and nontoxic when burned.

- Create a secure window opening.

3. Create sustainable assemblies and materials

- Design components to be disassembled and remanufactured or reused.

- Use recycled content materials.

- Use low VOC materials.

- Make materials biodegradable.

- Ensure a low overall life cycle impact from material extraction and production through installation, use and disposal.

4. Meet market expectations.

- Design to be compatible with traditional style and appearance. Design the wall panel so that siding and interior finishes can be attached or added later to facilitate coordination.

- Make IWWS usable with traditional framing or as a standalone system. Design the wall panel to be placed within a conventionally framed $2 \times 6$ wall.

- Windows must be operable.

- Provide a high degree of comfort near windows in summer and winter conditions.

- Provide view, daylight and glare control.

5. Integrate with other systems.

- Connect operation of window and any auxiliary devices (shades) to overall house control system. Integrate with house security system.

- Comfort near windows should be sufficient to eliminate need for perimeter heating.

- Provide controlled ventilation through the wall. Explore means of tempering/conditioning outside air.

- Provide raceways and access for future power, communications, and other utilities. 


\section{Prototypes}

\subsection{INTRODUCTION}

This section describes the conceptual designs developed in this first phase of the project. The first design, the manufactured stud wall, is a simple modification of standard panelized housing practices which will have small effect on the panel's overall Uvalue, but will provide a consistent means to achieve a water resistant, durable window installation. The second design, the foam wall, is a modification of the SIPS concept. The third design concept, the steel wall attempts to create an energy efficient panel while using steel as the structural element. The fourth concept is a stiffened plate system that eliminates typical stud framing. A prototype of each of these four concepts was built. An additional concept, the ventilated stiffened plate, is documented in this chapter but was not built.

\subsection{MANUFACTURED STUD WALL}

\subsubsection{Background}

The basic concept of the stud wall is to address problems with the current window installation.

- Rough openings are imperfect resulting in large, uneven gaps that must be covered. These gaps are prone to water and air intrusion, which can be a thermal weakness if not carefully insulated. (The advantage of conventional rough openings is that they are forgiving in terms of movement and they avoid placing any vertical loads on the window unit).

- Standard installation practice is prone to failure. With the barrier approach, the entire water protection system relies on sealants with a potential for failure. With the membrane approach, correct use and overlapping of flashing is often not done resulting in water penetration into walls.

- Improved installation practices are still tedious and require skilled labor, time, and attention. This is only beginning to be understood in residential construction and there are few 
trained installers. Even some of the best recommended practices still rely on paper flashings with adhesives and other details prone to long term failure.

- Strains applied to a window or window interface can cause proper installations to deteriorate. Even with the forgiveness of the conventional rough opening, strains caused by vertical loads are still being transferred through installation screw connections and over insulation of the rough opening gap.

A manufactured stud wall is a standard cavity wall made in a factory environment and shipped to the construction site. Almost all of the construction techniques are traditional.

The panelized manufacturing process can eliminate many of the inefficiencies associated with today's residential building construction. Optimal value engineering can be done on each home design. Job site waste is reduced. Proper dimensioning and experienced construction assembly can minimize many of the current problems with residential frame wall buildings. Cavities between the stud frame members are not optimal for insulation, electrical, and HVAC purposes. However, the placement of a hole in this delicate system that features thermal and moisture gradients seems ill-conceived. The window installation provides the interface between a high quality window and a hole in stud framed wall. The solution is to improve the window installation to make it fool-proof, require lower labor cost in the factory and the field, and address all of the problems listed above.

\subsubsection{Design Concept}

The concept of the stud frame opening is to change how the window sits in the rough opening and where and how the system seals. The window in this prototype is installed on the inside and sealed on the inside. The rough opening gap is pushed to the outside and the seal is maintained at the interior building temperature thereby extending the life of the joint. See Figures 7.1 through 7.4 .

Features

- Continuous vertical wash plane

- Integration between window flange and building wrap

- Interior window installation

- Rough opening on outside of the living space

- Liquid foam insulation

- Thermoformed wrap

- Insulation attachment addresses the overconstraint

- Integrates the rough opening to the house wrap and the window by using a thermoformed rough opening 


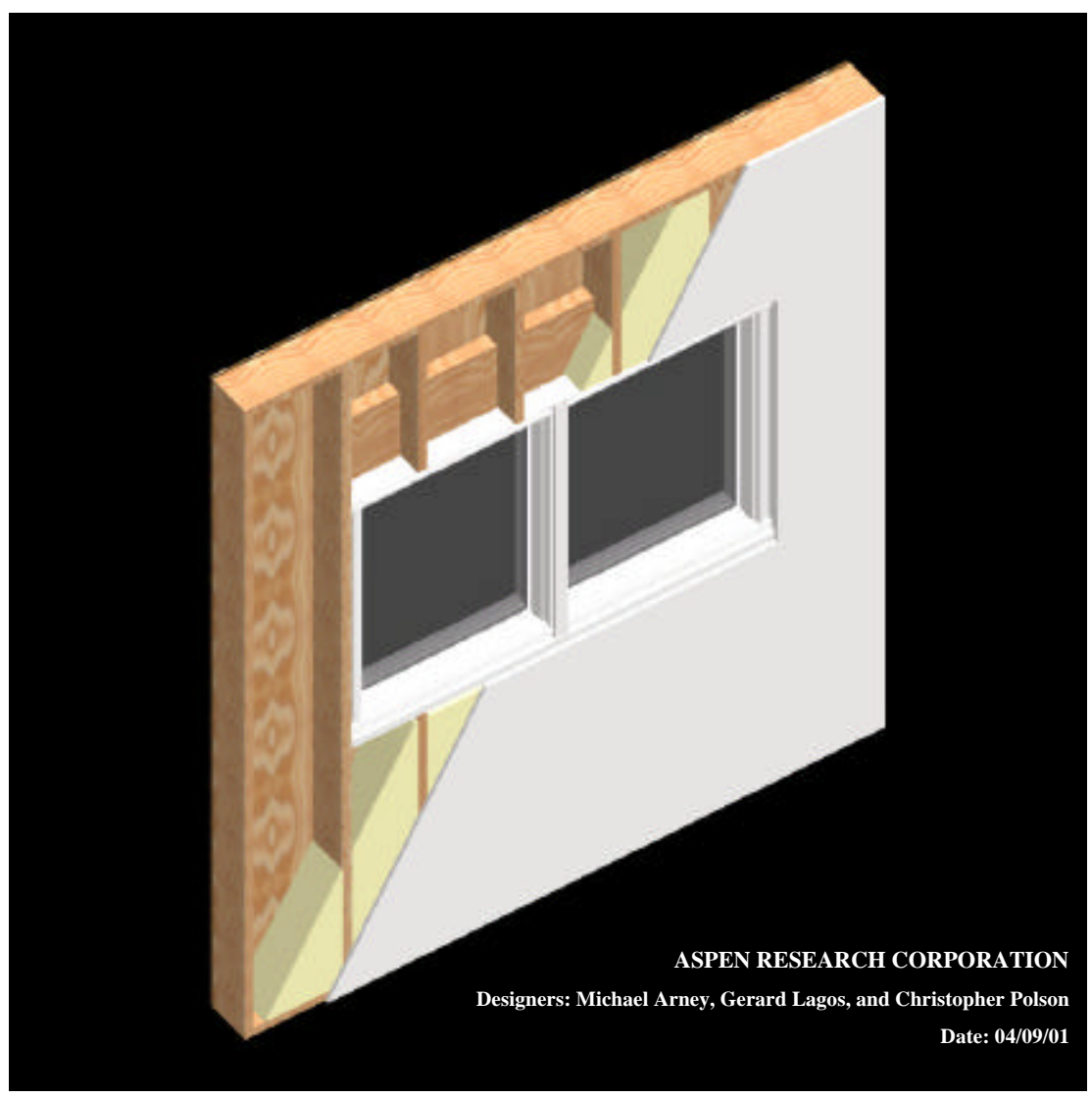

Figure 7.1. Manufactured stud wall.

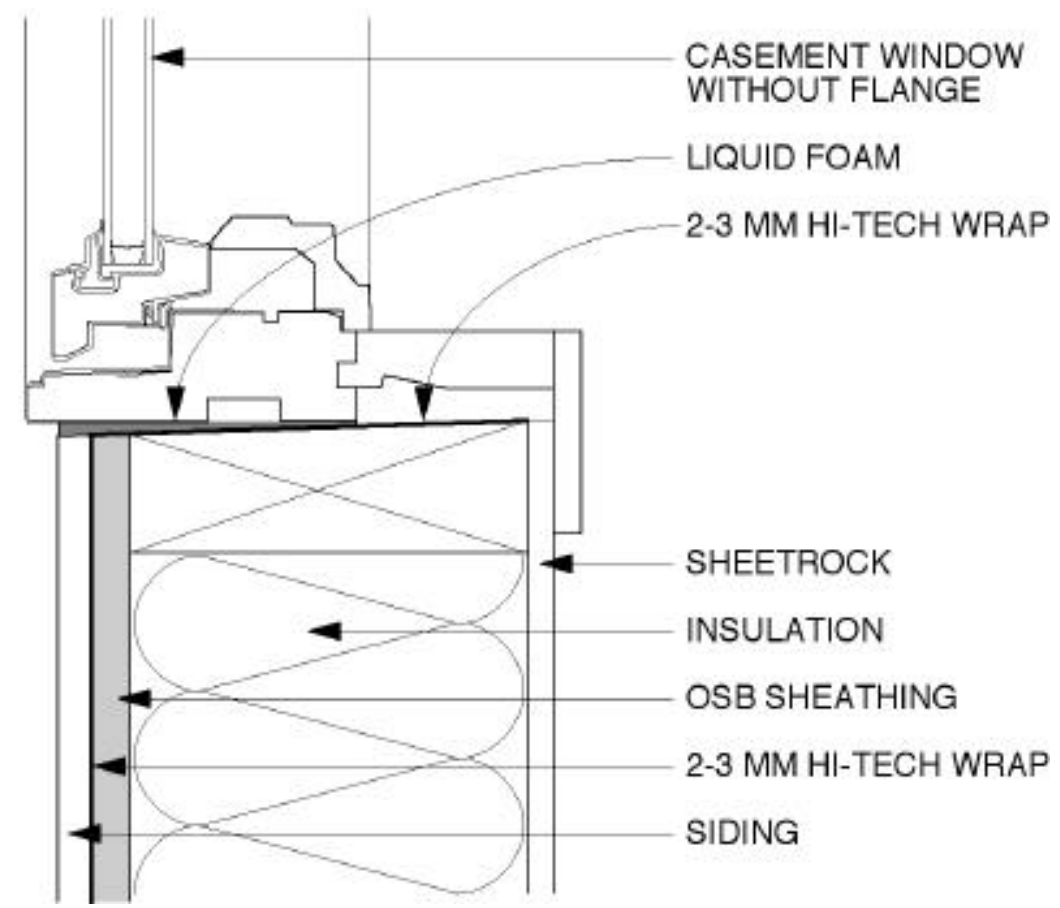

Figure 7.2. Sill detail of manufactured stud wall. 


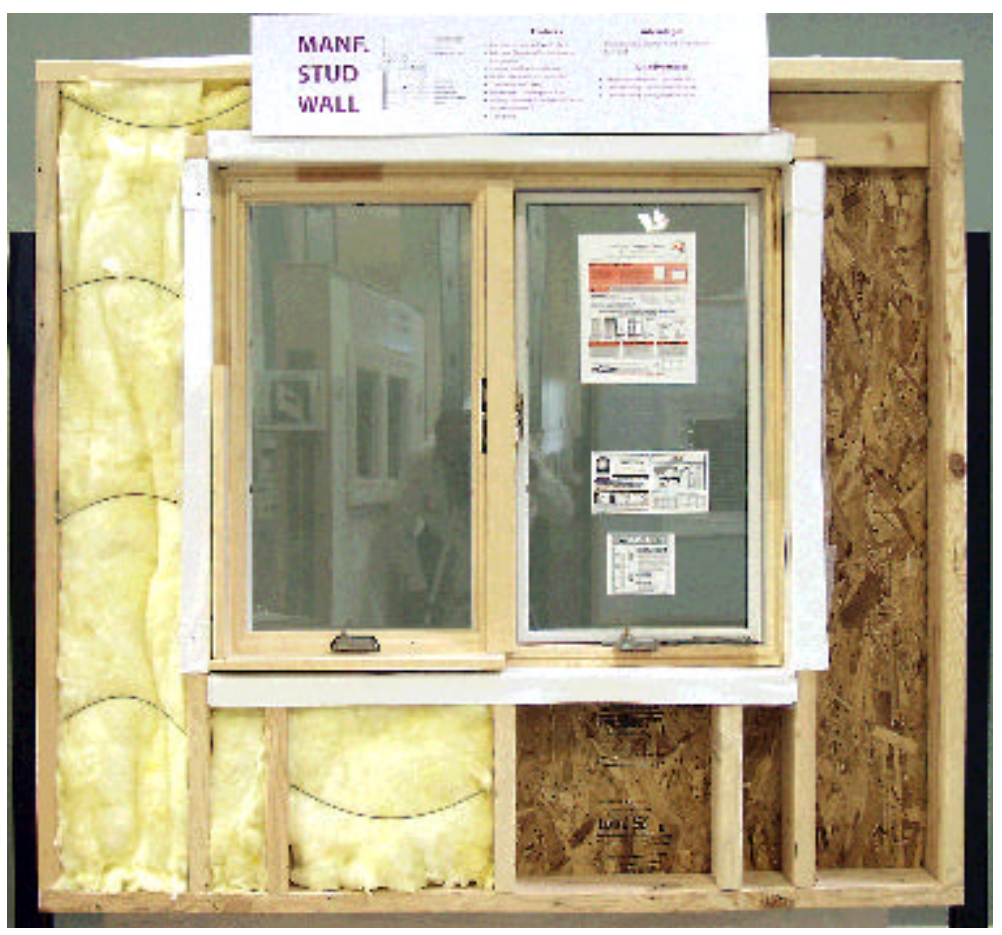

Figure 7.3: Prototype of the manufactured stud wall-interior view.

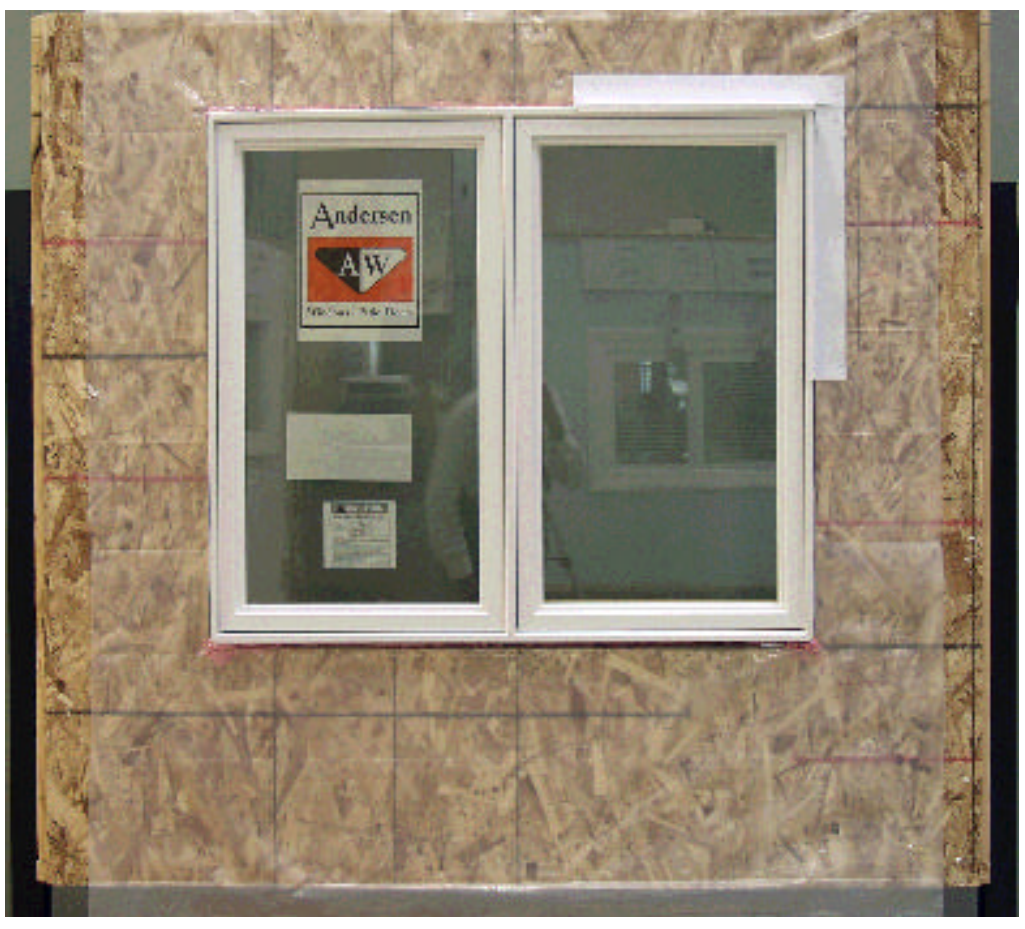

Figure 7.4: Prototype of the manufactured stud wall - outside view. 
Advantages

- Immediate acceptance in the marketplace

- Fits current building practices

- Greatly reduced air/water infiltration with a durable seal

- Low cost

- Simple changes to achieve better moisture management, lower strain on window, fewer installation errors, and lower air infiltration.

- No horizontal seams in the wash plane

- Full story house wrap extending past stiles

Disadvantages

- Simple changes address only the installation problems, not other problems associated with windows in wall cavities

- Raw materials subject to availability

- Limited ability to maintain tolerances

- Limited ability to engineer structure

\subsection{FOAM WALL}

\subsubsection{Design Concept}

The foam wall is a combination of a post-and-beam construction along with a structural insulated panel. It is meant to improve upon the SIPS design by providing better load-bearing capacity in the truss header system. The wall's load bearing capabilities are supplemented by polyisocyanurate foam. A membrane serving as a weather barrier is laminated to the sheathing to provide a continuous, durable wash plane. A vinyl wrapped window with a nailing flange is glued directly to the membrane. The nailing flange is flexible so that any distortions or deformations due to thermal changes do not transmit strains to the window. This prototype also features an electrochromic glazing system designed to control solar heat gain in response to high cooling loads. See Figures 7.5 through 7.9 .

\section{Features}

- Extruded composite posts. The posts are an extruded PVC/ wood composite (Fibrex TM) which are engineered for compressive strength.

- Truss. A truss serves as the load bearing plate and is constructed from MDF. The webs of the truss focus down to a point on the bottom, so as to avoid a thermal short-circuit.

- Structural foam. A polyisocyanurate foam serves as the panel insulation. Polyisocyanurate foam is also a structural material and supplements the load bearing capabilities of the window-wall panel. Polyisocyanurate has the same 
chemical functionality as most isocyanurate adhesives. Therefore, the foam forms an adhesive bond with the exterior sheathing, the $\mathrm{PVC} /$ wood window frame, the composite posts and the MDF truss.

- OSB Sheathing + wash plane. Oriented strand board is used for exterior sheathing. A polyethylene film is laminated to the exterior surface of the OSB to form a continuous wash plane.

- Fibrex Siding. The siding is extruded from Fibrex along with a PVC cap.

- Foam Pillow. In this design, it is important to insure that the window frame does not deflect even under a large, unexpected vertical load (e.g. from a heavy snow load). Therefore, in the space between the structural foam and the window frame there is a low density closed cell silicone foam pillow.

- Standard window frame and sash units. The window units were furnished by the Andersen Window Corporation and are a standard casement product. Wooden window frame is

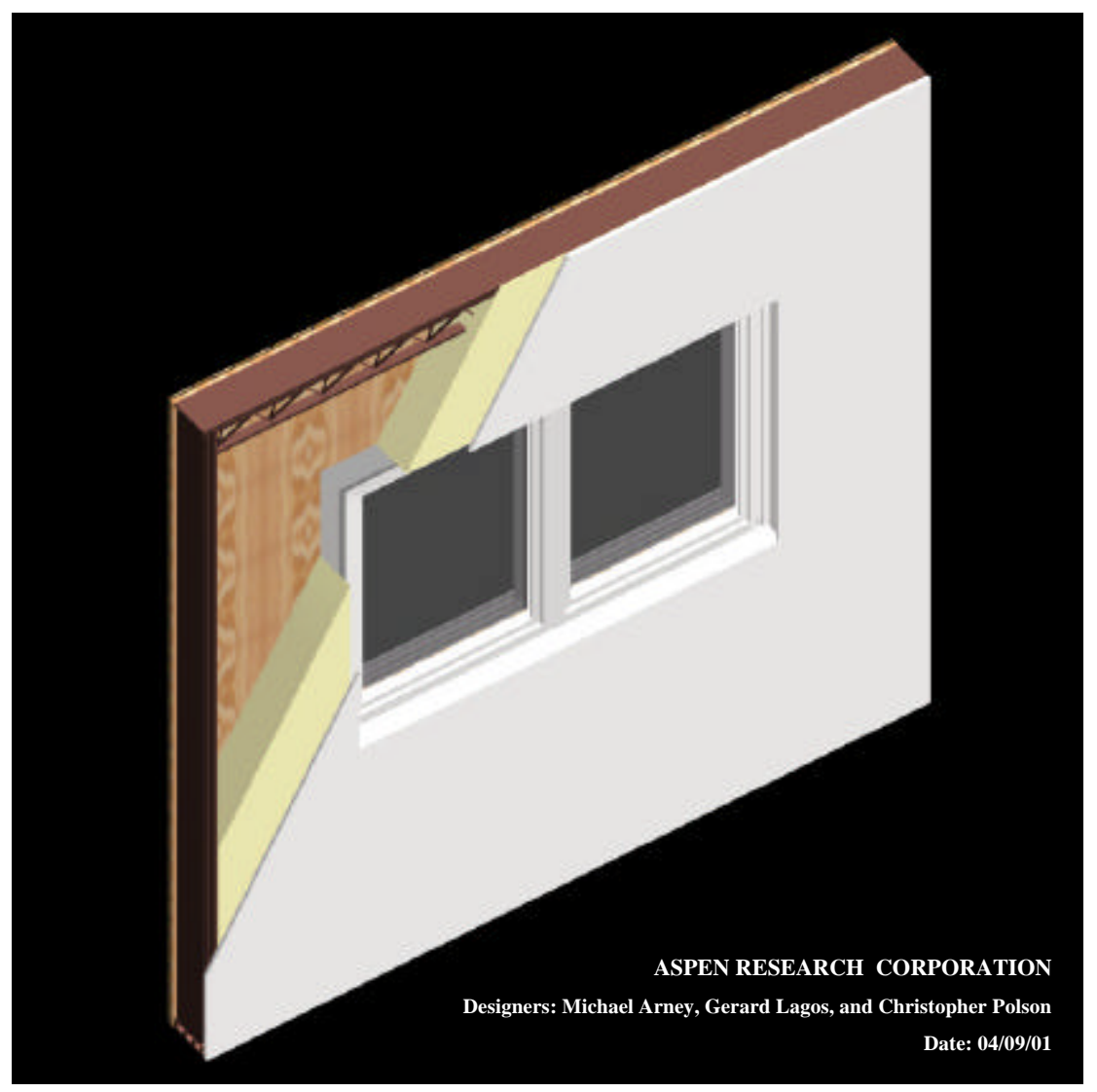

Figure 7.5. Foam wall. 


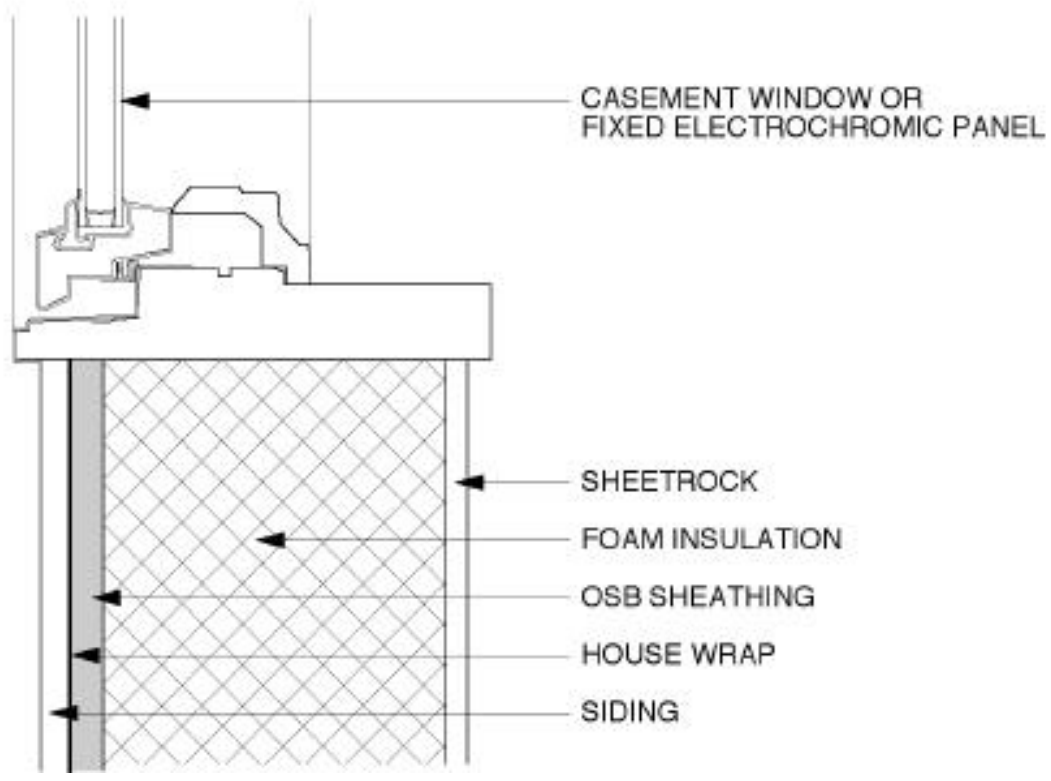

Figure 7.6. Sill detail of foam wall.

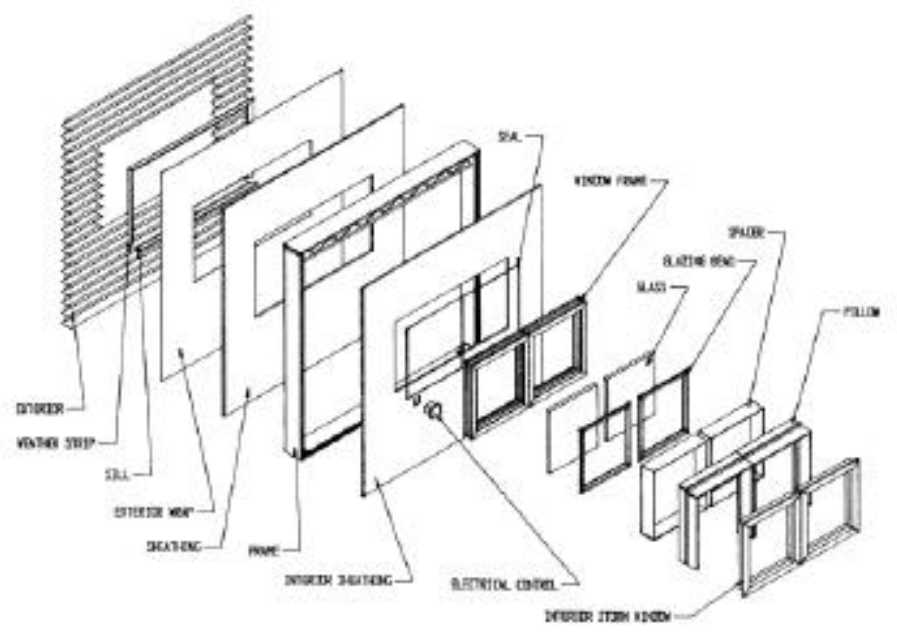

Figure 7.7. Exploded view of the foam wall. 


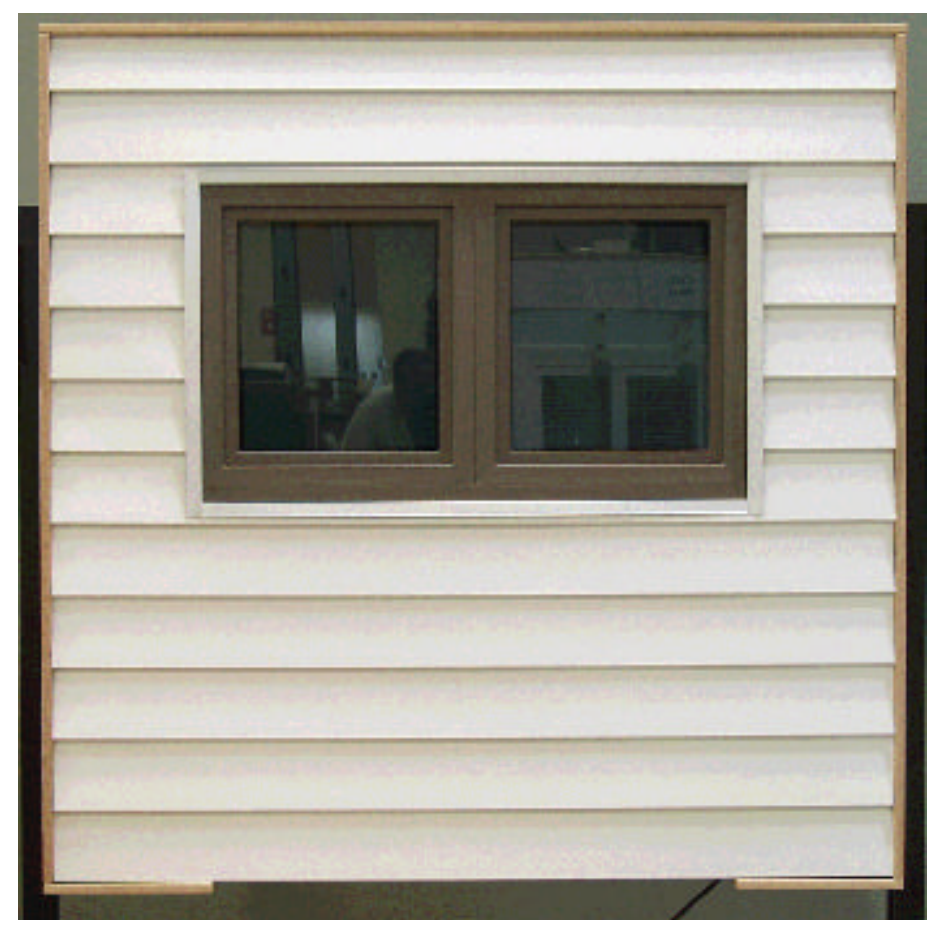

Figure 7.8: Prototype of foam wall - exterior view.

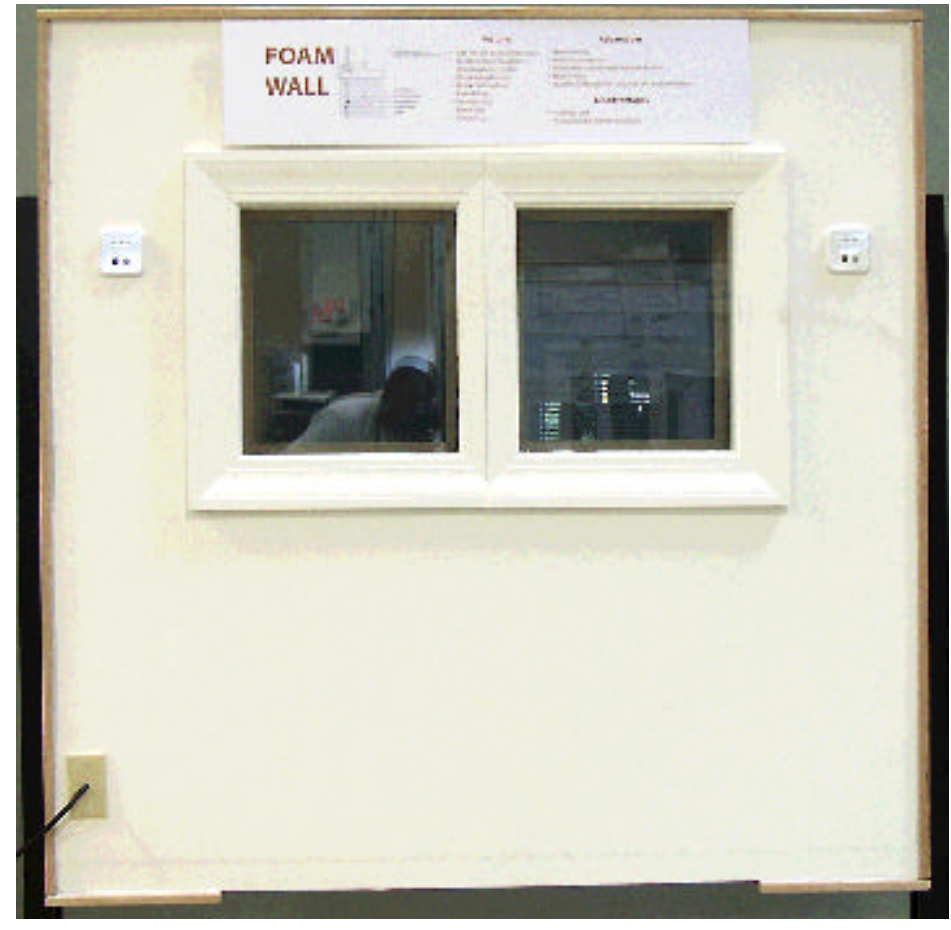

Figure 7.9: Prototype of foam wall - interior view. 
wrapped with a vacuum-formed PVC sheet. There is a nailing flange on the exterior perimeter of the frame which is glued to the polymer wash plane on the exterior surface to form a continuous skin with the wash plane, thus eliminating opportunities for air and water infiltration at the window-wall interface. The sash frame lineals were constructed from Fibrex and are joined with a corner key.

- Electrochromic glazing. The glass on the window unit is an electrochromic glass unit purchased from the Flabeg Company (Germany). This panel was selected with the lowest possible U-factor $\left(1.1 \mathrm{~W} / \mathrm{m}^{2} \mathrm{~K}\right)$.

Advantages

- Flexible sizes. All portions of the panel can easily be cut to any size without loss of functionality. Therefore, this panel will easily fit into most stick-built residential houses.

- Manufacturing ease. The wall unit uses a minimal number of parts. Each part can be manufactured using existing, well known manufacturing practices.

- High R-value. The wall R-value for everything except the insulated glass unit, is estimated to be $0.0418 \mathrm{Btu} / \mathrm{hr} \mathrm{ft}^{2}{ }^{\circ} \mathrm{F}$ $(\mathrm{R}$-value $=23.9)$.

Disadvantages

- Materials cost.

- VOC content of foamed insulation. The foamed material releases a number of volatile organic compounds. Any manufacturing process will require a process for trapping and containing the VOC's.

\subsection{STEEL WALL}

\subsubsection{Background}

The basic concept of the steel wall is to integrate steel into the structure while maximizing the materials benefits and minimizing its disadvantages.

Over time, the quality and availability of commercial lumber has decreased as its price has increased. High quality lumber requires many years to grow while new growth lumber exhibits much greater variability with respect to variables like dimensional stability, density, and warping. Meanwhile, steel prices have remained reasonable; steel is recyclable and renewable, and can be produced to exact standards because of the method in which it is produced. The break-even point where the cost of a steel-framed window wall is competitive with a wood framed wall is now within reach.

The advantages of steel are many. Steel is very strong, stiff and has a high natural frequency, which makes it less susceptible to 
vibration. Likewise, steel has a high strength to weight ratio, making it light and easier to handle. In addition, steel can be easily formed into various shapes. Steel is ideally suited for mass production. Steel designs can be engineered to meet load criteria by varying the thickness or other dimensions of the steel. The advantages of steel construction with respect to seismic resistance, termites, and resistance to moisture are well documented.

Steel's disadvantages include its high thermal conductivity, which can be minimized through clever engineering designs. It is difficult to modify in the field and is not fire resistant, because in high temperatures, steel softens and loses its structural load bearing capabilities.

\subsubsection{Design Concept}

The steel window wall is designed to be built in a factory by a panelized manufacturer, which eliminates many of the inefficiencies associated with today's residential building construction. Each window wall can be engineered for each wall design. By building the window wall in a factory setting many advantages are achieved. Computer aided design can be integrated with computer aided manufacturing (CAD/CAM), and process controls and factory automation techniques can be implemented reducing job site waste. In addition, tighter tolerances and quality controls are more easily implemented in a controlled environment. Likewise, cheaper labor can be used because of less skill required by factory workers instead of tradesmen. Another advantage achieved is the tighter integration of subsystems like electrical conduit, which can be accommodated by a cavity formed inside the wall during manufacturing. Also, the system that provides moisture and air infiltration can be controlled by making the window installation interface an integral part of the process. Instead of cutting a hole in the system on site and relying on site workers to perform the delicate and important job of fitting the components tightly together. By installing the window frame in the factory (the sash can be removed for shipping and reinstalled later) leads to a more foolproof system eliminating many of the integration problems common with today's residential building techniques.

The design of the steel wall is as follows: The steel wall uses steel truss members instead of traditional studs. Many different configurations of steel studs were evaluated to determine an optimum design. A common design is a sheet metal stud formed in the shape of a C-channel with the outside dimensions of a $2 \times 4$ or $2 \times 6$. This design is not very strong structurally and provides an excellent thermal bridge making it very inefficient with respect to heat transmission. An optimal design was selected that vastly improves on these weaknesses. Steel wire truss is commercially available at reasonable prices. A steel truss stud was designed using galvanized U-channel on both ends of two galvanized steel trusses. Galvanized components are used to minimize corrosion. Spot-welding at regular intervals fastens the truss and $\mathrm{u}$ channel. A steel truss frame is then created around the window and the 
window boot that surrounds it. The thermal efficiency is also increased by another system component, a Foam cap on the outside of the steel truss between the outside sheathing and steel truss. By keeping the steel truss further away from the outside of the wall, the temperature gradient is minimized greatly. Likewise, the truss angle is selected so that few members cross from one side to the other keeping thermal bridging to a minimum, for a more energy efficient system. A design feature called a window boot is an integral part of the design also. The window boot is tightly fitted to the window frame allowing the frame to be removed and reinstalled without damage to the systems integrity with respect to moisture and air infiltration management. The window frame to boot interface is a double seal that allows for slight movement of the window for compliance during settling or loading. Another feature is that a low-density polyurethane insulation is applied as liquid foam, which is very effective for filling gaps which effect how the system seals. Likewise, foam insulation allows for cavities to be created for electrical conduit and outlets. The foam can be of low density because the steel provides most of the structural load bearing capabilities. Another feature is an interior blind between

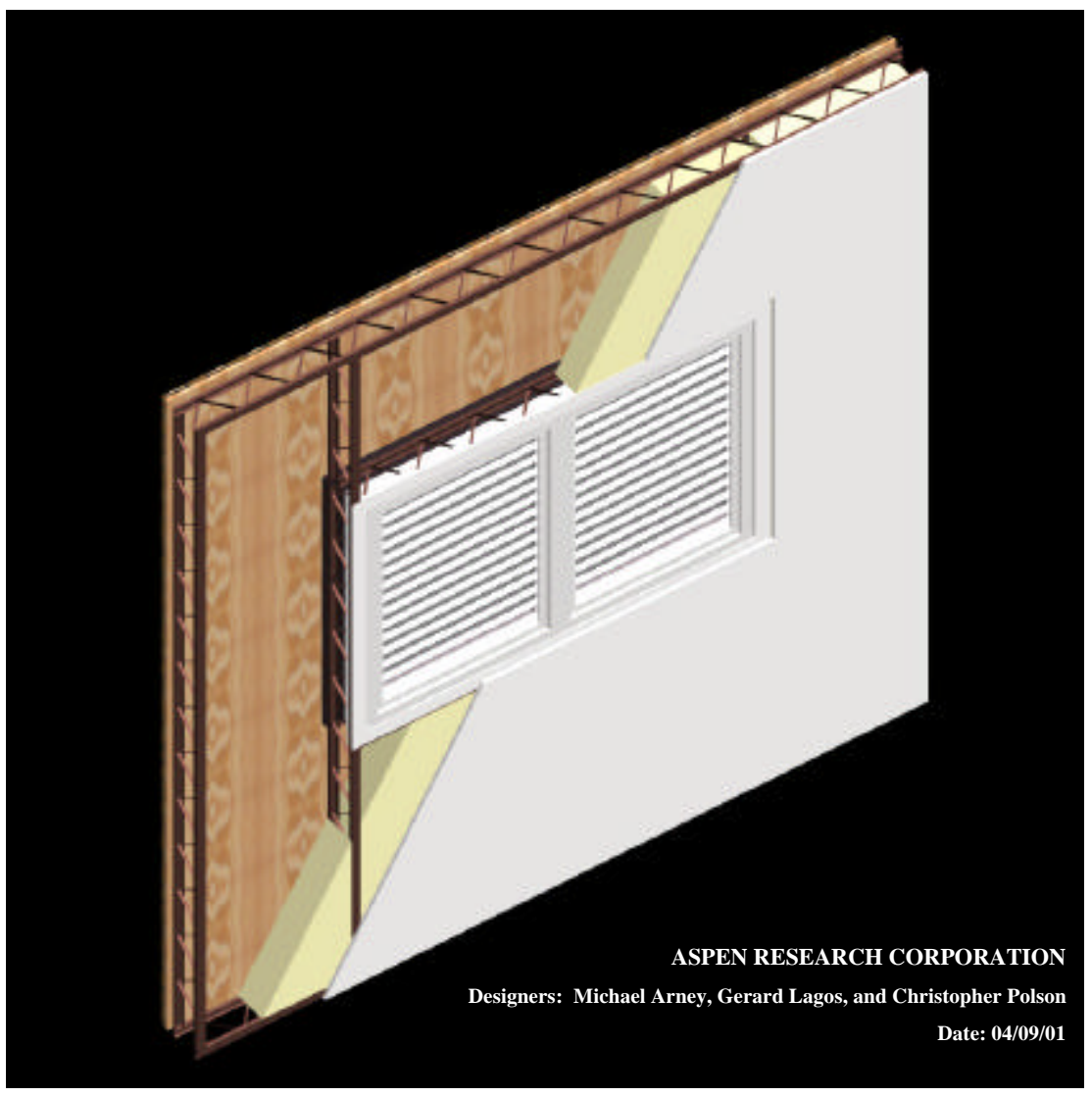

Figure 7.10. Steel wall with operating blinds. 
the windowpanes to minimize solar heat gain and eliminate cleaning of the blinds. See Figures 7.10 through 7.13.

\section{Features}

- Maximizes benefits of steel while minimizing its disadvantages

- Integrates window into wall to minimize air and moisture infiltration

- Liquid foam insulation

- Thermally efficient windows

- Window is easy to remove and reinstall

- Window to window boot interface has double seal

Advantages

- Low price

- Immediate acceptance in the marketplace

- Design is adaptable to manufacturing in a factory

- Great ability to engineer structure

- Highly integrated design

- Materials are readily available

Disadvantages

- Increased U-value

- Poor quality manufacturing can lead to moisture condensation inside the wall

\subsubsection{Steel Wall Manufacturing Process}

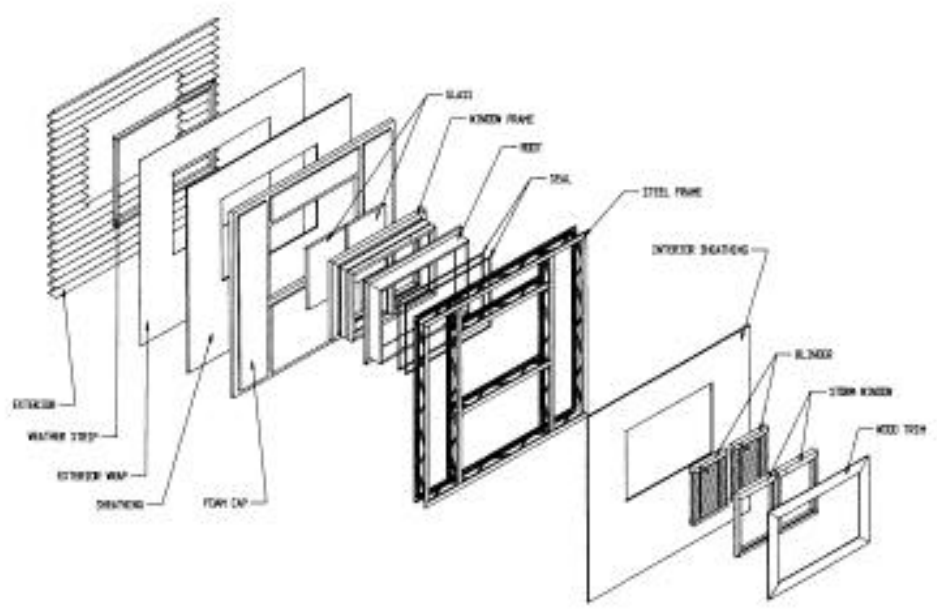

Figure 7.11: Exploded view of the steel wall 
The steel wall would be manufactured as follows: The builder would send all information to the manufacturer as far as wall size, number, type and size of windows etc. From there the wall structure would be engineered to fit the components. The outer frame dimensions are determined by the size of the wall and the thickness specified. The steel truss members can be engineered to structurally support each wall by increasing the thickness and dimensions of the $u$ channel and by the number of wire trusses used and their thickness'. Depending on the size of the window(s) a window boot or boots would be created. The steel window wall is then constructed around the boot and window frames. The manufacturing line would be set up so that the assembly would be built with the wall in the horizontal direction or lying down. The Outer sheathing would be cut to size with the proper openings for the windows. Next, the foam cap would be cut to fit the steel frame. The steel frame members would then be cut to length and formed around the window boot or boots and inside the outer frame. Then the steel frame members are bolted to each other. Next, the outer sheathing, foam cap, window boots and steel frame members are joined into an assembly using screws and the outer vapor barrier is also applied. After masking the assembly, liquid polyurethane foam is applied, followed by installation of the interior sheathing. Flashing is installed on the window, which is inserted last or can be shipped separately and installed on site.

Manufacturing time is limited mainly by the time to cure the liquid polyurethane foam. But this is typically less than about 5 minutes. All components could be pre assembled as sub assemblies or fabricated off line and then joined on a final assembly line.

The steel window wall design is successful at incorporating the positive attributes of steel and limiting its disadvantages while incorporating many other features that improve upon present day manufactured walls.

\section{START OF CONFIDENTIAL}




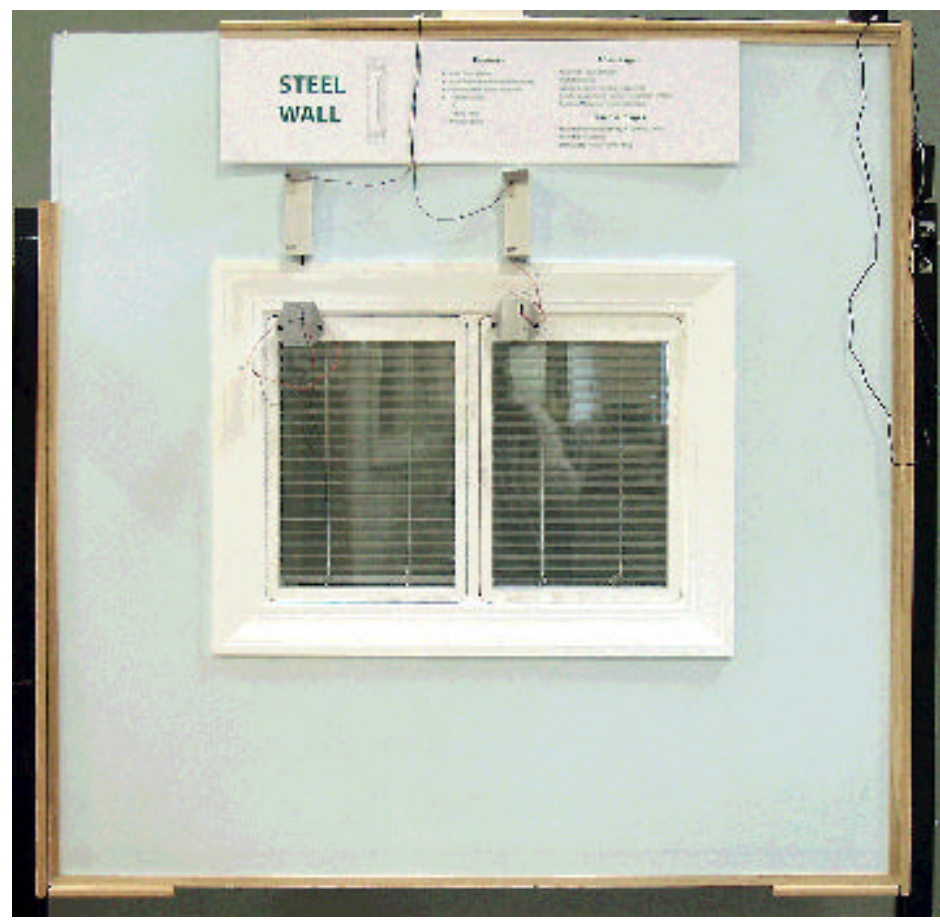

Figure 7.12: Prototype of steel wall - interior.

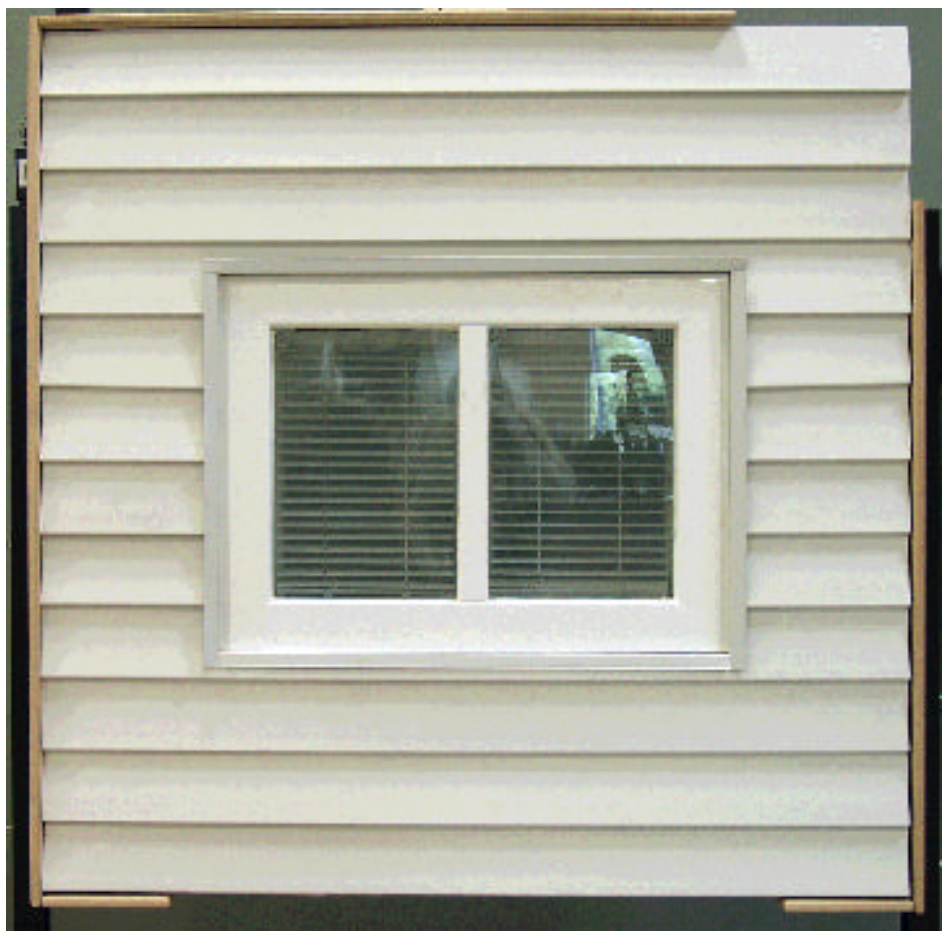

Figure 7.13: Prototype of steel wall - exterior. 
Pages $119-123$ and 128 are intentionally left blank. The information contained in this section has been move to Appendix A. 


\subsection{ENERGY ANALYSIS-PART 1}

To provide an energy performance evaluation of the IWWS concepts, two types of energy analysis were performed. The first analysis uses an enhanced one-dimensional heat transfer calculation to determine the U-factor of each wall panel. The wall $\mathrm{U}$-factor is identified separately from the window so that the same wall can be simulated with four different windows (Tables 7.1-7.3). The U-factor calculations are based on the five wall types shown in Figures 7.20-7.24.

Using the DOE-2 whole building simulation program, energy use and peak loads were calculated for a $2000 \mathrm{sq} f \mathrm{ft}$ house in six different climate zones-Minneapolis, Minnesota; Jacksonville, Florida; Washington, DC; Sacramento, California; Boston, Massachusetts; and Las Vegas, Nevada. Three wall types (standard stud, stiffened plate, and foam wall) combined with four window types were simulated. These results appear in Figures 7.25-7.30.

To provide an energy performance evaluation of the IWWS concepts, two types of energy analyses were performed. The first analysis uses an enhanced one-dimensional heat transfer calculation to determine the U-factor of each wall panel. The wall U-factor is identified separately from the window so that the same wall can be simulated with four different windows (Tables 7.1-7.3). The U-factor calculations are based on the five wall types shown in Figures 7.20-7.24.

Using the DOE-2 whole building simulation program, energy use and peak loads were calculated for a $2000 \mathrm{sq} f \mathrm{ft}$ house in six different climate zones-Minneapolis, Minnesota; Atlanta, Georgia; Washington, DC; Sacramento, California; Boston,

Table 7.1 Window properties used in Energy Analysis-Part 1.

\begin{tabular}{|lll|}
\hline Window & U-factor & SHGC \\
\hline $\begin{array}{l}\text { Window 349 (Base) } \\
\text { Double low solar gain low-E }\end{array}$ & 0.32 & 0.30 \\
$\begin{array}{l}\text { Window 349 with blinds } \\
\text { Double low solar gain low-E }\end{array}$ & 0.32 & $0.30^{*}$ \\
$\begin{array}{l}\text { EC window } \\
\text { Electrochromic-clear state }\end{array}$ & & \\
Electrochromic-colored state & 0.33 & 0.37 \\
$\begin{array}{l}\text { Window 351 } \\
\text { Triple low-E }\end{array}$ & 0.33 & 0.15 \\
\hline
\end{tabular}

* SHGC is reduced by $40 \%$ to $60 \%$ of its original. Blinds are closed when incident solar on each window is greater than $20 \mathrm{Btu} / \mathrm{sq} \mathrm{ft}$.

${ }^{* *}$ R5 night insulation added during nights (Oct-April) 
Massachusetts; and Las Vegas, Nevada. Three wall types

(standard stud, stiffened plate, and foam wall) combined with four window types were simulated. These results appear in Figures

7.25-7.30.

These results, based on a full scale conceptual design (Energy Analysis-Part 1), are necessarily different from the results that follow in the next section (Energy Analysis-Part 2) because of the omission of the window frame in the energy calculations as well as some different material property assumptions. These difference will be explored in phase two of the project.

\section{Design Evaluation}

The following assumptions have been made in performing the design evaluation analysis:

1. One-dimensional heat flow with an isothermal temperature at each layer interface.

2. Polyethylene vapor retarders have been ignored since their contribution to the net $\mathrm{R}$-value is less than the precision of the calculations.

Table 7.2: Composite IWWS R-values (sf- $\left.{ }^{\circ} \mathrm{F}-\mathrm{h} / \mathrm{Btu}\right)$.

\begin{tabular}{|c|c|c|c|c|c|}
\hline & & & & Window Type & \\
\hline & & & $\begin{array}{c}\text { Double-glazed } \\
\text { clear }\end{array}$ & $\begin{array}{c}\text { Double-glazed } \\
\text { spectrally selective }\end{array}$ & $\begin{array}{c}\text { Triple-glazed low- } \\
\text { E }\end{array}$ \\
\hline & & & $\begin{array}{l}\text { Wood or vinyl } \\
\text { frame }\end{array}$ & Wood or vinyl frame & $\begin{array}{l}\text { Insulated vinyl } \\
\text { frame }\end{array}$ \\
\hline & & & 2.04 & 3.45 & 6.67 \\
\hline & $\begin{array}{l}\text { Reference stud } \\
\text { frame }\end{array}$ & 14.89 & 5.95 & 8.31 & 11.5 \\
\hline & $\begin{array}{l}\text { Improved stud } \\
\text { frame with double } \\
\text { top plate }\end{array}$ & 15.91 & 6.07 & 8.54 & 11.95 \\
\hline$\frac{\sum^{\infty}}{\stackrel{1}{\pi}}$ & $\begin{array}{l}\text { lmproved stud } \\
\text { frame with single } \\
\text { top plate }\end{array}$ & 16.33 & 6.11 & 8.63 & 12.13 \\
\hline & Steel & 16.40 & 6.12 & 8.65 & 12.16 \\
\hline & Stiffened Plate & 19.74 & 6.43 & 9.28 & 13.44 \\
\hline & $\begin{array}{l}\text { Foam with double } \\
\text { top plate }\end{array}$ & 27.35 & 6.9 & 10.3 & 15.71 \\
\hline & $\begin{array}{l}\text { Foam with single } \\
\text { top plate }\end{array}$ & 29.30 & 6.99 & 10.5 & 16.18 \\
\hline
\end{tabular}

Table 7.3: Composite wall thermal properties (excluding window frame and glazing).

\begin{tabular}{|l|c|c|c|}
\hline \multicolumn{1}{|c|}{ Wall Type } & $\begin{array}{c}\text { Density } \\
\left(\mathrm{lb} / \mathrm{t}^{3}\right)\end{array}$ & $\begin{array}{c}\text { Heat Capacity } \\
\left(\mathrm{Btu} / \mathrm{lb} .{ }^{\circ} \mathrm{F}\right)\end{array}$ & $\begin{array}{c}\text { Conductance } \\
\left(\mathrm{Btu} / \mathrm{h} . \mathrm{ft}^{2} .{ }^{\circ} \mathrm{F}\right)\end{array}$ \\
\hline Reference Stud Frame & 13.36 & 0.301 & 0.0672 \\
\hline Stiffened plate & 13.44 & 0.282 & 0.0506 \\
\hline Foam with single top plate & 9.91 & 0.284 & 0.0341 \\
\hline
\end{tabular}




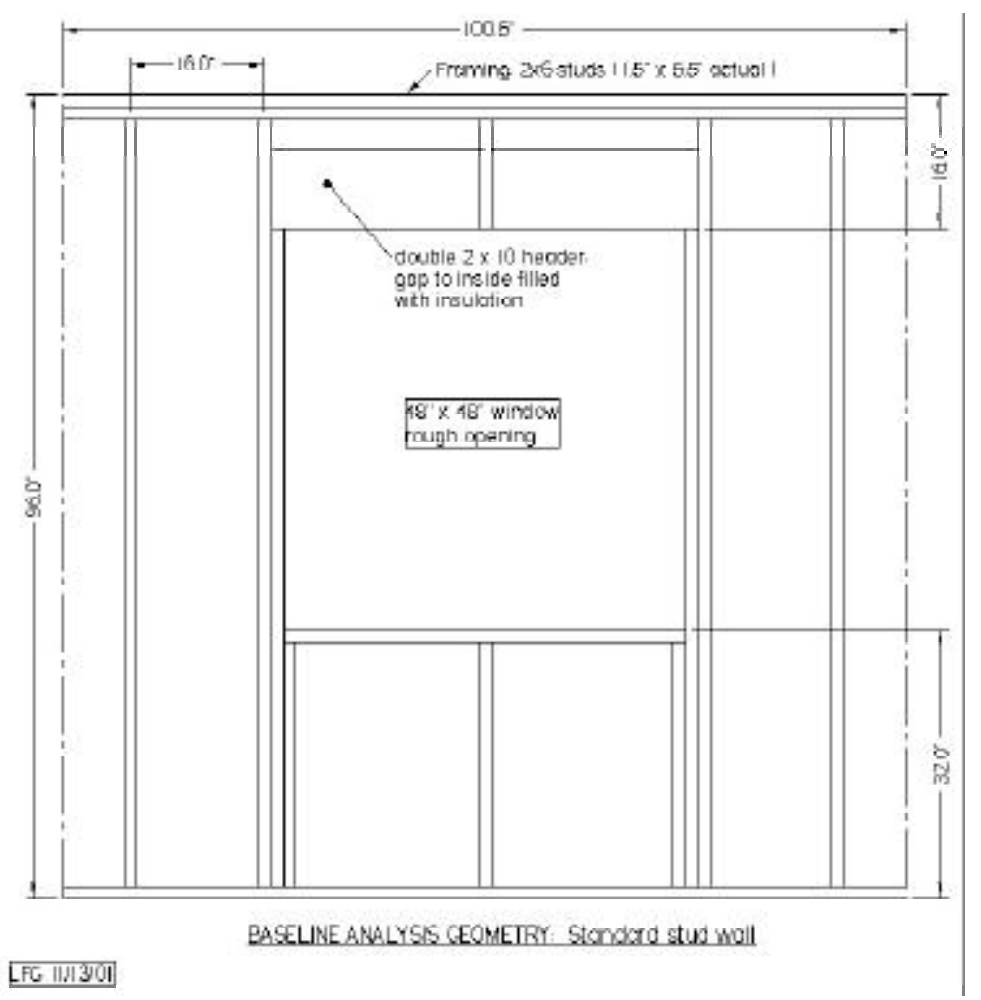

Figure 7.20: Layout of standard stud wall (base case) used in analysis.

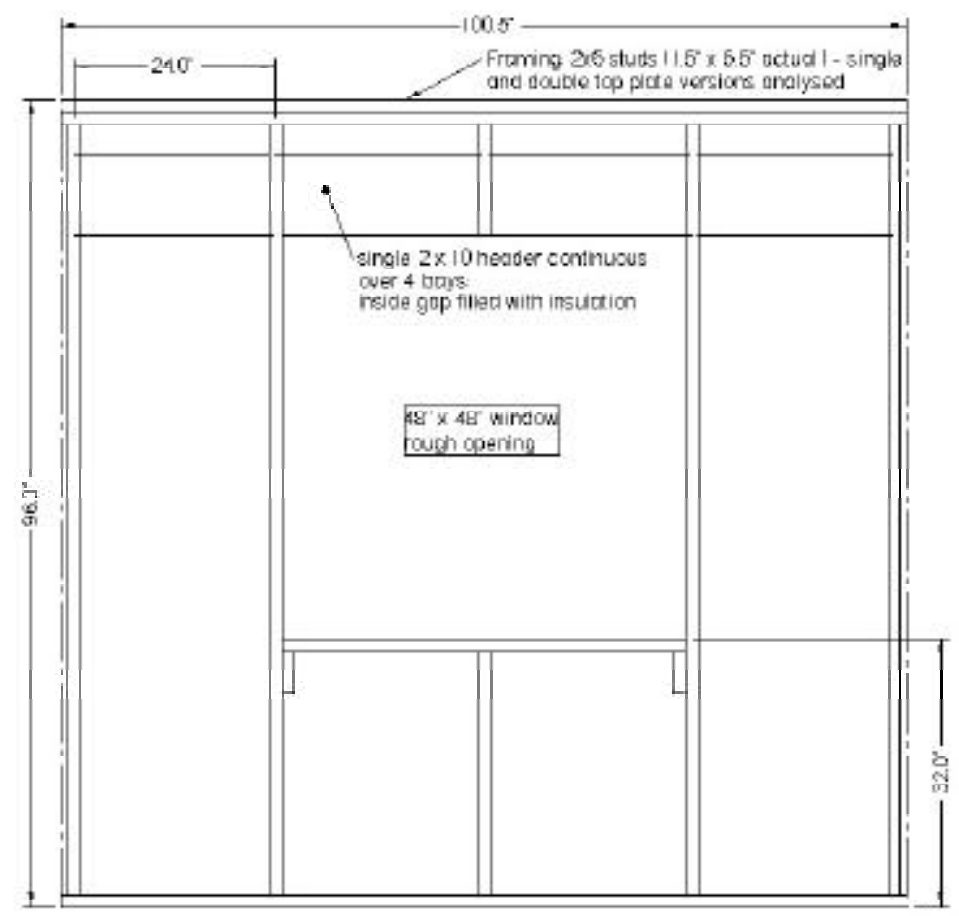

ANALYSSS CECWFIRY morowed stud wall

FE IE11010

Figure 7.21: Layout of manufactured stud wall used in analysis. 


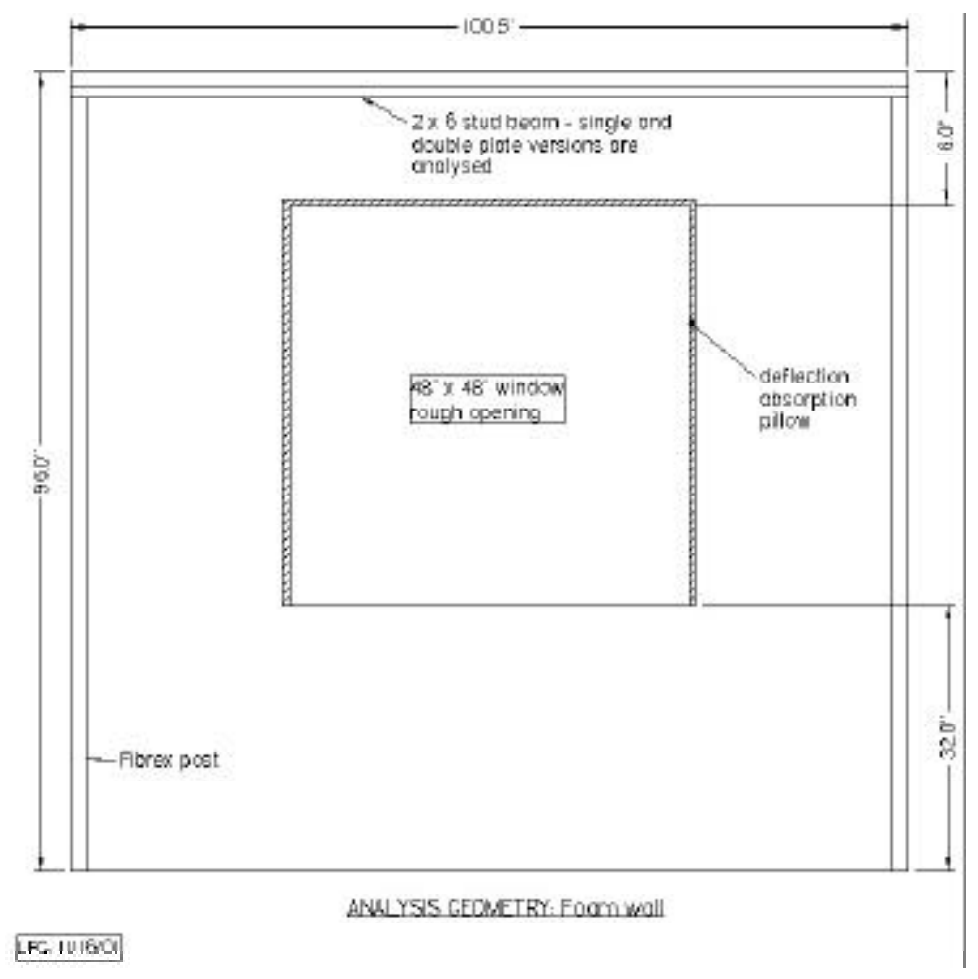

Figure 7.22: Layout of foam wall used in analysis.

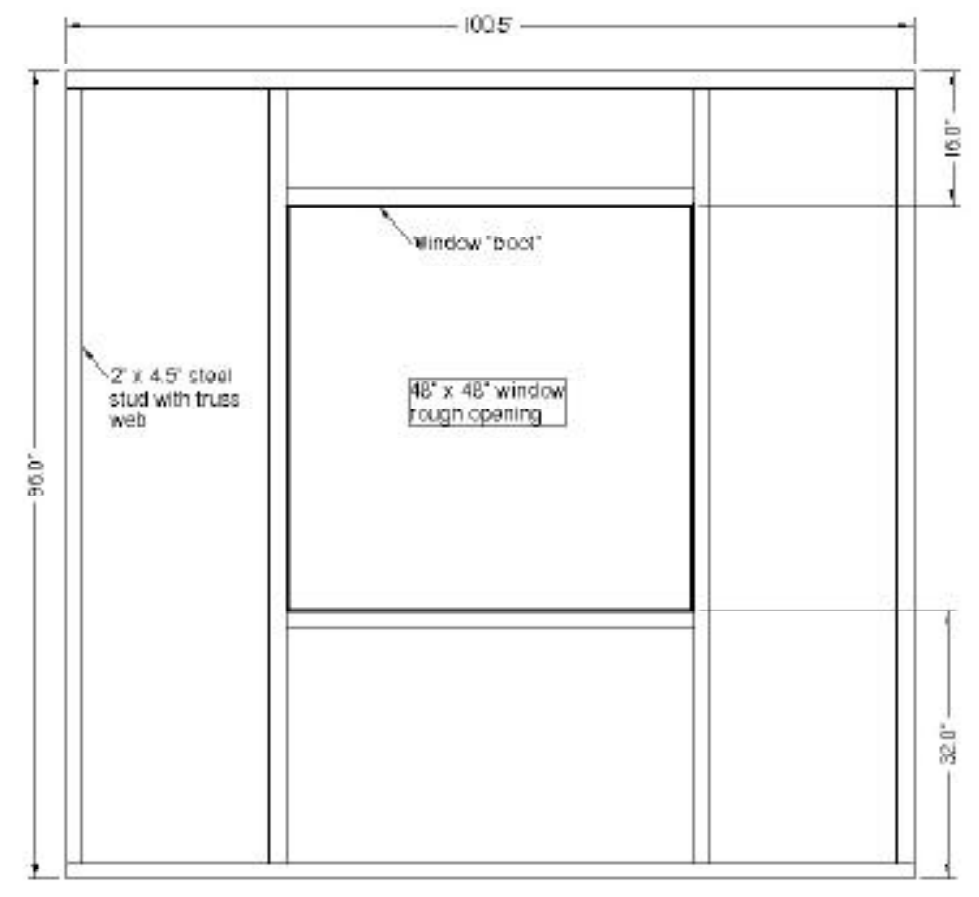

ANALYSIS CEOMEIRY: Sted fromed wall

\section{IFG 11:1600}

Figure 7.23: Layout of steel wall used in analysis. 


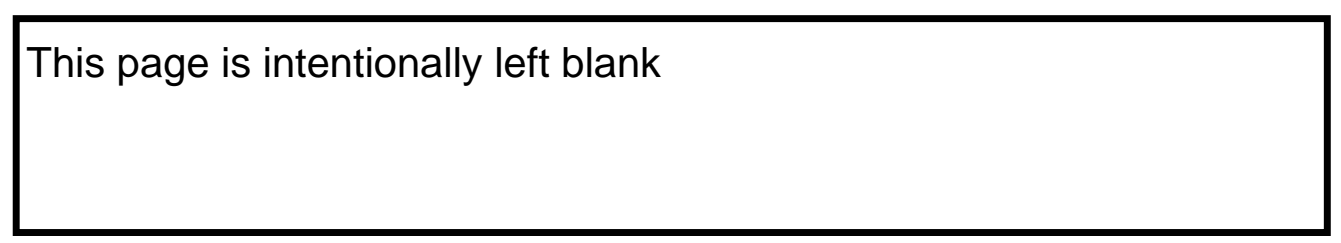



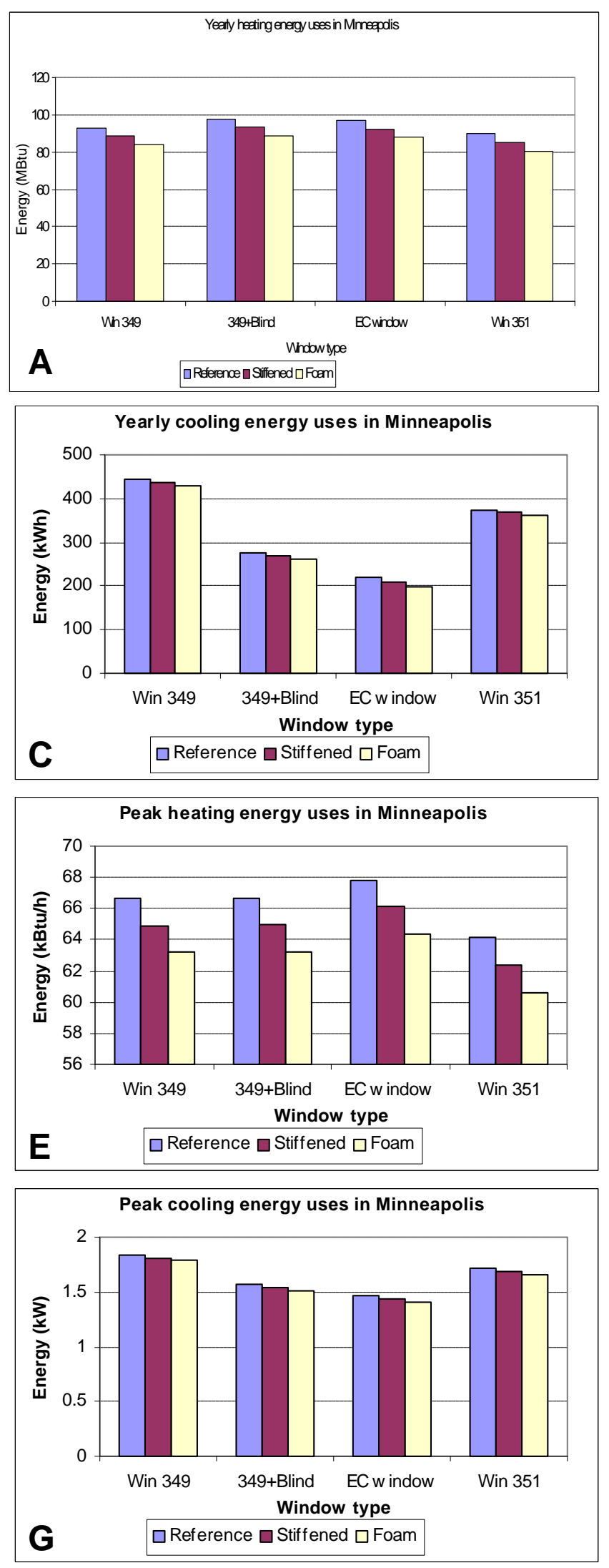
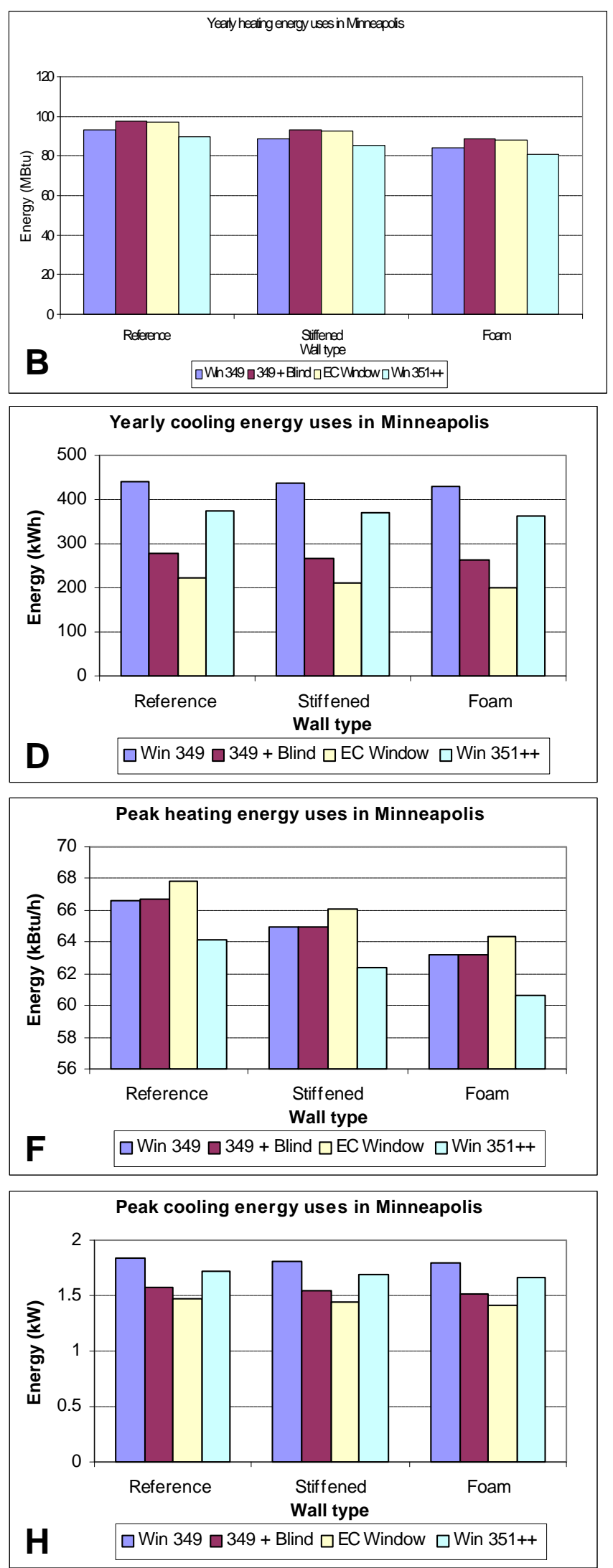

Figure 7.25: Energy analysis (Part 1) results for a house with all IWWS exterior walls in Minneapolis, MN. 

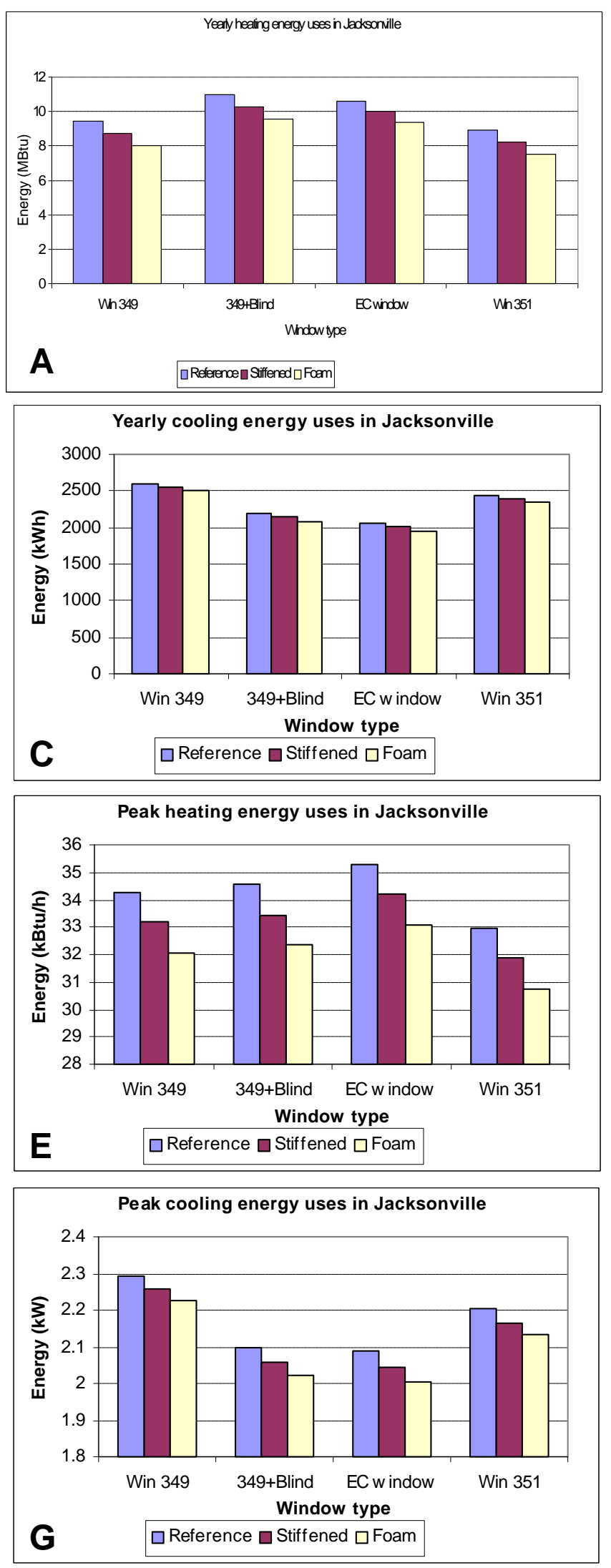
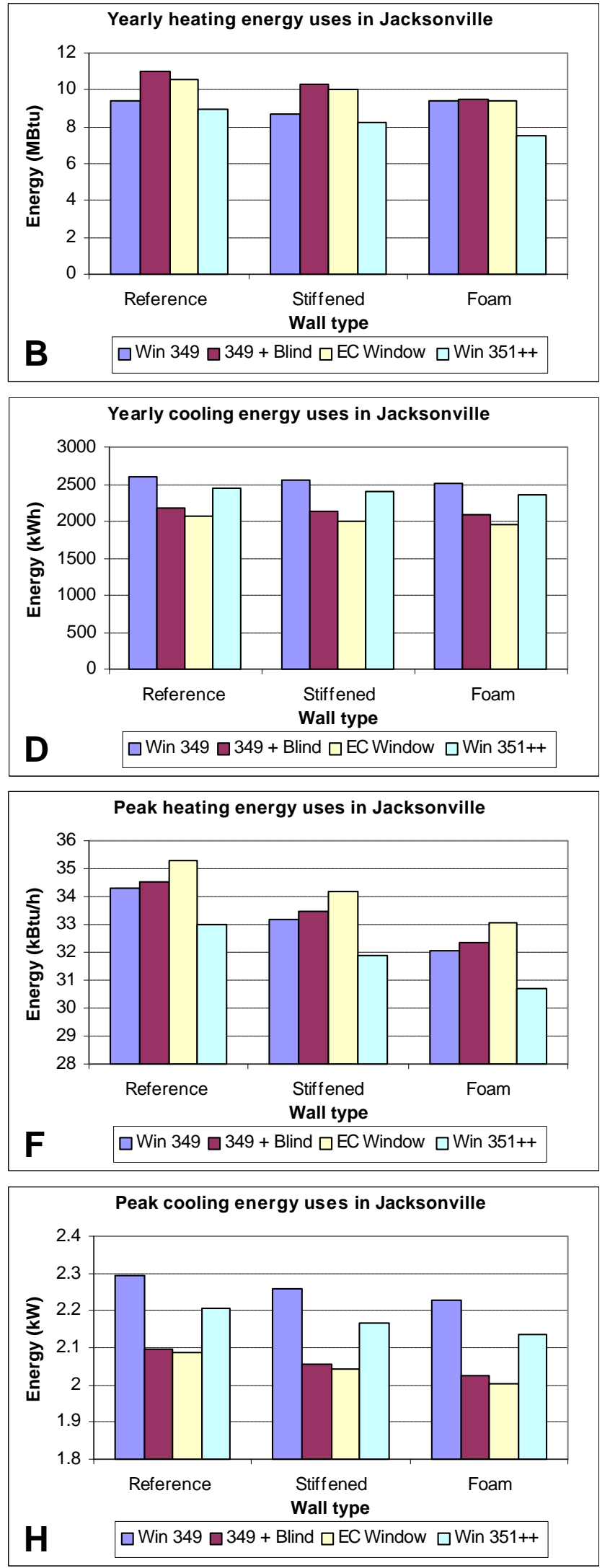

Figure 7.26: Energy analysis (Part 1) results for a house with all IWWS exterior walls in Atlanta, GA. 

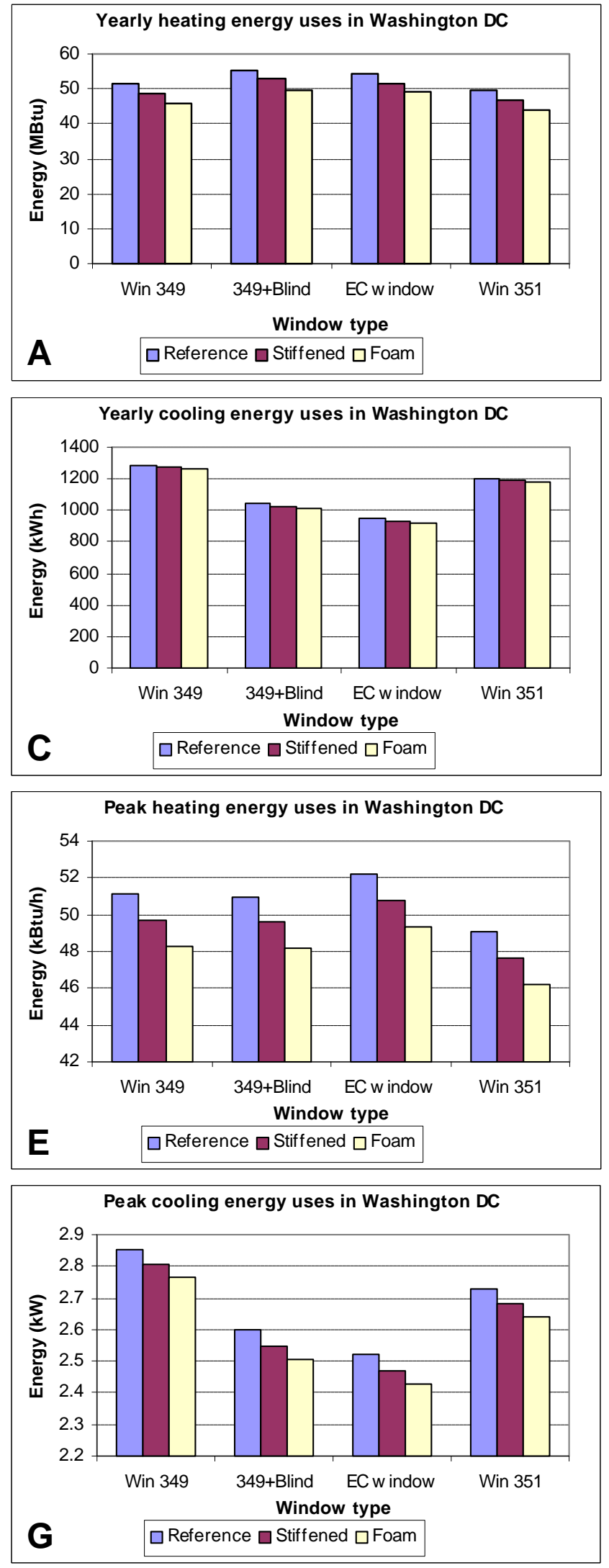
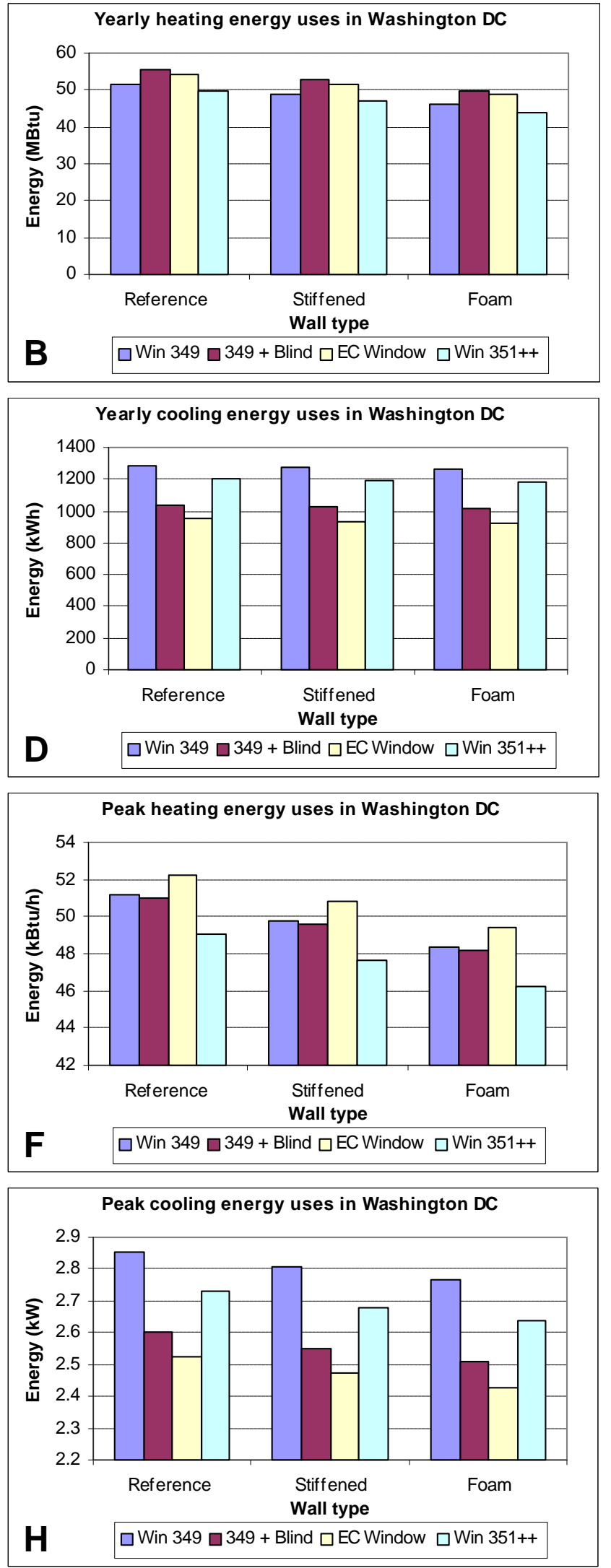

Figure 7.27: Energy analysis (Part 1) results for a house with all IWWS exterior walls in Washington, DC. 

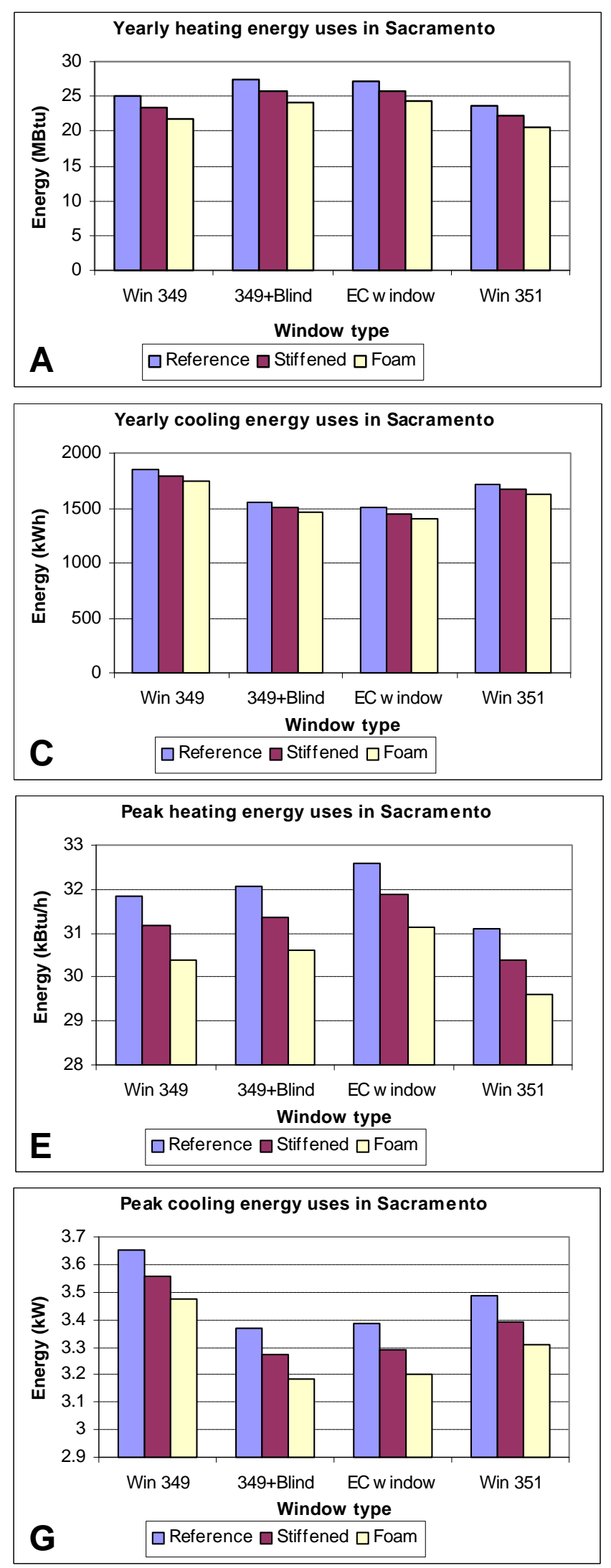
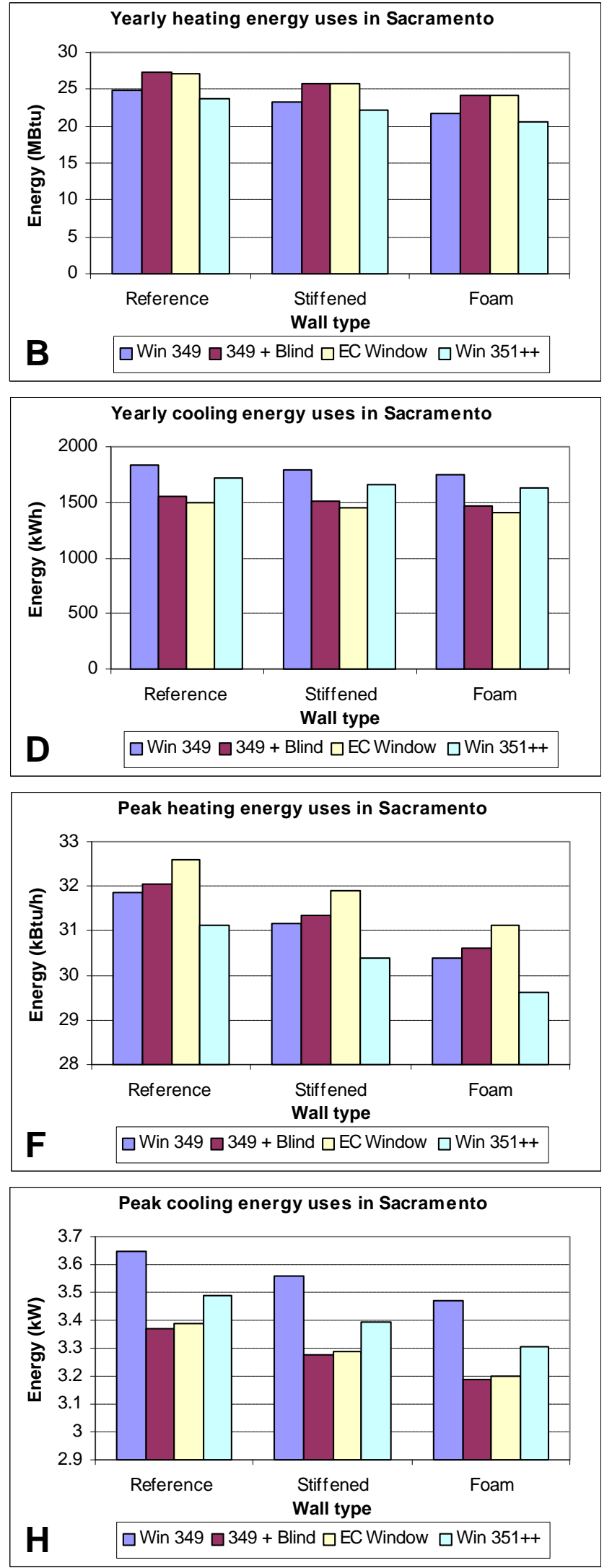

Figure 7.28: Energy analysis (Part 1) results for a house with all IWWS exterior walls in Sacramento, CA. 

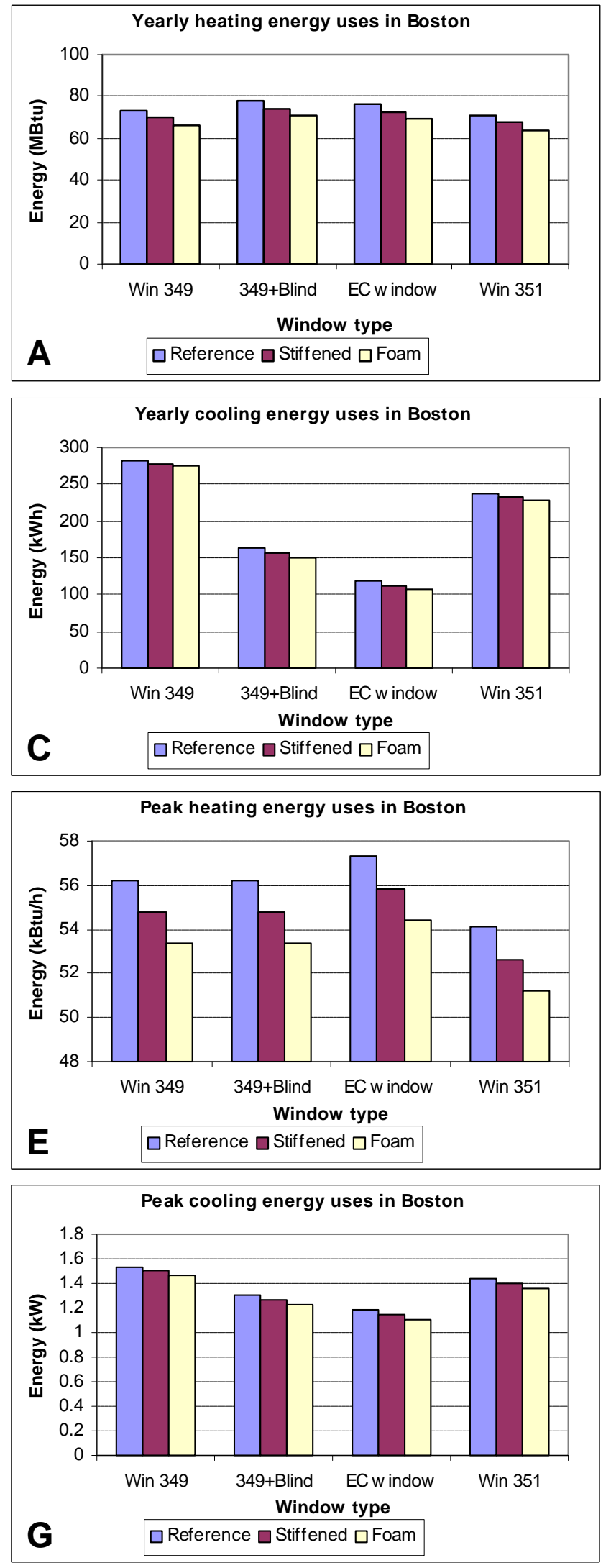
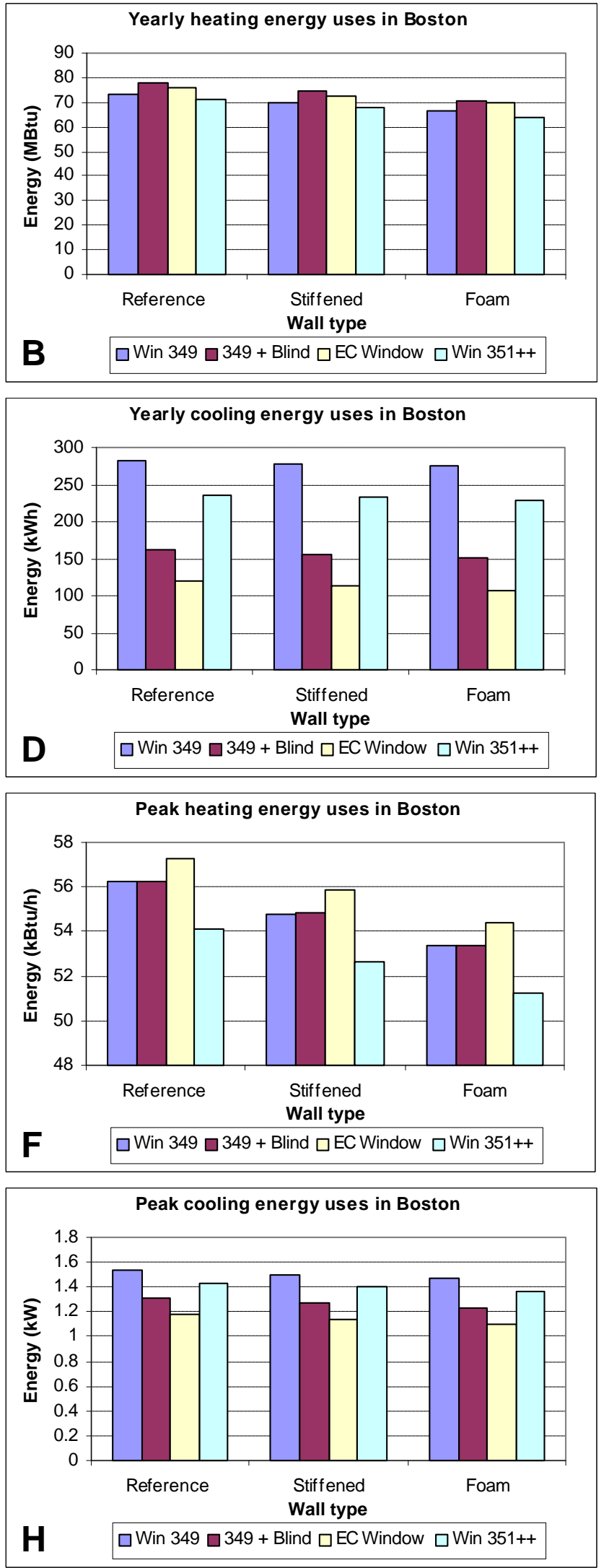

Figure 7.29: Energy analysis (Part 1) results for a house with all IWWS exterior walls in Boston, MA. 
Figure 7.30: Energy analysis (Part 1) results for a house with all IWWS exterior walls in Las Vegas, NV.
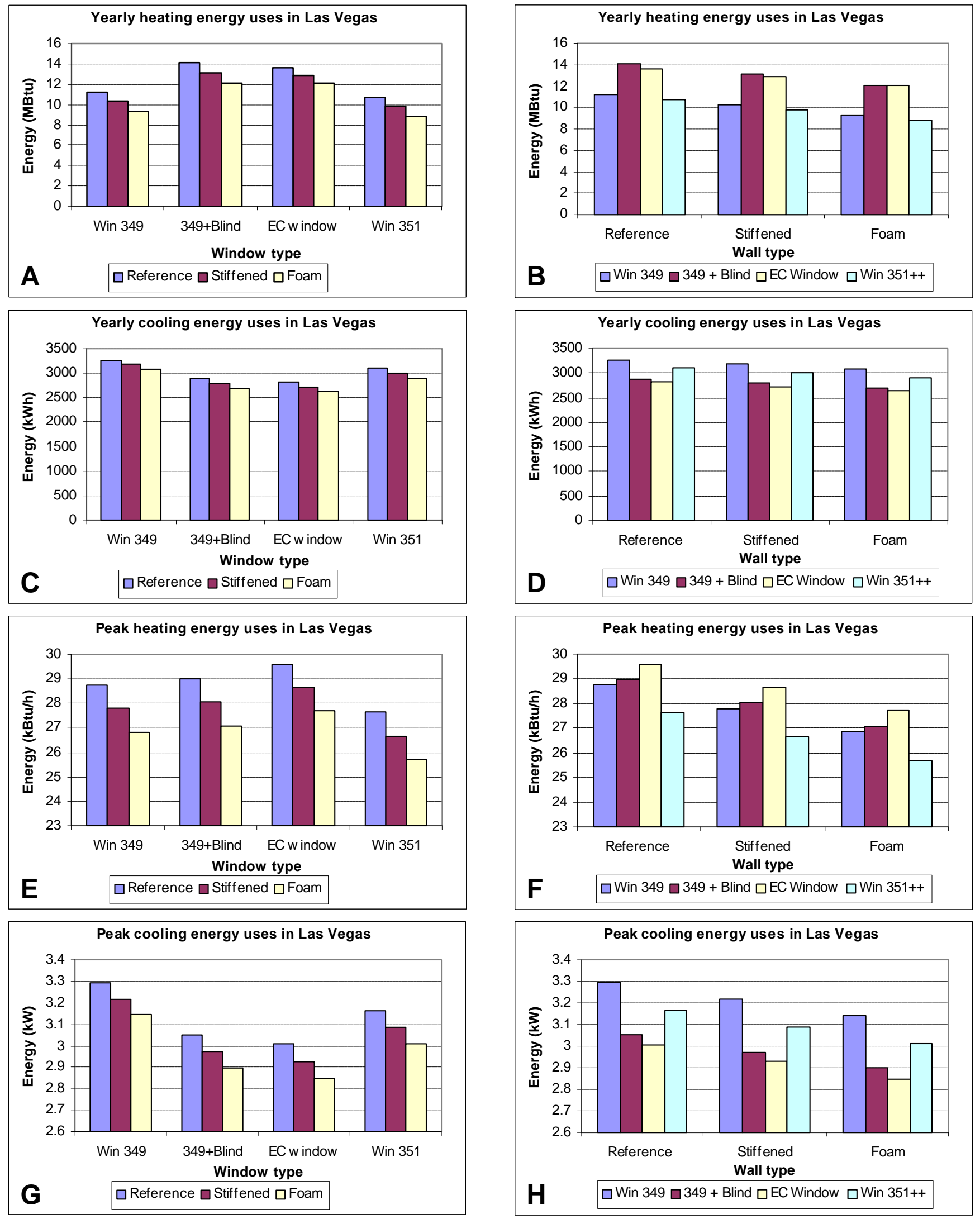


\subsection{ENERGY ANALYSIS-PART 2}

\subsubsection{Finite Element Analysis}

The composite U-values for each wall was computed by threedimensional finite element thermal analysis. These values were supplied to the Lawrence Berkeley National Labs for DOE-2 simulation (as shown below). The simulation took advantage of the fact that each design was symmetrical about the centerline. Therefore, only half of the window-wall was simulated. Also, the trusses that were featured in the steel wall were simulated using a network of beam elements. The foam wall, steel wall, and stiffened plate were simulated. The stud wall was assumed to have the same energy efficiencies as an ordinary stud wall of today.

\subsubsection{Discussion}

As in a normal situation the majority of the conductive heat escapes through the window glass and framing system. Theoretically, the actual wall design matters in a minor sense because it presents opportunities for numerous thermal short circuits. However, the glass and window frame still represents the majority of energy losses.

The foam wall showed the lowest theoretical U-value and this is due in large part to the use of a wooden window frame. Most thermal short circuits were reduced or eliminated by the use of composite structural beams. Further economies could be achieved by implementing a structural foam for the window frame.

The steel wall showed the second best thermal performance due, in large part, because of the use of a foam cap over the steel studs. Nevertheless, the analysis shows some minor thermal short circuits in the vicinity of the framing units and these represent an opportunity to improve the thermal efficiency of the panel.

The stiffened plate showed the highest U-value of the new construction exclusively because of its use of a commercial grade fenestration system. The window system was chosen in large part because it has already been qualified for light commercial use.

\subsubsection{Modeling of the IWWS prototypes}

\section{Objective}

The objective of this part of the project is to investigate the energy and peak demand savings of the four integrated wall/ window systems (IWWS) developed by Aspen and the University of Minnesota, as compared against a typical new frame house in six climates. This is achieved by performing simulations using the DOE-2 program.

Methodology

For each IWWS case, the IWWS prototype was compared against a Base Case house (standard stud construction). The Base 
Table 7.4: Material properties for the foam wall.

\begin{tabular}{|c|c|c|c|}
\hline Material & $\begin{array}{c}\text { Density } \\
\left(\mathrm{lbm} / \mathrm{in}^{3}\right)\end{array}$ & $\begin{array}{c}\text { Specific Heat } \\
\left(\mathrm{Btu} / \mathrm{lbm}{ }^{\circ} \mathrm{F}\right)\end{array}$ & $\begin{array}{c}\text { Thermal } \\
\text { Conductivity } \\
\left(\mathrm{Btu} / \mathrm{hr} \text { in }{ }^{\circ} \mathrm{F}\right)\end{array}$ \\
\hline $\begin{array}{c}\text { Polyisocyanurat } \\
\text { e Foam }\end{array}$ & 0.0012 & 0.238 & 0.00092 \\
Fibrex & 0.0506 & 0.393 & 0.00833 \\
Fiberglass & 0.0079 & 0.176 & 0.0025 \\
Wood & 0.0152 & 0.650 & 0.010 \\
OSB & 0.0152 & 0.650 & 0.0624 \\
Gypsum & 0.0650 & 0.210 & 0.008 \\
Foam Pillow & 0.0072 & 0.25 & \\
\hline
\end{tabular}

Table 7.5: Material properties for the Steel wall.

\begin{tabular}{|c|c|c|c|}
\hline Material & $\begin{array}{c}\text { Density } \\
\left(\mathrm{Ibm} / \mathrm{in}^{3}\right)\end{array}$ & $\begin{array}{c}\text { Specific Heat } \\
\left(\mathrm{Btu} / \mathrm{lbm}{ }^{\circ} \mathrm{F}\right)\end{array}$ & $\begin{array}{c}\text { Thermal } \\
\text { Conductivity } \\
(\mathrm{Btu} / \mathrm{hr} \text { in }\end{array}$ \\
\hline Poly $\mathrm{F})$
\end{tabular}

Table 7.6: Material properties for the stiffened plate.

\begin{tabular}{|c|c|c|c|}
\hline Material & $\begin{array}{c}\text { Density } \\
\left(\mathrm{lbm} / \mathrm{in}^{3}\right)\end{array}$ & $\begin{array}{c}\text { Specific Heat } \\
\left(\mathrm{Btu} / \mathrm{lbm}^{\circ}{ }^{\circ} \mathrm{F}\right)\end{array}$ & $\begin{array}{c}\text { Thermal } \\
\text { Conductivity } \\
\left(\text { Btu/hr in }{ }^{\circ} \mathrm{F}\right)\end{array}$ \\
\hline Gypsum & 0.0650 & 0.23700 & 0.0624 \\
Wood & 0.0152 & 0.650 & 0.00723 \\
$\begin{array}{c}\text { Expanded } \\
\text { polystyrene } \\
\text { Fibrex® }\end{array}$ & 0.0050 & 0.20000 & 0.00175 \\
Steel & 0.0506 & 0.3934 & 2.017 \\
PMMA & 0.282 & 0.114 & 0.00939 \\
\hline
\end{tabular}


Table 7.7: FEA simulation results. The U-values here represent all heat fluxes through the wall unit and window frame.

\begin{tabular}{|c|c|c|c|c|}
\hline Wall Design & $\begin{array}{c}\text { Composite } \\
\text { Density } \\
\left(\mathrm{lbm} / \mathrm{ft}^{3}\right)\end{array}$ & $\begin{array}{c}\text { Composite } \\
\text { Specific Heat } \\
\left(\mathrm{Btu} / \mathrm{lbm}{ }^{\circ} \mathrm{F}\right)\end{array}$ & $\begin{array}{c}\text { Composite U- } \\
\text { Value } \\
\left(\mathrm{Btu} / \mathrm{hr} \mathrm{ft}^{2}{ }^{\circ} \mathrm{F}\right)\end{array}$ & $\begin{array}{c}\text { Composite R } \\
\text { value }\end{array}$ \\
\hline Stud & 13.36 & 0.301 & 0.074 & 13.5 \\
Foam & 15.59 & 0.324 & 0.0434 & 23 \\
Steel & 20.28 & 0.276 & 0.0528 & 19 \\
Stiffened Plate & 25.69 & 0.389 & 0.0581 & 17 \\
\hline
\end{tabular}

Case house had a typical spectrally selective low-e window with a wood/vinyl frame. The Base Case house is the typical new construction house used by NFRC's Annual Energy Subcommittee and used in the RESFEN computer program (see Table 7.8 and the RESFEN manual). In order to quantify the savings from the IWWS systems, the stud walls were replaced with parameters which described the IWWS prototypes determined from FEA modeling provided by Aspen. Since each IWWS prototype has a different glazing system, we also simulated the IWWS prototypes with the same glazing as used in the base house - these cases are referred to as "foam wall only" and "steel wall only" and allow us to understand what effect is due to wall changes and what effect is due to glazing system changes.

\section{Climates}

Six climates are selected in the present study to represent a reasonable range of US climates and markets:

- Minneapolis

- Atlanta

- Washington DC

- Sacramento/Red Bluff

- Boston

- Las Vegas

\section{Base House Characteristics}

HVAC: A residential air conditioner and gas furnace are used as cooling and heating equipment in all the six climates.

Walls: Table 7.9 lists wall types and associated effective wall material properties. These properties were provided by Aspen.

Windows: Table 7.10 lists window types and associated control strategies. 


\subsubsection{Simulation results}

\section{Base House}

Table 7.11 lists yearly and peak cooling and heating energy uses for the base house in six climates.

\section{Foam Wall}

Table 7.12 lists yearly and peak cooling and heating energy use in six climates using the foam wall only. Table 7.13 lists yearly and peak cooling and heating energy uses in six climates using the foam IWWS in six climates. Figures 7.31-7.36 show cooling and heating savings for the foam wall only and the full foam IWWS. The largest percent savings using the foam IWWS are obtained in cold climates, such as Minneapolis (72\%) and Boston (74\%). The largest absolute savings using the foam IWWS are obtained in hot climates, such as Sacramento (523 kWh) and Las Vegas (743 kWh). It is worth noting that absolute energy savings obtained from electrochromic windows only are more than those using foam walls only in most climates and this is due to their low SHGC during the cooling season (0.13).

\section{Steel Wall}

Table 7.14 lists yearly and peak cooling and heating energy use in six climates using the steel wall only in six climates. Table 7.15 lists yearly and peak cooling and heating energy uses in six climates using the steel IWWS in six climates. Figures 7.37-7.42 show cooling and heating savings for the steel wall only and the full steel IWWS. The largest percent savings using the steel IWWS are obtained in cold climates, such as Minneapolis (43\%) and Boston (44\%). The largest absolute savings using the steel IWWS are obtained in hot climates, such as Sacramento (337 kWh) and Las Vegas (492 $\mathrm{kWh})$. It is worth noting that absolute energy savings obtained from SS Low-E with blinds windows are much more than those using steel walls only in all the six climates, due to the savings from the automated blind's operation.

\subsubsection{Conclusions}

- Both the steel wall and the foam wall systems save cooling energy and peak cooling demand.

- While the wall systems have lower effective conductivities, the heating savings are not as substantial as the cooling savings from the IWWS systems. This is due to the fact that the IWWS systems reduce solar gains throughout the year (detrimental to heating and an asset to cooling).

- The foam IWWS has better thermal performance than the steel IWWS, because the foam wall has a higher thermal resistance and the electrochromic window is better able to 
reduce cooling loads than the shading device modeled here.

The electrochromic is always turned down during the

cooling season while the shading system is only deployed

when there is direct solar radiation. Future research should

examine the assumption used in this study regarding the

shading system's impact.

Table 7.8: Base house characteristics

\begin{tabular}{|l|l|l|l|l|l|l|}
\hline Climate & $\begin{array}{l}\text { Foundation } \\
\text { type }\end{array}$ & Wall Type & $\begin{array}{l}\text { Wall } \\
\text { Insulation }\end{array}$ & $\begin{array}{l}\text { Ceiling } \\
\text { insulation }\end{array}$ & $\begin{array}{l}\text { lloor } \\
\text { insulation }\end{array}$ & $\begin{array}{l}\text { Basement wall } \\
\text { insulation }\end{array}$ \\
\hline Minneapolis & Basement & Frame & R-19 & R-38 & R-15 & R-15 \\
\hline Atlanta & Slab & Frame & R-19 & R-38 & R-2 & N/A \\
\hline Washington DC & Crawl & Frame & R-19 & R-38 & R-19 & N/A \\
\hline Sacramento & Slab & Frame & R-14 & R-38 & R-6 & N/A \\
\hline Boston & Basement & Frame & R-19 & R-38 & R-11 & R-11 \\
\hline Las Vegas & Slab & Frame & R-14 & R-30 & R-0 & N/A \\
\hline
\end{tabular}

Table 7.9: Effective material properties of five IWWS walls.

\begin{tabular}{|l|c|c|c|c|}
\hline Wall Types & $\begin{array}{c}\text { Thickness } \\
\text { (inch) }\end{array}$ & $\begin{array}{c}\text { Conductivity } \\
\left(\text { Btu/h.ft. }{ }^{\circ} \mathrm{F}\right)\end{array}$ & $\begin{array}{c}\text { Density } \\
\left(\mathrm{lb} / \mathrm{ft}^{3}\right)\end{array}$ & $\begin{array}{c}\text { Specific heat } \\
(\mathrm{Btu} / \mathrm{lb} .\end{array}$ \\
\hline Foam $\left.{ }^{\circ} \mathrm{F}\right)$
\end{tabular}

Table 7.10: IWWS windows and associated controls

\begin{tabular}{|c|c|c|}
\hline Wall trpe & Findow tipe & Contol \\
\hline Fa:m & Floheg Eloctrutromis & Caxling kand \\
\hline Pocket & $\begin{array}{l}\text { Suporglnring (BESFEN } \\
\text { wimdow } \$ 351 \text { ) }\end{array}$ & $\begin{array}{l}\text { RS Nipht inoulation and blind } \\
\text { opentign }\end{array}$ \\
\hline Strel & SS Low- $\mathrm{E}^{3}$ with blindr ${ }^{4}$ & blind coerrition \\
\hline $\begin{array}{l}\text { Monufhothmed otud } \\
\text { Fill }\end{array}$ & SSLOWH & $\mathbf{N} / \mathbf{A}$ \\
\hline Stiffened plete & SS Lonn-S & $\mathbf{N} / \mathbf{A}$ \\
\hline
\end{tabular}


Table 7.11: Cooling and heating energy uses in base houses in six climates.

\begin{tabular}{|l|c|c|c|c|c|c|}
\hline & Minneapolis & Atlanta & $\begin{array}{c}\text { Washington } \\
\text { DC }\end{array}$ & Sacramento & Boston & Las Vegas \\
\hline $\begin{array}{l}\text { House Heat } \\
\text { (MBtu) }\end{array}$ & 96.84 & 28.62 & 54.47 & 27.27 & 72.65 & 15.67 \\
\hline House Cool (kWh) & 394.28 & 1246.30 & 1214.00 & 1800.43 & 292.38 & 3238.04 \\
\hline $\begin{array}{l}\text { House Peak Heat } \\
(\mathrm{kBtu})\end{array}$ & 68.94 & 41.40 & 53.26 & 33.45 & 57.98 & 32.09 \\
\hline $\begin{array}{l}\text { House Peak Cool } \\
(\mathrm{kW})\end{array}$ & 1.84 & 2.12 & 2.86 & 3.67 & 1.55 & 3.29 \\
\hline
\end{tabular}

Table 7.12: Cooling and heating energy uses using foam walls only in six climates.

\begin{tabular}{|l|c|c|c|c|c|c|}
\hline & Minneapolis & Atlanta & $\begin{array}{c}\text { Washington } \\
\text { DC }\end{array}$ & Sacramento & Boston & Las Vegas \\
\hline House Heat MBtu & 83.50 & 23.63 & 45.86 & 21.88 & 62.59 & 12.25 \\
\hline House Cool kWh & 325.53 & 1116.60 & 1125.42 & 1539.22 & 243.34 & 2834.13 \\
\hline $\begin{array}{l}\text { House Peak Heat } \\
\text { kBtu }\end{array}$ & 61.67 & 35.93 & 47.03 & 30.02 & 51.42 & 27.53 \\
\hline $\begin{array}{l}\text { House Peak Cool } \\
\text { kW }\end{array}$ & 1.58 & 1.82 & 2.53 & 3.17 & 1.34 & 2.94 \\
\hline
\end{tabular}

Table 7.13: Cooling and heating energy uses using the foam IWWS in six climates.

\begin{tabular}{|l|c|c|c|c|c|c|}
\hline & Minneapolis & Atlanta & $\begin{array}{c}\text { Washington } \\
\text { DC }\end{array}$ & Sacramento & Boston & Las Vegas \\
\hline House Heat MBtu & 86.68 & 25.16 & 48.14 & 23.66 & 64.97 & 14.03 \\
\hline House Cool kWh & 158.46 & 803.10 & 852.11 & 1276.62 & 111.94 & 2494.88 \\
\hline $\begin{array}{l}\text { House Peak Heat } \\
\text { kBtu }\end{array}$ & 62.68 & 36.77 & 47.93 & 30.61 & 52.33 & 28.21 \\
\hline $\begin{array}{l}\text { House Peak Cool } \\
\text { kW }\end{array}$ & 1.24 & 1.64 & 2.26 & 2.96 & 1.06 & 2.72 \\
\hline
\end{tabular}

Table 7.14: Cooling and heating energy use using steel walls only in six climates.

\begin{tabular}{|l|c|c|c|c|c|c|}
\hline & Minneapolis & Atlanta & $\begin{array}{c}\text { Washington } \\
\text { DC }\end{array}$ & Sacramento & Boston & Las Vegas \\
\hline House Heat MBtu & 89.67 & 26.06 & 49.96 & 24.76 & 67.21 & 14.08 \\
\hline House Cool kWh & 359.98 & 1185.49 & 1170.62 & 1675.88 & 268.94 & 3043.98 \\
\hline $\begin{array}{l}\text { House Peak Heat } \\
\text { kBtu }\end{array}$ & 65.80 & 39.27 & 50.78 & 32.21 & 55.35 & 30.50 \\
$\begin{array}{l}\text { House Peak Cool } \\
\text { kW }\end{array}$ & 1.75 & 1.99 & 2.73 & 3.42 & 1.46 & 3.13 \\
\hline
\end{tabular}

Table 7.15: Cooling and heating energy use using steel IWWS in six climates.

\begin{tabular}{|l|c|c|c|c|c|c|}
\hline & Minneapolis & Atlanta & $\begin{array}{c}\text { Washington } \\
\text { DC }\end{array}$ & Sacramento & Boston & Las Vegas \\
\hline House Heat MBtu & 93.39 & 28.46 & 53.00 & 26.79 & 70.74 & 16.53 \\
\hline House Cool kWh & 238.12 & 956.46 & 976.51 & 1462.66 & 173.34 & 2745.42 \\
\hline $\begin{array}{l}\text { House Peak Heat } \\
\text { kBtu }\end{array}$ & 65.82 & 39.43 & 50.66 & 32.39 & 55.32 & 30.70 \\
\hline $\begin{array}{l}\text { House Peak Cool } \\
\text { kW }\end{array}$ & 1.53 & 1.83 & 2.53 & 3.20 & 1.29 & 2.94 \\
\hline
\end{tabular}




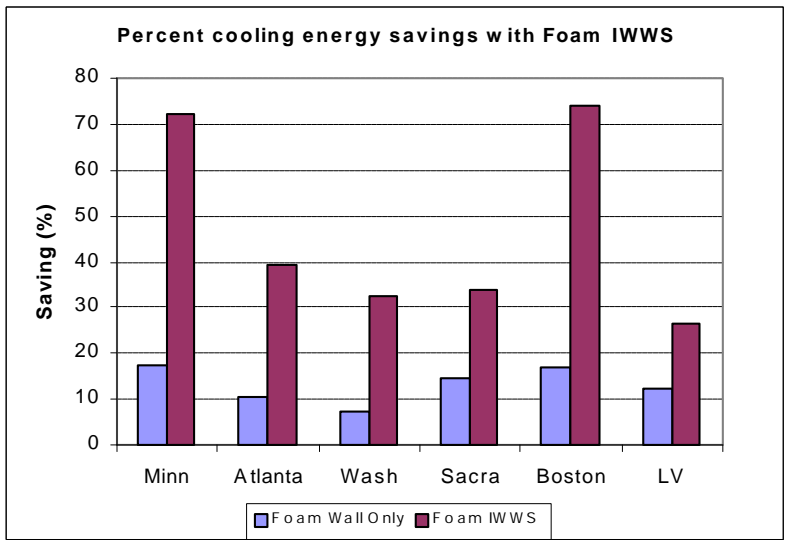

Figure 7.31: Percent cooling energy savings using foam walls only and with the full IWWS

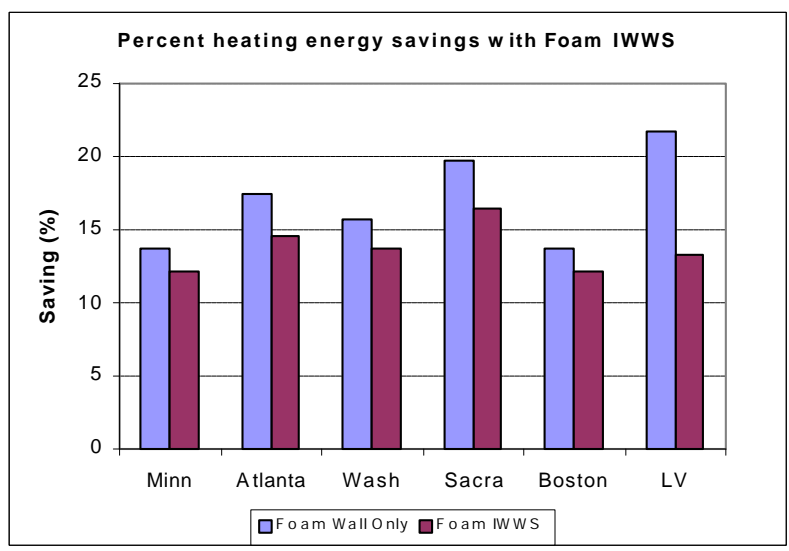

Figure 7.33: Percent heating energy savings using foam walls only and with the full IWWS

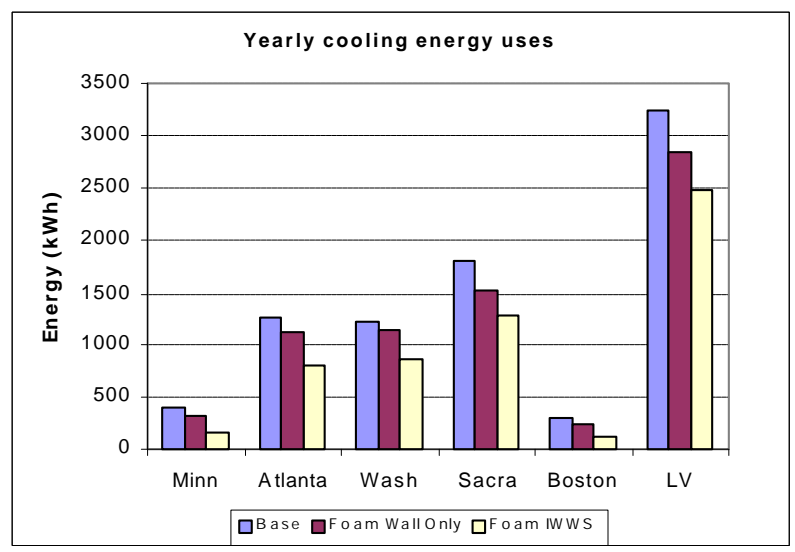

Figure 7.35: Cooling energy use with the base house, foam walls only, and with the full foam IWWS

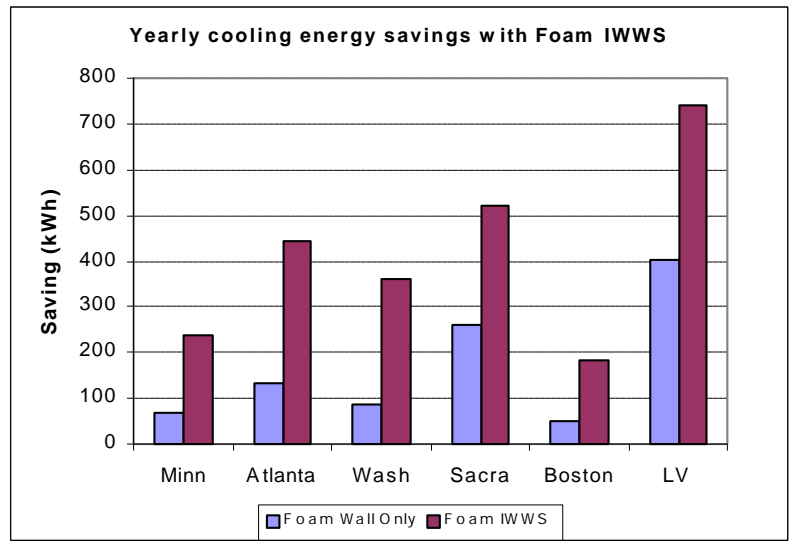

Figure 7.32: Absolute cooling energy savings using foam walls only and with the full IWWS

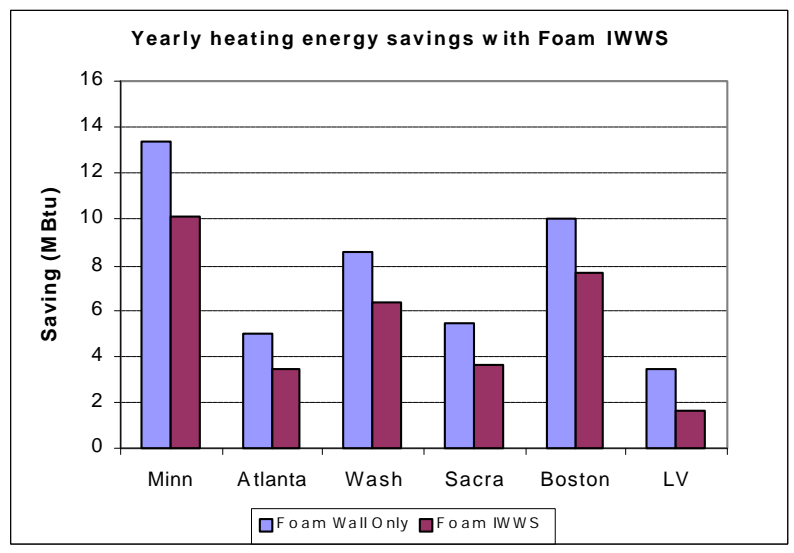

Figure 7.34: Absolute heating energy savings using foam walls only and with the full IWWS

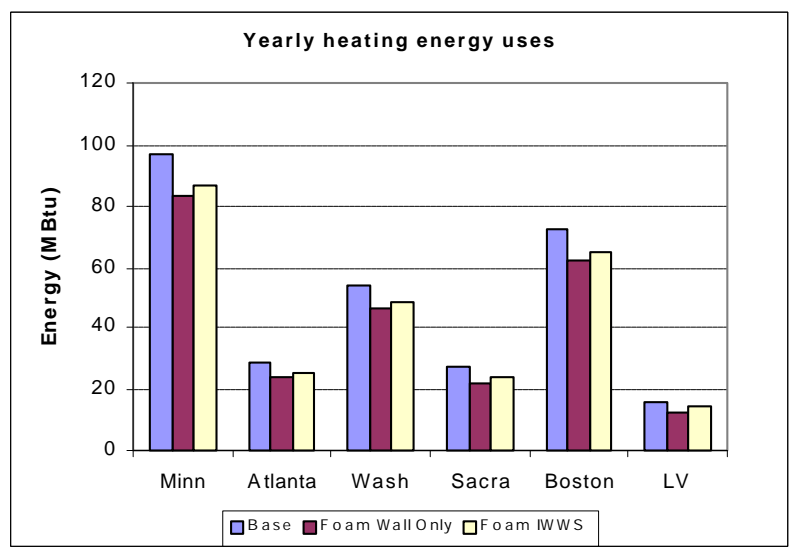

Figure 7.36: Heating energy use with the base house, foam walls only, and with the full foam IWWS 


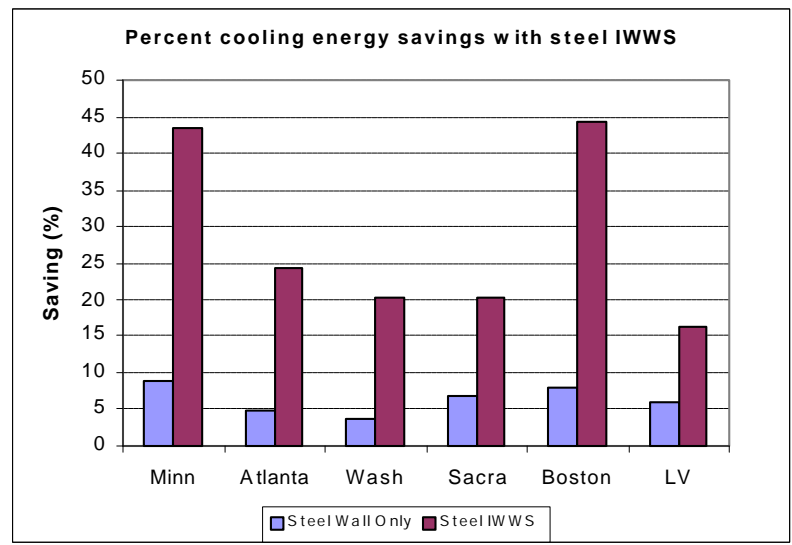

Figure 7.37: Percent cooling energy savings using steel walls only and with the steel IWWS

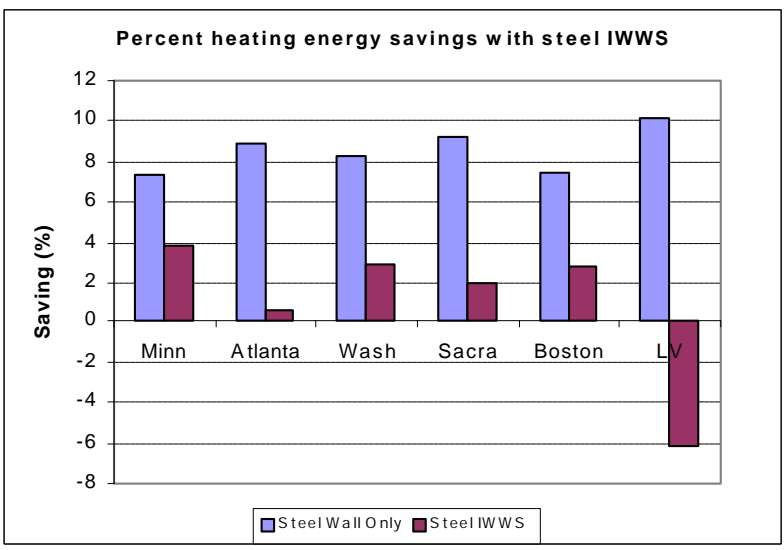

Figure 7.39: Percent heating energy savings using steel walls only and with the steel IWWS

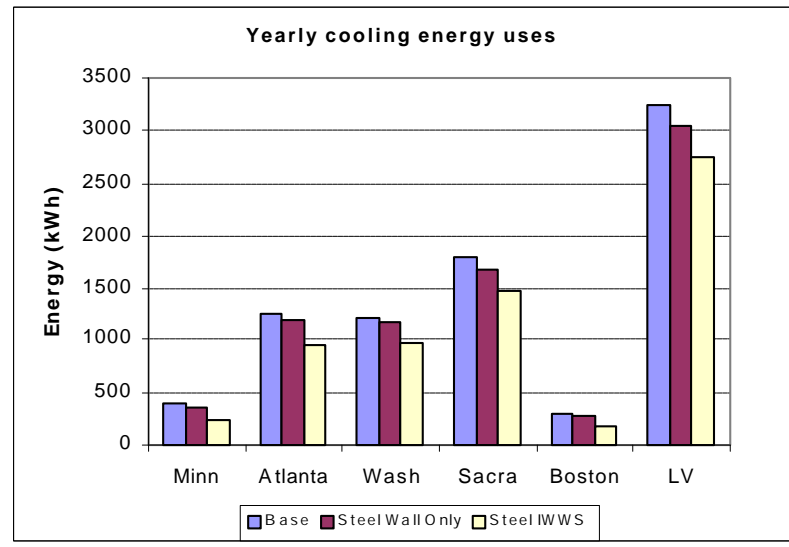

Figure 7.41: Cooling energy use with the base house, steel walls only, and with the full steel IWWS

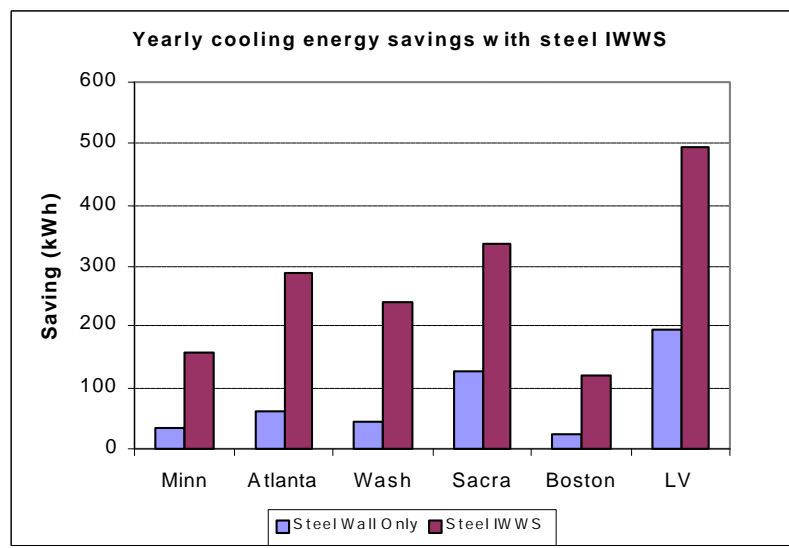

Figure 7.38: Absolute cooling energy savings using steel walls only and with the steel IWWS

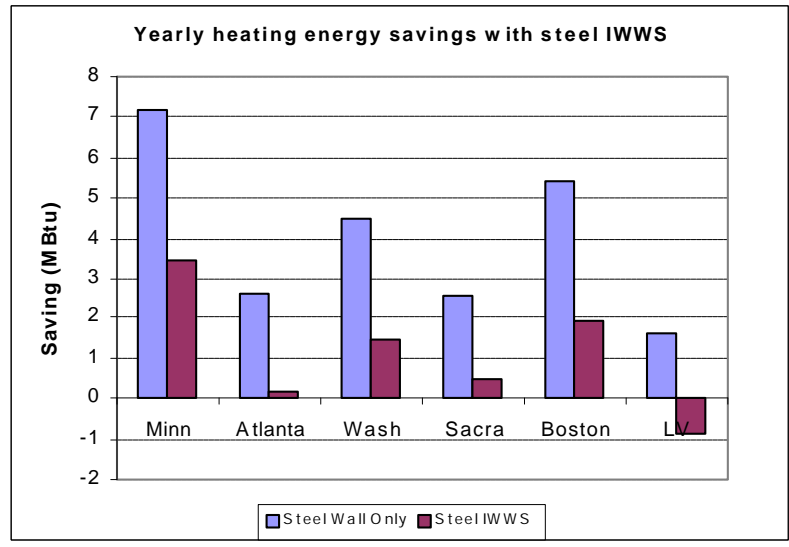

Figure 7.40: Absolute heating energy savings using steel walls only and with the steel IWWS

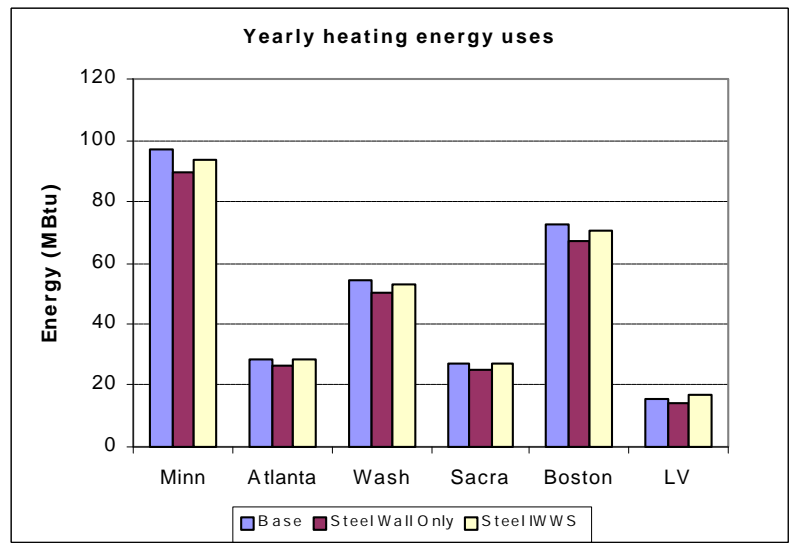

Figure 7.42 Heating energy use with the base house, steel walls only, and with the full steel IWWS 


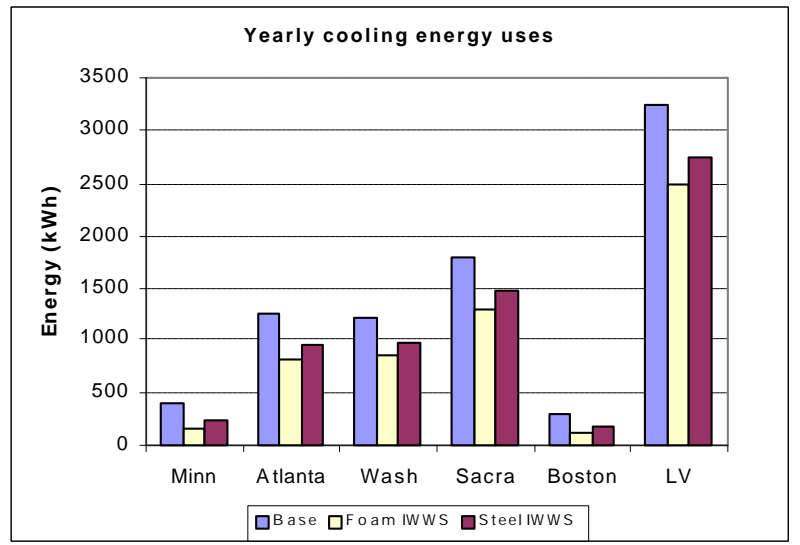

Figure 7.43: Cooling energy use with the base house, the foam IWWS, and the steel IWWS

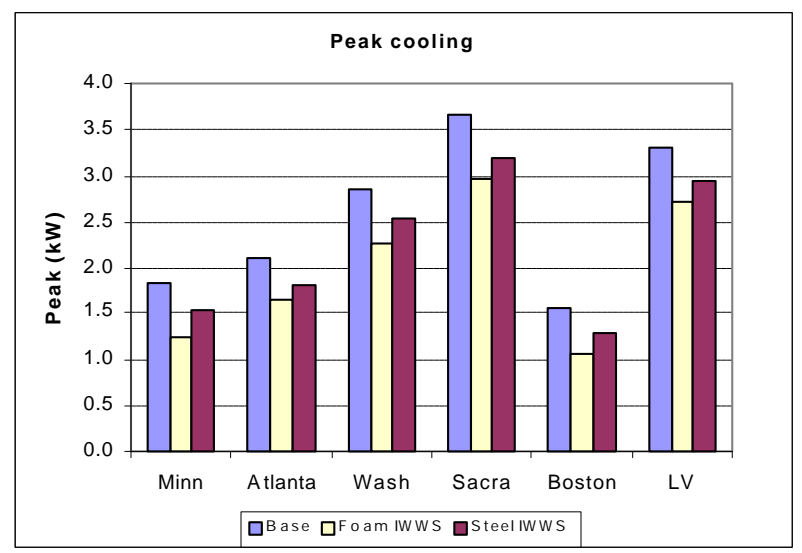

Figure 7.405 Peak cooling with the base house, the foam IWWS, and the steel IWWS.

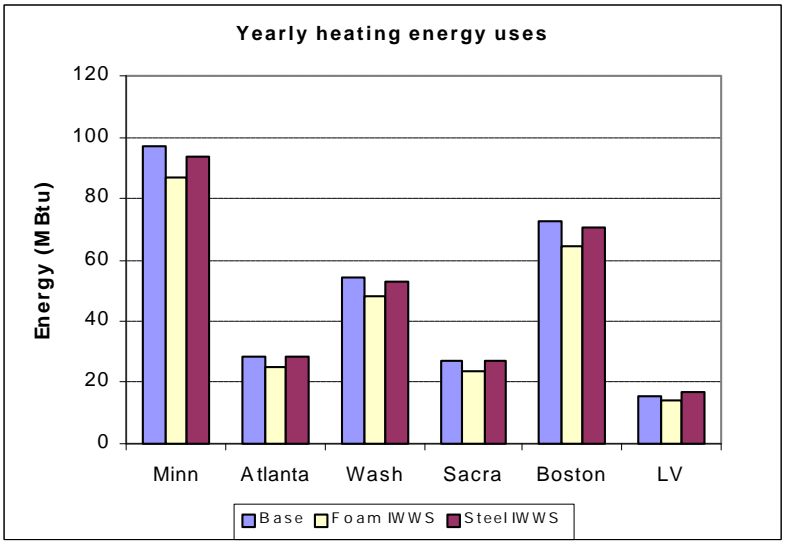

Figure 7.44: Heating energy use with the base house, the foam IWWS, and the steel IWWS

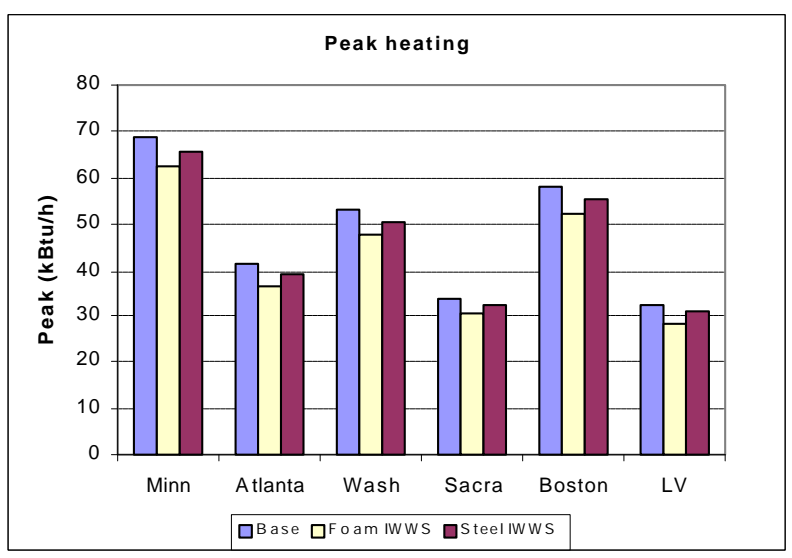

Figure 7.46: Peak heating with the base house, the foam IWWS, and the steel IWWS 

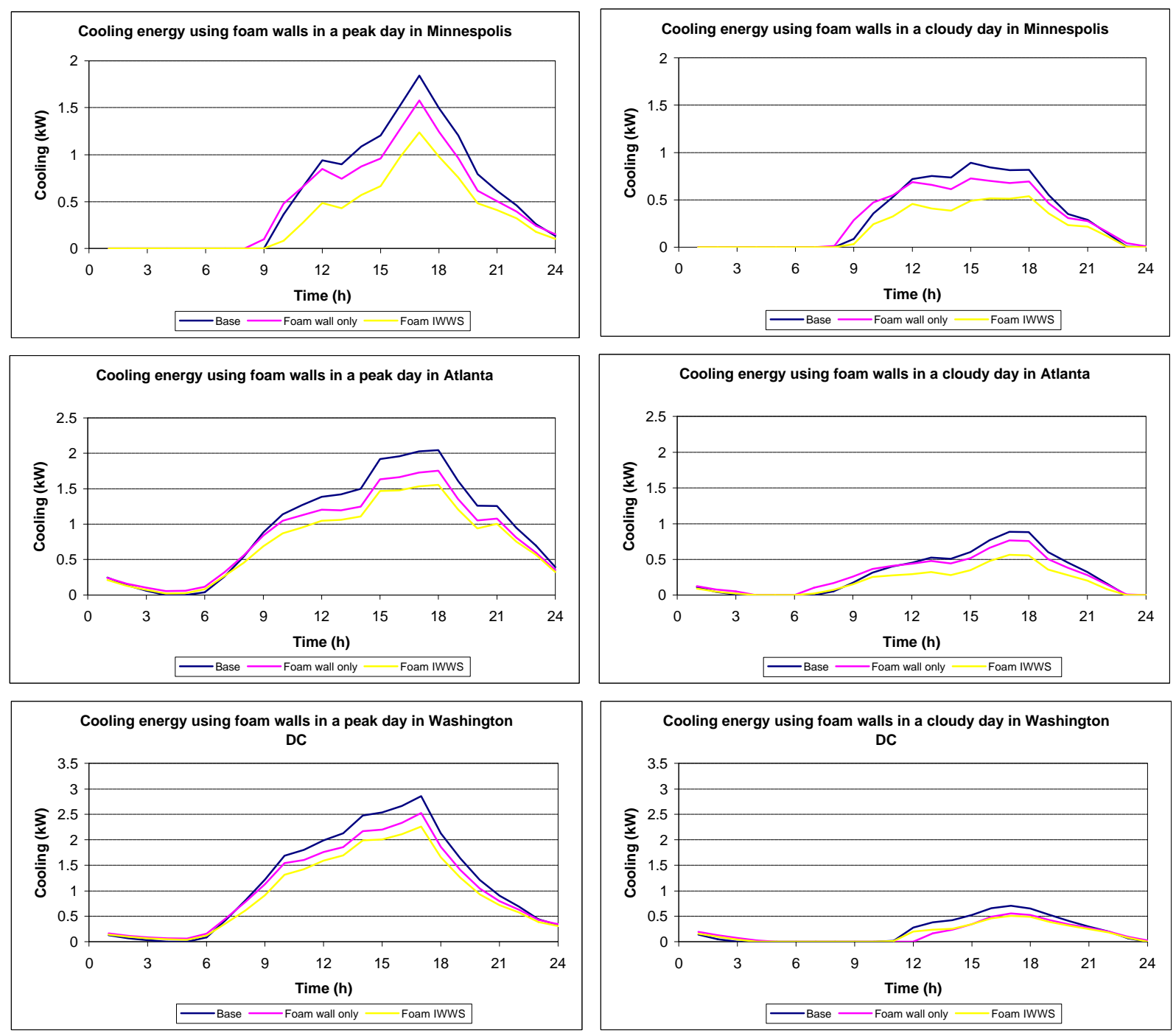

Figure 7.47: Peak cooling for the base case, foam walls only, and the foam IWWS in Minneapolis, Atlanta and Washington DC. 

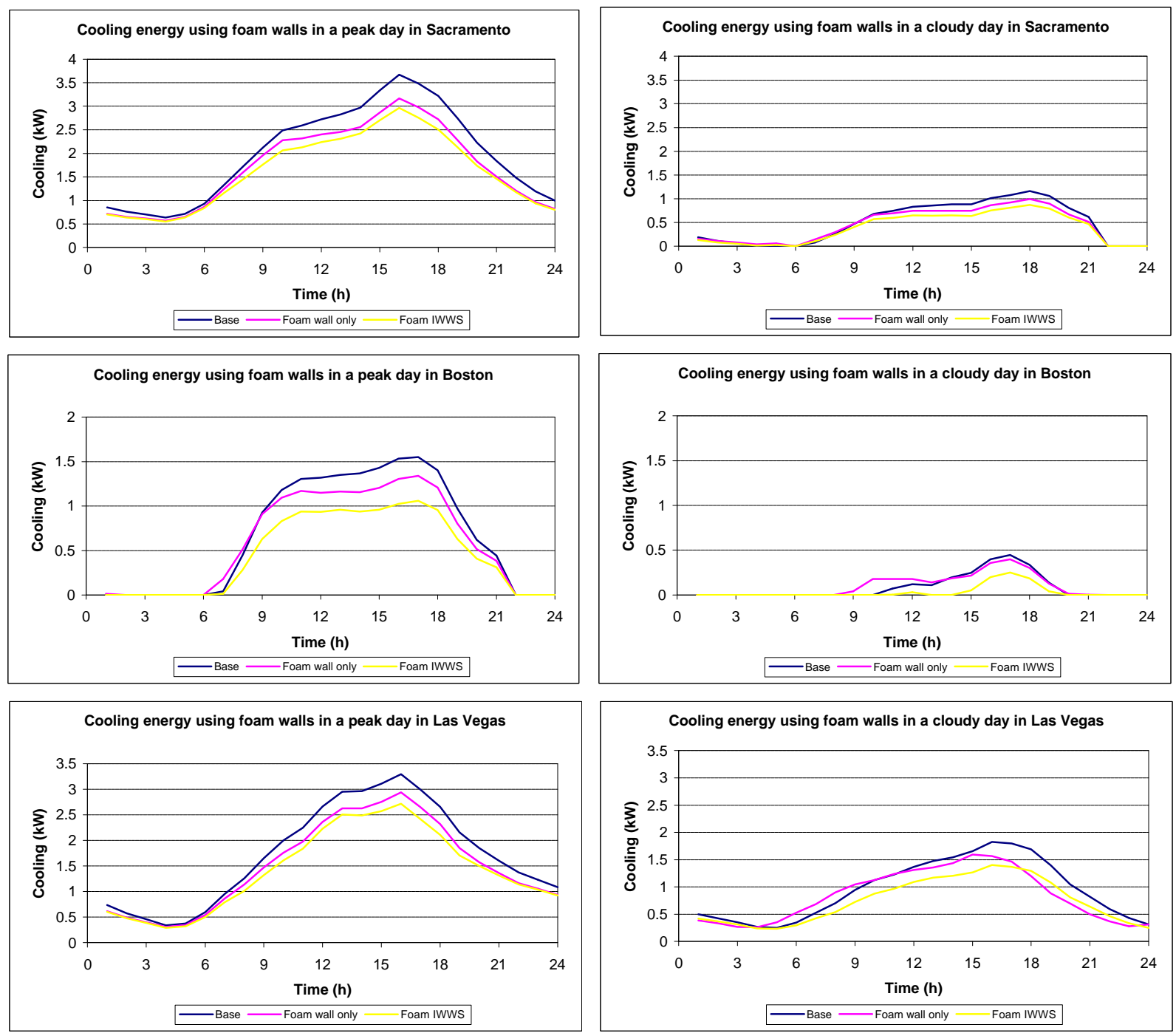

Figure 7.48: Peak cooling for the base case, foam walls only, and the foam IWWS in Sacramento, Boston and Las Vegas. 

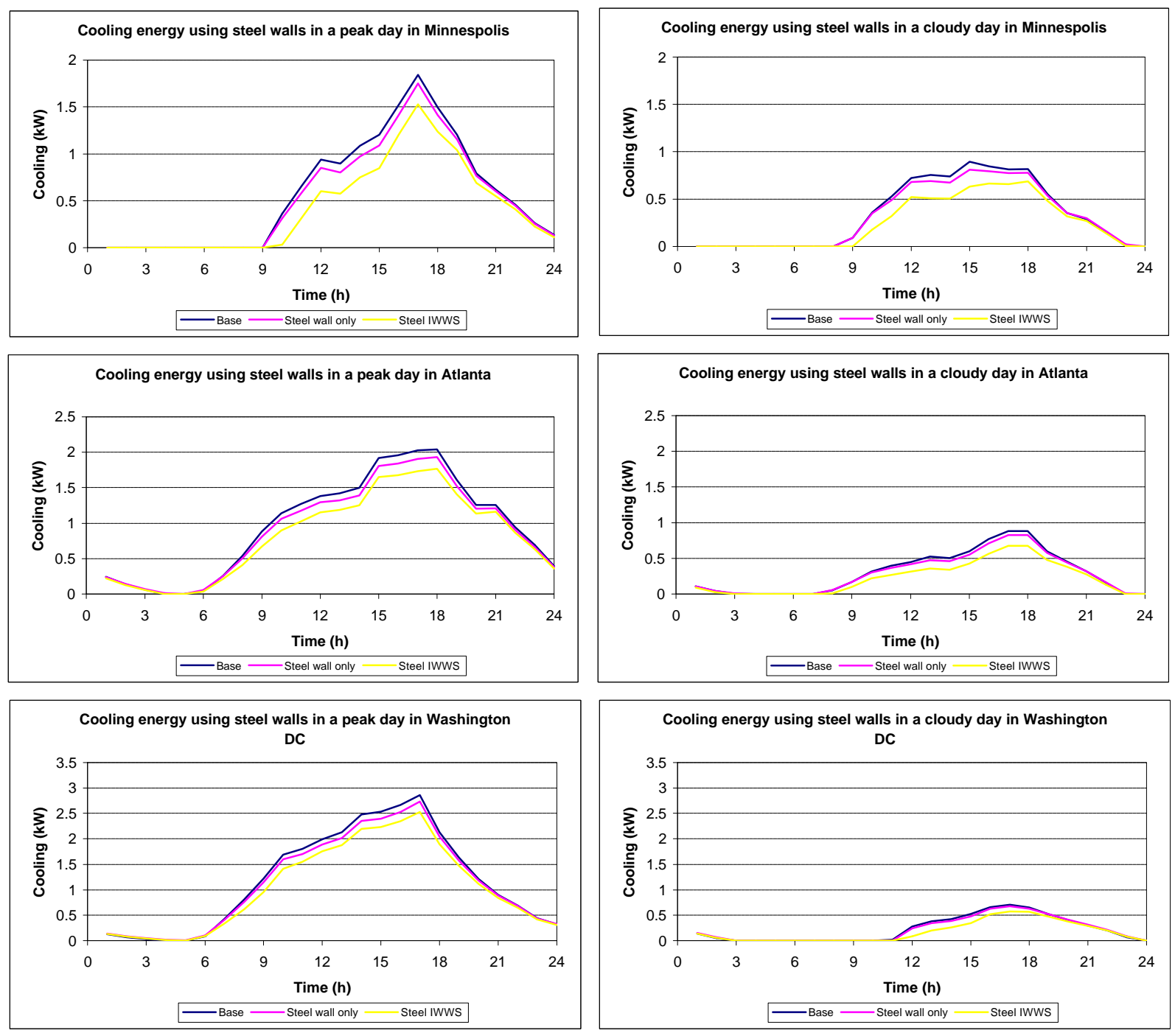

Figure 7.49: Peak cooling for the base case, steel walls only, and the steel IWWS in Minneapolis, Atlanta and Washington DC. 

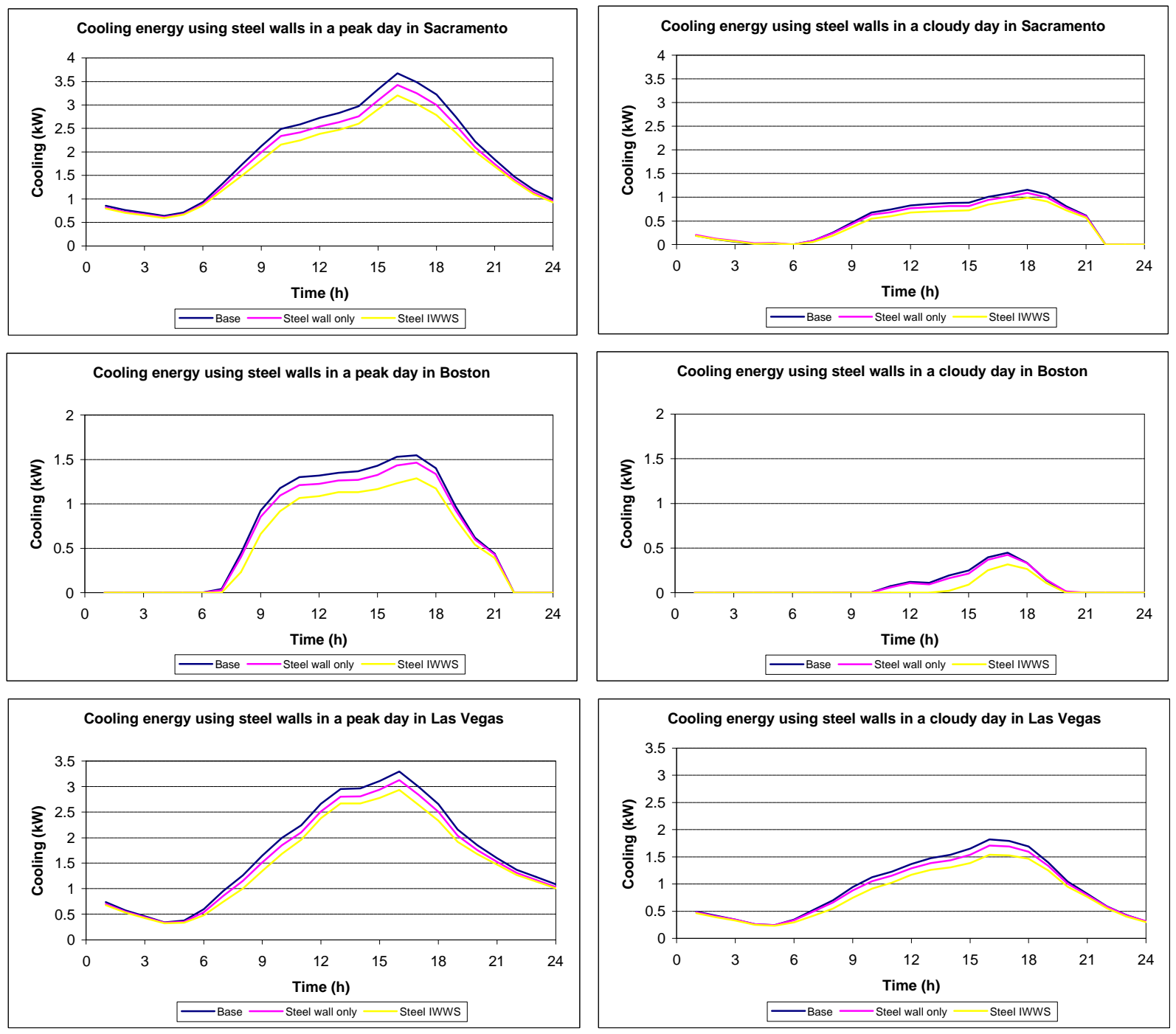

Figure 7.50: Peak cooling for the base case, steel walls only, and the steel IWWS in Sacramento, Boston and Las Vegas. 


\section{Conclusion}

\subsection{DISCUSSION}

\subsubsection{Lessons from a hot box test}

The assessment of a U-value by finite element analysis necessitates a simple guarded hot-box measurement for verification purposes. To be sure, such a measurement was attempted for this project. Both the steel wall and the foam wall were measured for a composite value using a guarded hot-box test. The results showed that the Foam wall achieved a composite $U$ value of 0.10 and the steel wall gained a $U$ value of 0.17 , which are substantially higher than predicted. However, a subsequent vacuum test revealed a few small air leaks in both structures (note: the hot-box measurements were performed according to AAMA 1503-98 standards. Therefore, the existence of an air leak renders the test INVALID and not usable). The fact that both prototypes resulted in air leaks is not surprising. It is rare for a first proof-ofconcept prototype to be constructed in an ideal manner. Therefore, the prototyping stage of a project should include steps to refine construction techniques. Such refinement was beyond the scope of the first half of this project and will be deferred to the final master prototype window-wall (the ultimate deliverable for this project). Nevertheless, the experience serves to illustrate the points previously made: the most thermally efficient window-wall envelope systems can be made inefficient through window installation defects.

\subsubsection{Efficacy of components}

A number of new and novel components were considered during the prototyping phase. Electrochromic glazing was actively considered in a potential window-wall prototype. Simulations on DOE-2 showed that substantial savings could be achieved through the intelligent, judicious use of electrochromics. Most of these savings were achieved through a reduction in solar heat gain. However, electrochromic glazing remains an expensive proposition. At the time of this report, the electrochromic insulated glass unit cost US\$500 for each insulated glass unit. Therefore, for each IWWS panel, one would expect to pay a premium of US\$1000 for each panel. Clearly, the cost of the 
electrochromic glazing system must be carefully weighed against its benefits.

An automated venetian blind system was offered as an attempt to improve the cost-to-benefits ratio for actively controlling solar heat gain. The electrochromic system was assumed to be left in the darkened state for the entire cooling season, while the venetian blind system was closed only during the peak solar heat gain portion of a given day. Nevertheless, the cost of the venetian blind system featured in the steel wall did not exceed \$250 US. Although the energy savings were not as impressive, the cost-to-benefits ratio is substantially improved.

\subsubsection{Comparison of the Various Systems}

The stiffened plate system was originally intended to demonstrate a method for intelligently controlling moisture levels inside a wall cavity. This passive ventilation system provides a means for dealing with any incidental moisture problem which could arise. This system is probably the most realistic since it creates a level of redundancy not featured in traditional housing. As stated above, the overall U-value could be lowered just by choosing another fenestration system.

The foam wall design represents a minimalist approach to building structural design. The structure relies primarily on the post and truss system for the overall strength and rigidity, with the foam inside the cavity providing the structure for the window system. The high-efficiency electrochromic along with the storm window is a triple pane system with the possibility of controllable solar heat gain.

Like the foam wall, the steel wall represents a minimalist approach to wall design if one were to assume that steel is to be used in the window-wall. It must be noted that steel offers an attractive material for construction because of its low cost. Moreover, the properties of steel are fairly well defined and controlled, meaning that it is easy to specify the mechanical properties of a window-wall based on steel. But, as stated above, the steel wall features a penalty in the overall U-value of the window-wall because of the thermal short-circuits.

The stud wall represents no theoretical improvements to a typical window-wall system being built today. The design merely represents a novel technique for installing energy efficient windows in a wood stud based panel. The stud wall represents energy savings in a practical sense because it reduces opportunities for air infiltration. Nonetheless, the benefits afforded a reduction in air infiltration should not be understated. The largest motivation for the IWWS project was to address problems associated with installation defects.

Each of these designs could allow for integrated ventilation and electrical systems. For example, the steel wall could easily accommodate a through-the-wall air by using a sub-framing system and an installation boot. The electrochromic glazing system or the automated venetian blind system necessitates the inclusion of both electrical and controls systems. The controls 
systems could be either hard-wired (electrochromic system) or implemented through radio frequency signals (venetian blind systems).

In addition, all of the designs are panelized and are therefore intended for easy installation and removal.

While exploring the issues of manufacturing and construction. The emphasis was on the wall system and the window-wall interface. Based on these results, phase two will involve further analysis and redesign of the prototypes resulting in one or two systems brought closer to commercialization. Phase two will involve market research for the system. Revised designs will explore a fuller integration of the window technologies and attachments with the wall system. Issues such as sustainable materials, ventilation, and control systems will be included in the redesigns.

\subsection{CONCLUSION}

A series of prototype integrated window-wall systems were designed and constructed that improve upon the concepts originally offered by Lawrence Berkeley National Labs. Many different components and building systems were assessed for their potential use in an integrated window-wall prototype. A number of systems were identified for their potential uses in an integrated system and, from this list, five designs were created resulting in four functioning prototypes. Each prototype is intended to illustrate different possible philosophies for energy efficient design, and results indicate that each prototype has the potential to create an energy-efficient envelope unit with a number of related advantages. These designs include:

- A manufactured window-wall panel which uses an improved stick built approach, and offers a new, foolproof technique for window installation that is defect-free.

- A manufactured foam window-wall, which merges SIPS panel technology with post-and-beam construction techniques.

- A manufactured steel wall, which demonstrates a technique for maximizing the benefits of steel while reducing the energy demands normally found in steel construction.

- A stiffened plate window-wall which creates an alternative to stick built methods. The panelized system increases the stiffness, structural integrity and moisture resistance of a panel while substantially reducing thermal short-circuits.

- A ventilated stiffened plate window-wall which utilizes a ventilated wall cavity as a heat exchange device. This system has the advantages of the stiffened plate structure, moisture resistance, and reduced thermal short-circuits. (A prototype was not built of this design during phase one). 
Each system has its advantages and disadvantages.

However, simulations show that the foam wall, steel wall, and stiffened plate designs potentially can yield substantial energy savings while solving a number of other problems. Energy analysis was done using a full house simulation of the wall systems with different windows ranging from standard low-E to advanced electrochromic glazing. A detailed energy analysis of the constructed prototypes was also conducted.

Phase one of the IWWS project focussed on the integration of energy efficiency, moisture management, and structural design while exploring the issues of manufacturing and construction. The emphasis was on the wall system and the window-wall interface. Based on these results, phase two will involve further analysis and redesign of the prototypes resulting in one or two systems brought closer to commercialization. Phase two will involve market research for the system. Revised designs will explore a fuller integration of the window technologies and attachments with the wall system. Issues such as sustainable materials, ventilation, and control systems will be included in the redesigns. 


\section{APPENDIX 1. WAUSAU HOMES FACTORY TRIP REPORT}

December 11, 2000

Trip Report: Forest Product Society

Panelized Construction and Wausau Homes Plant Tour

Wausau, WI Dec 5th, 2000

\section{Sum m a ry}

The growth of panelized home construction is of great importance to the building industry. The opportunity to gain knowledge in this growing segment of residential construction was presented by Forest Products Society's (FPS) one day conference on panelized home construction. The prospect of a plant tour of Wausau homes was important to observe the manner in which homes are manufactured in the factory. Attendance of this seminar and plant tour was pivotal in determining the selection of the different types of window-wall prototypes. Three speakers shared their experience in the home construction industry.

\section{Lectures from the Wood Products Society meeting}

Bob Berquist, Senior Vice President of Citation Homes, was the first speaker. He has 50 years of experience in panelized housing construction. Citation Homes engineers, manufactures and erects homes in the Midwestern and Western United States. His main focus was on the history of residential construction. The key point he made was that many things we (researchers, manufacturers, and builders) try to do have been tried and done before (good or bad). One interesting fact was that Bob had favorable experiences using the Strutwall product, which is an integrated window-wall product by Andersen Windows. The biggest changes in housing he sees are:

- Exterior siding: from wood to asbestos fiber to vinyl to fiber cement. In general wood is bad, some high quality woods are acceptable.

- Wood windows to vinyl windows - $45 \%$ of the windows he sells are vinyl.

- Steel is a potential material to replace wood and was considered especially during the wood price spikes of the mid 1990's.

- The general consensus of the group was that too much wood is used in conventional framing techniques today. The framing techniques largely are a result of the legacy of balloon-type construction.

Frank Opatik, Vice President of Wausau Homes, was the second speaker. He has 35 years of experience in panelized construction. He talked about Wausau Homes' experience in modular, panelized, and compartmental houses. Wausau Homes provides five improvements over typical construction: 
- Engineering,

- Quality,

- Cost Containment,

- Field Construction

- Speed of Business.

Two shipments come out of Wausau Homes: the A-pack, which has all structural components included in a kit so that a house can be fully enclosed within three days; and the B-pack which includes trim and cabinets, but must be completed by the builder.

Jeff Wick, President and CEO, Wick Building Systems, has 30 years experience in the construction industry. He spoke of the boom-bust cycle in modular (mobile) homes. He said that, historically, these homes are targeted toward the economically disadvantaged segments of society. The home builders partner with banks and other mortgage institutions to offer these lowincome people high risk loans at a very high interest rate. Therefore the homeowners find it difficult to meet their mortgage obligations and also maintain their mobile homes. Therefore, the mobile home industry has a negative image in the nation. Another problem of the modular home industry is lack of land ownership by homeowners. Because the modular homes have been marketed in this manner, the marketplace for modular homes is perceived as cyclical. By contrast, his company strives to sell homes to landowners and therefore has not been as harshly affected by the boom-bust cycle. The company has \$160 million in sales: \$35 million in sales for Wick Homes (similar to Wausau panelized homes), 40 million in sales for agricultural-commercial buildings and $\$ 85$ million in sales for Modular homes. Average cost to build a double wide modular $1600 \mathrm{sq}$. $\mathrm{ft}$ is $\$ 50,000$.

During the afternoon, the conference participants were given a plant tour of Wausau Homes. The tour was in the original of seven Wausau Homes locations. Some highlights were:

- The Factory is 9-10 acres under roof

- Three types of homes are in production: modular, panelized, and compartmental

- Good linear production flow right onto truck trailer

- Between seven and ten homes are made per week using 275350 man-hours per home (Modular home lines)

- The building methods are traditional. They merely build a home in a factory

Please read below for more details on the plant tour. Refer to attached picture and plant drawing for clarification.

The plant tour started near the lumber-processing center, which is new and not optimized for Wausau Homes. The intent of the processing center is to optimally cut framing lumber for concurrent houses being processed at once. With this aspect, Wausau Homes hopes more efficiently use their uncut lumber. 
Wausau Homes buys their lumber directly from the mill and has it shipped to them via rail. It then is stored outside under lumber covers in their receiving yard. They use relatively higher quality lumber than is found on most construction job sites. By keeping the lumber and building materials under roof or cover, Wausau Homes was more able to maintain a supply of good quality raw materials with less waste. These raw materials were transferred indoors for processing or assembly only as needed.

The next station toured was the panelized wall assembly area. All walls were built lying down on large roller beds. The framing materials were received from the lumber processor and grouped together on carts, with each component labeled for a specific job and location. The beams and headers for structural support over windows and door openings were assembled near the lumber processor and put on carts. While most of the panels are not shipped with insulation, headers and non 16-inch spacers are shipped to the job site with insulation. All walls were nailed together using pneumatic nailers. Minimal manual fastening was present in the whole plant tour.

One observation which was confirmed by tour guides was that each assembly station is dedicated to one particular work function. This is because the repetition and control over more variables further assures desired quality product. Wausau Homes hires its people untrained and then puts them through an extensive training program. With this approach Wausau Homes does not fight the tight labor market characteristic of the building trades.

Once framed, the walls are squared up and sheathed using hydraulic squaring and typically OSB sheathing. The openings for windows and doors are then cut out and building paper is applied. Wausau Homes was using Tyvek brand during the tour and was their product of choice. Building paper seams were taped using builders tape to seal the membrane.

Wausau Homes currently was using a Vetter window product made by SNE Enterprises. Windows are installed while wall panels are lying down. Window units are centered and squared in rough openings and fastened using a nailing flange (no shimming was noticed).

Entire wall sections were picked up using an overhead crane and horizontally stacked on the flat-bed trailer. Each wall section included a series of looped steel bands for use with hooks attached to overhead cranes. Wausau Homes does not experience much window breakage in shipping and handling; this is somewhat remarkable considering how much they are moved around at the plant, in shipment and on job site. Wausau Homes says that they have figured out the shipping and handling of walls to a point where it just doesn't happen.

In addition to the wall panel line, we observed a roof truss operation and a modular home construction line. Both lines illustrated the facility of panelized construction. For example, the modular home line exclusively used panels that were constructed from the panel line. From this trip, we observed an opportunity to improve upon the design and process of a manufactured stud wall line. The visit to this plant strongly influenced the prototype designs, especially the Manufactured Stud Wall prototype. 


\section{APPENDIX 2. COMPOSITE QFD MATRIX}

Many common building components and systems were included in a wall envelope quality functional deployment matrix to assess the desireability and effectiveness of different building components. This matrix was then sent to contractors and builders as a form to be filled out. Ultimately, the strengths and weaknesses of the most popular building components were evaluated and opportunities for improvement were found. The results provided useful information for the design of the different prototypes.

The functions in the system that fit into the wall envelope include:

- Exterior finish- an aesthetically pleasing barrier to outside elements. Generally not a complete seal

- Exterior wrap- controls moisture and air passage to some extent

- Exterior sheathing- provides some structure and exterior closure to wall envelop

- Structure- the main load carrying system

- Insulation- the bulk of the control of energy for thermal performance

- Interior wrap- controls moisture and air passage to some extent

- Interior sheathing- attempts just be an interior closure to wall envelope

- Interior finish- an aesthetically pleasing finish provides some barrier effects

Every wall system was not included in this matrix; however, the matrix greatly influenced the potential designs which are acceptable in the market place. The final function of the QFD matrix will be used to apply customer wants and needs into technical characterizations and specifications, leading to a more marketable product line. The QFD matrix eventually led to concept and prototype developments for this project. It also identified several problem areas and how they are overcome by the current design. The matrix clearly showed that all the components of a wall system must integrate with the window and the window must to some extent contain the same qualities that make up the wall system.

A Quality Functional Deployment study is a prerequisite to a high quality, customer-focused design. This particular study, however, shows that the people surveyed are ambivelent to standard construction elements. But, since the study includes only eight participants, we are forced to conclude that the work which follows is incomplete. During the second phase, the concepts embodied in the QFD matrix will be more fully developed. 


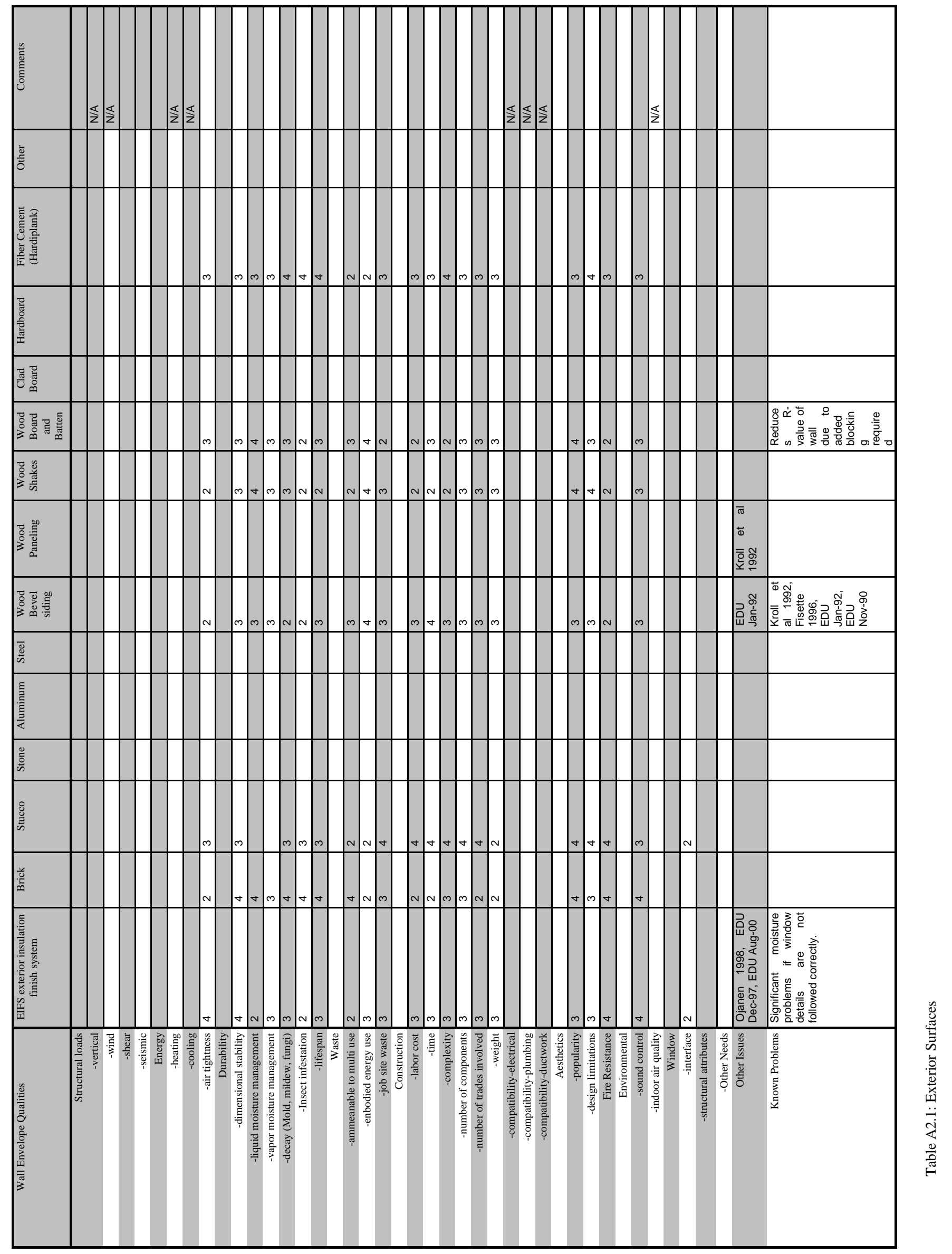




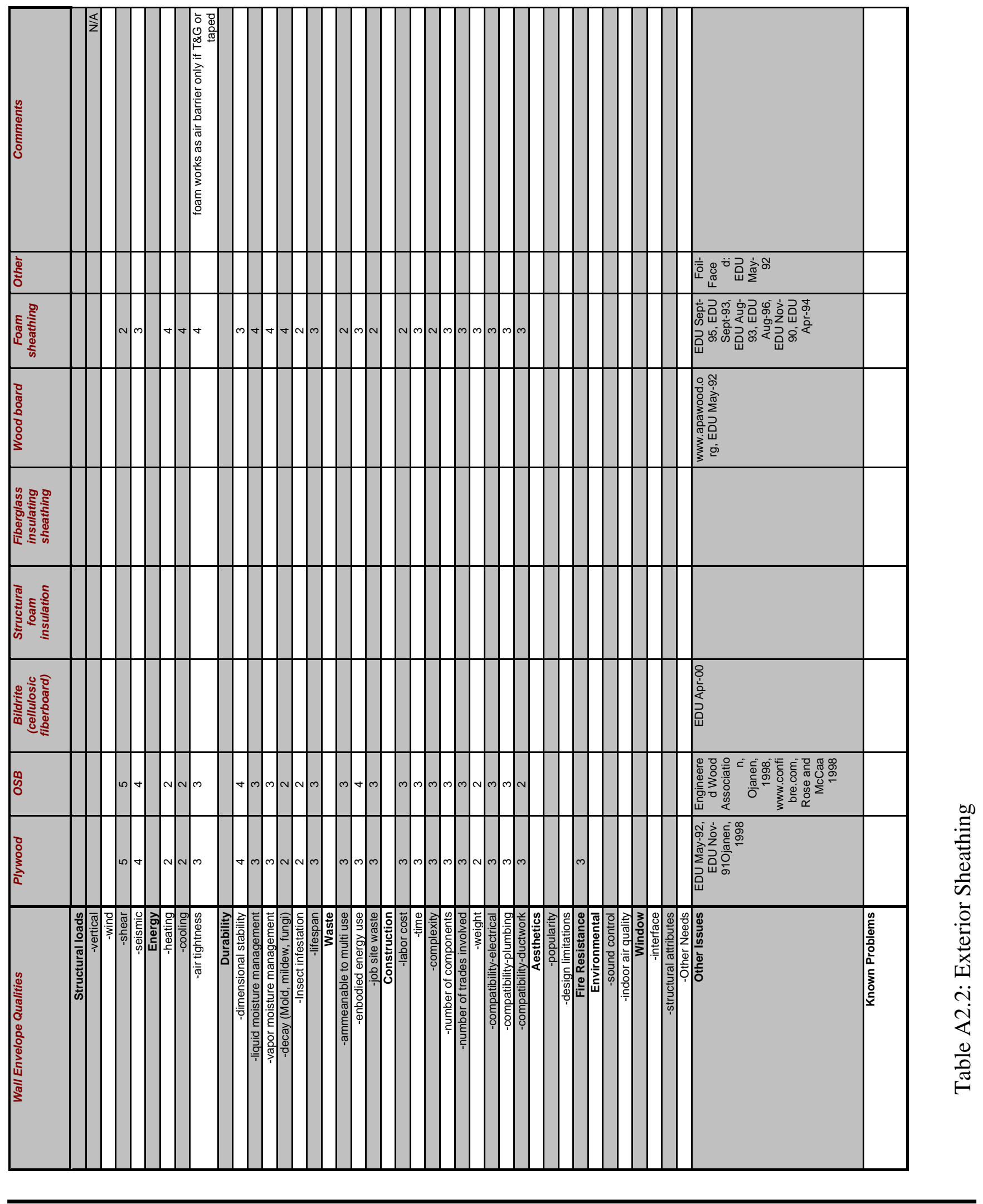




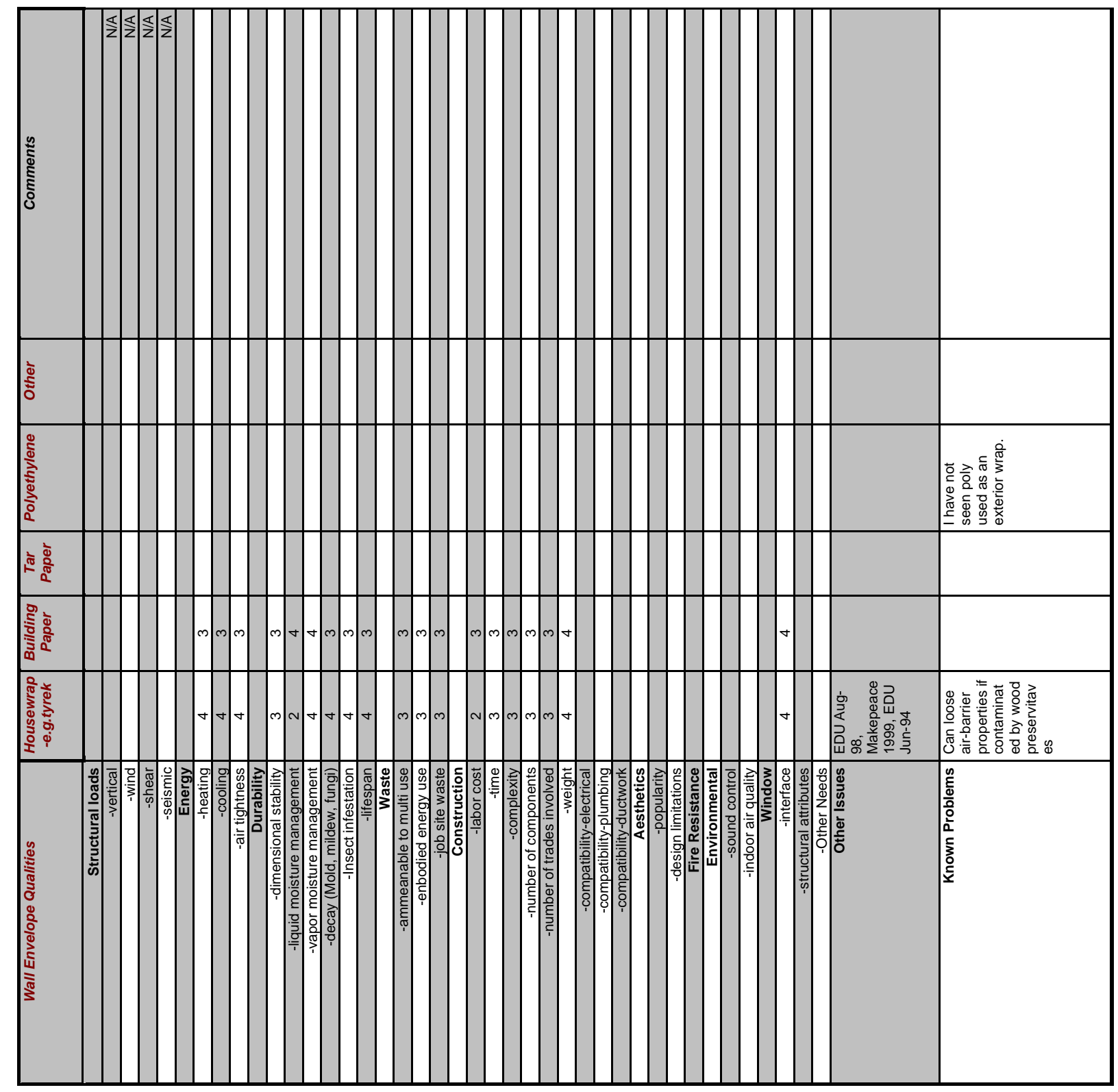

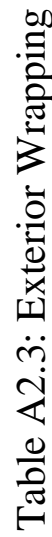




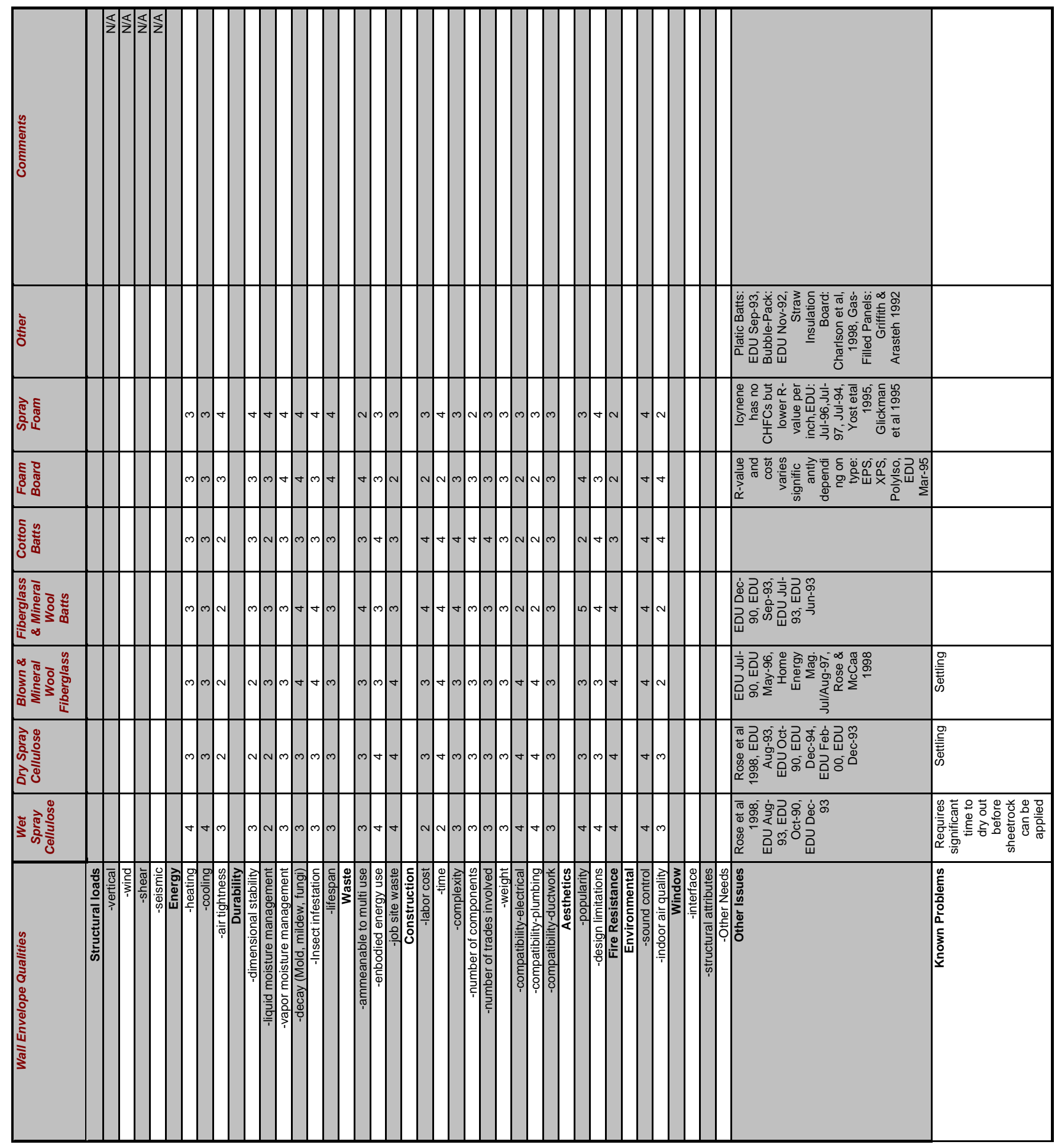

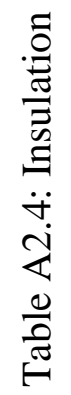




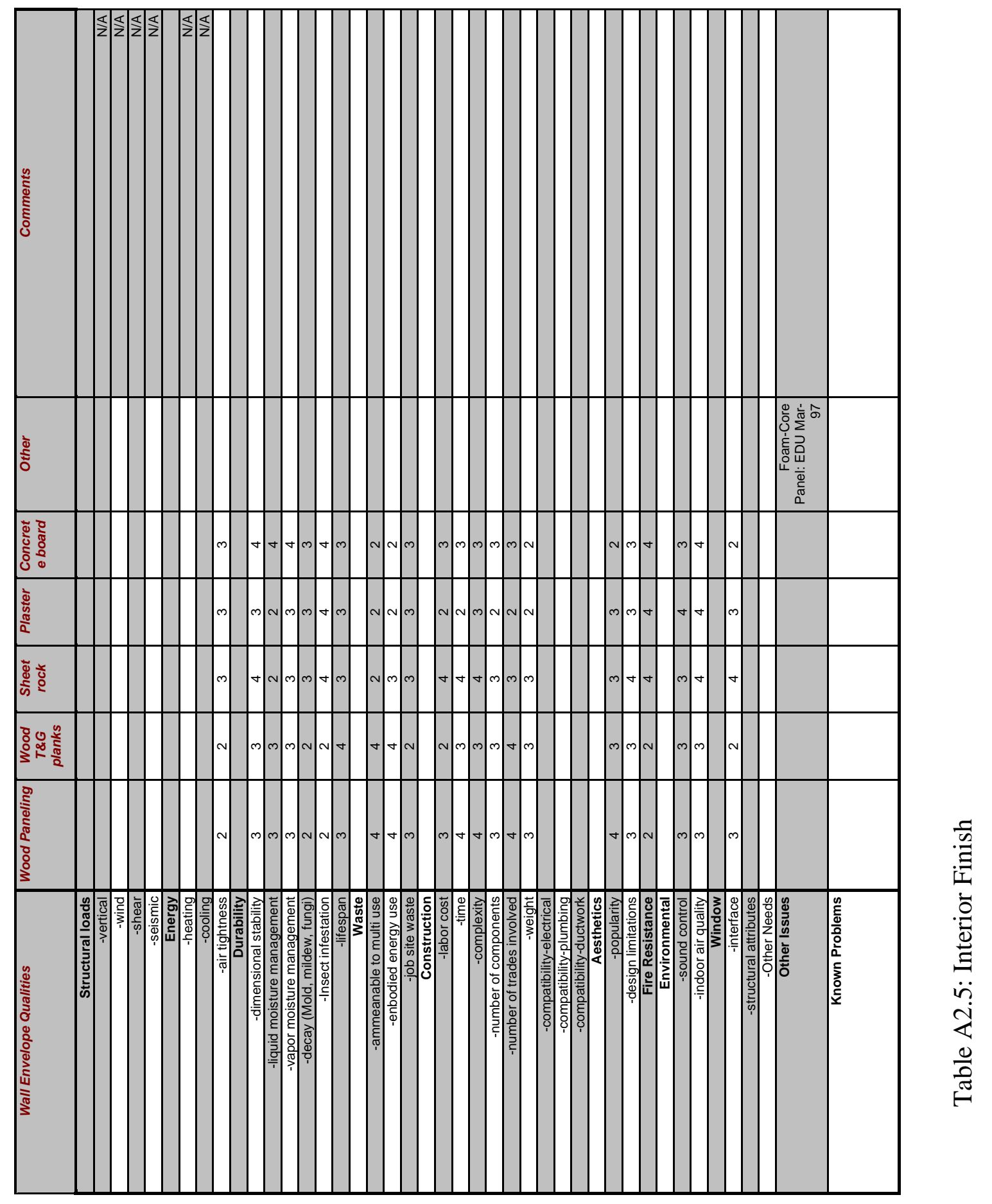

Page 162 


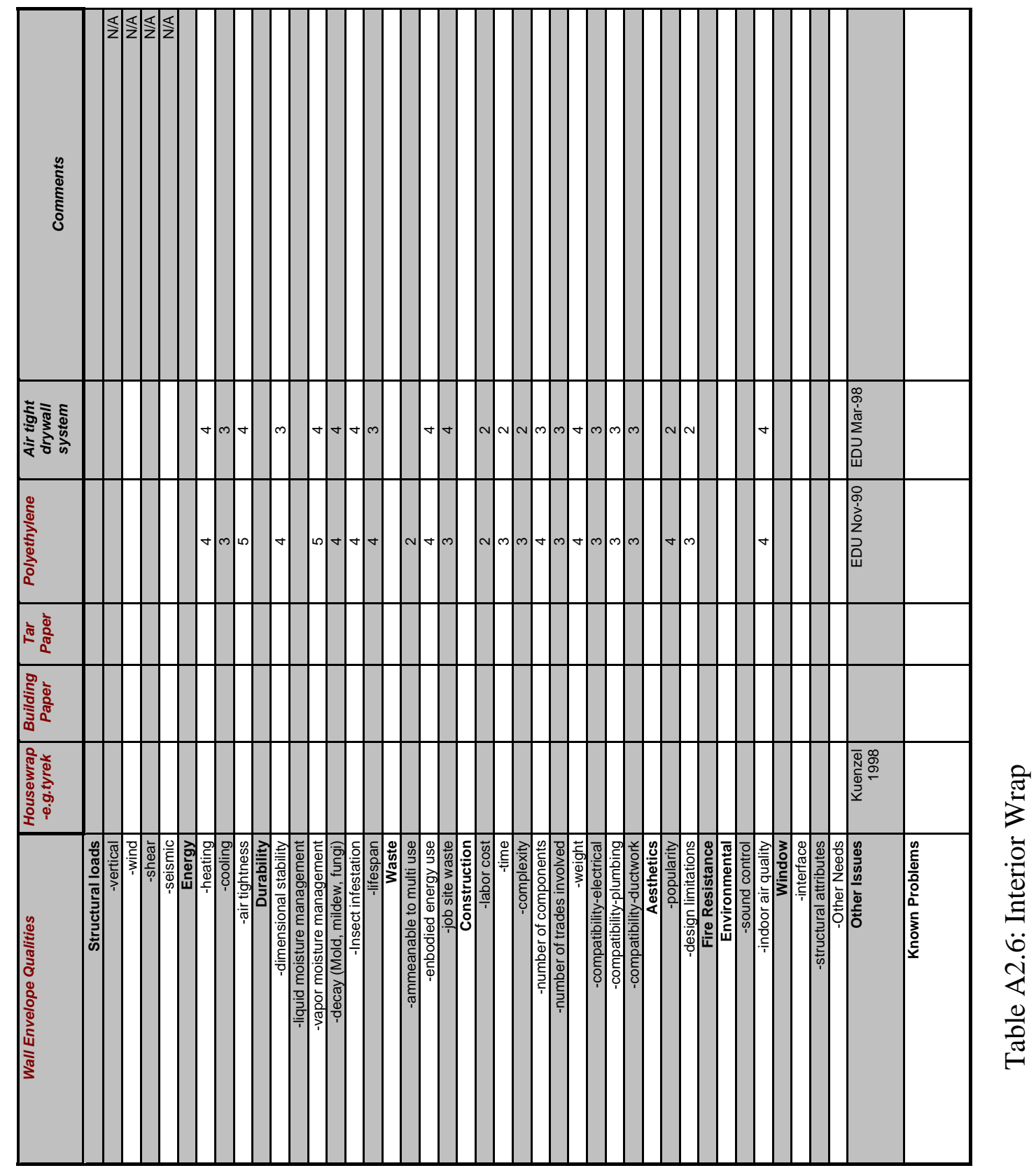




\section{REFERENCES AND BIBLIOGRAPHY}

"Active Homes." Standard Specifications.

Ahdoul, O.A., K. Murali, and A. Morsi. "Performance Evaluation of a Prefabricated Fiber Reinforced Plastic Building Envelope System." Energy and Buildings 22, 1995.

"Air Leakage and Wet Sheathing in Houses." Energy Design Update, November 1991.

"Air Retarder Systems for Residential Walls." Energy Design Update, June 1994.

"American Standard Building Systems." Vendor Brochure.

Andersen Corporation. "Andersen Strutwall Door Frame." Informational Literature, 1959.

Andrews, Steve. "Perry Bigelow: Energy-Efficient Maestro." Home Energy, March 1994.

Andrews, Steve. "What the Future Holds for SIP's: 20 Trends to Watch." Energy Design Update, August 1999.

Arasteh, D., R.E., J. Huang, R.D. Mitchell, R. Clear, and C. Kohler. "A Database of Window Annual Energy Use in Typical NorthAmerican Single-Family Houses." $19^{\text {th }}$ Century National Passive Solar Conference, American Solar Energy Society, Inc., 1994.

Arasteh, D., B. Griffith, and P. LaBerge. "Integrated Window Systems: An Advanced Energy-Efficient Residential Fenestration Product." ASHRAE Transactions 2000, V. 106, Pt. 1.

"Ark-Seal BIBS - R-Value, Density, and Effects of Freezing." Energy Design Update, April 1990.

Athienitis, A.K. and J.D. Dale. "A Study of the Effects of Window Night Insulation and Low-Emissivity Coating on Heating Load and Comfort." ASHRAE Transaction 1987, V. 93, Pt. 1, 1987.

"The Best Air Barrier Systems." Energy Design Update, May 1997.

Best, Don. "Innovative Energy-Efficient Homes." Reports for Energy and Building Professionals, December 1999.

"Beyond R-Value - Insulating for the Environment." ED\&C Magazine, January/February 1999.

"The Bible on Wood Frame Housing Construction Just Got Better." Energy Design Update, April 1998.

Bilgen, E. "Experimental Study of Thermal Performance of Automated Venetian Blind Window Systems." Solar Energy, V. 52, No. 1, 1994.

Branchaud, T.R., D. Curcija, Ph.D., and W.P. Gross, Ph.D. "Local Heat Transfer in Open Frame Cavities of Fenestration Systems." ASHRAE, Thermal Performance of the Exterior Envelopes of Buildings II, 1998. 
Brandle, K. and R.F. Boehm. "Airflow Windows - Performance Applications." ASHRAE/DOE Conference, Thermal Performance of the Exterior Envelopes of Buildings II, 1982.

Braun, B., J. Hansen, and T. Woods. "Urethane Foams and Air Leakage Control." Home Energy, July/August 1995.

Brown, W.C., B. DiLenardo, P.Eng., G.F. Poirier, P.Eng., and Mark D. Lawton, P.Eng. "An Evaluation Guide for Performance Assessment of Air Barrier Systems." ASHRAE, Thermal Performance of the Exterior Envelopes of Buildings VII, 1998.

"BT Building Systems." Vendor Brochure.

"Cam-Lock Foam-Core Panels." Energy Design Update, March 1993.

"CanFibre Creates a Revolutionary Alternative to Oriented Strandboard (OSB)." CanFibre News Release, February 2000.

"CARB's Townhouse Tests Focus on Marketable Innovations." Energy Design Update, April 1997.

Carmody, J., J. Christian, and K. Labs. "Builder's Foundation Handbook." U.S. Department of Energy, 1991.

Carpenter, S.C. and A.G. McGowen. "Frame and Spacer Effects on Window U-Value." ASHRAE Transaction 1989, V. 95, Pt. 1.

"Cellulose Insulation Fire Resistance - More on Permeancy." Energy Design Update, October 1990.

"Certified Engineered Wood from Standard Structures." Environmental Building News, February 1999.

Charleson, J.A., L.R. Glicksman, Ph.D., H.S. Harvey, Jr., and L. Norford. "Development of Straw Insulation Board: Fabrication, Testing, Performance Modeling." ASHRAE, Thermal Performance of the Exterior Envelopes of Buildings VII, 1998.

Charleson, J.A. "Thermal and Shear Wall Performance of Building Assemblies with Insulated Frames." ASHRAE, Thermal Performance of the Exterior Envelopes of Buildings VII, 1998.

Chini, S.A. and K. Gupta. "A Comparison Between Steel and Wood Residential Framing Systems." Journal of Construction Education, V. 1, No. 4, 1997.

Christian, J.E. and J. Kosny, Ph.D. "Toward a National Opaque Wall Rating Label." Thermal Envelopes VI / Heat Transfer in Walls II - Principles.

Christian, J.E. and J. Kosny, Ph.D. "Wall R-Values That Tell It Like It Is." Home Energy, March/April 1997.

Christian, J.E., J. Kosny, Ph.D., A.O. Desjarlais, and P.W. Childs. "The Whole-Wall Thermal Performance Calculator - On the Net." Thermal Envelopes VII / Walls - Practices. 
"Cold-Weather Performance of R-19 Fiberglass Batts." Energy

Design Update, December 1990.

"Composite Wall Panels Win Research Grant." Composites

Technology, July/August 2000.

"Concrete Homebuilding Reaches New Levels." Concrete Homes Newsletter, August 1999.

"Concrete Homebuilding Surges Past 10\% Market Share in 1999." Concrete Homes News Release, January 2000.

"The Cost-Effectiveness of Energy Improvements." Energy Design Update, February 1997.

"Crest Homes." Standard Specifications.

"Customized Structures, Inc." Vendor Brochure.

"Deluxe Homes of PA, Inc." Vendor Brochure.

"Density and Settling of Cellulose Wall Insulation." Energy Design Update, December 1993.

DiBartolomeo, D.L, E.S. Lee, F.M. Rubinstein, and S.E. Selkowitz. "Developing a Dynamic Envelope/Lighting Control System with Field Measurements." JIES, V. 26, No. 1, Winter 1997.

"Does Energy Efficiency Complicate the Construction Process?" Energy Design Update, August 1997.

“Does Insulation Choice Really Affect Infiltration?" Energy Design Update, July 1997.

"Duct (In)efficiency." Energy Design Update, August 1996.

"Duo-Gard Offers Energy Efficient Glazing Panels." ED\&C Magazine, March/April 1998.

Eastin, I.L., S.R. Shook, and D.D. Simon. "Softwood Lumber Substitution in the U.S. Residential Construction Industry in 1994." Forest Products Journal, V. 49, No. 5.

"Echelon - The LonWorks Company." Vendor Brochure.

"The Effect of Metal Fasteners on Foam Sheathing Bad News Update." Energy Design Update, September 1993.

"The Effect of Nails on the Performance of Foam Sheathing." Energy Design Update, August 1993.

Ek, Howard, P.E. "On Outdoor Air for Moisture-Control Ventilation." Letter to the Editor.

Elmahdy, A.H. and T. Frank. "Heat Transfer at the Edge of Sealed Insulating Glass Units - Comparison of Hot Box Measurements with Finite-Difference Modeling." ASHRAE Transaction 1993, V. 99, Pt. 1.

"Energy Saving House." ED\&C Magazine.

"Engines of Our Ingenuity." \{www.uh.edu\}

"Engineered Lumber Studs from TJM." Engineered Building News, May/June 1996. 
"Epoch Corporation." Vendor Brochure.

Fanjoy, Rob. "Building Smarter, Faster, Better." $\{$ www.housingzone.com\}

"Fantastic New R-1 5-Inch Insulation Material." Energy Design Update, September 1990.

"F.A.T.S. Spray-Applied Rockwool Wall Insulation." Energy Design Update, July 1990.

"Fiberglass Advanced ThermaCube Plus Insulation." Energy Design Update, January 1992.

"Fiberglass Wall Spray - Move Over BIBS?" Energy Design Update, May 1996.

"Finding Air Leakage in Log Homes - A Few Surprises." Energy Design Update, October 1990.

Fisette, Paul. "Roofing and Siding Rehabs Get an Energy Fix." Home Energy, November/December 1996.

"Foam-Core Panels with Interior Finish." Energy Design Update, March 1997.

"Foam-Core Panels with Recycled PVC Studs." Energy Design Update, December 1993.

"Foam-Core Panel Versus Stud-Frame Construction - Side-by-Side Test Results." Energy Design Update, July 1993.

"Foam-Drywall Composite for Steel Framing." Energy Design Update, March 1998.

"Foam Forming System with Vertical Panels." Energy Design Update, March 1997.

"Foam Sheathing Over Steel Framing - Does It 'Fix' Thermal Bridging?" Energy Design Update, July 1993.

Foresman, Paul. "Panelized Homes - Panel by Panel." \{www.buildingsystems.org\}

"Forest Homes." Vendor Brochure.

Glicksman, L.R., J. Stewart, N. Solomou, and A. Cunningham. "Improvement of Foam Insulation: Fine Cell Size and Compositel Foam Vacuum Panels." Thermal Envelopes VI / Insulation Principles.

"Good-Bye to Innovative Water Heater." Energy Design Update, July 1993.

Grasso, M. and J.J. Anderson. "On-Site Evaluation of an Insulating Window Shade in Actual Use." ASHRAE Transaction 1986, V. 92, Pt. 1A.

"Greco Homes." Standard Specifications.

Griffith, B.T. and D. Arasteh. "Gas-Filled Panels: A Thermally Improved Building Insulation." Lawrence Berkeley National Laboratory.

Griffith, B.T., D. Arasteh, and D. Turner. "Gas-Filled Panels: 
An Update on Applications in the Building Thermal

Envelope."

Gunther, Judith Anne. "Wall Window." Today's Homeowner, March 1997.

Halle, S. and M.A. Bernier. "Surface Temperature Measurements Inside an Insulated Glazing Unit Liquid Crystals." ASHRAE Transactions 2000, V. 106, Pt.2.

"Harvest Homes." Standard Specifications.

Hauser, G., Ph.D., Kempke, C., and Olesen, B.W., Ph.D. "Computer Simulation of Hydronic Heating/Cooling System with Embedded Pipes." ASHRAE Transactions 2000, V. 106, Pt. 1.

Hawthorne, W.A., P.E., and S. Reilly, P.E. "The Impact of Glazing Selection on Residential Duct Design and Comfort." ASHRAE Transactions 2000, V. 106, Pt. 1.

"Heritage Homes of Nebraska." Vendor Brochure.

"Housewrap Manufacturers Prescribe New Details for Windows and Doors." Energy Design Update, August 1998.

"How Thermal Shorts and Insulation Flaws Can Degrade an R-19 Stud Wall to a Measly R-11." Energy Design Update, September 1999.

"How Wood Details Can Bolster the Thermal Performance of SteelFramed Houses." Energy Design Update, April 1998.

“Hybrid Modular/Panelized Housing." \{www.nahbrc.org\}

Ibamoto, T., et.al. "Study on Solar Shading Performance of Ventilation Windows." ASHRAE, Far East Conference on Air Conditioning in Hot Climates, 1987.

"IBM." Vendor Brochure.

"Icynene: Ozone-Friendly Open-Cell Polyurethane." Environmental Building News, October 1995.

"I-Joist Wall Studs." Energy Design Update, December 1996.

"Insealation comes to the U.S." Energy Design Update, December 1991.

Iovine, Julie V. "Smart Houses Can Outsmart Owners." San Francisco Chronicle, January 2000.

"Is TradeReady the Long-Awaited Breakthrough in Steel Framing." Energy Design Update, July 1999.

"Is $2 \times 6$ Framing Worth the Cost?" Energy Design Update, February 1998.

Jaccaci, Alex and Steven Bodzin. "New Pioneering in Straw Bale Building." Home Energy, July/August 1996.

Jones, D.C., P.E. "Impact of Airflow on the Thermal Performance of Various Residential Wall Systems Utilizing a Calibrated Hot Box." Thermal Envelopes VI / Heat Transfer in Walls II Principles. 
Katz, Arnie. "Rock Wool Fills the Void." Home Energy, July/ August 1997.

Kelly, Ann. "'Telltale House' Revealed." Home Energy, July/ August 1998.

Klems, J.H., M. Yazdanian, and G.O. Kelley. "Measured Performance of Selective Glazings." ASHRAE Conference, Thermal Performance of the Exterior Envelopes of Buildings VI, 1995.

Koch, P. "Wood Versus Non-Wood Materials in U.S. Residential Construction: Some Energy-Related Global Implications." Forest Products Journal, V. 42, No. 5.

Kolderup, E.P. and Charles N. Eley, Jr. "Evaluating the Impact of Overhangs and Sidefins." Eley Associates, 1992.

Kosny, J. "Advances in Residential Wall Technologies - Simple Ways of Decreasing the Whole Building Energy Consumption." ASHRAE 2001, V. 107, Pt. 1.

Kosny, J., Ph.D., J.E. Christian, A.O. Desjarlais, E. Kossecka, and L. Berrenberg. "Performance Check Between Whole Building Thermal Performance Criteria and Exterior Wall Measured Clear Wall R-Value, Thermal Bridging, Thermal Mass, and Airtightness." ASHRAE Transactions: Symposia.

Kosny, J., Ph.D., A.O. Desjarlais, and J.E. Christian. "Steel-Framed Buildings: Impacts of Wall Detail Configurations on the WholeWall Thermal Performance." ASHRAE Transactions: Symposia.

Kosny, J. and J.E. Christian. "Structural Stability Versus Thermal Performance: Old Dilemma, New Solutions." Oak Ridge National Laboratory.

Kosny, J., Ph.D. and J.E. Christian. "Thermal Evaluation of Several Configurations of Insulation and Structural Materials for Some Metal Stud Walls." Energy and Buildings 22, 1995.

Kosny, J., Ph.D., A.O. Desjarlais, and J.E. Christian. "Thermal Performance of 'Energy-Efficient' Metal Stud Wall Systems." Thermal Envelopes VI / Whole Building Performance Practices.

Kossecka, E. Ph.D. and Jan Kosny, Ph.D. "The Effect of Insulation and Mass Distribution in Exterior Walls on Dynamic Thermal Performance of Whole Buildings." ASHRAE Conference, Thermal Performance of the Exterior Envelopes of Buildings VII, 1998.

Kroll, R.E., Ph.D., K.C. Au, Ph.D., and R.O. Gertjejansen, Ph.D. "Performance of Wood-Based Siding in Energy-Efficient Homes Located in Cold Climates."

Kuenzel, H.M., Ph.D. "More Moisture Load Tolerance of Construction Assemblies Through the Application of a Smart Vapor Retarder." ASHRAE Conference, Thermal Performance of the Exterior Envelopes of Buildings II, 1998. 
Laquatra, J., Ph.D., J.A. McCarty, M.E. Levy, and P. Romano. "The Potential for Improved Affordability and Energy Efficiency in Panelized Housing."

"Largest Hardwood Plywood Manufacturer Offers Certified Line." Environmental Building News, February 1999.

Lee, E.S., S.E. Selkowitz, F.M. Rubinstein, J.H. Klems, L.O. Beltran, and D.L. DiBartolomeo. "A Comprehensive Approach to Integrated Envelope and Lighting Systems for New Commercial Buildings." ACEEE Summer Study on Energy Efficiency in Buildings, Building Tomorrow: The Path to Energy Efficiency, 1994

Lee, E.S. and S.E. Selkowitz. "The Design and Evaluation of Integrated Envelope and Lighting Control Strategies for Commercial Buildings." ASHRAE Transactions 101(1), 1995.

Lee, E.S. and S.E. Selkowitz. "Design and Performance of an Integrated Envelope/Lighting System." ICBEST '97 International Conference on Building Envelope Systems \& Technology, 1997.

Lee, E.S., S.E. Selkowitz, F.M. Rubinstein, J.H. Klems, L.O. Beltran, D.L. DiBartolomeo, and R. Sullivan. "Developing Integrated Envelope and Lighting Systems for Commercial Buildings." Solar '94, Golden Opportunities for Solar Prosperity, American Solar Energy Society, Inc., June 1994.

Lee, E.S. and S.E. Selkowitz, "Integrated Envelope and Lighting Systems for Commercial Buildings: A Retrospective." ACEEE Summer Study on Energy Efficiency in Buildings, 1998.

Lee, E.S., D.L. DiBartolomeo, E.L. Vine, Ph.D., and S.E. Selkowitz. "Integrated Performance of an Automated Venetian Blind/Electric Lighting System in a Full-Scale Private Office." ASHRAE Conference, Thermal Performance of the Exterior Envelope of Buildings VII, 1998.

"LeRoy Landers' Marvelous Steel Stud." Energy Design Update, June 1995.

Loffler, M. and D. Buck. "Glazing Edge-Seal Using Foamglass as Spacer and Frameless Window Design." Solar Energy, V. 61, No. 5, 1997.

"Log and Timber Frame Home Virtual Exhibit Hall." Building Systems Magazine.

Lotz, W.A., P.E. "Insulation Failure and Moisture Problems Resulting from Inadequate Installation of Insulation and/or Vapor Retarders." ASHRAE Transactions: Symposia.

Luhr, Stan. "Energy-Conscious Construction: Litigation Insurance." Home Energy, November/December 1997.

Lyons, P.R., Ph.D., D. Arasteh, and C. Huizenga. "Window Performance for Human Thermal Comfort." ASHRAE

Transactions 2000, V. 106, Pt. 1. 
Macbin, A.D, D. Naylor, S.J. Harrison, et.al. "Experimental Study of Free Convection at an Indoor Glazing Surface with a Venetian Blind." International Journal of HVAC \& Research, ASHRAE 1998, V. 4, No. 2.

Makepeace, Chris. "Wrap it Up: Building Houses with the Skin on the Outside." Home Energy, November/December 1999.

"Manufactured Housing Registers Big Gains." $\{$ www.nahbrc.org $\}$

McGinley, L. "Fast Framing with Panels." JLC, November 2000.

McGowen, A., P.Eng. and A.O. Desjarlais. "A Comparison of Thermal Bridging Calculation Methods." Thermal Envelopes VI / Heat Transfer in Walls II - Principles.

McGrath, R.D. "Compact Superinsulated Wall and Roof System Featuring AURA® Superinsulation Panels." Owens Corning OEM Solutions Group.

McQuillen, Daniel. "Virtual Office Showcases Green Technology." ED\&C Magazine, March/April 1998.

"Measured R-Value of Reflective Insulation." Energy Design Update, May 1990.

"Measured R-Value of Thermo-Ply Foil-Faced Sheathing." Energy Design Update, May 1992.

Meckler, G. "Thermal Window Louvre System Reduces Heating and Cooling Loads and Uses Excess Solar Energy and Building Waste Heat." ASHRAE/DOE Conference, Thermal Performance of the Exterior Envelopes of Buildings II, 1982.

Medved, S. and P. Novak. "Heat Transfer Through a Double-Paned Window with an Insulation Screen Open at the Top." Energy and Buildings 28, 1998.

Miller, R.G. and R.I. Carey. "Evaluation of Thermal Insulating Shutters by Means of a Guarded/Calibrated Hot Box Facility." ASHRAE/DOE Conference, Thermal Performance of the Exterior Envelopes of Buildings II, 1982.

"Minnesota Library Information Network." \{www.mnlink.org\}

"Moisture Accumulation in Walls without Vapor Retarders." Energy Design Update, May 1992.

Morrison, I.D., A.N. Karaglozis, and K. Kumaran. "Thermal Performance of a Residential Dynamic Wall."

"NAHB Field Study Assess Alternative Wall Insulation Products." Energy Design Update, May 1998.

“Nailbase Foam Sheathing." Energy Design Update, August 1996.

"New BIBS Support System Designed for Steel Framing." Energy Design Update, September 1998.

"New Era Building Systems, Inc." Standard Specifications.

"New Habitat Homes Showcase SIP's, Modular Utility Wall." 
Energy Design Update, December 1997.

"New Lightweight Spray Foam - Move Over Icynene?" Energy Design Update, May 1996.

"New Standard Specifies Criteria for Airtight Wall Construction." Energy Design Update, November 1995.

Nisson, J.D. Ned, Ed. "New CABO Code Includes Effective Ban on Cellulose." Energy Design Update, November 1995.

Nisson, J.D. Ned. "Radiant Barriers, Air Barriers, and Vapor Barriers." Reports for Energy and Building Professionals.

"No More Recycled-Content Extruded Polyurethane Insulation." Environmental Building News, February 1997.

"No Stress Panel System for Timber Framing." Environmental Building News, April 1999.

"Norse Homes." Standard Specifications.

"The Northside Project, Affordable and Environmental - Case Study." ED\&C Magazine, March/April 1998.

"Norvell \& Wallace." Vendor Brochure.

Ojanen, T. "Improving the Drying Efficiency of Timber Frame Walls in Cold Climates by Using Exterior Insulation." ASHRAE, Thermal Performance of the Exterior Envelopes of Buildings II, 1998 .

Onysko, D.M. "Airtightness of Joints in Wall Sheathing as a Function of Lumber Drying and Attachment."

"ORNL Concludes Steel Framing Can Perform as Well as, or Even Better than, Wood." Energy Design Update, March 1997.

Otto, D.P. "Installed Performance of Two Insulation Systems During Simulated Wind Conditions." ASHRAE, Thermal Performance of the Exterior Envelopes of Buildings II, 1998.

"Owens Corning Miraflex Now Available for Walls." Environmental Building News, January 1999.

Park, S.D., et.al. "The Analysis of Thermal Performance in an Airflow Window System Model." ASHRAE/DOE/BTECC/ CIBSE Conference, Thermal Performance of the Exterior Envelopes of Buildings IV, 1989.

"Penn Lyon Homes Corporation." Vendor Brochure.

"Performance of Wood Sidings Over Foil-Faced Sheathing." Energy Design Update, January 1992.

Perlack, B., J.E. Christian, and S. Schexnayder. "Whole-Wall Building Sustainability Index for IEA ANNEX 32 Integral Building Performance." 1998.

Petrie, T.W., J. Kosny, P.W. Childs, J.E. Christian, and R.S. Graves. "Performance of Powder Filled Evacuated Insulation Versus Conventional Insulation in a Single-Wide Manufactured Home Unit." Thermal Envelopes VI / Insulation - Principles. 
"Pinnacle Building Systems Corporation." Vendor Brochure.

"Plastic Fiber Batts - The 'Next' Insulation Material?" Energy Design Update, September 1993.

Proskiw, G., P.Eng. "Performance of Energy-Efficient Residential Building Envelope Systems." Thermal Envelopes VI / Whole Building Performance - Practices.

"PSG Controls, Inc.." Vendor Brochure.

"R-4 Bubble-Pack Insulation System for Walls." Energy Design Update, November 1992.

"R-4.2 Clear Window?? - Say it Ain't So." Energy Design Update, May 1990.

Rainer, Leo. "Is an R-19 Wall Really R-19?" Trends in Energy.

"R-Anell Custom Homes, Inc." Vendor Brochure.

"Ray-Core Panels." Informational Literature. \{www.nahbrc.org\}

"Rethinking the Way that Wells are Braced." Energy Design Update, October 2000.

Ripatti, H. "Airflow Window System - Making Fenestration the Solution Rather than the Problem in Energy Use." ASHRAE Transaction 1984, V. 90, Pt. 1B, 1984.

Riskowski, G.L., L.L. Christianson, and R.G. Miller. "Thermal Performance of Typical Light-Frame Walls with Reflective Surface Insulations." ASHRAE Transaction 1989, V. 95, Pt. 2.

"Rockwool Batts." Energy Design Update, June 1993.

Rode, C., Ph.D. "Organic Insulation Materials: Effect on Indoor Humidity and Necessity of a Vapor Barrier." ASHRAE, Thermal Performance of the Exterior Envelopes of Buildings II, 1998.

Rose, W.B. and D.J. McCaa, Ph.D. "Temperature and Moisture Performance of Wall Assemblies with Fiberglass and Cellulose Insulation." ASHRAE, Thermal Performance of the Exterior Envelopes of Buildings VI.

Salonvaara, M. and Jyri Nieminen. "Hygrothermal Performance of a New Light Gauge Steel-Framed Envelope System." ASHRAE Transactions: Symposia.

"Shades of Things to Come." Popular Science, June 1996.

Sherman, M.H. and Darryl J. Dickerhoff. "Airtightness of U.S. Dwellings." ASHRAE Transactions: Symposia.

"Simplex Industries." Vendor Brochure.

"Simpson Strong-Wall." Vendor Brochure.

"SIP's Without Foam Save the Ozone." Energy Design Update, November 1997.

Sluis, T. and S. Bodzin. "Insulation Systems: Same Tightness." Home Energy, July/August 1998.

Smith, G.R., F. Grobler, and J.B. Miller. "A Comparison of Framing 
Productivity in Traditional and Prefabricated Residential

Construction." Building Research Journal, 1992.

"Snap-Cap Tackles Thermal Bridging in Steel Framing." Energy Design Update, November 1997.

Spelter, H. "Emerging Non-Wood Building Materials in Residential Construction." Forest Products Journal, V. 46, No. 7/8.

Sprenger, P. "Five Steps to Tract Home Success." Home Energy, March/April 1998.

"Staggered $2 \times 4$ Stud Wall Reduces Thermal Bridging." Energy Design Update, February 1998.

"Steel or Wood Framing - Which Way Should We Go?" Environmental Building News, July/August 1994.

"Steel Studs: Thermal Performance." Energy Design Update, February 1993.

Steinfeld, C. "A Bamboo Future." ED\&C Magazine, September/ October 1998.

Steven Winter Associates. "A New Kind of Manufactured Home." RUSH Magazine, January/February 2000.

"Straw: The Next Great Building Material?" Environmental Building News, May/June 1995.

"Structural Engineered Wood: Is it Green?" Environmental Building News, November 1999.

Sullivan, R., M. Rubin, Ph.D., and Stephen E. Selkowitz. "Reducing Residential Cooling Requirements Through the Use of Electrochromic Windows." Thermal Envelopes / Heat Transfer in Fenestration II - Principles.

"Taping Foam Sheathing for Energy Performance and Moisture Control." Energy Design Update, September 1995.

"Teifs Wall Systems." Vendor Brochure.

TenWolde, A., C.G. Carll, and V. Malinauskas. "Air Pressures in Wood Frame Walls." ASHRAE Conference, Thermal Performance of the Exterior Envelopes of Buildings VII, 1998.

"Thermal Mass and R-Value: Making Sense of a Confusing Issue." Environmental Building News, April 1998.

"Thermally Efficient (?) Steel Studs." Energy Design Update, April 1994.

"Thicker Windows Versus Better Windows - Challenging the Common Wisdom." Energy Design Update, November 1991.

"Thinner Studs Save Wood." Environmental Building News, February 1997.

Tjelflaat, P.O. and B. Bergesen. "Improved Thermal Insulation in Windows by Laminar Airflows." ASHRAE/DOE/BTECC Conference, Thermal Performance of the Exterior Envelopes 
of Buildings III, 1985.

Tooley, John. "Handling Framing Details in High Performance Homes." Home Energy, May/June 1999.

Tsangrassoulis, A., M. Santamouris, D. Asimakopoulos. "Theoretical and Experimental Analysis of Daylight Performance for Various Shading Systems." Energy and Buildings 24, 1996.

Tsongas, George. "Moisture and Mobile Home Weatherization." Home Energy, July/August 1995.

Turiel, I., P. Albrand, Y.J. Huang, et.al. "Parametric Analysis of Impact of Reflective/Absorptive Glazing and Moveable Window Insulation on Heating and Cooling Loads in Residential Buildings." 1985.

Ullah, M.B., Ph.D., C.Eng., G. Lefebure. "Estimation of Annual Energy-Saving Contribution of an Automated Blind System." ASHRAE Transactions 2000, V. 106, Pt. 2.

"Untreated Studs for Wood Foundations?" Energy Design Update, October 1990.

U.S. Department of Urban Development, Office of Policy Development and Research. "Manufactured Home Installation Training Manual."

"USG's New Fiberock Aqua-Tough Sheathing." Energy Design Update, April 2000.

"Vacuum Insulation Panel." Informational Literature. $\{w w w . n a h b r c . o r g\}$

Van Dyck, R.L. and T.P. Konen. "Solar Heat Gain Through Single Glass-Blind Fenestrations." ASHRAE/DOE Conference, Thermal Performance of the Exterior Envelopes of Buildings II, 1982.

"Ventilation Facts and Fallacies in Manufactured Homes." Home Energy, July/August 1997.

"Viracon Introduces Low-E Coated, Laminated Glass." Energy Design Update, August 1998.

Vohra, A., A.H. Rosenfeld, M.D. McDiarmid, et.al. "Thermal Performance of a Low-Cost Sustainable Wall Construction System." ASHRAE Conference, Thermal Performance of the Exterior Envelopes of Buildings VII, 1998.

Walker, I. "Field Monitoring of a Vented Cavity Wall System." Thermal Envelopes VI / Whole Building Performance Practices.

"Wall Moisture Study Wrap-Up - Foam Sheathing, Vapor Retarders, Wood Siding and More." Energy Design Update, November 1990.

“Wall System Reduces Waste." ED\&C Magazine, November/ December 1998.

Warner, Jeffrey. L. "Selecting Windows for Energy Efficiency." 
Home Energy, July/August 1995.

"We Hope That Something Better Comes Along." Energy Design Update, May 2000.

"Westchester Modular Homes, Inc." Standard Specifications.

"What We Learned in Pittsburgh." Energy Design Update, August 1997.

Wilkinson, G., "Building for the Future." ED\&C Magazine, March/ April 1999.

Wilson, T., R. Belshe. "Moveable insulation Systems." ASHRAE Journal, V. 29, No. 2, 1987.

Wise, D.J. and B.V. Shah. "An Assessment of Interlaboratory Reducibility in Fenestration Energy Ratings." ASHRAE Transactions 2000, V. 106, Pt. 1.

Woodson, E.M., P.E. Horridge, and S. Khan. "Interior Insulators Problem Solvers at the Windows." ASHRAE Transaction 1986, V. 92, Pt. 1A.

"Wood Stove Emissions Worse than Expected." Energy Design Update, October 1990.

“Wood Used in New Residential Construction, 1998 and 1995." www.apawood.org

Xanthos, M., R. Dhavalikar, V. Tan, S.R. Dey, and U. Yilmazer. "Properties and Applications of Sandwich Panels Based on Pet Foams."

Yener, A.K. "A Method of Obtaining Visual Comfort Using Fixed Shading Devices in Rooms." Building and Environment, V. 34, Issue 3, 1998.

Yost, P.A. and C.E. Barbour. "An Evaluation of the Performance of a Modified Urethane Foam Insulation." Thermal Envelopes VI / Whole Building Performance - Practices. 


\section{WALL CONSTRUCTION REFERENCES}

Contributed by Davis Energy

1. Andrews, Steve, Perry Bigelow: Energy Efficiency Maestro, Home Energy, Home Energy Magazine, pp13, March/April 1994

2. Arasteh, Dariush, Brent Griffith, and Paul LaBerge, Integrated Window Systems: An Advanced Energy-Efficient Residential Fenestration Product, Lawrence Berkeley Laboratory, $p p 2$,

3. Athienitis, A.K. and J.D. Dale, A Study of the Effects of Window Night Insulation and Low-Emissivity Coating on Heating Load and Comfort, ASHRAE, ASHRAE Transactions, $p p 279,1987$

4. Belgen E., Experimental Study of Thermal Performance of Automated Venetian Blind Window Systems, Pergamon Press Ltd., Solar Energy, pp3, Jan-94

5. Best, Don, Innovative Energy-Efficent Homes, Cutter Information Corp., Dec-99

6. Branchaud, Thomas R., Dragan Curcija, Ph.D., and William P. Goss, Ph.D., Local Heat Transfer in Open Frame Cavities of Fenestration Systems, ASHRAE, Thermal Performance of the Exterior Envelopes of Buildings VII, pp6a107, Dec-98

7. Brandle, K. and R.F. Boehm, Airflow Windows - Performance and Applications, ASHRAE, Thermal Performance of the Exterior Envelopes of Buildings II, pp361, Dec-82

8. Braun, Bob, Janet Hansen, and Tony Woods, Urethane Foams and Air Leakage Control, Home Energy, Home Energy Magazine, pp25, July/August 1995

9. Brown, William C., Bruno Di Lenardo, P.E., Gilles F. Poirier, P.E., and Mark D. Lawton, P.E., An Evaluation Guide for performance Assessment of Air Barrier Systems, ASHRAE, Thermal Performance of the Exterior Envelopes of Buildings VII, pp9b118, Dec-98

10.Carpenter, S.C. and A. G. McGowan, Frame and Spacer Effects on Window U-Value, ASHRAE, ASHRAE Transactions, pp604, 1989

11.Charlson, Joseph A., Thermal and Shear Wall Performance of Building Assemblies with Insulated Frames, ASHRAE, Thermal Performance of the Exterior Envelopes of Buildings VII, pp645, Dec-98

12.Charlson, Joseph A., Leon R. Glicksman Ph.D., Henry S. Harvey, Jr., and Leslie K. Norford, Development of Straw Insulation Board: Fabrication, Testing, Performance Modeling, ASHRAE, Thermal Performance of the Exterior Envelopes of Buildings VII, pp10b50, Dec-98

13.Chini S. Abdol, and Kavita Gupta, A Comparison Between Steel and Wood Residential Framing, Associated Schools of 
Construction, Journal of Construction Education, pp234, 1997

14.Christian, Jeffrey E. and Jan Kosny, Wall R-Values That Tell It Like It Is, Home Energy, Home Energy Magazine, pp15, March/ April-1997

15.Christian, Jeffrey E. and Jan Kosny, Ph.D., Toward a National Opaque Wall Rating Label, ASHRAE, Thermal Performance of the Exterior Envelopes of Buildings VI, pp221, Dec-95

16.Eastin, Ivan L., Steven R. Shook, and Douglas D. Simon, Softwood Lumber Substitution in the U.S. Residential construction Industry in 1994, Forest Products Society, Forest Products Journal, pp21, Jul-98

17.Elmahdy, A.H. and T. Frank, Heat Transfer at the Edge of Sealed Insulating Glass Units - Comparison of Hot Box Measurements with Finite-Difference Modelling, ASHRAE, ASHRAE Transactions, pp915, 1993

18.Fisette, Paul, Roofing and Siding Rehabs Get an Energy Fix, Home Energy, Home Energy Magazine, pp25, November/ December 1996

19.Glicksman, Leon R., Nicholas Solomou, Jeffrey Stewart, and Anthony Cunningham, Improvement of Foam Insulation: Fine Cell Size and Composite/Foam Vacuum Panels, ASHRAE, Thermal Performance of the Exterior Envelopes of Buildings VI, pp25, Dec-95

20.Grasso, M. and J.J. Anderson, On-Site Evaluation of an Insulating Window Shade in Actual Use, ASHRAE, ASHRAE Transactions, pp420, 1986

21.Griffith, B.T. and D. Arasteh, Gas-Filled Panels: A Thermally Improved Building Insulation, ASHRAE, Thermal Performance of the Exterior Envelopes of Buildings $V$, pp96, Dec92

22.Griffith, Brent T,. Dariush Arasteh, and Daniel Turler, GasFilled Panels: An Update on Applications in Building Thermal Envelope, Lawrence Berkeley Laboratory,

23.Gunther, Judith Anne, Wall Window, Today's Homeowner, pp16, Mar-97

24.Ibamoto, T. et al, Study on Solar Shading Performance of Ventilation Windows, ASHRAE, Far East Conference on Air Conditioning in Hot Climates, pp66, Sep-87

25.Jaccaci, Alex and Steven Bodzin, New Pioneering in Straw Bale Building, Home Energy, Home Energy Magazine, pp27, July/ August 1996

26.Jones, David D., P.E., Impact of Airflow on the Thermal Performance of Various Residential Wall Systems Utilizing a Calibrated Hot Box, ASHRAE, Thermal Performance of the Exterior Envelopes of Buildings VI, pp247, Dec-95

27.Klems, J.H., M. Yazdanian, and G.O. Kelley, Measured 
Performance of Selective Glazings, ASHRAE, Thermal

Performance of the Exterior Envelopes of Buildings VI, pp625,

Dec-95

28.Kline, Merritt, Answers to Your Common Questions About Engineered Wood Products, McKellar Publications, Inc., Design/Build Business, pp34, Mar-00

29.Koch, Peter, Wood Versus Nonwood Materials in U.S. Residential Construction: Some Energy-Related Global Implications, Forest Products Society, Forest Products Journal, pp31, Oct-91

30.Kolderup, Erik P. and Charles N. Eley, Evaluating the Impact of Overhangs and Sidefins, American Council for an EnergyEfficient Economy, 1992 Summer Study on Energy Efficiency in Buildings Proceedings, pp1.149, 1992

31.Kosny, Jan and Jeffrey E. Christian, Structural Stability vs. Thermal Performance: Old, American Council for an EnergyEfficient Economy, 1996 ACEEE Summer Study on Energy Efficiency in Buildings, pp10.77, 1996

32.Kosny, Jan, Ph.D., Andre O. Desjariais, and Jeffrey E. Christian, Thermal Performance of "Energy-Efficient" Metal Stud Wall Systems, ASHRAE, Thermal Performance of the Exterior Envelopes of Buildings VI, pp717, Dec-95

33.Kosny, Jan, Ph.D., Andre O. Desjarlais, and Jeffrey E. Christian, Steel-Framed Buildings: Impacts of Wall Detail configurations on the Whole Wall Thermal Performance, ASHRAE, ASHRAE Transactions, pp1263, 1998

34.Kosny, Jan, Ph.D., Andre O. Desjarlais, Jeffrey E. Christian, Elisabeth Kossecka, and Lance Berrenberg, Performance Check Between Whole Building Thermal Performance Criteria and Exterior Wall Measusred Clear Wall R-Value, Thermal bridging, Thermal Mass, and Airtightness, ASHRAE, ASHRAE Transactions, pp1379, 1998

35.Kossecka, Elisabeth, Ph.D. and Jan Kosny, Ph.D., Effect of Insulation and Mass Distribution in Exterior Walls on Dynamic Thermal performance of Whole Buildings, ASHRAE, Thermal Performance of the Exterior Envelopes of Buildings VII, pp9a78, Dec-98

36.Kroll, R.E., Ph.D., K.C. Au, Ph.D., and R.O. Gertjejansen, Ph.D, Performance of Wood-Based Siding in Energy-Efficient Homes Located in Cold Climates, ASHRAE, Thermal Performance of the Exterior Envelopes of Buildings $V$, pp260, Dec-92

37.Kuenzel, Hartwig M., Ph.D., More Moisture Load Tolerance of Contruction Assemblies Through thte Application of a Smart Vapor Retarder, ASHRAE, Thermal Performance of the Exterior Envelopes of Buildings VII, pp2a119, Dec-98

38.Laquatra, J. Ph.D., J.A. McCarthy, M.E. Levy, and P. Romano, The Potential for Improved Affordability and Energy 
Efficiency in Panelized Housing, ASHRAE, Thermal

Performance of the Exterior Envelopes of Buildings V, pp219,

Dec-92

39.Lee, Eleanor S., Dennis L. DiBartolomeo, Edward L. Vine, Ph.D., and Stephen E. Selkowitz, Integrated performance of an Automated Venetian Blind/Electric Lighting System in FullScale Private Office, ASHRAE, Thermal Performance of the Exterior Envelopes of Buildings VII, pp7b51, Dec-98

40.Loffler, M. and D. Buck, Glazing Edge-Seal Using Foamglass as Spacer and Frameless Window Design, Elsevier Science S.A., Solar Energy, pp303, Nov-97

41.Lotz, William A., P.E., Insulation Failure and Moisture Problems Resulting from Inadequate Installation of Insulation and/or Vapor Retarders, ASHRAE, ASHRAE Transactions, pp1368, 1998

42.Luhr, Stan, Energy-Conscious Construction: Litigation Insurance, Home Energy, Home Energy Magazine, pp31, Nov/ Dec. 1997

43.Machin, A.D., D. Naylor, S.J. Harrison, et al, Experimental Study of Free Convection at an Indoor Glazing Surface with a Venetian Blind, ASHRAE, International Journal of HVACER Research, pp153, Apr-98

44.Makepeace, Chris, Wrap it Up: Building Houses with the Skin on the Outside, Home Energy, Home Energy Magazine, pp13, November/December 1999

45.McGowan, Alex, P.E. and Andre O. Desjarlais, A Comparison of Thermal Bridging Calculation Methods, ASHRAE, Thermal Performance of the Exterior Envelopes of Buildings VI, pp241, Dec-95

46.McGrath, Ralph, Compact Superinsulated Wall and Roof System Featuring AURA Superinsulation Panels, ACEEE, 1996 ACEEE Summer Study on Energy Efficiency in Buildings, pp10.111, 1996

47.McQuillen, Daniel, Vitual Office Showxases Green Technology, Business News Publishing II L.L.C., Environmental Design $\mathcal{E}$ Construction, March/April 1998

48.Meckler, G., Thermal Window Louvre System Reduces Heating and Cooling Loads and Uses Excess Solar Energy and Building Waste Heat, ASHRAE, Thermal Performance of the Exterior Envelopes of Buildings II, pp628, Dec-82

49.Medved, S. and J. Novak, Heat Transfer Through a Double Pane Window with an Insulation Screen Open at the Top, Elsevier Science S.A., Energy and Buildings, pp257, Nov-98

50.Miller, R. G. and R.I. Carey, Evaluation of Terhmal Insulating Shutters by Means of a Guarded/Calibrated Hot Box Facility, ASHRAE, Thermal Performance of the Exterior Envelopes of Buildings II, pp617, Dec-82 
51.Morrison, I.D., A.N. Karaqiozis, and K. Kumaran, Thermal Performance of a Residential Dynamic Wass, ASHRAE, Thermal Performance of the Exterior Envelopes of Buildings $V$, pp229, Dec-92

52.Nisson, J.D. Ned, Radiant Barriers, Air Barriers, and Vapor Barriers, Cutter Information Corp., Jun-98

53.Ojanen, Tuomo, Improving the Drying Efficiency of Timber Frame Walls in Cold Climates by Using Exterior Insulation, ASHRAE, Thermal Performance of the Exterior Envelopes of Buildings VII, pp3a17, Dec-98

54.Onysko, D.M, Airtightness of Joints in Wall Sheathing as a Function of Lumber Drying and Attachment, ASHRAE, Thermal Performance of the Exterior Envelopes of Buildings $V$, pp225, Dec-92

55.Otto, Donald P., Installed Performance of Two Insulation Systems During Simulated Wind Conditions, ASHRAE, Thermal Performance of the Exterior Envelopes of Buildings VII, pp8b27, Dec-98

56.Park, S.D. et al, The Analysis of Thermal Performance in an Airflow Window System Model, ASHRAE, Thermal Performance of the Exterior Envelopes of Buildings IV, pp361, Dec-89

57.Perlack, Bob, Jeff Christian, and Susan Schexnayder, Whole-Wall Building Sustainability Indax for IEA ANNEX 32 Integral Building Performance, American Council for an EnergyEfficient Economy, 1998 Summer Study on Energy Efficiency in Buildings Proceedings, pp5.261, 1998

58.Petrie, T.W., Jan Kosny, P.W. Childs, Jeffrey E. Christian, and R.S. Graves, Performance of Powder-Filled Evacuated Insulation VS. Conventional Insulation in a Single-Wide Manufactured Home Unit, ASHRAE, Thermal Performance of the Exterior Envelopes of Buildings VI, pp3, Dec-95

59.Proskiw, Gary, P.E., The Performance of Energy-Efficient Residential Building Envelope Systems, ASHRAE, Thermal Performance of the Exterior Envelopes of Buildings VI, pp343, Dec-95

60.Ripatti, H., Airflow Window System - Making Fenestration the Solution Rather than the Problem in Energy Use, ASHRAE, ASHRAE Transactions, pp917, 1984

61.Riskowski, G.L., L.L. Christianson, and R.G. Miller, Thermal Performance of Typical Light Frame Walls with Relflective Surface Insulations, ASHRAE, ASHRAE Transactions, pp671, 1989

62.Rode, Carsten, Ph.D., Organic Insulation Materials: Effect on Indoor Humidity and Necessity of a Vapor Barrier, ASHRAE, Thermal Performance of the Exterior Envelopes of Buildings VII, pp2a65, Dec-98 
63.Rose, William B., and David J. McCaa, Ph.D., Temperature and Moisture Performance of Wall Assemblies with Fiberglass and Cellulose Insulation, ASHRAE, Thermal Performance of the Exterior Envelopes of Buildings VII, pp2a121, Dec-98

64.Sherman, Max H. and Darrly J. Dickerhoff, Airtightness of U.S. Dwellings, ASHRAE, ASHRAE Transactions, pp1359, 1998

65.Solonvaara, Mikael and Jyri Nieminen, Hygrothermal Performance of New Light Gauge Steel-framed Envelope System, ASHRAE, ASHRAE Transactions, pp1256, 1998

66.Spelter, Henry, Emerging Nonwood Building Materials in Residential Construction, Forest Products Society, Forest Products Journal, pp29, Aug-95

67.Sprenger, Polly, 5 Steps to Tract Home Success (from 'trends in energy' section), Home Energy, Home Energy Magazine, pp7, March/April 1998

68.Sprenger, Polly, SIPs Face the Skeptics, Home Energy, Home Energy Magazine, pp13, March/April 1998

69.Steinfeld, Carol, A Bamboo Future, Business News Publishing II L.L.C., Environmental Design \& Construction, Sep/Oct 1998

70.Sullivan, Robert, Michael Rubin, Ph.D., and Stephen Selkowitz, Reducing Residential Cooling Requirements Through the Use of Electrochromic Windows, ASHRAE, Thermal Performance of the Exterior Envelopes of Buildings VI, pp613, Dec-95

71.TenWolde, Anton, Charles G. Carll, Vyto Malinauskas, Air Pressures in Wood Frame Walls, ASHRAE, Thermal Performance of the Exterior Envelopes of Buildings VII, pp8b8, Dec-98

72.Tjelfaat, P.O. and B. Bergesen, Improved Thermal Insulation in Windows by Laminar Air flows, ASHRAE, Thermal Performance of the Exterior Envelopes of Buildings III, pp992, Dec- 85

73.Tooley, John, Handling Framing Details in High-Performance Homes, Home Energy, Home Energy Magazine, pp22, May/ June 1999

74.Tsongas, George, Moisture and Mobile Home Weatherization, Home Energy, Home Energy Magazine, pp29, July/August 1995

75.Turiel, I., P. Albrand, U.J. Huang, et al, Parametric Analysis of Impact of Reflective/Absorptive Glazing and Movable Window Insulation on Heating and Cooling Loads in Residential Buildings, ASHRAE, Thermal Performance of the Exterior Envelopes of Buildings III, pp891, 1985

76.Van Dyck, R.L. and T.P. Konen, Solar Heat Gain Through single Glass-Blind Fenestrations, ASHRAE, Thermal Performance of the Exterior Envelopes of Buildings II, pp589, Dec-82 
77.Vohra, Arun, P.E., Arthur H. Rosenfeld, Ph.D., Michael D. McDiarmid, P.E., Therese K. Stovall, P.E., Kenneth B. Wildes, Ph.D., P.E., Andre O. Desjarlais, Jan Kosny, Ph.D., Thermal Performance of a Low-cost Sustainable Wall Construction System, ASHRAE, Thermal Performance of the Exterior Envelopes of Buildings VII, pp4b126, Dec-98

78.Walker, Iain, Ph.D., Field Monitoring of a Vented Cavity Wall System, ASHRAE, Thermal Performance of the Exterior Envelopes of Buildings VI, pp727, Dec-95

79.Warner, Jeffrey L., Selecting Windows for Energy Efficiency, Home Energy, Home Energy Magazine, pp11, July/August 1995

80.Wildinson, Glen, Building for the Future, Business News Publishing II L.L.C., Environmental Design \& Construction, March/April 1999

81.Wilson, T. and R. Belshe, Movable Insulation Systems, ASHRAE, ASHRAE Journal, pp26, Feb-87

82.Wittwer, $V$., The Use of Transparent Insulation Materials and Optical Switching Layers in Window Systems, Renewable Energy, pp318, Aug-94

83.Woodson, E.M., P.W. Horridge, and S. Khan, Interior Insulators - Problem Solvers at the Windows, ASHRAE, ASHRAE Transactions, pp439, 1986

84.Yener, A.K., A Method of Obtaining Visual Comfort Using fixed Shading Devices in Rooms, Elsevier Science S.A., Building and Environment, pp285, May-99

85.Yost, Peter A. and C. Edward Barbour, An Evaluation of the Performance of a Modified Urethane Foam Insulation, ASHRAE, Thermal Performance of the Exterior Envelopes of Buildings VI, pp635, Dec-95

86.A Practical Cellulose Wall Insulation System for New Home Construction, Cutter Information Corp., Energy Design Update, pp9, Aug-93

87.Air Leakage and Wet Sheathing in Houses, Cutter Information Corp., Energy Design Update, pp5, Nov-91

88.Air Retarder Systems for Residential Walls, Cutter Information Corp., Energy Design Update, pp6, Jun-94

89.Ark-Seal BIBS - R-Value, Density, and Effects of Freezing, Cutter Information Corp., Energy Design Update, pp6, Apr-90

90.Beyond R-value-Insulating for the Environment, Business News Publishing II L.L.C., Environmental Design $\mathcal{E}$ Construction, January/February 1999

91.Builders Favor Structural Wood Panel Wall Sheathing, Survey Shows, Apr-99, www.apawood.org/news/releases/9911. html

92.Building Solutions: A Problem Solver for Builders, Renovators, Cutter Information Corp., Energy Design Update, 
pp13, Apr-99

93.Cam-Lock Foam-Core Panels, Cutter Information Corp., Energy Design Update, pp12, Mar-93

94.Canfibre Creates a Revolutionary Alternative to Oriented Strandboard ("OBS"), Feb-00, www.confibre.com/021100.html

95.CARB's Townhouse Tests Focus on "Marketable" Innovations, Cutter Information Corp., Energy Design Update, pp8, Apr-97

96.Cellulose Insulation Fire Resistance - More on Permanency, Cutter Information Corp., Energy Design Update, pp6, Oct-90

97.Certified Engineered Wood from Standard Structures, E Build, Inc., Environmental Building News, pp6, Feb-99

98.Cold-Weather Performance of R-19 Fiberglass Batts, Cutter Information Corp., Energy Design Update, pp6, Dec-90

99.Density and Settling of Cellulose Wall Insulation, Cutter Information Corp., Energy Design Update, pp6, Dec-93

100. Does Energy Efficiency Complicate the Construction Process?, Cutter Information Corp., Energy Design Update, Aug-97

101. Does Insulation Choice Really Affect Infiltration, Cutter Information Corp., Energy Design Update, pp6, Jul-97

102. Duo-Gard offers Energy-Efficient Glazing Panels, Business News Publishing II L.L.C., Environmental Design $\mathcal{E}$ Construction, March/April 1998

103. EIFS Manufacturers and Window Makers Aren't Working off the Same Page, Cutter Information Corp., Energy Design Update, pp7, Dec-97

104. Engineered Wood Defined, Apr-00, www.apawood.org/products/defined.html

105. Engineered Wood Products, McKellar Publications, Inc., Design/Build Business, pp32, Mar-00

106. Engineered-Lumber Studs from TJM, E Build, Inc., Environmental Building News, pp8, May/June 1996

107. Environmental Comparison of Insulation Materials, Cutter Information Corp., Energy Design Update, pp15, Mar-95

108. F.A.T.S. Spray-Applied Rockwool Wall Insulation, Cutter Information Corp., Energy Design Update, pp10, Jul-90

109. Fantastic New R-15/inch Insulation Material, Cutter Information Corp., Energy Design Update, pp9, Sep-90

110. Fiberglass Wall Spray. Move Over BIBS, Cutter Information Corp., Energy Design Update, pp11, May-96

111. Finding Air Leakage in Log Homes - A Few Surprises, Cutter Information Corp., Energy Design Update, pp6, Oct-90 
112. Fixing Steel Framing - What Works and What

Doesn't, Cutter Information Corp., Energy Design Update, pp7, Mar-95

113. Foam Sheathing Over Steel Framing - Does it "Fix" Thermal Bridging?, Cutter Information Corp., Energy Design Update, pp6, Jul-93

114. Foam Sheathing over Steel Studs, Cutter Information Corp., Energy Design Update, pp5, Nov-94

115. Foam-Core Panel Versus Stud-Framed Construction - Side-by-Side Test Results, Cutter Information Corp., Energy Design Update, pp4, Jul-93

116. Foam-Core Panels with Interior Finish, Cutter Information Corp., Energy Design Update, pp15, Mar-97

117. Foam-Core Panels with Recycled PVC Studs, Cutter Information Corp., Energy Design Update, pp14, Dec-93

118. Foam-Drywall Composite for Steel Framing, Cutter Information Corp., Energy Design Update, pp13, Mar-98

119. Housewrap Manufacturers Prescribe New Details for Windows and Doors, Cutter Information Corp., Energy Design Update, pp13, Aug-98

120. How Thermal Shorts and Insulation Flows Can Degrade and "R-19" Stud Wall to a Measly "R-11", Cutter Information Corp., Energy Design Update, pp8, Sep-99

121. How Wood Details can Bolster the Thermal Performance of Steel-Framed Houses, Cutter Information Corp., Energy Design Update, pp7, Apr-98

122. Improving Wall R-value, Home Energy, Home Energy Magazine, pp6, March/April 1995

123. I-Joist Wall Studs, Cutter Information Corp., Energy Design Update, pp15, Dec-96

124. Insealation Comes to the US, Cutter Information Corp., Energy Design Update, pp11, Dec-91

125. Insulation Systems: Same Tightness, Home Energy, Home Energy Magazine, pp11, Jul/Aug-1998

126. Is 2x6 Framing Worth the Cost?, Cutter Information Corp., Energy Design Update, pp11, Feb-98

127. Is an R-19 Wall Really R-19?, Home Energy, Home Energy Magazine, pp5, March/April 1995

128. Is TradeReady the Long-Awaited "Breakthrough" in Steel Framing/, Cutter Information Corp., Energy Design Update, pp11, Jul-99

129. Ixynene: Ozone-Friendly, Open-Cell Pylyurethane, E Build, Inc., Environmental Building News, pp8, Sept/Oct 1995

130. LeRoy Landers' Marvelous Steel Stud, Cutter Information Corp., Energy Design Update, pp4, Jun-95 
131. Measured R-Value of Reflective Insulation, Cutter Information Corp., Energy Design Update, pp9, May-90

132. Measured R-Value of Thermoo-Ply Foil-Faced Sheathing, Cutter Information Corp., Energy Design Update, pp10, May-92

133. Moisture Accumulation in Walls Without Vapor Retarders, Cutter Information Corp., Energy Design Update, pp8, May-92

134. More on the (Non?) Effect of Nails on Foam Sheathing, Cutter Information Corp., Energy Design Update, pp9, Apr-94

135. NAHB Field Study Assesses Alternative Wall Insulation Products, Cutter Information Corp., Energy Design Update, pp8, May-98

136. Nailbase Foam Sheathing, Cutter Information Corp., Energy Design Update, pp8, Aug-96

137. New BIBS Support System Designed for Steel Framing, Cutter Information Corp., Energy Design Update, pp12, Sep-98

138. New Habitat Homes Showcase SIPS, Modular Utility Wall, Cutter Information Corp., Energy Design Update, pp3, Dec-97

139. New Loghtweight Spray foam - Move Over Icynene (?), Cutter Information Corp., Energy Design Update, pp9, Jul96

140. New Standard Specifies Criteria for Airtight Wall Construction, Cutter Information Corp., Energy Design Update, pp1, Nov-95

141. New Test Results Should End Hype About Plastic Foam Insulation, Cutter Information Corp., Energy Design Update, $p p 7$, Jul-97

142. Non-CFC Cavity-Fill Foam Insulation, Cutter Information Corp., Energy Design Update, pp9, Jul-94

143. Now Stress Panel System for Timber Framing, E Build, Inc., Environmental Building News, pp6, Apr-99

144. ORNL Concludes Steel Framing Can perform as Well as, or Even Better than, Wood, Cutter Information Corp., Energy Design Update, pp8, Mar-97

145. Owens Corning Miraflex Now Available for Walls, E Build, Inc., Environmental Building News, pp5, Jan-99

146. Performance of Wood Sidings Over Foil-Faced Sheathing, Cutter Information Corp., Energy Design Update, pp7, Jan-92

147. Plastic Fiber Batts - the "Next" Insulation Material?, Cutter Information Corp., Energy Design Update, pp12, Sep-93 
148. R-4 Bubble-Pack Insulation System for Walls, Cutter Information Corp., Energy Design Update, pp7, Nov-92

149. Rock Wool Fills the Void, Home Energy, Home Energy Magazine, pp8, July/August 1997

150. Rockwool Batts, Cutter Information Corp., Energy Design Update, pp12, Jun-93

151. No Stress Panel System for Timber Framing, E Build, Inc., Environmental Building News, Apr-99

152. Movabel Insulation, 1999, www.dulley.com/ref/ fe008.htm

153. Shades of Things to Come, Times Mirror Magazines, Popular Science, Jun-96

154. SIPs Without Foaom Save the Ozone, Cutter Information Corp., Energy Design Update, pp16, Nov-97

155. Snap-Cap Tackles Thermal-Bridge in Steel Framing, Cutter Information Corp., Energy Design Update, pp15, Nov-97

156. Staggered 2x4 Stud Wall Reduces Thermal Bridging, Cutter Information Corp., Energy Design Update, pp13, Feb-98

157. Steel or Wood Framing Which Way Should We Go?, E Build, Inc., Environmental Building News, pp1, July/ August 1994

158. Steel Studs: Thermal Performance, Cutter Information Corp., Energy Design Update, pp4, Feb-93

159. Straw: The Next Great Building Material?, E Build, Inc., Environmental Building News, pp1, May/June 1995

160. Structural Engineered Wood: Is it Green?, E Build, Inc., Environmental Building News, pp1, Nov-99

161. Taping Foam Sheathing for Energy Performance and Moisture Control, Cutter Information Corp., Energy Design Update, pp6, Sep-95

162. Technology Fact Sheet: Wall Insulation, U.S. Department of Energy, Feb-00

163. The (Non?) Advantage of Thermal Mass in Log Homes, Cutter Information Corp., Energy Design Update, pp8, Sep-93

164. The Best Air Barrier Systems, Cutter Information Corp., Energy Design Update, pp9, May-97

165. The Bible on Wood Frame Housing Construction Just Got Better, Cutter Information Corp., Energy Design Update, pp16, Apr-98

166. The Cost-Effectiveness of Energy Improvements, Cutter Information Corp., Energy Design Update, pp10, Feb-97

167. The Effect of Air Gaps on Wall Insulation 
Performance, Cutter Information Corp., Energy Design Update, pp7, Jul-92

168. The Effect of Metal Fasteners on Foam Sheathing Bad News Update, Cutter Information Corp., Energy Design Update, $p p 7$, Sep-93

169. The Effect of Nails on the Performance of Foam Sheathing, Cutter Information Corp., Energy Design Update, pp8, Aug-93

170. Thermal Mass and R-Value: Making Sense of a Confusing Issue, E Build, Inc., Environmental Building News, pp1, Apr-98

171. Thermally Efficient (?) Steel Studs, Cutter Information Corp., Energy Design Update, pp10, Apr-94

172. Thinner Studs Save Wood, E Build, Inc., Environmental Building News, pp4, Feb-97

173. USG's New Fiberock Aqua-Tough Sheathing, Cutter Information Corp., Energy Design Update, pp14, Apr-00

174. Vented Rainscreen Walls - Two New Products, Cutter Information Corp., Energy Design Update, pp11, Jul-94

175. Ventilation Facts and Fallacies in Manufactured Homes, Home Energy, Home Energy Magazine, pp7, July/ August 1997

176. Wall Moisture Study Wrap-Up - Foam Sheathing, Vapor retarders, Wood Siding, and More, Cutter Information Corp., Energy Design Update, pp6, Nov-90

177. We Hope that Something Better Comes Along, Cutter Information Corp., Energy Design Update, pp8, May-00

178. What the Future Holds for SIPs: 20 Trends to Watch, Cutter Information Corp., Energy Design Update, pp16, Aug-99

179. What We Learned in Pittsburgh, Cutter Information Corp., Energy Design Update, pp7, Aug-97

180. Whole-Wall R-Values, Cutter Information Corp., Energy Design Update, pp7, Jan-96

181. Wood Used in New Residential Construction, 1998 \& 1995, 2000, www.apawood.org/publications/reports.html 